Florida International University

FIU Digital Commons

FIU Electronic Theses and Dissertations

University Graduate School

3-8-2019

\title{
Silenced Bodies: (En)Gendering Syrian Refugee Insecurity in Lebanon
}

Jessy Abouarab

Florida International University, jabou002@fiu.edu

Follow this and additional works at: https://digitalcommons.fiu.edu/etd

Part of the International Law Commons, International Relations Commons, and the Near and Middle Eastern Studies Commons

\section{Recommended Citation}

Abouarab, Jessy, "Silenced Bodies: (En)Gendering Syrian Refugee Insecurity in Lebanon" (2019). FIU Electronic Theses and Dissertations. 4052.

https://digitalcommons.fiu.edu/etd/4052

This work is brought to you for free and open access by the University Graduate School at FIU Digital Commons. It has been accepted for inclusion in FIU Electronic Theses and Dissertations by an authorized administrator of FIU Digital Commons. For more information, please contact dcc@fiu.edu. 


\section{FLORIDA INTERNATIONAL UNIVERSITY}

Miami, Florida

SILENCED BODIES: (EN)GENDERING SYRIAN REFUGEE (IN)SECURITY IN LEBANON

A dissertation submitted in partial fulfillment of the requirements for the degree of DOCTOR OF PHILOSOPHY

in

INTERNATIONAL RELATIONS

by

Jessy Abouarab 
To: Dean John F. Stack, Jr.

Steven J. Green School of International and Public Affairs

This dissertation, written by Jessy Abouarab, and entitled Silenced Bodies: (En)gendering Syrian Refugee (In)security in Lebanon, having been approved in respect to style and intellectual content, is referred to you for judgment.

We have read this thesis and recommend that it be approved.

Harry Gould

\begin{tabular}{r} 
Eric Lob \\
\hline Dennis Wiedman \\
Susanne Zwingel, Major Professor
\end{tabular}

Date of Defense: March 8, 2019

The dissertation of Jessy Abouarab is approved.

Dean John F. Stack, Jr. Steven J. Green School of International and Public Affairs

\section{Andrés G. Gil Vice President for Research and Economic Development and Dean of the University Graduate School}

Florida International University, 2019 
(C) Copyright 2019 by Jessy Abouarab

All rights reserved. 


\section{DEDICATION}

I humbly dedicate this dissertation to the memory of my beloved father 


\section{ACKNOWLEDGMENTS}

I could not have produced this dissertation without the many inspiring friends and colleagues who have profoundly influenced my academic life and work. I wish to express my sincere gratitude to my Supervisor, Susanne Zwingel for her limitless patience, invaluable guidance, and constructive criticism. I am equally indebted to my committee members, Harry Gould, Eric Lob, and Dennis Wiedman for their conscientious supervision and endless support they have shown me the past couple of years. A special thank you to Maria Wilkinson-Diaz, Martha Rodriguez, and the many good friends at SIPA who encouraged and supported me in my efforts the past six years. Thank you, Nicholas Terradas, Bibek Chand, Zenel Garcia, and Onur Erpul, for your thought-provoking discussions and enriching advice that have greatly expanded my knowledge. I am inspired by your strength, energy, and dedication to our friendship.

I would also like to thank FIU University Graduate School for granting me the Dissertation Year Fellowship in Summer 2018. Their generous funding helped me focus on writing my dissertation and defend in a timely manner. Thank you, Yesim Darici for welcoming me to the Center for Women's and Gender Studies. I am further grateful for all the opportunities that you provided me to grow as a scholar and to complete this research. I greatly enjoyed studying and working in a center that I am honored to call my second home.

I am also grateful to my friends and colleagues in Lebanon, whose dedication to the Syrian refugee crisis in Lebanon is a constant source of motivation and difficulty to do good by others. I wish to thank the various humanitarian experts and Lebanese constituents who agreed to invest their time, energy, and wisdom in enriching this dissertation. I have learned so much from our discussions and I hope that your voices are heard and reflected adequately within this manuscript. 
Finally, I cannot thank enough my family in Lebanon, whose love and kindness are my pillar. A special thank you to my late father, Said Abouarab, mother, Wedad Zard, Julie Abouarab, Norman Abouarab, Raymond Abouarab, Oscar Yamin, Katya Segovia, and Antoinette Hernani for being my rock and always encouraging me to finish what I have started. Your unconditional love has made me the privileged and proud person that I am today. 


\section{ABSTRACT OF THE DISSERTATION}

\section{SILENCED BODIES: (EN)GENDERING SYRIAN REFUGEE INSECURITY IN}

\section{LEBANON}

by

Jessy Abouarab

Florida International University, 2019

Miami, Florida

\section{Professor Susanne Zwingel, Major Professor}

While there has been a shift in security studies from the security of states to that of people, realpolitik still takes place under the banner of an emerging discourse of 'refugee crisis.' Refugee insecurities are (en)gendered and experienced where their depth and breadth pose significant challenges to asylum seekers, neighboring host-states, and humanitarian agencies. To this end, this research captures the unique dynamics of a South-South refugee crisis in Lebanon, in which Syrians residents make up nearly one-third of its population. It applies a transnational feminist framework to trace how refugee security norms get defined, are managed, and how they impact local context. In effect, a gender lens enables an in-depth investigation of the day-to-day challenges Syrian refugee women experience and manage within an unreceptive environment that disproportionately affect their resilience efforts.

Located at the intersection of Security Studies and Refugee scholarship, this dissertation provides a much-needed feminist approach that can bridge the tension between two paradigms previously perceived as exclusionary when exploring a transnational phenomenon such as forced migration. In a refugee-security context, an interdisciplinary study sheds light on how impromptu choices made by involved bodies-such as the Lebanese 
government and the UNHCR — can significantly impact local realities, creating a vicious cycle of refugee insecurities. This research, thus, addresses the political, sociocultural, and organizational dynamics that disproportionately affect the majority of registered Syrian refugees in Lebanon: Syrian women. It utilizes several tools, including expert interviews, indepth longitudinal cultural-theme analysis, and an action-oriented participatory method called Photovoice. These tools help this research explore the multilayeredness of Syrian refugee (in)security in Lebanon with structural and gendered implications. Hence, this study adds to the critical knowledge from Security Studies, Refugee Protection Regimes, and Women's and Gender Studies, serving as a useful tool for future projects on the contested politics of refugee (in)security and gender practices. 
I. INTRODUCTION

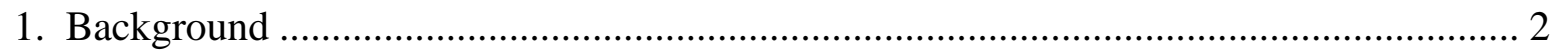

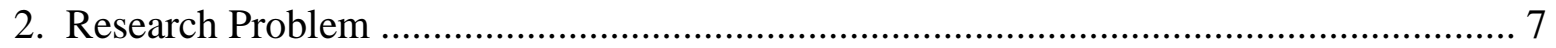

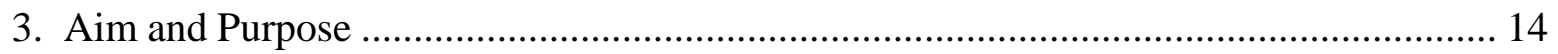

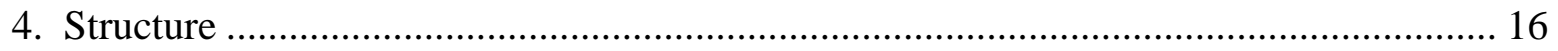

II. A FRAMEWORK FOR UNDERSTANDING REFUGEE (IN)SECURITY: ................ 20

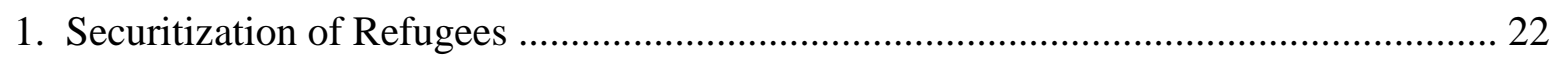

2. Refugee Protection Regime ……………………….............................................. 39

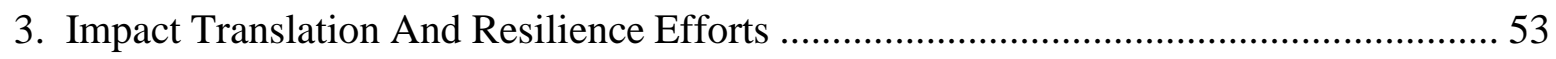

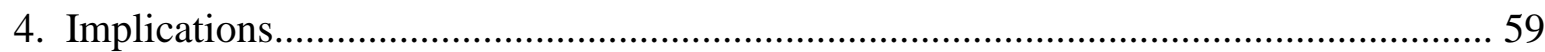

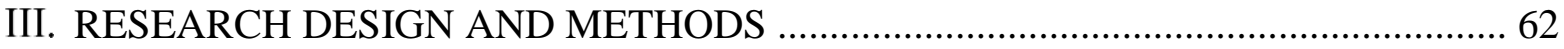

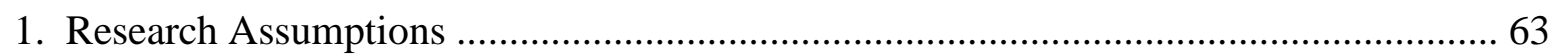

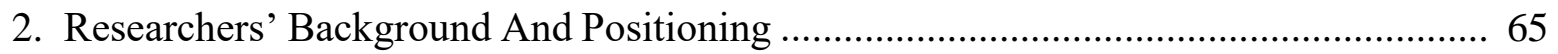

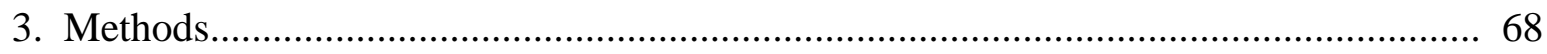

3.1 Thematic Analysis ........................................................................................... 70

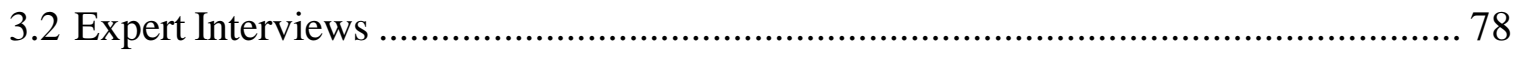

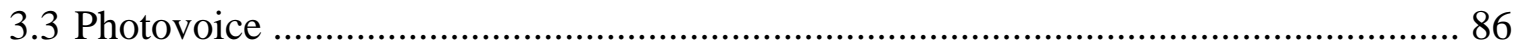

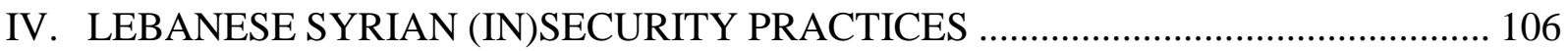

1. Critical Junctures in the Lebanese Syrian Relations ........................................................107

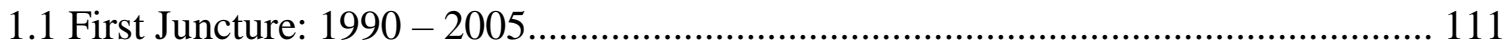

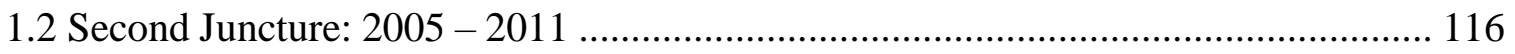

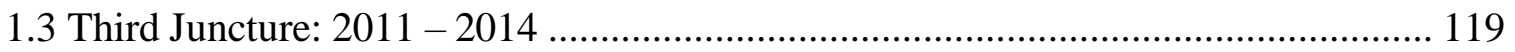

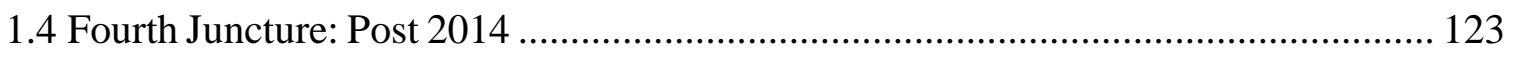

2. Lebanon's Sensitivity Toward the Word "Refugee" .................................................... 127

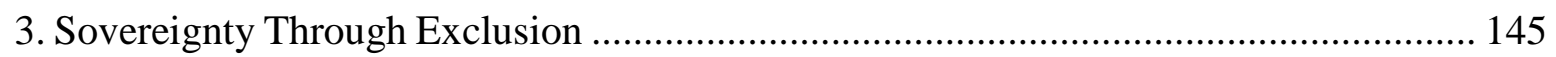

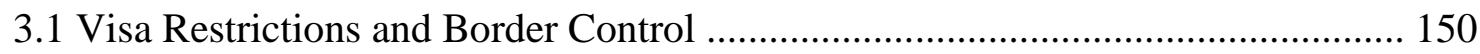

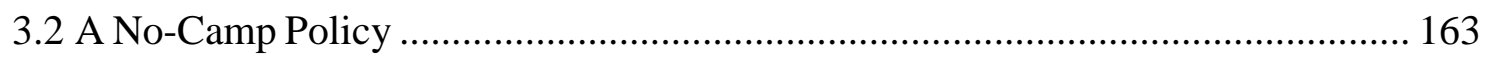

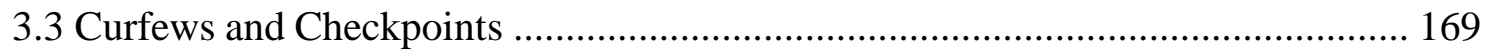

4. Systemic Discrimination of Syrian Women: A Double Tragedy .................................. 171

5. Analytical Implications ................................................................................... 184

V. (EN)GENDERING LEBANON CRISIS RESPONSE PLAN(S) .............................. 188

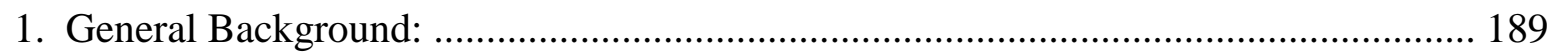

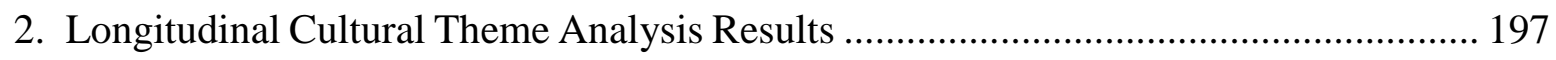




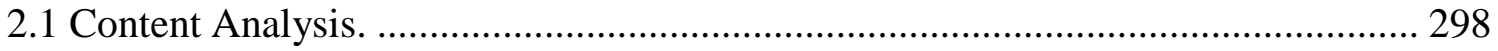

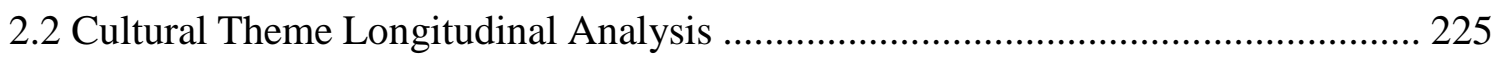

3. Triangulation of Themes with Additional Evidence .................................................. 226

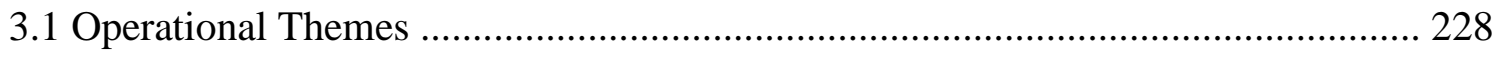

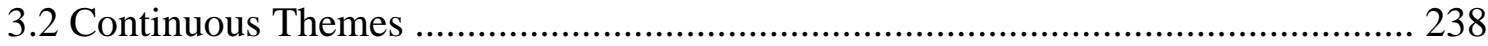

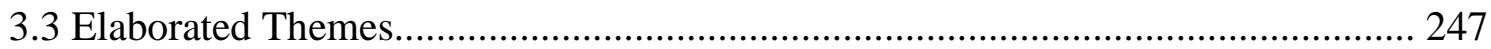

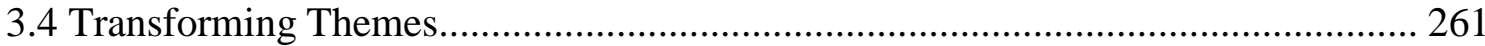

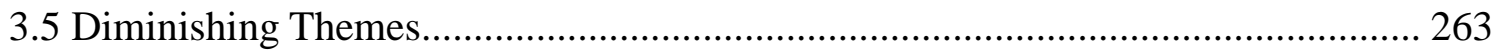

4. Analytical Implications ………………………...................................................... 267

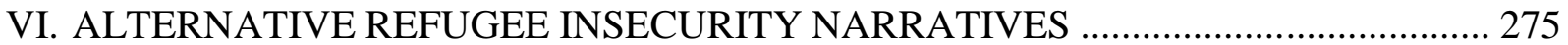

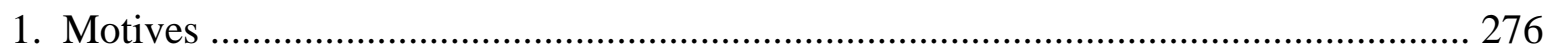

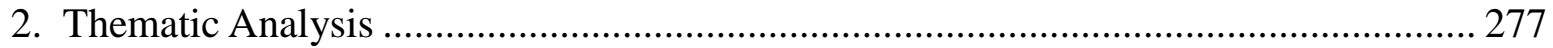

Theme 1: Extreme Impoverishment and Devastating Living Conditions ..................... 279

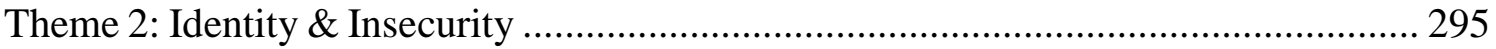

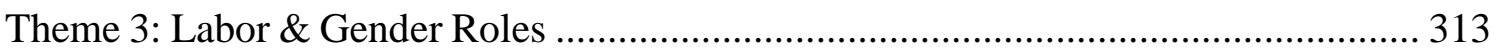

3. Photovoice Results and General Findings ................................................................... 324

VII. A VICIOUS CYCLE OF SYRIAN REFUGEE INSECURITIES ……....................... 341

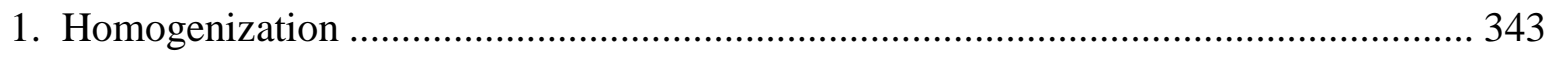

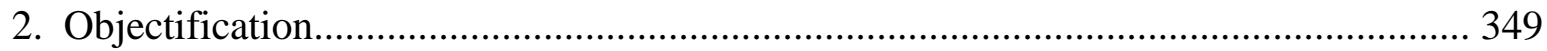

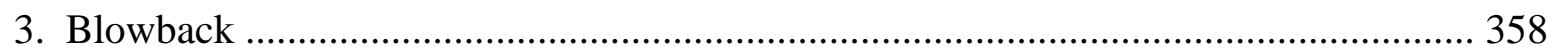

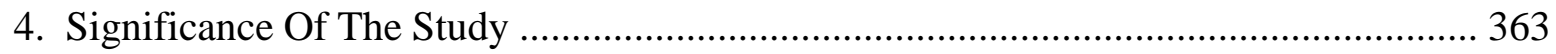

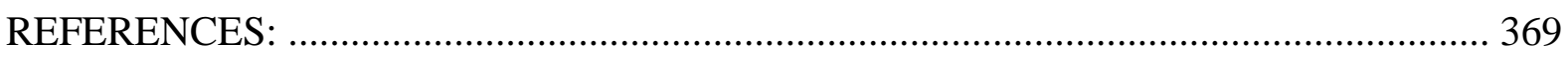

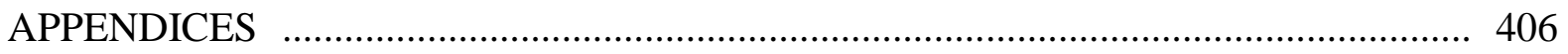

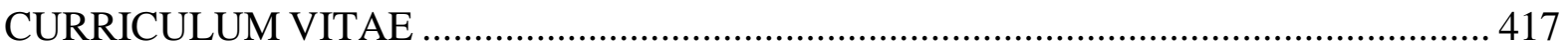




\section{LIST OF TABLES}

TABLE

PAGE

1. Longitudinal Cultural Theme Categories

78

2. Comparative Table of the 2015-2016 \& 2017-2020 Appealing Partners in Lebanon Crisis Response Plan

3. Longitudinal Analysis of Major Cultural Themes From 2015 to 2017

4. Summary of Attacks in Lebanon Post-Syrian Conflict 


\section{LIST OF FIGURES}

FIGURE

PAGE

1. Refugee (In)security

2. Syrian Registered Refugees with the UNHCR_August 2016

3. Lebanese Syrian Relations and Syrian Refugee (In)Security Practices 110

4. UNHCR Registered Syrian Refugees (2016) 126

5. Registered Syrian Refugees with the UNHCR By September 2018

6. Comparative Figure of Both LCRPs’ Response Strategies 194

7. Cover Images of Lebanon Crisis Response Plans 198

8. Word Cloud Comparison of Most Frequent Words 200

9. Crisis Response Plan Project Map 222

10. Refugee Insecurities Project Map 224

11. LCRP Sectors 2015-2016 236

12. LCRP Sectors 2017-2020 236

13. Diminishing Themes 263

14. New Themes 266

15. I am Thirsty! $\quad 280$

16. I Am Disinfecting Bread 283

$\begin{array}{ll}\text { 17. Scavengers } & 287\end{array}$

18. W.A.S.H. 291

19. I Want, But I Do Not Need 296

20. Refugee Food Assistance 300

21. Lost Identity 303 
22. Raising Awareness 306

23. Fear Of The Other 309

24. Child Labor 314

25. Shift Of Gender Roles 318

26. The Future 322

27. The Vicious Cycle Of Refugee (In)security 341 


\section{LIST OF ABBREVIATIONS AND ACRONYMS}

\begin{tabular}{|c|c|}
\hline UNSF & United Nations Strategic Framework \\
\hline UNHCR & United Nations High Commission for Refugees \\
\hline $\mathrm{RC} / \mathrm{HC}$ & UN Resident and Humanitarian Coordinator \\
\hline NGO & Non-Governmental Organizations \\
\hline ILO & International Labor Organization \\
\hline ICJ & International Court of Justice \\
\hline ICCPR & International Covenant on Civil and Political Rights \\
\hline ICESCR & $\begin{array}{l}\text { International Covenant on Economic, Social, and Cultural } \\
\text { Rights }\end{array}$ \\
\hline CEDAW & $\begin{array}{l}\text { Convention on the Elimination of all Forms of } \\
\text { Discrimination Against Women }\end{array}$ \\
\hline SDGs & Sustainable Development Goals \\
\hline GBV & Gender-Based Violence \\
\hline $\mathrm{MoU}$ & Memorandum of Understanding \\
\hline $3 \mathrm{RP}$ & Regional Refugee \& Resilience Plan \\
\hline LCRP & Lebanon Crisis Response Plan \\
\hline IASC & Inter-Agency Standing Committee \\
\hline MENA & Middle East and North Africa region \\
\hline GCC & Gulf Cooperation Council \\
\hline MoIM & Lebanese Ministry of Interior and Municipalities \\
\hline MoSA & Lebanese Ministry of Social Affairs \\
\hline IMC & Inter-Ministerial Committee \\
\hline GS & Lebanon's Directorate for General Security \\
\hline
\end{tabular}


GSO

LAF

MoE

MoIM

IASC

PAR

ITS
Lebanon's General Security Officers'

Lebanese Armed Forces

Ministry of Environment

Ministry of Interior and Municipalities

Inter-Agency Standing Committee

Participatory Action Research Approach

Informal Tented Settlements 


\section{INTRODUCTION}

This dissertation investigates the inherently political concept of "security" as it permeates a forced migration case of Syrian refugees in Lebanon. In that respect, since the refugee status belongs to "a movement of populations between existing and autonomous juridical states, ${ }^{1}$ various sites of refugee crisis construction, management, and implication are contextually relevant. One finds that global discourses and local attitudes often differ, (re)shaping host states' perception and juridical practices towards incoming refugees. Although the diversity of Lebanese political opinions is often vast, it seems that most Lebanese public and social outlets now have one commonality: "The Syrian displaced persons have no place in our home country." ${ }^{2}$ Even when not long ago many Lebanese witnessed similar displacement challenges during recent wars, some of them even question the legitimacy of Syrian refugees being forced to flee their homes, willingly disregarding the widely televised human atrocities that are happening in Syria. The projected official Lebanese anxieties, mostly found in public statements and policy reports, focus solely on repressing and resisting an overwhelming number of Syrian asylum seekers, preventing diverse groups of people with different needs from posing further damage to the already destabilized Lebanese state.

\footnotetext{
${ }^{1}$ Judith Butler and Gayatri Chakravorty Spivak, Who Sings The Nation-State?: Language, Politics, Belonging (London, England: Seagull Books, (2007), 6.

${ }^{2}$ Human Rights Watch, Our Homes Are Not for Strangers: Mass Evictions of Syrian Refugees by Lebanese Municipalities, (April 20, 2018), https://www.hrw.org/report/2018/04/20/our-homes-are-not-strangers/massevictionssyrian-refugees-lebanese-municipalities.
} 


\section{Background}

My consideration for this study derives from being a Middle Eastern, LebaneseAmerican female with an Arabic, French, and American background. My longstanding interest in social justice, women's rights, and gender equality have directed my interest in international law, field organizing, and recent doctoral studies. My interest in Syrian women's rights in Lebanon and refugee protection materialized in 2015 during a family visit. Throughout this time, Lebanese media outlets and local politicians were highlighting the burdens that Lebanon was enduring due to the increasing Syrian refugee influx. On the one hand, host states' public discourse of masculinized threats—-such as Syrian men committing crimes and terrorist attacks in several Lebanese towns-legitimized their ad hoc aggressive practices of stripping Syrians of refugee status, disqualified from being fully integrated into the host communities. On the other hand, humanitarian agencies' feminizing depictions of passive Syrian women and children living in impoverished areas in need of saving accorded Syrians a de facto refugee status, actively qualifying them for international protection and assistance.

The previous anti-Syrian sentiments towards their presence continued in Lebanon. This fact was evident during my two-month pre-dissertation field research in Lebanon, where a substantial amount of Lebanese families continued to dislike the Syrian presence, despite the change of the latter's status in the country from an occupying force to a group of forced migrants, who continue to threaten the country's security, economy, and demographic structure. Syrians prior to the refugee crisis were perceived as an extension of the occupying army of the Assad 
regime. My father, General Said Abouarab, was a Lebanese army officer who fought for Lebanon's stability his entire life. He witnessed several wars, deterred several coups d'états, and even took bullets and missiles that marked his body when he was safeguarding his country from any foreign and domestic threats. His resilience did not extinguish when the Syrian army took over the Ministry of Defense in October 1990, marching all the way to his office that still had the residue of a missile blast that went in, a few weeks earlier. While shredding all sensitive documents that might put other people in jeopardy, my father outwardly welcomed the new Syrian occupiers, keeping a low profile, while still serving his country.

My mother, like many Lebanese mothers, was a "forgotten soldier"3 whose resilience protected four children from bombshells and Syrian captivity. We were internally displaced for almost a year but privileged for having strong family support and allies, sheltering us until the end of the Lebanese Liberation War in 1990. Although I was very young at the time, this experience carried on with my parents long after the war, from health problems to psychological traumas that forced them to migrate in the early 1990s for a year to the United States of America. The fact is that the Lebanese civil war was one of the most gruesomely convoluted long-term conflicts lasting 15 years, from 1975 till 1990. ${ }^{4}$ The collective memory of modern Lebanese society mostly blames the start of the Lebanese civil war on

\footnotetext{
${ }^{3}$ Svetlana Alexievich, The Unwomanly Face of War: An Oral History of Women in World War II (New York: Random House, 2017), 5.

${ }^{4}$ Hassan Krayem, "The Lebanese Civil War and the Taif Agreement," in Conflict Resolution In The Arab World: Selected Essays, ed. Paul Salem (Beirut, Lebanon: American University of Beirut, 1997), 411-436.
} 
the actions of Palestinian refugees, trickling to a sectarian war, where a person's identity card served as a potential death warrant and "people would often be shot on the spot if their documents revealed the "wrong' sort of sectarian affiliation." Military checkpoints spread across the country where different militia groups would ask those who tried to pass for their identity cards, which revealed a person's sectarian affiliation.

It is important to note that, coming from a Christian-Maronite family, I was socialized in an all-French Christian school, living in an anti-Syrian and an antiArab bubble, not knowing and yet fearing the Muslim "other." I later became highly involved in anti-Syrian occupation student organizations and local resistance efforts. I witnessed Syrian soldiers arresting several of my friends in street protests, harshly interrogating and torturing them. During that time, I enrolled in the American University of Beirut (AUB), in 2001, pursuing a bachelor's degree in political science. This experience allowed me to be submerged in a diverse group of academics, significantly different from the protective anti-Syrian culture I was accustomed to. Not only did I learn a great deal about the intricacies of Lebanese politics and street cultures, but I also became more aware of the complexities within the Lebanese sects and the multiple views of the Syrian role in Lebanon. Accordingly, I took part in political arguments within safe student spaces about the

\footnotetext{
5 “Lebanon 'Moves Right Way' On ID,"
2009, http://news.bbc.co.uk/2/hi/middle_east/7906125.stm
} 
Syrian presence in Lebanon, while avoiding voicing anti-Syrian opinions too publicly for fear of Syrian retaliation.

Before AUB, I always thought that all Lebanese wanted the Syrians out of the country. Nevertheless, attending a diverse campus with a plethora of religious sects challenged some of my subconscious beliefs, assumptions, and prejudices related to this occupying Syrian presence. With time, I formed close and meaningful relationships with many Syrian students from different religious backgrounds. I regularly engaged them in heated political and religious discussions about Lebanese, Syrian, and regional dynamics. On the one hand, I witnessed the lack of political justice and the often-intersecting impacts of socio-cultural discriminations that hinder Lebanese from overcoming previous conceptions of Syrians. On the other hand, I had the privilege of participating in community engagements and cultural awareness exercises, strengthening individual rapprochement towards the Syrian "other."

These experiences allowed me to connect on an empathetic level and appreciate the common humanity within the diverse Lebanese-Syrian communities, siding politics and government activities from respective individuals' views and religious beliefs. Still, conversations about the gendered power relations and the daily challenges of the conflict were nonexistent at that time. Most research and policies sidelined women-centered issues and agency for the sake of other issues deemed more important when exploring people's experiences and government activities during that time. 
Being privileged enough to later travel, live abroad, and experience the world, my conception of race, class, ethnicity, nationality, and faith matured. Having meaningful conversations about gender, religion, and other multiple identities that affect people's everyday experiences enhanced my perception of the relationality of world politics. I came to understand how backgrounds and cultures (re)shape one's identity, values, and beliefs, influencing the type of topics a person felt suitable to discuss.

Many years away from the region's torments, I found myself back in Lebanon in 2015 for a family visit with a million and some officially registered Syrian refugees present in the country. ${ }^{6}$ During this time, I was asked to help organize and facilitate a municipal electoral campaign for a relative. My attempt barely lasted one night before I realized that his anti-Syrian rhetoric shifted from the Syrian government of Bashar al-Assad to the Syrians displaced in Lebanon, scapegoating al-Assad's reign. It was surprising to me how fast and easy political rhetoric changes. A few years back, I remember that same relative catechizing about the duty of Syria to host and assist their displaced Lebanese "brothers" during the 2006 Lebanon-Israeli war. However, his position switched as circumstances shifted with now millions of Syrians seeking refuge in Lebanon, considering them a risk and a burden, not welcomed in the country. Meanwhile, ironically like many

\footnotetext{
6 “Refugees From Syria: Lebanon,” UNHCR, March 2015, 6, http://reliefweb.int/report/lebanon/refugees-syrialebanonmarch-2015.
} 
other Lebanese employers, most of the employees he illicitly hires, till this date, are Syrians who can be paid lower wages with no legal benefits.

This personal experience motivated me to critically question the current Syrian refugee crisis in Lebanon. I initially found the various excuses for not wanting Syrians in Lebanon to be very challenging. The former Lebanese resilience, strength, and optimism of ending the Syrian occupation of Lebanon after the Syrian troops withdrew at the end of April 2005 shifted to extraordinary discriminatory claims of Syrian refugees becoming a never-ending occupying menace. Such types of mixed feelings and experiences that Lebanese have had with Syrians in their country, mostly as occupiers, led to my research in exploring the web of power relations that exacerbated this type of rhetoric in Lebanon and the significance of all the contentions that accompanied it in terms of refugee management and impact.

\section{Research Problem}

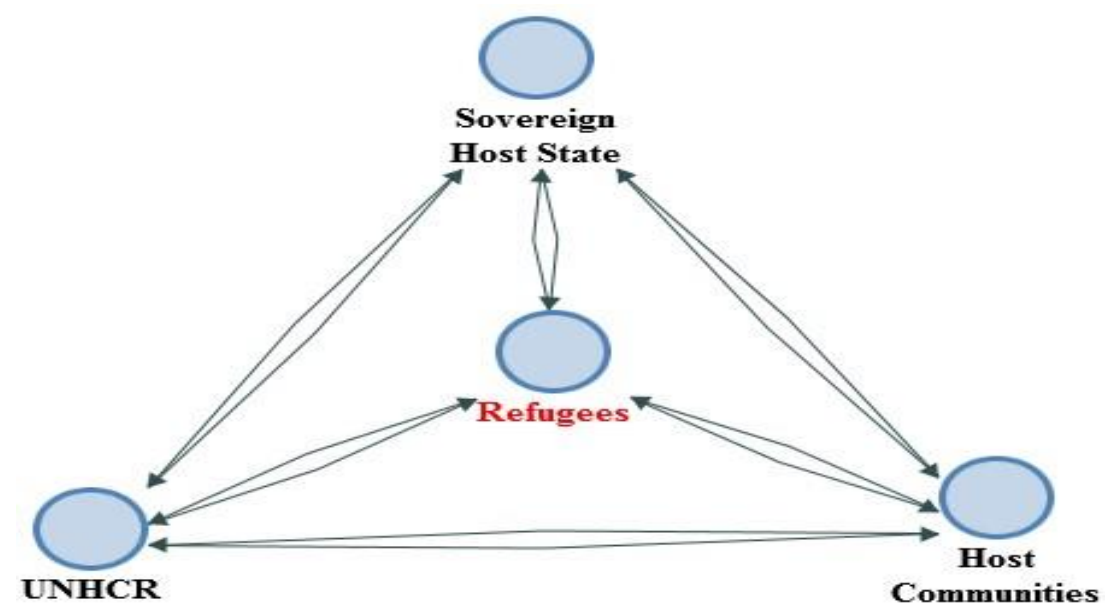

Figure 1. Refugee (In)security 
The figure above displays how forced migration due to warfare is one of the most traumatic types of human experience, where its depth and breadth pose significant challenges to interweaving refugees, neighboring host states and their communities, and humanitarian agencies, such as the Office of the United Nations High Commissioner for Refugees (UNHCR). Moreover, a massive and sudden inflow of refugees embodies great security and socio-political concerns for hosting communities. In that respect, this dissertation explores the following research question: "How do refugee security norms get defined, how are they managed, and how do they impact local contexts, for women particularly?" The dissertation chose the Syrian refugee crisis in Lebanon as a case study that illustrates how various socio-political dynamics lead to the construction, management, and practice of Syrian refugee (in)security in Lebanon. The reason behind this choice is that contrary to popular perception, most global forced migration trends occur between less developed or developing countries — often referred to as the "Global South"with contiguous borders. ${ }^{7}$ Triggered by the ongoing war in Syria, millions of Syrian nationals sought refuge in neighboring countries such as Lebanon, a nation populated by roughly four million people.

Although Lebanese authorities made tremendous efforts in containing the refugee crisis, their attention has primarily focused on direct short-term solutions such as providing their most vulnerable Lebanese citizens shelter, food, or securing

\footnotetext{
${ }^{7}$ Ratha, Dilip, and William Shaw. "South-South Migration And Remittances.” The World Bank, (2007), p 2.
} 
their borders against the influx of new refugees. ${ }^{8}$ This narrow, traditional framework of security prioritization has thus been implemented by focusing first on the national security of the state, then on citizen security, and only last on the security of refugees - in a genderless, over-generalized manner. Moreover, since Lebanon's stability is still an ongoing challenge, capturing the unique dynamics of this South-South forced migration case between contiguous developing countries, in which Lebanon is undergoing a massive demographic transformation - in which Syrian refugees make up nearly one-third of its population-is a thought-provoking research task.

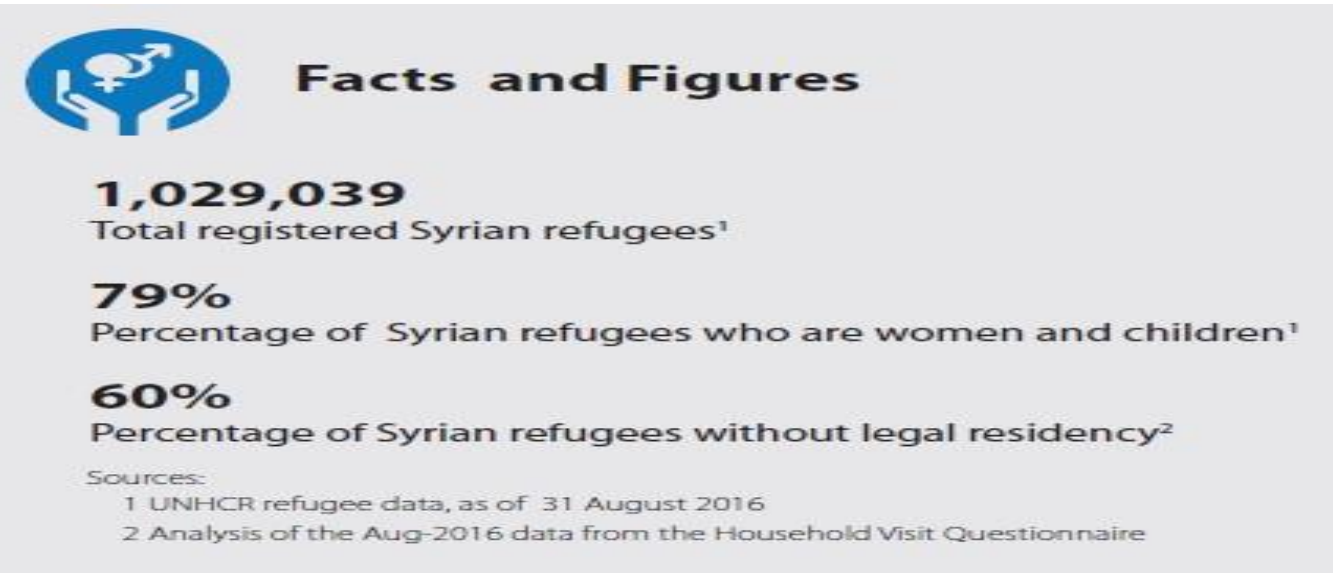

Figure 2. Syrian Registered Refugees with the UNHCR-August $20169^{9}$

The figure above provides the number of Syrian refugees registered with the UNHCR in Lebanon and some demographic estimates of the particular groups that

\footnotetext{
${ }^{8}$ Mark Manly, "UNHCR's Mandate And Activities To Address Statelessness In Europe," European Journal of Migration and Law 14, no. 3 (2012): 261-277.

$9 \quad$ "SGBV Dashboard," Interagency, Lebanon, January-August 2016. http://data.unhcr.org/syrianrefugees/working_group.php? Page=Country\&LocationId=122\&Id=47.
} 
it includes. Correspondingly, this figure shows an estimated sixty percent of registered Syrian refugees are without legal residency in Lebanon due to various biased laws and security practices that generate or perpetuate an unabated cycle of refugee insecurities. In that respect, despite the effort Syrian refugee women and children make to escape the horrors of war, the Lebanese government and international agencies seem to provide little to no relief to the majority of the Syrian refugees.

In theory, a refugee has a special status in international law and is defined by the United Nations as a person who:

"Owing to a well-founded fear of being persecuted for reasons of race, religion, nationality, membership of a particular social group or political opinion, is outside the country of his nationality and is unable or, owing to such fear, is unwilling to avail himself of the protection of that country; or who, not having nationality and being outside the country of his former habitual residence, is unable or, owing to such fear, is unwilling to return to it." ${ }^{10}$

However, it is critical to note that women are, mostly, absent from this traditional refugee definition. ${ }^{11}$ In fact, Syrian women refugees are not isolated from the various types of insecurities as they form most of the officially registered

\footnotetext{
10 “1951 Refugee Convention And 1967 Protocol Relating To The Status of Refugees," United Nations, General Assembly, http://www.unhcr.org/3b66c2aa10.

${ }^{11}$ Elisabeth Olivius, "Constructing Humanitarian Selves and Refugee Others: Gender Equality and the Global Governance of Refugees," International Feminist Journal of Politics 18, no. 2 (2016): 276.
} 
refugees in Lebanon. ${ }^{12}$ Moreover, since women and men experience (in)securities distinctively spatially and by gender, ${ }^{13}$ refugee women, in this regard, are doubly marginalized, due to their refugee status and gender. Congruently, gendered power relations are everywhere in global politics and "whenever they are not recognized, the silence is loud." 14 That is why understanding these dynamics is essential when contextualizing the different (re)productions of Syrian refugee security strategies and protection mechanisms in the case of Lebanon. With so much attention going towards both; the need for international aid to protect refugees, as well as national security concerns to assure state stability, a gender lens would provide a more indepth exploration of how the plight of Syrian women does not seem to receive the necessary attention that they so desperately need. In turn, the study investigates how Lebanese refugee policy plans and practices tend to silence Syrian refugee women, where their insecurities are often absent, not prioritized, and are generally neglected.

Under the guise of sovereignty, state-centric structures for addressing forced displacement and the lack of a commonly agreed international legal framework are severe obstacles for addressing both short and long-term refugee insecurities and resilience efforts that displaced persons endure within a specific

\footnotetext{
${ }^{12}$ Rola Yasmine and Catherine Moughalian, "Systemic Violence Against Syrian Refugee Women and the Myth of Effective Intrapersonal Interventions," Reproductive Health Matters 24, no. 47 (2016): 27-35.

${ }^{13}$ Lene Hansen, “The Little Mermaid's Silent Security Dilemma And The Absence Of Gender In The Copenhagen School,” Millennium: Journal of International Relations 29, no. 2 (2000): 285-306.

${ }^{14}$ J. Ann Tickner and Laura Sjoberg, "Feminism", in International Relations Theory, Discipline and Diversity, 3rd ed., ed. Tim Dunne, Milja Kurki, and Steve Smith (Oxford: Oxford University Press, 2013), 209.
} 
host country such as Lebanon. Concurrently, state-centric research on the securitization-refugee protection nexus-what the study refers to as "refugee (in) security" - and how they matter in global politics, are limited from being potentially useful for examining the critical gaps within the (en)gendered politics of Syrian forced migration into Lebanon. That is why this research asserts that the transnational politics of forced migration requires a multileveled initiative under a gender lens to better explore these gaps within the divergent perceptions and practices of Syrian refugee insecurity in the case of Lebanon soundly and ethically. $^{15}$

Correspondingly, gender, as a term, possesses a dual meaning: firstly, this research defines gender as a social construction of being perceived as a male or a female, and secondly, as a structural system of privileging male behaviors that can feminize or masculinize diverse groups of asylum seekers and their interrelationships_-what the study refers to as "gender(ing)". ${ }^{16}$ Accordingly, this study uses a gender lens to highlight the current dyadic construction of Syrian refugees as either men/masculine, framed as a security threat, or women/feminine, depoliticized with no agency, in which the meaning of one is dependent on the

\footnotetext{
${ }^{15}$ Amitav Acharya, "The Limitations of Mainstream International Relations Theories for Understanding the Politics of

Forced Migration" (lecture, Centre for International Studies, Oxford University, 27 October, 2008). Karen Jacobsen and Loren B. Landau, "The Dual Imperative in Refugee Research: Some Methodological and Ethical Considerations in Social Science Research on Forced Migration," Disasters 27, no. 3 (2003): 185-206. Alexander Betts, Forced Migration and Global Politics (New York, NY: John Wiley \& Sons, 2009).

${ }^{16}$ Jane Freedman, Gendering the International Asylum and Refugee Debate (Palgrave Macmillan, 2015), 19.
} 
meaning of the other. ${ }^{17}$ By exploring this dyadic social construction and cultural representation of Syrian refugees and their gendered performance in the case of Lebanon, this research aims to disrupt the perceived dichotomy of refugee perception within the schemes of refugee insecurity, providing a space for productive dialogue across disciplines. Thus, the study explores how underlying factors, such as geopolitics and biased cultural influence on strategic policy planning, that significantly inform this research affect social perceptions and subsequently impact how policies are to be professed and implemented.

In that regard, the Middle East and, in specific, Lebanon has a long history with Syrians, in which political and sectarian conflicts have altered the fabric of its society, influencing attitudes, opinions, and politics both internally and on a regional scale. Communities are products of historical and social contingencies that shape specific cultural identities, reflecting individual and collective security interests and practices. Lebanon's case with the Syrian refugees is still an ongoing problem awaiting a resolution. In particular, public policies play a huge part in that they delineate a de facto refugee's ability to secure their life without discriminatory labels that might constrain, and marginalize them as unwelcomed displaced persons that threaten the host state's stability. ${ }^{18}$ After all, being recognized as a refugee signifies that the international community and government agencies should strive

${ }^{17}$ Ibid.

${ }^{18}$ Sue Lautze and John Hammock, Saving Lives and Livelihoods: The Fundamentals of a Livelihood Strategy (Medford, MA: Feinstein International Famine Center, Tufts University 1997). 
to ensure the empowerment of the acknowledged groups of people for equal access to education, healthcare, safety, shelter, and most importantly, gender sensitive employment opportunities. Still, refugee integration and assimilation processes are state dependent, manifesting asymmetrically within populations, with women often being subjected to greater adversity than others. These dynamics, thus, necessitate an empirically motivated gender approach to meaningfully examine how the Syrian refugee crisis is (en)gendered in the case of Lebanon and how it profoundly impacts Syrian refugee women.

\section{Aim and Purpose}

This research draws on feminist critiques of security studies and refugee-protection regimes to enhance the examination of the refugee-protection regimes' efficiency, while also accommodating host states' security concerns in a constructive way. It aims to shed light on the relational challenges across the different stages of refugee (in)security with a focus on the majority of registered Syrian refugees in Lebanon; Syrian women, who seem to be silenced the most through this entire process. I chose Lebanon's case of the Syrian refugee crisis because it adds value to the general debate on security construction and gender norm translation in refugee governance mechanisms within a neighboring developing country. Considering the absence of extensive South-South forced migration studies, Lebanon's case in light of the Syrian refugee crisis serves as a starting point to further investigate such a heated topic.

In this context, incorporating a gender dimension into analyzing the nuances of security norms' construction and implementation can improve our understanding of how these norms are formed and internalized, as well as shed light on their local 
impact. In that regard, a feminist read on the refugee protection regime unearths many issues and gives voice to people who have been marginalized by traditional security and refugee protection methods. The study uses cross-disciplinary tools such as expert interviews, in-depth longitudinal cultural-theme analysis, and a participatory method named Photovoice, to understand the multilevel challenges of the Syrian refugee crisis in Lebanon, in which Syrian refugee insecurity is gendered and experienced. These tools contribute methodologically to the understanding of how gender plays into an increasingly securitized refugee migration and how this, in turn, affects Syrian women's experiences and resilience efforts in the case of Lebanon. The study is significant in a refugee security context, in which (inter)national decisions impact diverse groups of refugees for the rest of their lives. Accordingly, this approach gives a much more applied assessment, offering, at an additional level, a critique, and expansion of appropriate IR methods.

\section{Structure}

The dissertation is structured as follows. Chapter II outlines the dissertation's essential concepts and analytical framework, situating gender within critical scholarship in the field of security studies and refugee scholarship. This chapter brings a suitable strategy for the dissertation inquiry that would bridge both micro and macro refugee (in)security discourses and provide multiple research techniques as the best frames to study the Syrian refugee case in Lebanon. Through a transnational feminist lens, this chapter is both a process and a product that discusses the various relevant literature of security studies and global governance, highlighting the research's fundamental concepts and tools for inquiry. Each 
literature focus builds on the previous one, tracing normatively the construction, management, and impact of the politics of refugee (in)security. Accordingly, this chapter critically examines both kinds of literature on securitization of forced migration and the refugee-protection regime, which explicitly and implicitly (en)gender the refugee (in)security conception and management between host states, refugee protection regimes, and refugees, with particular attention to women. It then explores the literature on impact translation, where power hierarchies (re)shape intersectional refugee realities and resilience efforts, not recognized in dominant IR scholarships, such as Realism and Liberalism.

Chapter III describes the research design and methods applied in this dissertation. It evaluates a combination of three areas of research method scholarship under a qualitative multi-methods approach aiming to provide a sophisticated understanding of refugee (in)security constructions, practices, and experiences. The study uses multiple tools - such as expert interviews, in-depth longitudinal cultural-theme analysis, and a participatory method named Photovoice - to fully understand the multifaceted connections and challenges between traditional security and human security regarding gender insecurities confronting the Syrian refugee crisis in Lebanon. By providing complementary insights, this section discusses the potential of comprehensively triangulating all three methods as a dialectical process to trace the securitization-refugee protection nexus and process in the case of Lebanon. These methods combined would then bridge the international, national, and local contexts, formulating an adequate analytical approach in the field of IR. 
Chapter IV traces the shift of geopolitical and Lebanese social attitudes towards Syrian refugees by highlighting important critical junctures in the Lebanese-Syrian relationship. It, then, explores the official Lebanese sensitivities towards the term 'refugee,' and official attitudes toward refugees, in general, and Syrians in Lebanon, in specific. Lastly, this section analyzes the political implication on explicit and implicit changes in security practices right after the last significant political juncture post-2014. It, ALSO, highlights the aggressive and regulative refugee control approach that bolstered the role of local authorities and municipalities to legitimize ad hoc and, at times, illegal actions furthering securitized practices across Lebanon.

Chapter V analyzes the contextual dynamics, tension, and resistance that shape and are shaped by specific refugee crisis response plans between collaborating political institutions with distinct visions and goals. Specifically, the focus will be on two core institutions: the Lebanese government and the United Nations High Commissioner for Refugees (UNHCR). The study chose Lebanon as an example of a sovereign developing state that hosts refugees, while the UNHCR is the leading international organization responsible for refugees' protection. Although roles played by other UN agencies and regional organizations to prevent and reduce statelessness as well as to protect refugees are important, the UNHCR plays a significant role, in the case of Lebanon, where most response projects are either funded or implemented between Lebanon and the UNHCR. A longitudinal comparison of consecutive Syrian Crisis Response Plans-LCRPs-and their triangulation with other primary sources highlights the transformation of Lebanon's 
Syrian refugee crisis management. It brings to view the power dynamics between two collaborating bodies of different knowledge-claims and approaches to managing the Syrian crisis.

Chapter VI explores how gender (in)security norms are applied on the ground. It highlights the gendered impact on refugees' (in)securities practices in general, Syrian women in specific. Accordingly, trough Photovoice methodology, this chapter enables local Lebanese volunteers to facilitate some visibility to the Syrian refugees by recording and reflecting their views of the Syrian refugee realities through pictures and voice to reach normative policy change. Through a participatory action research approach, this section helps the study observe, analyze, and transform our understandings of the daily Syrian refugee anxieties and resilience efforts in ways that extend beyond the narrow policies that hinder contextual contributions to general knowledge. It elaborates the local participants' important contributions to the study by voicing out complex realities of different Syrian refugees' daily insecurities, while, at the same time, recognizing their anxieties as Lebanese citizens towards the Syrian presence within their communities.

As for the concluding chapter, it explores the local repercussions of the Syrian refugee crisis in Lebanon due to the imposition of restrictive policies on the entry, movement, and residence of Syrians in Lebanon after December 2014. It provides a synthesis by discussing the importance of situating gender within critical scholarship in the field of security studies, refugee protection regimes, and norm translation, when highlighting what seems to be a vicious cycle of insecurities 
across Lebanon due to securitized Syrian refugee management practices that legitimized ad hoc and, at times, illegal actions. In that respect, this concluding section highlights the benefit of an interdisciplinary research method in IR scholarship as a strategy to integrate insights across disciplines and levels of analysis, furthering our knowledge of multi-layered social phenomena with structural and gendered implications. 


\section{A FRAMEWORK FOR UNDERSTANDING REFUGEE (IN)SECURITY}

As forced migration is a multidisciplinary field of study, to understand the way refugee (in)security norms get defined, are managed, and how they affect local contexts, specifically Syrian women, an interdisciplinary exploration is required. This chapter provides a general overview of interweaving feminist scholarships on security studies, refugee politics, and norm translation that are relevant to this research study, situating my research question in a broader range of academic work. Accordingly, this chapter is divided into three parts. The first section explores feminist literature on security studies as it highlights the relevance of gender in the (re)production of refugee insecurity by questioning explicitly and implicitly the securitization of refugees as a threat to host state's security. Most importantly, this section examines feminist critiques of securitization theory that is of relevance to this study for it is a process that explains the extreme prioritization of a specific issue that is not inherently threatening, moving it beyond ordinary politics, where securitized objects increasingly become homogenized, objectified and alienated as faceless imminent threats. ${ }^{19}$

The following section identifies the structural limitations and gender biases inherent within the refugee-protection regime. It explores the sites at which power hierarchies (re)shape securitized refugee protection practices. Thus, the literature

19 Sara Meger, "The Fetishization Of Sexual Violence In International Security," International Studies Quarterly 60, no. 1 (2016): 149-159. 
review of this section covers postcolonial feminist critics of the refugee-protection regime. It assesses the benefit of including a social theory to provide an adequate framework to explore the multilayered humanitarian rationalities and mechanisms used in translating refugee protection norms into concrete response practices that, according to Elisabeth Olivius, seem to objectify, alienate, and subordinate the diverse groups of refugees. ${ }^{20}$

The third section sums an analysis of the securitization-refugee protection nexus in that they mostly dismiss contextual realities and resilience efforts of refugees, women in specific. It draws on Susanne Zwingel's transnational theoretical framework on norm translation and, more precisely, "impact translation" gearing the third part of the study to pursue a bottom-up, communitybased, participatory approach that would better examine the local repercussions of securitized refugee practices and Syrian refugees' resilience efforts in the case of Lebanon. ${ }^{21}$ Accordingly, uncovering the scholarship on resilience is of the essence in providing a complementary framework to explore the missing link between the current humanitarian and security practices toward Syrian refugees that seem to silence them and ignore their agency through systematic securitization and genderneutral protection practices that reinforce a cycle of depoliticized refugee victimization.

\footnotetext{
${ }^{20}$ Elisabeth Olivius, “(Un)Governable Subjects: The Limits of Refugee Participation In The Promotion Of Gender Equality In Humanitarian Aid,” Journal of Refugee Studies 27, no. 1 (2013): 42-61.

${ }^{21}$ Susanne, Zwingel. “Translating International Women's Rights.” Palgrave Macmillan UK, 2016. p 156.
} 


\section{Securitization of Refugees}

The use of the term security in the field of international relations (IR) is not novel and has been subject to extensive debate. ${ }^{22}$ While Feminist theorists hold distinct theoretical frameworks and lenses, bringing unique perceptions and experiences, they mostly critique traditional IR's state-centric conception of security for the lack of attention it gives to both people, let alone women, and gender as a category of analysis. ${ }^{23}$ One main critique of ahistorical traditional IR paradigms - such as Realism, Liberalism, and their subsequent "neos"- is that they are primarily defined in state terms with gendered qualities, as there is no higher authority above the state in legal and governance terms. ${ }^{24}$ Their grand narratives essentialize a refugee's identity, silence the different factors and bodies involved, and (re)produce simplistic, somewhat harmful, readings of refugees' insecurities. On the one hand, Realist security concerns focus on the sovereign states as unitary actors securing themselves from any form of threat to survival, reinforcing territorial boundaries through hard military control and balance of power practices. ${ }^{25}$ Within an "anarchic" state-based system, Realists construct asylum seekers in security discourses, mostly portraying them as opportunistic masculine threats to national security and socio-economic stability. On the other hand, the human security

\footnotetext{
${ }^{22}$ David Baldwin, “The Concept Of Security.” Review of International Studies, no. 23 (1997): 5-26.

${ }^{23}$ Dipti, Tamang. "Gendering International Security: Seeing Feminist Theories As International Relations." International Studies 50, no. 3 (2013): 226-239.

${ }^{24}$ Anna M. Agathangelou and Lily HM Ling. "Power, borders, security, wealth: Lessons of violence and desire from September 11." International Studies Quarterly 48, no. 3 (2004): 517-538.

${ }^{25}$ Alexander Wendt. Social Theory Of International Politics. Cambridge University Press, (1999), 1.
} 
literature, dominated by Liberalism, identifies a broader human security approach that commits to generalized, inalienable human rights, and promotes a state's legal and moral state responsibility to protect and secure human lives. Consequently, Liberalism frames refugees as passive, feminized, and depoliticized victims, awaiting humanitarian assistance and protection. Still, both paradigms' concerns seem to be ahistorical and state-focused on national and international security policies.

Congruently, Feminist approaches made outstanding contributions to the literature on security, where only with the reduction of all forms of physical, structural, and social violence can security be achieved. ${ }^{26}$ Feminism played an essential role in widening the security agenda, challenging the idea of the state monopoly over the provision of security that often causes insecurities to a large section of its subjects, specifically women, due to their social positioning. Accordingly, these feminist theories are of interest to this research in expanding and enriching the concept of security by bridging the gap between theory and practice. Many feminist critics build upon social constructivist theories' view that ideas shape the world, not just rules or legal treaties, which are necessary but insufficient. ${ }^{27}$ The state-centric conceptions of security are essentialist, inaccurate,

\footnotetext{
${ }^{26}$ Tickner, J. Ann. "Re-Visioning Security." International Relations Theory Today (1995): 175-97.

${ }^{27}$ Susanne Zwingel. Translating International Women's Rights The CEDAW Convention In Context. Palgrave Macmillan UK, (2016), 123.
} 
and biased. ${ }^{28}$ According to social constructivist scholars, a state's security interests are multilayered, carried out by distinct people ot different social levels with different values, who, in turn, unevenly affect local contexts. Therefore, widening and expanding the concept of security, beyond the safety of a state and its duty to its citizens, would deepen our understanding of the commonly known concept of Human Security. ${ }^{29}$

As a matter of fact, the concept of "securitization" developed out of social constructivism's focus on perception and interpretation, in which security is a "selfreferential practice." ${ }^{30}$ Securitization theory highlights the process of how and why specific issues and subjects are constructed as security threats, prioritizing perceived problems over other issues deemed tributary with normative consequences. ${ }^{31}$ Local contexts that are contingent on specific geopolitical, social factors, and connotations, unique to their respective political cultures, are essential in understanding the concept of securitization within that context. What is perceived as a security threat is subjective, relatively dependent on the observer and their intersectional background. It is a result of a process of social construction,

\footnotetext{
${ }^{28}$ Barry Buzan, "Peace, Power And Security: Contending Concepts in the Study of International Relations," Journal of Peace Research, 21 (1984): 109-25.

${ }^{29}$ Paris Roland. "Human Security: Paradigm Shift Or Hot Air?” International Security 26, no. 2 (2001): 87102.

${ }^{30}$ Barry Buzan, Ole Wæver and Jaap De Wilde. Security: A New framework for Analysis. Lynne Rienner Publishers, Harvard. (1998), 25.

31 Thierry Balzacq. “Constructivism and Securitization Studies." The Routledge Handbook of Security Studies (2010): 56-72.
} 
which calls into mind that "theory is always for someone and for some purpose." 32 How security threats emerge, evolve, and dissolve, shapes "the intersubjective establishment of an existential threat, which demands urgent and immediate attention, as well as the use of extraordinary measures to counter this threat." 33

One example is based on Lene Hansen's definition of "security as silence." ${ }^{34}$ Her article, "The Little Mermaid's Silent Security Dilemma and the Absence of Gender in the Copenhagen School," criticized the lack of gender in a particular tradition of IR security research framework, silencing or even aggravating alternative threats being faced. ${ }^{35}$ In that context, securitized discourses reflect gendered, constructed identities - who are we-and what is considered a national threat. Moreover, security approaches might not be necessarily positive nor universal. Instead, they are subject-dependent and, unevenly, harmful at times.

A gender lens helps this research focus on particular kinds of power relations that are absent in traditional IR security scholarships, further complicating the heterogeneity of multilayered (in)security dynamics. ${ }^{36}$ Hansen's study uses (in)security as an umbrella term for describing a range of security discourses that

32 Robert W. Cox. "Social Forces, States And World Orders: Beyond International Relations Theory," Millennium 10, no. 2 (1981): 128.

${ }^{33}$ Mark McDonald. "Securitization And The Construction of Security", European Journal of International Relations 14, no 4. (2008): 563-587.

${ }^{34}$ Lene Hansen. “The Little Mermaid's Silent Security Dilemma And The Absence Of Gender In The Copenhagen School," Millennium 29, no. 2 (2000): 285-306.

${ }^{35}$ Ibid.

${ }^{36}$ Jill Steans. Gender And International Relations: An Introduction. Rutgers University Press, NJ. (1998), 5. 
reproduce gender hierarchies and hegemonies, negatively affecting local experiences. Therefore, Hansen's argument provides valuable theoretical insights into this research. According to Hansen, gender is one crucial component that statecentered security perspectives ignore when homogenizing intersectional asymmetric problems. As a matter of fact, the gendered concept of security through state sovereignty, in the modern world, is enshrined in the notion of masculinist governmental leadership, effectiveness, and control within a feminized subordinate state's territory. Their creation is associated with the notion that a state's leadership is "monolithic, hierarchical, and violent." 37

Hansen's critique casts new light on how two images simultaneously silence and structurally oppress alternative femininities and masculinities within a refugee population, stripping away their agency and homogenizing their resilience capabilities. In fact, the whole process of becoming a refugee becomes dependent on a constructed patriarchal international system of nation-states with security implications. On the one hand, Hansen argues that securitized political discourses that exaggerate the stereotypical male behavior through an emphasis on sexuality, aggression and physical strength become hypermasculine. ${ }^{38}$ On the other hand, feminization tactics, such as humanitarian rhetoric, reinforce an image of people,

\footnotetext{
${ }^{37}$ John Hoffman, "Gender And Sovereignty: Feminism, The State And International Relations." Springer, (2001). 9.

${ }^{38}$ Lene Hansen. "The Little Mermaid's Silent Security Dilemma And The Absence Of Gender In The Copenhagen School," Millennium 29, no. 2 (2000): 285-306.
} 
in this case, refugees, as "backward, disempowered, passive and helpless." 39 Consequently, Hansen's analysis informs this research regarding how two images get simultaneously projected and securitized: faceless numbers of refugees become both potential masculine threat with the ability to cause physical aggression and danger, and feminized mothers, elderly, and children who are a burden, in dire need of protection.

As a transnational phenomenon, labeling a person a "refugee" challenges the political territoriality of a state, as it operates across national boundaries, entailing legal obligations for sovereign host states regarding how to manage people entering their territory. This transnational phenomenon becomes simultaneously descriptive and controversially transformative as it engenders a homogenized identity of individuals who cross state borders, providing them an internationally recognized legal status depending on the definitions ascribed to them. In that regard, these people's political, cultural, and national identities are constructed through discursive differences by comparing two or more things as right or wrong. We find that in the ever-evolving literature on forced migration and security studies various labels were used to define individuals that forcibly leave their home countries such as "asylum seeker" or "refugee" silencing them and striping away their agency. ${ }^{40}$

\footnotetext{
${ }^{39}$ Elisabeth Olivius. "Governing Refugees Through Gender Equality: Care, Control, Emancipation,” $P h D$. dissertation, Umeå universitet, (2014), 2.

${ }^{40}$ Sharon, Pickering. "Women And Extra Legal Border Crossing." In Women, Borders, And Violence, pp. 116. Springer, New York, NY, (2011): 4.
} 
With the modern proliferation of forced migration, the very concept of becoming a refugee took a negative turn. Refugees, in that case, are especially portrayed as foreigners attempting to seek asylum within state borders of what Benedict Anderson calls an imagined homogeneous community that is limited. ${ }^{41}$ From that aspect, Anderson's depiction of this homogeneous community sheds light upon the inaccurate construction of refugees as a security burden that legitimizes 'extraordinary measures' as the only way of protecting a false community identity of the insecure " $U s$ " (citizens) from the dangerous visualized "Other" (a foreign threat). ${ }^{42}$ These generalized constructions of identity gradually reinforce statist assumptions about the importance of securitizing citizenship and immigration control, framing the humanitarian identity of the host state as a vulnerability it cannot afford. Sovereign states become reluctant to accept a group of 'intrusive' people with this label for fear of regularizing the refugees' legal status and potential assimilation. Therefore, granting refugee status politicizes and stereotypes refugees as a threat to a state's national security, welfare, and, most importantly, identity. ${ }^{43}$ All refugees become homogenized into one big group of threats that is politicized as an uncontrollable transnational group of homogenized

\footnotetext{
${ }^{41}$ Benedict Anderson. “Imagined Communities: Reflections On The Origin And Spread Of Nationalism Verso. London. (2006), 6-7.

42 Annabelle Cathryn, Wilmott. "The Politics Of Photography: Visual Depictions Of Syrian Refugees In UK Online Media." Visual Communication Quarterly 24, no. 2 (2017): 67-82.

${ }^{43}$ Jef Huysmans. The Politics Of Insecurity: Fear, Migration And Asylum In The EU. Routledge, (2006), 46.
} 
individuals, whose rights and duties depend on the jurisdiction of the sovereign host state.

Still, as a highly politicized current crisis, protecting the forcibly displaced is a transnational collective problem that no state can handle alone. Threats do not exist independently from the discourses that mark them as such. ${ }^{44}$ Because this study is concerned with Syrians forcibly crossing Lebanese borders and (un)successfully registering with the UNHCR as refugees with inalienable rights, this study chose to explore the host state's juridical translation of their legal status, management, and (in)securities.

As a political act, the visual securitization of refugees as distant "others" transforms them into matters of security rather than humanity, legitimizing strict border security mechanisms on the entry and status determination of politicized asylum seekers. ${ }^{45}$ In his article "Manufacturing Threats: Asylum Seekers as Threats or Refugees," Scott D. Watson studies the influx of refugees from Sri Lanka to Canada to assess the implemented refugee policies. Watson's research provides evidence on how refugee policies shift from the societal to the political. The author's argument is critical in unlocking how forced migration push host states to securitize their borders, where refugees get framed as opportunistic individuals seeking to take advantage of the host state's vulnerability; “"bogus' refugees,

\footnotetext{
${ }^{44}$ Alison Gerard, and Sharon Pickering. "Gender, Securitization And Transit: Refugee Women And The Journey To The EU.” Journal of Refugee Studies 27, no. 3 (2014): 338-359.

45 Scott D. Watson. "Manufacturing Threats: Asylum Seekers As Threats Or Refugees." Journal of International Law \& Internationall Relations. 3 (2007): 100.
} 
criminals, terrorists or otherwise threaten the nation by virtue of the magnitude of the flow," thereby imposing a threat to the nation. ${ }^{46}$ This theoretical view explains the framing and stigmatization of distinct groups of individuals as either potential terrorists and criminals or victims who institutionalize dependency on both the state and the international community. The Sri Lankan asylum seeking process in the Canadian context established both: securitized mechanisms of racial exclusion through background security checks - designed to either weed out potential refugee applicants or surveil post-intakes - and institutionalized aid programs that force asylum seekers to depend on them when adapting to their new realities. This conduct reinforces a dyadic privilege of the benevolent host state granting securitized Sri Lankans conditional asylum. ${ }^{47}$ The portrayal of a "global-local divide" between protecting refugees and protecting host state sovereignty reinforces narrow securitization approaches as a zero-sum game. The outcome leads to what seems like a paradoxical shift from aid to deterrence, detention, and deportation, justifying individual and institutional violence as a means to control the foreign population in a dialectical manner. ${ }^{48}$

Watson's literature provides adequate empirical work on the shift of the social attitudes in local contexts, building on Canadian cultural biases towards the

46 Ibid.

${ }^{47}$ Emma Haddad. The Refugee In International Society: Between Sovereigns. Cambridge University Press, (2008), 24.

${ }^{48}$ Scott D. Watson. "Manufacturing Threats: Asylum Seekers As Threats Or Refugees." Journal International Law \& International Relations. 3 (2007):100. 
homogenized Sri Lankan refugees. The perceived mutually exclusive categories reinforce the framing of the opportunistic 'Other, ' who is taking advantage of the host state's benevolence. With nationalism and xenophobia on the rise, recent perceptions of refugees - a burden and a threat—erroneously push back the need of protecting the displaced who are forcibly fleeing from war, conflict, and persecution. Controversially politicized local practices against refugees get either justified or criticized for securitizing national measures governing the entry, and status determinants of refugees. ${ }^{49}$ By constructing refugees as potential security threats, their humanity is denied; making it dangerous to engage the "Other" inclusively. Projecting a threat as existential impedes refugee integration and assimilation.

Meanwhile, it is imperative to know those forced migrants entering the host communities. Even though refugee men do witness gendered discrimination and marginalization, Syrian women's (in)securities are the focus of this study. After all, they represent the majority of Syrians who registered as refugees with the UNHCR in the case of Lebanon. ${ }^{50}$ And, borrowing Sara Meger's theoretical framework regarding securitization, this study can highlight the fact that Syrian refugee women's everyday insecurities are multidimensional and go beyond just the physical. They cut across many aspects of human security, starting from the

\footnotetext{
49 Jef, Huysmans. The Politics Of Insecurity: Fear, Migration And Asylum In The EU. Routledge, (2006):7.

50 “Refugees From Syria: Lebanon," UNHCR, (March 2015), 6. http://reliefweb.int/report/lebanon/refugeessyrialebanon-march-2015.
} 
fundamental right to live free from torture and slavery, to different political, socioeconomic, cultural, physical and psychological safety.

In Merger's article entitled "The Fetishization of Sexual Violence in International Security," the author detects a non-linear chain of securitization processes of homogenization, objectification, and "blowback"- a metaphor to denote unintended negative consequences of operations. ${ }^{51}$ By objectifying security problems, state-focused securitization processes tend to decontextualize and homogenize the process, oversimplifying and exploiting specific approaches that fail to adequately address issues such as gender violence. Consequently, women refugees, specifically, tend to be affected by the host states' securitization discourse, silenced and portrayed as passive victims. Her work backs the feminist call for academic and policy practices to go beyond gender-blind efforts that tend to strip the different types of violence of their contextual meaning, becoming objects of fascination, consumable, and banal-fetishization, maximizing counterintuitive approaches. ${ }^{52}$

According to Meger, women's victimhood only served as an instrument for patriarchal political interest that silence intersectional gender inequalities. ${ }^{53}$ It is crucial to note that women are not one homogenous group that host states discriminate against. Interlocking dynamic systems of privileges such as class, ethnicity, and gender play a dominant role in (re)positioning some at an advantage

\footnotetext{
${ }^{51}$ Sara Meger, "The Fetishization Of Sexual Violence In International Security," International Studies Quarterly 60, no. 1 (2016): 149-159.

52 Ibid
} 
over others. ${ }^{53}$ Through state-centered securitized rhetoric, distinct groups of female refugees get exposed to various types of marginalization, often linked to their socioeconomic, cultural, and political backgrounds. Instead, Meger presents an important solution that this study could benefit from; the need for the desecuritization of gendered violence encouraging unexceptional practices that would not fetishize nor obscure the root causes of the problem at hand, namely gender hierarchy. ${ }^{54}$ That way, gender-sensitive sustainable development approaches would better promote inclusive human rights and social justice. ${ }^{55}$

Then again, securitization processes are multileveled frequently politicized procedures through different forms of representations, such as political speeches, media representation, provocative images, and local legislation. ${ }^{57}$ Their depoliticization would require deeper research. Speech acts are influential in the construction and legitimization of specific security measures. ${ }^{56}$ However, they are not the only form of action that constructs security frameworks. Security studies underlining the role of practice can reveal patterns of securitization that might not be shown when focusing solely on discourse or speech act. Practices are cultures in

\footnotetext{
${ }^{53}$ Sumi Cho, Kimberlé Williams Crenshaw, and Leslie McCall, "Toward A Field Of Intersectionality Studies: Theory, Applications, And Praxis," Signs: Journal of Women in Culture and Society 38, no. 4 (2013): 785-810.

${ }^{54}$ Sara Meger, "The Fetishization Of Sexual Violence In International Security," International Studies Quarterly 60, no. 1 (2016): 149-159.

${ }^{55}$ Ibid

${ }^{56}$ Barry Buzan, People. States \& Fear: An Agenda for International Security Studies in the Post-Cold War Era (Colchester, England: ECPR Press, 2008), 36.
} 
action. ${ }^{57}$ Emanuel Adler and Vincent Pouliot's "practice turn" provides a hands-on analytical framework for operationalizing security research and enhancing a crosstheoretical conversation..$^{58}$ It allows the study to bridge the different paradigms and disciplines in order to understand refugee (in)security better. Complex security activities are made up of countless local everyday practices- -"patterned ways of doing things" - that tend to get overlooked in mainstream scholarly research. ${ }^{59} \mathrm{By}$ bridging theories into empirical cases, security practices change the physical environment as well as the discursive social ideas surrounding them. ${ }^{60}$ Practices are performances and contextually meaningful patterns of action, socially developed through learning and training.

As a matter of fact, Lene Hansen investigates how insecurity discourse and bodily threats become framed as sporadic instances of "individualizing practices." According to Hansen, even though these latter are directed at specific individuals, they simultaneously (re)produce collective fear. ${ }^{62}$ Gender-blind bureaucratic prioritization and stratification of perceived masculinized individual threats create

${ }^{57}$ Emanuel Adler and Vincent Pouliot. "The Practice Turn In International Relations: Introduction and Framework." In International Studies Association 49th Annual Convention, San Francisco. (2008): 26-29.

${ }^{58}$ Emanuel Adler and Vincent Pouliot. “International Practices,” International Theory 3, no. 1 (2011): 1-36.

${ }^{59}$ Emanuel Adler and Vincent Pouliot. "The Practice Turn In International Relations: Introduction and Framework." 2629.

${ }^{60}$ Ibid.

${ }^{61}$ Lene Hansen, “The Little Mermaid's Silent Security Dilemma And The Absence Of Gender In The Copenhagen School," Millennium 29, no. 2 (2000): 285-306.

${ }^{62}$ Emanuel Adler and Vincent Pouliot. "The Practice Turn In International Relations: Introduction and Framework." 26-29. 
painful policies that silence women's basic needs. ${ }^{63}$ These practices reciprocally represent, enact, and possibly change the organizational culture and related discourses in (and on) the material world. ${ }^{64}$ Unlike habits, practices do not need extensive repetition to be acquired. Also, their performances, correctly or incorrectly done, are appraised on a social level ${ }^{65}$ Practices are highly political for they could sustain or undermine existing patterns of power relations. ${ }^{66}$ Therefore, with continuous feedback and change, new iterative problem-solving mechanisms will build on new shared practices and experiences.

Moreover, security practices tend to be contextually relative due to different viewers' interests. Security, according to Didier Bigo, is neither about survival nor urgency. ${ }^{67}$ Practices engage with their respective environment and its objects, whether those are natural, cultural, or political. The process of securitization could be linked to routinized practices of security professionals as well as "anchoring" practices, which means that a certain body would define their own set of strategies for action over others by setting new standards for "good" or "bad" domestic policies within specific sovereign states. ${ }^{70}$ As such, routinized or anchoring

\footnotetext{
${ }^{63}$ Lene Hansen, "Theorizing The Image For Security Studies: Visual Securitization And The Muhammad Cartoon Crisis," European Journal of International Relations 17, no. 1 (2011): 51-74.

${ }^{64}$ Ibid, p4.

${ }^{65}$ David M. McCourt, "Practice Theory And Relationalism As The New Constructivism." International Studies Quarterly 60, no. 3 (2016): 475-485.

${ }^{66}$ Ibid. p 50.

${ }^{67}$ Didier Bigo, "Security And Immigration: Toward A Critique Of The Governmentality Of Unease," Alternatives 27, no. 1 suppl (2002): 63-92 ${ }^{70}$ Ibid.
} 
practices make other related local practices flourish or diminish. ${ }^{68}$ Accordingly, Bigo's concept of securitization — as mundane bureaucratic practices, drawn from everyday politics - further elaborates this research's argument by explaining how the process of a host society's conduct of unease can direct the security norms and expectations of homogenized Syrian uncertainties. Routinized practices of security professionals, bureaucrats, and police reinforce counterintuitive "conditional hospitality." 69 Through hyper-regulated visa requirements, these practices counterintuitively silence refugee insecurities and inhibit them from accessing much needed essential services.

In that regard, practices possess a co-constitutive structural power of reinforcing and (re)producing securitized issues and rules. ${ }^{70}$ Norms in that sense are not static. They are continuously (re)interpreted, localized, and contextualized, forming organized and meaningful behaviors that create a variety of meanings, different patterns of accepted practices, and lead to a variety of outcomes. ${ }^{71}$ Accordingly, Susanne Zwingel's book Translating International Women's Rights helps this research demonstrate how international norms resonate in local settings. ${ }^{72}$

\footnotetext{
${ }^{68}$ Philippe Bourbeau, "The Practice Approach In Global Politics." Journal of Global Security Studies 2, no. 2 (2017): 170-182.

${ }^{69}$ Sarah Gibson, “Abusing Our Hospitality: Inhospitableness And The Politics Of Deterrence," Mobilizing Hospitality: The Ethics of Social Relations in a Mobile World (2007): 159-177.

${ }^{70}$ Emanuel Adler and Vincent Pouliot, “International Practices," International Theory 3, no. 1 (2011): 1-36.

${ }^{71}$ Elizabeth Olivius. "Governing Refugees Through Gender Equality: Care, Control, Emancipation.” Doctoral dissertation, Umeå universitet. 2014, 44.

${ }^{72}$ Susanne Zwingel. Translating International Women's Rights: The CEDAW Convention In Context. Palgrave Macmillan, (2016), 32.
} 
Zwingel states that there is no global consensus, but rather sites for various constructions, (re)definitions, and contestations of what gender equality norms mean to engaged, often competing, interest groups. ${ }^{73}$ Even though the author's work does not discuss security specifically, it traces how norms in general are negotiated between various interest groups when they aim to translate their shared vision into actual transnational activities and contextual policy practices. ${ }^{74}$ Consequently, practices of adoption, resistance, and opposition to refugee migration transform universal norms, such as human rights, into securitized state practices of controlling refugee migration, legitimizing ad hoc discriminatory agendas in the name of sovereignty.

These practices, in turn, explain how national interest measures lead to justifying exceptional mechanisms of refugee deterrence with counterproductive consequences. Not recognizing the gendered hierarchies and security practices result in a limited understanding of the issues at hand, (en)gendering what constitutes refugee (in)security practices. ${ }^{75}$ In turn, their strategies have gendered dimensions in which practices of hypermasculinity and feminization have diverging effects on women's and men's opportunities and experiences of seeking asylum.

\footnotetext{
${ }^{73}$ Susanne Zwingel. "How Do Norms Travel? Theorizing International Women's Rights In Transnational Perspective," International Studies Quarterly 56, no. 1 (2012): 115-129.

${ }^{74}$ Susanne Zwingel. Translating International Women's Rights: The CEDAW Convention In Context, 156.

75 Tamang, Dipti. "Gendering International Security: Seeing Feminist Theories As International Relations." International Studies 50, no. 3 (2013): 226-239.
} 
Gender, in that sense, is performatively constituted, establishing the identity it is purported to be. ${ }^{76}$ Judith Butler's thesis on performativity states that recurrent gendered actions and practices within a rigid regulatory frame "congeal over time to produce the appearance of substance, of a natural sort of being." ${ }^{77}$ Moreover, in the case of refugee power politics, security is understood as a means, a process rather than an ideal end. Security practices expose different social and structural hierarchies that might be invisible to external investigators, showcasing how these hierarchies construct and are constructed by a patriarchal system. ${ }^{78}$ Accordingly, local dynamics and biased social attitudes are crucial in influencing how specific policies appear as local discriminative practices, even in the case of sympathetic political rhetoric. A testament to this reality is forced migration, in which governments show empathy to forcibly displaced people while, at the same time, their contextual interests are silenced through securitized practices of maintaining state stability when asylum seekers attempt to come in. ${ }^{79}$

\footnotetext{
${ }^{76}$ Judith Butler. Gender Trouble: Feminism and the Subversion of Identity. New York: Routledge, (1990), 24.

${ }^{77}$ Ibid, 12.

${ }^{78}$ J. Ann Tickner, “You Just Don’t Understand: Troubled Engagements Between Feminists and IR

Theorists," International Studies Quarterly 41, no. 4 (1997): 611-632.

${ }^{79}$ Philippe Bourbeau. "Migration And Security: Securitization Theory And Its Refinement," in Annual Meeting Of The International Studies Association, Town \& Country Resort and Convention Center, San Diego, California, USA. 2006.
} 


\section{Refugee Protection Regime}

Since the modern system of nation-states inhabits an evolving international humanitarian regime, the study of refugee protection policy construction and practice is essential to understanding the (en)gendered Syrian refugee protection. Within the realm of refugee assistance, the United Nations High Commission for Refugees (UNHCR) is commonly the most authoritative agency. ${ }^{80}$ Till this date, the 1951 Convention relating to the Status of Refugees and its 1967 Protocol, through UNHCR, remain the sole legal instrument that determines the policy of refugee legal protection and assistance. ${ }^{81}$ Even with official declarations in favor of refugee protection, in general, most refugee security rhetoric portrays refugees as faceless people who need saving, while posing a burden on the already prevailing social, political, economic, and environmental troubles within the host state's communities. Therefore, it is essential to establish an adequate framework that better explores the explicit and latent power dynamics that guide this refugee protection regime construction and goals, where an (en)gendered refugee insecurity is often a matter of context. ${ }^{82}$

Accordingly, this section builds of interweaving Feminists theories when examining and criticizing international organizations, such as the UNHCR, for

\footnotetext{
${ }^{80}$ Jennifer Hyndman, "Managing Difference: Gender And Culture In Humanitarian Emergencies," Gender, Place and Culture: A Journal of Feminist Geography 5, no. 3 (1998): 241-260.

${ }^{81}$ Anne Hammerstad, The Rise And Decline Of A Global Security Actor: UNHCR, Refugee Protection, and Security. Oxford University Press, (2014), 2.

82 Kerstin Rosenow-Williams and Katharina Behmer, "Gendered Environmental Security in IDP and Refugee Camps," Peace Review 27, no. 2 (2015): 188-195.
} 
using mismatched procedural measures that often end up blurring the already marginalized population. ${ }^{83}$ Elizabeth Olivius' thesis on "how gender equality norms operate as governing tools $[\ldots]$ in refugee camps in the context of global relations of power and marginalization," is of relevance. ${ }^{84}$ Her thesis findings examine how gender equality in global refugee governance is "rarely treated as a goal in its own right." 85 Notably, governing refugee management's processes of gender equality construction, interpretation and application are, either promoted on "the basis of their usefulness" or as a means to different ends, limiting refugee gender empowerment and social change.

Effectively, Heather Johnson's argument that "the refugee has been racialized and victimized, she has also been feminized" in the international refugee regime is of interest. ${ }^{86}$ Johnson's article "Click To Donate: Visual Images, Constructing Victims And Imagining The Female Refugee," sheds light on the visual construction of the myth of a refugee identity, in which female refugees are portrayed as innocent people, whereas men lose their status as fathers, husbands, or sons, becoming potential terrorists or economic opportunists existentially threatening the host state's security. Her analysis helps this research push the idea

\footnotetext{
${ }^{83}$ Elisabeth Olivius. "Governing Refugees Through Gender Equality: Care, Control, Emancipation,” $P h D$. dissertation, Umeå universitet, (2014), 2.

${ }^{84}$ Ibid.

${ }^{84}$ Ibid.

${ }^{86}$ Heather L. Johnson, “Click To Donate: Visual Images, Constructing Victims And Imagining The Female Refugee.” Third World Quarterly 32, no. 6 (2011): 1015-1037.
} 
that various groups of refugees, as subjects of the refugee protection regime, become heavily dependent on the framing of different aid agencies, not capable of capitalizing on their own skills as self-help mechanisms. Johnson argues that refugee protection policies silence the diversity within the refugee population through the use of visual techniques and rhetoric that construct a 'female' refugee, depoliticizing refugees legally, socially, and economically for the success of humanitarian missions. ${ }^{87}$ Their feminization entice the curbing preexisting dialogical representation of refugees as radicalized foreigners, in which women and children are perceived as a lesser threat than men, who are still under the scrutiny of being an imminent menace. ${ }^{88}$

Consequently, as Johnson concludes; "how we imagine particular categories of people determines how we engage with them." 89 Tracing the contemporary history of UNHCR's media images of refugees, Johnson states that the inherent bias of the international community and humanitarian workers' personal values tends to perceive refugees as different - a radicalized foreign threat to their way of life. ${ }^{90}$ Therefore, Johnson's argument reinforces this research's theoretical claim that gender is significantly in humanitarian aid to the refugees, for gendered expectations of these agencies intersect with their aid workers' class,

$$
\begin{aligned}
& { }^{87} \text { Ibid. } \\
& { }^{88} \text { Ibid. } \\
& { }^{89} \text { Ibid. } \\
& { }^{90} \text { Ibid. }
\end{aligned}
$$


national, and background privileges, constructing a false refugee identity in their quest to protect asylum seekers.

In that respect, Charli Carpenter, in her article "Women, Children, and Other Vulnerable Groups," observed the repeated and exclusive frame of women and children within the transnational donor-seeking literature as one innocent, vulnerable, and a passive group of civilians who require saving and protection. Without a comprehensive understanding of the gendered underpinnings, this neoliberal portrayal of a vulnerable community seems to narrowly focus on just the utility perspective of gender in garnering international and host states' support and funds. ${ }^{91}$ Consequently, neoliberal practices get stuck between the tendencies of developing and modernizing the perceived "backward" refugee society and the need to respect harmful cultural relativist state practices that challenge basic women's rights. Thus, Carpenter's article also reinforces the argument that false gender identities are hierarchically displayed between the benevolent, altruistic aid workers and the backward, oppressed victims who host governments can neither criminalize nor manage on their own. ${ }^{92}$ Consequently, relief efforts often undermine the potentials for refugee resilience and coping strategies, whether

\footnotetext{
${ }^{91}$ R. Charli Carpenter, "Women, Children, And Other Vulnerable Groups: Gender, Strategic Frames, And The Protection Of Civilians As A Transnational Issue," International Studies Quarterly 49, no. 2 (June 2005): 295355.

92 Emma Haddad, "The Refugee In International Society: Between Sovereigns." Vol. 106. Cambridge University Press, (2008), 35.
} 
positive or negative, through the way in which humanitarian selves and refugee others are constructed. ${ }^{93}$

One of the problematic issues with emergency relief is that its design is based on the assumption that it has the moral capacity and the role to save refugees and do for them rather than work with them and empower them. ${ }^{94}$ The construction of altruistic selves assumes that the providers and administrators of relief are in a power position since they possess a mandate to save those who are silent, oppressed, and in need. The visual narratives' construction of the feminized victims or masculinized threats strips away the diverse asylum seekers' voice, agency, and humanity in public humanitarian discourse once they are labeled as a refugee "victim." 95 Those refugees are survivors. By labeling refugees as victims, this otherness of the refugee is constructed with the assumption that refugees are all needy, helpless, and passively dependent on those who will help, save, and modernize them. ${ }^{96}$ The representation of humanitarian workers as the sole promoters of gender equality strips refugees of their agency. It tends to mask the power dynamics of social relations, reinforcing structural and individual gender hierarchies between the different micro-groups that form the refugee population.

\footnotetext{
${ }^{93}$ Elisabeth Olivius, "Constructing Humanitarian Selves And Refugee Others: Gender Equality And The Global Governance Of Refugees,” International Feminist Journal of Politics 18, no. 2 (2016): 270-290.

${ }^{94}$ Ibid.

${ }^{95}$ Ibid.

${ }^{96}$ Ibid.
} 
As much as initiatives push for refugee security, there is a disjuncture between international norms promoted by state representatives, international agencies, and bureaucrats, and the reality on the ground. Refugees are thus being structurally gendered and silenced through refugee protection practices privileging feminizing standard operating procedures ${ }^{97}$ Looking at the covers of refugee crisis response plans or any other humanitarian "promotional" brochures or pamphlets, there often seems to be an image of a powerless yet exotic foreigner, mostly a young girl, a mother, or a powerless old couple displayed to incite empathy. ${ }^{98}$ These images are necessary for the refugee protection regime's survival in theory and practice - for these are the tools that will generate enough money to keep their relief programs and their jobs up and running within the host communities. The depoliticized representation of refugees has been strategic in the construction of political (non)agency, mobilizing public support and gathering more funds to curb the plight of worthy refugees and their insecurities further objectifying them. ${ }^{99}$

One issue that seems to be missing in Johnson's argument is that bureaucratic organizations, such as the UNHCR, struggle to adapt their

\footnotetext{
${ }^{97}$ Alison Gerard and Sharon Pickering, "Gender, Securitization And Transit: Refugee Women And The Journey To The EU,” Journal of Refugee Studies 27, no. 3 (2014): 338-359.

${ }^{98}$ Haddad. Emma. "The refugee in international society: between sovereigns." Vol. 106. Cambridge University Press, (2008) p 35.

${ }^{99}$ Heather L. Johnson, “Click To Donate: Visual Images, Constructing Victims And Imagining The Female Refugee,” Third World Quarterly 32, no. 6 (2011): 1015-1037.
} 
internationally recognized norms within a sovereign domestic polity. ${ }^{100}$ Unsurprisingly, celebrated gender mainstreaming norms in refugee protection principles get distorted when translated domestically. Zwingel offers a novel theoretical insight and extensive empirical research findings on the process of norms, which she calls; "trans-nationalization" and gender mainstreaming. Using different case studies of how an international norm resonates in different local realities, Zwingel in her book; "Translating International Women's Rights," highlights how the gap between international norms and local contexts gets closed through a continual long-term process of (re)negotiation and (re)interpretation. ${ }^{101}$ In that respect, contested global refugee norms do not linearly diffuse in the local context. A translation process occurs depending on engaged translation work through norm entrepreneurs and social advances. However, in the refugee context, humanitarian agencies, such as the UNHCR, are not just biased, but they are also codependent on a state-based system. They tend to work closely with host states that would ultimately influence whom to feminize as a refugee victim and whom to label as a hyper-masculine foreign threat. After all, host states and the international community, at large, play a significant role in the refugee crisis policy plans, constructing and (re)shaping their 'strategic partnership' with concerned

\footnotetext{
100 Jane Freedman, "Mainstreaming Gender In Refugee Protection," Cambridge Review of International Affairs 23, no. 4 (2010): 589-607.

${ }^{101}$ Susanne Zwingel. “Translating International Women's Rights.” Palgrave Macmillan UK, 2016. p 32.
} 
humanitarian agencies in managing a refugee situation, such as securitizing it a 'crisis.'

Managing actors, such as sovereign states and humanitarian agencies are too interested and at the same time constrained to apply these international norms without any compromise. When collaborating with host states in refugee management policy creation and implementation, the neutrality and independence of humanitarian agencies, such as the UNHCR, is undermined, becoming more politicized than ever. ${ }^{102}$ Most refugee protection policies are shared with host government authorities, humanitarian NGOs and other UN agencies, among many other interest groups. While these bodies have different security interests and a considerable say in the refugee protection regime, humanitarian and refugee security practices become integrated, and not merely parallel endeavors. This would mean that the UNHCR's multilateral involvement in refugee protection can never be objectively altruistic as states, interest groups, and multilateral governing institutions inter-subjectively prioritize their interests in securitizing the refugee threat through different processes, such as institutional funding or labeling a situation as a "humanitarian crisis."

This argument reinforces the study's goal in highlighting how gender mainstreaming efforts based on need get downgraded to sustainable long-term programs and future goals as a compromise to gain access to refugees within

\footnotetext{
102 Michael Barnett, "Humanitarianism Transformed," Perspectives On Politics 3, no. 4 (2005): 723-740.
} 
culturally relativist host communities and concerned donor funds with distinct securitized goals-realpolitik. ${ }^{103}$ In that respect, the UNHCR operations rely on and compete almost entirely for, voluntary contributions from member states, international and regional organizations, as well as some pooled funding mechanisms that include the private and politically affiliated sectors. Donor states became the UNHCR's main patrons with up to $98 \%$ of funds provided by sovereign states, limiting thus the organization's commitments to refugees. ${ }^{104}$ According to Michael Barnett, donor states possess considerable influence over the UNHCR's agenda while refugees become voiceless recipients in need of the international community to compassionately help them. ${ }^{105}$ Donor states voluntarily choose who, what, where, and when to fund. ${ }^{106}$ Accordingly, the universally recognized human rights regime translates into a plethora of competing humanitarian agencies whose specialization depends on the number of funds they get from different interest groups.

For the sake of success, UNHCR programs that promote women's participation do not capture the discriminations that refugee women brave through

\footnotetext{
103 James Milner, “Introduction: Understanding Global Refugee Policy,” Journal of Refugee Studies, Oxford Press, (2014): 477-494.

104 Jane Freedman, "Mainstreaming Gender In Refugee Protection," Cambridge Review of International Affairs 23, no. 4 (2010): 596.

${ }^{105}$ Michael Barnett, “Humanitarianism Transformed,” Perspectives On Politics 3, no. 4 (2005): 723-740.

${ }^{106}$ Claudena, Skran. "UNHCR's Gender Policy for Refugees and Returnees in Sierra Leone." African and Asian Studies 14, no. 1-2 (2015): 108-133.
} 
as women. ${ }^{107}$ Ultimately, they reinforce existing rhetoric that depoliticizes women and children refugees as passive victims heavily dependent on aid assistance. ${ }^{108}$ Their response techniques end up downplaying their Global-Refugee-Policy practices that would theoretically guarantee the asylum seekers local integration and assimilation for the sake of funding and practical opportunities among others. Meticulous exercises of counting, calculating, and coding refugees, and the genderneutral methods of "knowing" the refugees, contrast with and contradict the idea of gendered refugee protection that was meant to alleviate their daily (in)securities. ${ }^{109}$ Moreover, in the case of Lebanon, the primary agency managing refugees is the UNHCR whose responsibility is to support the Lebanese government in procuring technical, administrative state support in managing registered refugees and not just providing much-needed protection and assistance to individual asylum seekers. ${ }^{110}$ Refugee managing organizations like the UNHCR face many ethical criticisms to reconsider their operational practices that end up securitizing refugees by adopting controversial technological practices.

In that regard, Laura Barnett's article "Global Governance and the Evolution of the International Refugee Regime" situates this research within the

\footnotetext{
${ }^{107}$ Dipti Tamang. "Gendering International Security: Seeing Feminist Theories As International Relations." International Studies 50, no. 3 (2013): 226-239.

${ }^{108}$ Heather L. Johnson. "Click to Donate: Visual Images, Constructing Victims And Imagining The Female Refugee," Third World Quarterly 32, no. 6 (2011): 1015-1037.

109 Alice Szczepanikova. "Performing Refugeeness In The Czech Republic: Gendered Depoliticisation Through NGO Assistance," Gender, Place \& Culture 17, no. 4 (2010): 461-477.

110 “Country Operations Plan.” UNHCR, 2004. Retrieved from. http://www.unhcr.org/3fd9c6a14.pdf
} 
literature on the securitization-refugee protection nexus. By employing evolution as a historical technique, Barnett's article traces the historical genealogy of the UNHCR, as mandated by the United Nations, whose main task is to protect the governing standards for how to treat and protect individuals labeled as 'refugees. ${ }^{111}$ These include the promotion of international legal frameworks that develop and strengthen durable solutions of monitoring and protecting refugees, in order to ensure their safety and wellbeing. Defining and expanding the minimum standards of treatment for refugees, the UNHCR's main goal is to support hosting states in providing safe refuge, critical emergency, and basic assistance in the form of shelter, food, healthcare, water, and sanitation, among many other services. ${ }^{12}$ This effort was designed to ensure voluntary repatriation, local integration, or resettlement to a third country, aiming to ensure refugees' self-sufficiency in the country of asylum.

With time, the purpose of the UNHCR and humanitarian action expanded significantly, collaborating with compromised states in order to eliminate the root causes of conflict before their citizens are forced to become refugees. ${ }^{113}$ However, and as the UNHCR bureaucratically expanded, with around five thousand employees, refugee participation in the planning, implementation, or management

\footnotetext{
${ }^{111}$ Laura Barnett, "Global Governance And The Evolution Of The International Refugee Regime," International Journal of Refugee Law 14, no. 2/3 (2002): 238-262.

${ }^{112}$ Ibid.

${ }^{113}$ Ibid.
} 
of operations remained very limited, especially for women refugees. ${ }^{114}$ This expansion led to a change of approach, in which incremental protection tasks and social services were subcontracted to other NGOs that, according to Jane Freedman's article, "Mainstreaming Gender In Refugee Protection,” are biased, and most of the time insufficiently trained to target the diverse groups that make up the refugee population sensitively. ${ }^{115}$ This leads to prioritizing genderblind assistance over others, increasing the gap between the theory of protecting the refugee population and the actual mitigation of gender-related political or socioeconomic problems to a perceivably homogenized refugee population.

Barnett's study reinforces this dissertation's claim that there is, today, a refugee regime complex of overlapping competing regimes dependent on economic, ideological, and practical considerations. Barnett draws attention to how certain aspects of the refugee protection regime were used by the host state to justify and impose securitized refugee measures as a deterrence mechanism. Despite the humanitarian rhetoric fo supporting and aiding Syrian refugees, local practices end up projecting the organizational cultures and domestic social anxieties upon the faceless refugees, further complicating refugee realities. ${ }^{116}$ Even when refugee protection policies tend to lump images of women and children as feminized

\footnotetext{
114 Jane Freedman, "Mainstreaming Gender In Refugee Protection," Cambridge Review of International Affairs 23, no. 4 (2010): 597.

${ }^{115}$ Michael Barnett, “Humanitarianism Transformed,” Perspectives On Politics 3, no. 4 (2005): 723-740.

${ }^{116}$ Peter J. Katzenstein. ed. The Culture Of National Security: Norms And Identity In World Politics. Columbia University Press, (1996), 26.
} 
victims, refugee management practices end up using aggressive filtering techniques that target who fits into this category to get the aid needed. Ultimately, the international community's "benevolence" would reinforce the binary system made by the host state's securitization practices that were discussed in the first section. ${ }^{117}$ UNHCR's refugee management processes such as biometric refugee registration would also end up only benefiting host-state security personnel in tracking the refugees' movements and potentially sharing this information with other interest groups. ${ }^{118}$ In this case technology measures are seen as a double-edged sword with unequal consequences. This type of bureaucratization of refugee protection and assistance agendas, such as refugee camps' containment, is associated with the growing priority of what Barnett calls "base organizational interests" such as host state security and refugee management policy funding. ${ }^{119}$ Accordingly, searching for funds, NGOs become subcontractors of governments or the United Nations, using feminizing practices that depoliticize refugees and foster their oppression. ${ }^{120}$ Such representations trap refugees in the position of "clients lacking political means of influencing their place in the receiving society." ${ }^{121}$

\footnotetext{
117 Tara McCormack, "Power and Agency In The Human Security Framework," Cambridge Review of International Affairs 21, no. 1 (2008): 113-128.

118 Katja Lindskov Jacobsen. The Politics Of Humanitarian Technology: Good Intentions, Unintended Consequences And Insecurity. Routledge, (2015), 57.

${ }^{119}$ Michael Barnett, “Humanitarianism Transformed,” Perspectives On Politics 3, no. 4 (2005): 723-740.

${ }^{120}$ Alice Szczepanikova. "Performing Refugeeness In The Czech Republic: Gendered Depoliticisation Through NGO Assistance," Gender, Place \& Culture 17, no. 4 (2010): 461-477.

${ }^{121}$ Ibid. p 461.
} 
Moreover, with increasing refugee flows and enhanced member states' restrictive asylum mechanisms, the UNHCR proactively expanded its operational approach from mere refugee protection to include wider state cooperation in refugee containment measures, restricting refugee access to genuine humanitarian relief as a compromise for operating on host state's territory. ${ }^{122}$ The UNHCR's refugee crisis responses became increasingly institutionalized, rationalizing patriarchal Standard Operating Procedures (SOP) for intervention and control in the interests of nationalist donor and host states, devoid of genuine concerns regarding the multifaceted needs and risks refugee women experience in their daily lives. ${ }^{123}$ Consequently, a wider humanitarian approach ends up failing to recognize the gendered character of refugees' actual needs. Barnett's argument further supports this research in understanding why securitized interests are pushed over the provision of sensible refugee protection and practical solutions to the complexly gendered emergency need. ${ }^{124}$ Correspondingly, the conceptual apparatus of refugee security as host state's survival cannot be viewed as objective. It reinforces the host state's power to include and exclude refugees within.

Subsequently, limited refugee emergency relief can offer refugees neither gender inclusive aid, protection, nor real prospects in the long term, especially in

\footnotetext{
122 Michael Barnett, “Humanitarianism Transformed," Perspectives On Politics 3, no. 4 (2005): 723-740.

123 Jane Freedman, "Mainstreaming Gender In Refugee Protection," Cambridge Review of International Affairs 23, no. 4 (2010): 597.

${ }^{124}$ Shelly Culbertson, Olga Oliker, Ben Baruch, and Ilana Blum. "Rethinking Coordination Of Services To Refugees In Urban Areas: Managing The Crisis In Jordan And Lebanon.” Rand Corporation, (2016). 3.
} 
the context of a protracted crisis that is context dependent. ${ }^{125}$ Several factors, such as organizational cultures and networks of power, actively conjoin in influencing local humanitarian assistance practices that transform the local environment in unexpected ways, forcing refugees to adapt. ${ }^{126}$ Without a well-informed refugee protection, gender-sensitive programs would overlook the various refugee (in)security dimensions that are present in certain situations. Mainstreaming gender requires the acknowledgment of intersectional gender inequalities occurring within many socially constructed spaces and contexts. The structural implications of these strategies reinforce the perceived dualism that is reproduced and contextualized, neither benefiting refugees nor the host communities. ${ }^{127}$ They emphasize the politicization of the refugee crisis while at the same time depoliticizing all refugees through the creation of meaningful behavior, different patterns, and mundane bureaucratic arrangements of newly accepted norms.

\section{Impact Translation And Resilience Efforts}

While considerable scholarship sees universal human rights and statist cultural relativism as oppositional, the process of translating refugee protection norms from a global discourse of refugee protection into securitized local understandings of social justice, bridges this divide. Therefore, Susanne Zwingel's theoretical notion

\footnotetext{
125 Sue Lautze and John Hammock, "Saving Lives And Livelihoods: The Fundamentals Of A Livelihood Strategy." Feinstein International Famine Center, Tufts University, (1997).

${ }^{126}$ Raffaela Puggioni, "Refugees, Institutional Invisibility, And Self-Help Strategies: Evaluating Kurdish Experience In Rome,” Journal of Refugee Studies 18, no. 3 (2005): 319-339.

127 Jane Freedman, Gendering the International Asylum and Refugee Debate (Basingstoke: Palgrave Macmillan, 2015), 19.
} 
of "impact translation" as different types of reactions to global norms in a domestic context provides a necessary lens to explore the local dynamics in which Lebanese communities and Syrian refugees adapt to new adversities through resilience efforts. Even when there are clear differences between refugees, host communities, and humanitarian aid agencies, Zwingle's theory of impact translation asserts that these refugees are not passive recipients of refugee security norms ${ }^{128}$. Instead, refugees appropriate, negotiate, reject, and modify established rules as norm entrepreneurs for personal uses, further complicating the translation effects of refugee humanitarian interventions.

In that respect, Alice Szczeoanikova, in her article "Gender Relations in a Refugee Camp: A Case of Chechens Seeking Asylum in the Czech Republic," studies how refugee realities are complex, with room for both opportunities and misfortunes. Based on her study, undiversified perception and "gender-blind construction of refugees position refugee women as passive objects of aid," awaiting the impact of universal norms translation in their local realities, latently sustain gendered violence. ${ }^{129}$ According to Szczeoanikova, abstract macro-level norms do not deterministically shape localized refugee politics for assumptions of a top-down direction are biased and inaccurate. ${ }^{130}$ Her argument about how

\footnotetext{
${ }^{128}$ Elizabeth Olivius. “Governing Refugees Through Gender Equality: Care, Control, Emancipation.” Doctoral dissertation, Umeå Universitet. (2014).

${ }^{129}$ Alice Szczepanikova, "Gender Relations In A Refugee Camp: A Case Of Chechens Seeking Asylum In The Czech Republic,” Journal of Refugee Studies 18, no. 3 (2005): 281-298.

${ }^{130}$ Elizabeth Olivius. "Governing Refugees Through Gender Equality: Care, Control, Emancipation.” Doctoral dissertation, Umeå Universitet. (2014), 38.
} 
geography and different social elements influence the active translation of refugee protection norms and impact helps my research understand the Lebanese political and socioeconomic predicaments that (re)produce a vicious cycle of Syrian refugee insecurities. Therefore, both Zwingel's transnational theory and Szczeoanikova's refugee fieldwork approach inspired my work in conducting a multilevel, bottomup approach to exploring the power relations between different bodies, working across local, national and international levels, shaping contextual ideas and practices. ${ }^{131}$ This analytical framework would enrich this research by underlying the dialectical experiences of power relations and refugee (in)security microdynamics, reproducing Syrian refugee (in)securities.

In that respect, exploring the issue of accountability is key. Knowing the different institutions' responsibilities, and to whom these institutions answer, also affects the way refugee protection norms get translated and the types of local impact they aim for. ${ }^{132}$ Context-sensitive measures and strategies are essential for impacttranslation, and norm entrepreneurs-agents interested in changing social normsto further the rights of Syrian refugees, especially women. ${ }^{133}$ Accordingly, through norm entrepreneurs and social developments, this research needs to explore the

\footnotetext{
131 Susanne Zwingel. Translating International Women's Rights: The CEDAW Convention In Context. Palgrave Macmillan, (2016), 9.

${ }^{132}$ Volker Turk and Elizabeth Eyster, "Strengthening Accountability In UNHCR," International Journal of Refugee Law 22, no. 2 (2010): 159-172.

133 Susanne Zwingel. Translating International Women's Rights: The CEDAW Convention In Context. Palgrave Macmillan, (2016), 9.
} 
complex dynamics between the different refugee (in)security bodies that are decentralized in a multidisciplinary, outside the box manner.

On another note, identity with all its ramifications is particularly relevant for exploring a silenced body such as the Syrian refugees who experience multidimensional and (dis)continuous (in)securities in the case of Lebanon. A refugee's identity construction influences their agency. Histories and contexts are significant in appropriating, translating, and remaking transnational discourses into the vernacular. ${ }^{134}$ Therefore, a study separating the local from national and international politics will not be efficient in providing adequate research on refugee insecurities and resilience efforts. After all, the story of every refugee is a story of resilience. Resilience, in this context, may be defined as a social process in which groups and communities can 'bounce back' by engaging in everyday life activities and creating a form of normalcy. ${ }^{135}$ This resilience does not happen only at the individual level, but also through a micro-meso-macro supportive environment that empowers individuals in ways that are relevant to their culture. ${ }^{136}$ The traditional literature on securitization and refugee protection has generally discounted these dimensions of normalcy and silenced refugee resilience. In fact, refugees were defined as needy communities at best, and as a liability at worst.

\footnotetext{
134 Sally Engle Merry. Human Rights and Gender Violence: Translating International Law Into Local Justic.Chicago, IL: University of Chicago Press, (2009), 3.

${ }^{135}$ Caroline Lenette, Mark Brough, and Leonie Cox, "Everyday Resilience: Narratives Of Single Refugee Women With Children," Qualitative Social Work 12, no. 5 (2013): 637-653.

${ }^{136}$ Michael Ungar, Marion Brown, Linda Liebenberg, and Rasha Othman, "Unique Pathways To Resilience Across Cultures," Adolescence 42, no. 166 (2007): 287.
} 
Approaches that highlight resilience and livelihoods, on the other hand, challenge such essentialist assumptions. As such, Philippe Bourbeau's notion of resilience as a dynamic process, continually changing and highly relevant to the context, helps emphasize on the need to establish normalcy in the lives of asylum-seeking groups in adversity. ${ }^{137}$ Accordingly, Zwingel's concept of norm internalization-"the phase where the norm is implemented in domestic settings, e.g., in state bureaucracies"-is also relevant when examining domestic dynamics of gender norm translation depending on gender biased local policies. ${ }^{138}$ Her concept sheds light on how transnational actors, such as Syrian refugees, could appropriate, negotiate, modify, and contest gender-blind policies, if imposed, with the ability to connect or bounce back, (re)producing refugee (in)securities. Consequently, various resilience practices of refugees, particularly women, internalize and externalize different localized norms and practices for personal goals, further complicating issues of agency and ownership.

In the article "Everyday Resilience: Narratives of Single Refugee Women with Children," Caroline Lenette, Mark Brough, and Leonie Cox argue that "more attention should be paid to daily pathways through which refugee resilience practices are achieved" and go beyond simplistic binaries of whether resilience is

\footnotetext{
${ }^{137}$ Philippe Bourbeau. "Resiliencism: Premises And Promises In Securitisation Research," Resilience Journal, no.1 Taylor \& Francis. (2013): 3-17.

138 Susanne Zwingel. Translating International Women's Rights: The CEDAW Convention In Context. Palgrave Macmillan, (2016), 33.
} 
present or absent. ${ }^{139}$ According to the authors, the complex nature of resilience is influenced by biological, socioeconomic, cultural, and legal factors that intersect with one another, determining how one responds to stressful experiences. Accordingly, through resilience practices, refugees attempt to contest, resist, and (re)construct their gendered insecurities. ${ }^{140}$ By "shifting, changing, building, learning and moving on," ${ }^{141}$ refugee resilience is dynamic and multilayered in nature, and these practices cannot be stereotyped as signs of resilience or not. ${ }^{142}$ When disturbances happen, resilience occurs through various adapting practices. According to the authors, "it is the day-to-day pathways through which resilience outcomes are achieved." ${ }^{\prime 143}$ Different individuals witnessing the same disturbances might practice resilience differently at different times, making resilience a relative concept. Refugee resilience can be interpreted in many ways by different interested bodies; it can range from adapting to new realities and maintaining the securitized refugee system to contesting unfavorable practices and creating disturbances within the status quo. ${ }^{144}$

\footnotetext{
${ }^{139}$ Caroline Lenette, Mark Brough, and Leonie Cox, "Everyday Resilience: Narratives Of Single Refugee Women With Children." Qualitative Social Work 12, no. 5 (2013): 637-653 
Accordingly, Lenette, Brough, and Cox's argument reinforce the normative aspect of my work by stating that without inclusive support, resilience as a contestation can become counterproductive to all the involved bodies. As a result, this type of resilience would reinforce the (in)security vicious cycle by reproducing more insecurities within host states, such as Lebanon, affecting the Arab region and the international system as a whole. In turn, through the practice of resilience, the more oppressed refugees are through securitized refugee management practices, the more their retaliatory grievances would cause a backlash on host state's security. This gendered phenomenon is central to my research in exploring the impact translation of Syrian refugee (in)security norms and their multifaced experiences through fieldwork.

\section{Implications}

This chapter aimed to examine interweaving feminist scholarship on humanitarian and security practices toward refugees. It specifically sought to explore theoretical and practical contributions to refugee security and refugee protection concerns. The chapter focused on three general trends; the first concerned the contested concept of security, in which security-threat construction and practices of refugee securitization depend on the gender bias in the host state's sociocultural, political, economic structure. Therefore, the feminist critiques of securitization theory direct this research's attention to the fetishization of refugee insecurity discourse with real-world implications. However, this approach only challenges the role of the state in managing refugee insecurity, while disregarding other forces. That is why 
bringing a second set of literature on postcolonial feminist theory constitutes a necessary point in exploring the refugee protection regime.

The second section brings out relevant literature on (en)gendered humanitarian norm construction and its translation within domestic contexts. This scholarship sheds light on the gender bias and structural limitations that are inherent within the refugee-protection regime by exploring the sites where power hierarchies (re)shape humanitarian norms into compromised and gendered Standard Operating Procedures-(SOPs) in managing a refugee crisis. By exposing the rationalities and power relations of managing refugees, this approach challenges the universalist assumptions of a universal human right approach diffusing into gender-sensitive local refugee practices.

That is why combining a transnational feminist theory with a relevant analytical tool of organizational longitudinal cultural change of governmentality provides a useful analytical framework for the analysis of how refugee protection norms translate in a local context. While the second body of literature sheds light on the collective experiences in translating refugee security norms into local practice, their gendered implications are still missing. That is why the third body of literature on norm impact translation and resilience guide the research in addressing the impact of the securitization-refugee protection nexus, where Syrian refugees' agency is highlighted within particular spaces of research interactions.

In effect, the contributions of this dissertation are twofold. In that respect, my dissertation expands existing literature on security studies, refugee governance, and norm translation by exploring the Syrian refugee crisis in Lebanon. First, this 
dissertation offers an alternative understanding of what it means to be a refugee in a neighboring Middle Eastern country that shares a long history with the home country that a person is trying to escape. Although there has been sufficient scholarly attention to refugee (in)security and protection mechanisms, there is little academic writing focused on the views and perspectives of silenced stakeholders, especially local host communities and refugees themselves, particularly in securitizing southern neighboring countries, where refugee crises have been extensive and protracted. Accordingly, this dissertation is responding to feminists' call for implementing a multileveled research approach that will close the gap between the knowledge of what works and their practical solutions. This brings us to the second contribution, methods as adequate tools to improve research on a transnational phenomenon of refugee insecurities. Accordingly, the following chapter seeks to address this second gap by combining and developing a relevant research design and methods through which to examine the (en)gendering of refugee (in)security. 


\section{RESEARCH DESIGN AND METHODS}

This section discusses the methodological choices made to address this research task. As outlined before, the overarching aim of this research is to trace how refugee (in)security norms get constructed, are managed, and with what effects. The exploratory study engages a wide range of sources, including newspaper articles, journals, scholarly works, research assessments, and reports mostly published by international aid organizations involved in the relief process. In that respect, using a case study design, this study requires applied qualitative research methods rooted in phenomenological ontological perspectives of 'beingin-the-world' and having 'inalienable presence,' emphasizing the utility of the study rather than explaining a perceived absolute truth. ${ }^{145}$ By using a case study design, this research provides insights into how gender plays a vital role in (re)shaping specific refugee (in)security contexts, where international refugee norms and (in)security structures materialize across different stages. Accordingly, this chapter first discusses the research assumptions that guide this project. It, then, narrates a detailed account of the main researchers' positioning towards the case selection and methods. As for the third section, it explores the various methods, including the recruitment of participants, data collection activities, and data analysis processes.

\footnotetext{
145 Richard Price and Christian Reus-Smit. "Dangerous liaisons? Critical International Theory And Constructivism." European Journal of International Relations 4, no. 3 (1998): 259-294.
} 


\section{Research Assumptions}

This research aims to uncover the various systems of oppression regarding Syrian refugee (in)security in the case of Lebanon. In that respect, positivist research methods would narrowly capture contextual, relational dynamics engendering refugee (in)securities with no parallel narratives. ${ }^{146}$ However, there is no absolute external truth but the belief in the existence of multiple evolving realities. The individual and shared systems of meaning are fluid-co-constructed through intersubjective lived experiences and social interactions. ${ }^{147}$ Realities can be (re)created and expressed in different settings, which are influenced by the spatiotemporal conditions and cultural norms of their respective communities. ${ }^{148}$ Accordingly, a transnational feminist approach informs and shape this research's methodology providing the tools needed for this study to trace Syrian refugee (in)security across different levels of analysis and explain how gender and power play an essential role in the (re)production of specific empirical constructs as more influential than others. ${ }^{149}$

\footnotetext{
${ }^{146}$ Elisabeth Prügl. "Social Mechanisms: A Methodological Tool For Feminist IR." In The Art of WorldMaking, pp. 160-174. Routledge, 2017, 302.

${ }^{147}$ Patrick Thaddeus, Jackson. "Foregrounding Ontology: Dualism, Monism, And IR theory." Review of International Studies 34, no. 1 (2008): 129-153.

148 Martha Finnemore and Kathryn Sikkink. "Taking Stock: The Constructivist Research Program In International Relations And Comparative Politics." Annual Review of Political Science 4, no. 1 (2001): 391416.

${ }^{149}$ Elisabeth Prügl and Birgit Locher. "Feminism And Constructivism: Worlds Apart Or Sharing The Middle Ground?" International Studies Quarterly 45, no. 1 (2001): 111-129.
} 
In that respect, a constructivist ontology is of value for this research, where reflexivity relies on varied theorizations of gender and interpretive methods to identify the generative force of gender in a multiplicity of contexts. ${ }^{150}$ Elizabeth Prüegl's statement is consistent with the study's assumptions about the ontological nature of refugees, in general, and, in this case, the double marginalization of Syrian refugee women's insecurities in Lebanon. As Prüegl states: power as a social and gendered construct play an essential role in shaping gendered social phenomena where agency and structure are co-constituted as "multi-faceted, encompassing multilayered processes of identity formation,

institutionalization, and symbolization." 151 In that respect, the refugees' lived experiences of forced migration, resettlement, and integration processes within the host communities create subjective implications of what refugee (in)security means. Therefore, this research understands refugee (in)security as being a social construct based on relational experiences. Through localized experiences, this study traces the different perceptions and interpretations of refugee (in)security rather than making possible generalization beyond the specific case at hand.

Congruently, interweaving feminist scholarships help develop an interdisciplinary approach, drawing on insights from a range of disciplines, across all level, to broaden the knowledge on the inherent gender hierarchies within

\footnotetext{
${ }^{150}$ Ibid, 307.

${ }^{151}$ Ibid, 306.
} 
refugee-(in)security studies. And, since this research strives to acquire a sophisticated understanding of refugee (in)security practices and experiences, a qualitative pluralist approach would guide this study to implement exploratory and inductive research techniques to triangulate and evaluate the gendering processes of the transnational phenomena of refugee insecurities adequately. By exploring several social mechanisms of norm translation; cooptation, exploitation, reproduction, and normalization across different levels, this research would better trace the (re)production of Syrian refugee (in)security norms and practices as mechanisms implicated in the perpetuation of a masculine rule.

Epistemologically, the referent subjects, in this study, interact to co-produce shared understandings of Syrian refugee (in)securities, creating a collaborative exploration of diverse refugee experiences and their underlying connotations. The study's findings become the product of the Lebanese government, UNHCR, nongovernmental organizations, local communities' and co-researchers' lived experiences. For that reason, it is essential to recognize some of the researchers' background and positioning, especially when interpreting the views on Syrian refugees' local insecurities. Only then will there be an original interpretive understanding of historically situated data regarding the topic of inquiry.

\section{Researchers' Background And Positioning}

As the principal investigator, I am both an emic and etic. Despite being born in Lebanon, I was privileged to live abroad and possess dual citizenship. Given that I am both physically and culturally detached from the daily Lebanese intricacies, I am conscious of the gender differences between Lebanon and the country I chose 
to call home, the United States of America. It was these types of spaces that made me both an insider and an outsider to the Syrian refugee crisis in Lebanon, in need of constant reflexivity in determining how this research is conducted and to whom it is intended.

The question that must inevitably be asked is: for whom am I speaking? To which my answer would be: Anyone who studied, witnessed, or heard of someone who braved through, some type of displacement. Accordingly, this dissertation project is at its core a personal project aiming to explore the gendering of refugee (in)security in the case of Lebanon. Although the diversity of Lebanese political opinions was often vast, it seemed that most Lebanese public and social outlets differed from my personal opinion, having one commonality: "The Syrian displaced persons have no place in our home country." $" 152$

I had many Lebanese acquaintances even questioning the legitimacy of Syrian refugee claims of being forced to flee their homes, oblivious of the widely televised human atrocities that were happening in Syria - even though not long ago, they witnessed, like I did, similar challenges during the many wars. Still, unlike me, their projected anxieties focused on how to deter Syrian residents from "taking over” Lebanon. This positionality geared me towards planning and conducting a multi-leveled exploration of refugee (in)security in accordance with the everyday practices that are subject of this study.

152 Human Rights Watch, Our Homes Are Not For Strangers: Mass Evictions Of Syrian Refugees By Lebanese Municipalities, April 20, 2018, https://www.hrw.org/report/2018/04/20. 
In that respect, a participatory research approach with the people who lived through these experiences enriches this research by fundamentally questioning and rethinking previously established top-down knowledge. No matter how wellintentioned, this research runs the risk of missing out on the securitization-refugee protection inner dynamics of Syrian refugees without collaborating with local Lebanese supporting Syrian refugees in a genuine participatory way. This process would also allow the participants to reflect on their daily practices and power relationships, questioning and rethinking established gendered structures and rhetoric that mostly silence variant Syrian refugees' everyday practices, contributing fruitful knowledge-generating narratives. Even though the five research participants_-Lebanese volunteers assisting Syrian refugees - are not the subjects of research, their interaction and knowledge of their surroundings enrich this research.

Therefore, it is important to highlight their positioning as co-researchers, emphasizing their background and expertise. The co-researchers' lived experiences within both Lebanese, and Syrian refugee communities put them at a unique advantage of being privileged to understand the intricacies and perceptions within both groups. Even though the participants come from different Lebanese social upbringings, all of them come from relatively privileged middleclass settings, where the Syrian refugee presence in their country does not threaten their livelihoods (in)directly. As a matter of fact, three of the co-researchers' livelihoods (in)directly depend on working with the Syrian refugee population across Lebanon. 
Meanwhile, most of the participants acknowledged that their Lebanese entourage (sub)consciously pressures them to perceive the Syrian crisis as a threat to the overall Lebanese society, even though they believe that the media and official rhetoric (un)intentionally simplify the contextual dynamics of the Syrian crisis in Lebanon. The coresearchers' dissenting views of the Syrian refugee situation are of essence when producing knowledge for "they promise a new and different take on the subject under study" by elaborating their own opinion and experiences. ${ }^{153}$ Their collaborative input provided important contributions to the study by voicing out relational complexities of different Syrian refugees' daily (in)securities, while, at the same time, recognizing their anxieties as Lebanese citizens towards the Syrian presence within their communities.

\section{Methods}

The theoretical approach is qualitative using multiple methods to ensure a comprehensive triangulation and in-depth analysis of refugee (in)security in the case of Lebanon. ${ }^{154}$ This triangulation process conjuncts the different attitudes towards Syrian refugees through exploratory frameworks using multiple methods and research, while reviewing a broad array of relevant secondary sources, official documents, research studies, and statistics. Through a gender lens, the study utilizes

\footnotetext{
153 Jarg Bergold And Stefan Thomas, "Particpatory Research Methods: A Methodological Approach In Motion." Forum Qualitative Social Research, Volume 13, January (2012). https://www.academicpublishingplatforms.com/downloads/pdfs/fqs/volume1/201204082012_FQS_Vol13_1_ 2012_1.p df

${ }^{154}$ Royce A. Singleton Jr. and Bruce C. Straits. Approaches To Social Research. Oxford University Press, (2005), 381.
} 
the following methods, complementing them with primary and secondary sources to strengthen the gathering of information and research findings: (1) a longitudinal cultural theme analysis of refugee crisis response plans; (2) semi-constructed expert interviews, and (3) a grassroots participatory action-oriented method called Photovoice. This project triangulates all three methods as a dialectical process to provide a more in-depth understanding of the research findings while highlighting the various results. ${ }^{155}$

The study is based on field research completed in Lebanon from April till August 2017. Before that, the research process began in Miami, with an analysis of the Lebanese Crisis Response Plan-LCRP. During that time, the required processes of acquiring the approval to conduct the fieldwork from the University Institutional Review Board (IRB) were essential for involving human subjects in this study. Having to conduct the fieldwork on international grounds, it was necessary to get an expert in the field for IRB purposes. Dr. Guitta Hourani- the Director of the Lebanese Emigration Research Center (LERC) and Assistant Professor at the Faculty of Law and Political Science at Notre Dame University (NDU), and Director of the International Campaign, as well as the Secretary General of the Lebanon Dialogue Initiative (LDI) - facilitated the participatory methodologies, as she had access to Notre Dame University facilities to conduct the expert interviews and Photovoice sessions. This process allowed me to

\footnotetext{
${ }^{155}$ Donna M. Mertens and Sharlene Hesse-Biber. "Triangulation And Mixed Methods Research: Provocative Positions" Sage Journals (2012): 75-79.
} 
understand all the considerations required to conduct successful research while collaborating with a local expert from an accredited institution. The informed consent adequately protected the welfare and rights of human subjects, thus providing prospective interview and photovoice participants the detailed procedures, risks, and benefits from collaborating in this research.

\subsection{Thematic Analysis}

The Lebanon Crisis Response Plan (LCRP) provides an example of how international norms are translated and managed in a local context, through a joint strategic response plan, co-created by the Lebanese government, the UNHCR, and a growing collective effort of different interest groups at the sectoral level. Accordingly, the power dynamics between differing institutions, with distinct understandings of refugee (in)security and goals, influence a plan's agenda and policy tools. ${ }^{156}$ Therefore, studying the organizational culture and tracing the changes within offers significant insights into the Syrian refugee protection strategy in Lebanon, reflecting the previously silenced collective group dynamic and divergent interests when formulating specific response plans.

To that end, this study uses Dennis Wiedman's applied methodology of longitudinal cultural theme analysis of strategic planning and organizational change. ${ }^{157}$ It builds from a grounded theory's epistemological and methodological

\footnotetext{
${ }^{156}$ Anne Schneider and Helen Ingram, "Social Construction Of Target Populations: Implications For Politics And Policy.” American Political Science Review 87, no. 2 (1993): 334-47.

${ }^{157}$ Dennis Wiedman, "Effective Strategic Planning Roles For Anthropologists," Practicing Anthropology 20, no. 1 (1998): 37.
} 
approach, guiding this research in tracing the significant themes of Syrian refugee crisis management policies and their development. ${ }^{158}$ Wiedman's article "Organizational Culture Theme Theory and Analysis of Strategic Planning for a New Medical School," in collaboration with Iveris Martinez, provides valuable insights into organizational themes/patterns changing over time. This method creates a relevant analytical tool to read into explicit and latent cultural themes that guide a policy's mission, goals, and specific practices. Culture here signifies the norms and values of interacting groups and stakeholders identified within a strategic plan. When initiated, this culture stimulates predictable practices, becoming central in all aspects of organizational planning and cooperation. ${ }^{159}$

On the one hand, Wiedman's method enabled me to highlight the norms and values that shape specific interests and choices of which the refugee policies prioritized. Different organizations' stakeholders manage dynamic norms by underscoring standards for their mission's success, highlighting and framing specific refugee insecurities that are deemed relevant to their goals. Meanwhile, strategic planners manage the differing sets of concepts, procedures, and tools in an effort to assist organizational leaders with the task of creating a common policy framework that enhances their organization's dynamic achievements. ${ }^{160}$

\footnotetext{
${ }^{158}$ Dennis Wiedman and Iveris L. Martinez. "Organizational Culture Theme Theory And Analysis Of Strategic Planning For A New Medical School." Human Organization 76.3 (2017). 266.

${ }^{159}$ Ibid., 36.

160 John M. Bryson, Strategic Planning For Public And Nonprofit Organizations: A Guide To Strengthening And Sustaining Organizational Achievement. Hoboken, NJ: John Wiley \& Sons, (2018), xiii.
} 
On the other hand, the method brought insight to rethinking policy documents, such as the LCRP, as dynamic. These plans are products of dynamic relational practices between diverse social entities and interest groups becoming what John Bryson refers to as moving actants. These moving actants also have agency in (re)structuring local refugee (in)security practices and social relations. Even though local practitioners rarely implement the plans as intended, their translation of the LCRP documents still shape the daily activities of government employees and humanitarian workers concerning refugees. When initiated, a specific policy establishes contextual knowledge and a management culture within. It becomes central in all aspects of organizational planning, strategies, and cooperation, stimulating predictable practices. ${ }^{161}$ After all, from public professional meetings and accords to informal private local spaces, these cultural organizational themes impact what become accepted norms, expectations, behavior, and experiences, increasing the influential power of language in shaping everyday refugee management practices. ${ }^{162}$

To that end, this project analyzed two versions of the LCRP: the first twoyear plan (2015-2016), and its revised four-year version (2017-2020). The framework of the inquiry included textual interpretation and systemic coding that I developed to focus the data collected on key ideas/themes. Analyzing the major

\footnotetext{
${ }^{161}$ Dennis Wiedman, "Effective Strategic Planning Roles For Anthropologists," Practicing Anthropology 20, no. 1 (1998): 37.

${ }^{162}$ Dennis Wiedman and Iveris L. Martinez, "Organizational Culture Theme Theory And Analysis Of Strategic Planning For A New Medical School,” Human Organization 76, no. 3 (2017): 266.
} 
themes longitudinally in both LCRP documents yielded further insights into how strategic plans emerge, elaborate and are transformed based on their original intent, thus reflecting contextual variances. ${ }^{163}$ Reading through the documents, I began to identify what themes the plans commonly mentioned and the contexts that they were brought into the discussion. Through an intuitive interpretive strategy, I familiarized myself with the context, subjectively discerning the important themes and categories that informed the collected data. This reflexive method sheds light on the different descriptions, interpretations, and critical analyses of the attempts of gender norm translation reflected within the texts.

The first stage of the thematic data analysis looked at the general background of the Syrian refugee crisis in Lebanon to situate the construction of the LCRP. Using NVivo, computer-assisted qualitative data analysis software (CAQDAS), this study provided a thematic qualitative analysis of contextual themes and patterns within both documents. It highlighted the specific cultural themes of the evolving crisis as well as key definitions within the crisis response. While there is intersubjectivity when examining the language of the LCRP documents, the research findings were triangulated with other sources, making the content interpretation reliable. Thus, this methodology drew on primary mediasources and expert interviews to establish a contextual foundation for the refugee crisis in Lebanon, enriching the study in gaining more insight into the sociopolitical environments and critics that were present during the (re)production of the

\footnotetext{
163 Ibid, 266.
} 
Syrian refugee crisis response plans. Accordingly, local newspapers are a relevant information source for social research. They are often complementary to research, containing unique detailed information about local events. They also reflect the socio-cultural values of a specific time and place, which cannot be found outside context. ${ }^{164}$, critically tracing the experts' perceptions of the changes of themes and patterns in the 2017 version of the LCRP. Such patterns are what the NVivo program identifies as "nodes." According to Bruno Latour's concept of the "network" - the circulation of strategic characters-is pertinent to this study. ${ }^{165}$ These networks/nodes are heavily interconnected and "have as many dimensions as they have connections." ${ }^{166}$ Accordingly, nodes are not fixed, for connections and practices are relational and contested.

\subsubsection{Steps for Cultural Theme Longitudinal Analysis}

Time Period: The 2017 updated version of the LCRP portrays the cultural changes that occurred from the time when the first strategic plan was made in 2015. A longitudinal cultural theme analysis helped compare both crisis response plans in order to provide an empirical example of how norm construction gets affected by the dynamics of refugee (in)security management. Given that both LCRP plans are dealing with a "crisis," the comparatively short timeframe between both plans

\footnotetext{
164 Sanjica Faletar, Tanacković, Maja Krtalić, Darko Lacović. "Newspapers As A Research Source: Information Needs And Information Seeking Of Humanities Scholars." In "Digital Transformation And The Changing Role Of News Media In The 21st Century.” IFLA Newspapers Section Pre-Conference. 2014.

${ }^{165}$ Bruno Latour, “On Actor-Network Theory: A Few Clarifications,” Soziale Welt (1996): 369-381.

166 Ibid.
} 
is justified by the highly dynamic changes and interests, happening at a fast pace, when coping with volatile contextual realities.

Using NVivo software, the 2015-2016 Crisis Response Plan was analyzed, containing the first details of the proposed delivery of "integrated and mutually reinforcing humanitarian and stabilization interventions." 167 The first plan established the platform baseline against which strategic program change resulted in the second plan. The longitudinal comparative analysis with the following 20172020 version thereby provided a view of how of the second crisis response plan built from the previous one when conceptualizing and operationalizing its Syrian crisis response.

Units of Analysis: A careful selection of the units of analysis was necessary to conduct a preliminary examination of Lebanon crisis response strategy towards the increasing number of Syrian refugees. By having both LCRP documents serving as my primary unit of analysis, the research presented and traced the overall intentions of the major parties regarding the future direction of refugee (in)security management in the case of Lebanon. At an average of thirty-two pages, both plans tackled similar topics. The first included a "Forward/Preface," and an "Introduction." Then, they presented the overall local impact of the forced migration from Syria to Lebanon, with the intentions of "Needs Overview" providing the foundational concepts related to the refugee crisis. Finally, both plans

${ }^{167}$ Government of Lebanon and UNHCR, Lebanon Crisis Response Plan 2015-2016 (2015), 1. 
conveyed the LCRP "Response Strategy" and "Monitoring and Evaluation" processes, serving the collective vision and aim at how to manage refugee (in)security strategically. ${ }^{168}$

Through NVivo, the Organizational Evaluation Coding (OEC) systematically collected the major themes of the different activities, characteristics, and outcomes within both plans. ${ }^{169}$ In the first coding cycle, a "word frequency" analysis provided a visualization of the lists of word clouds highlighting the rank order of the words in each LCRP document. Then, an "In Vivo" coding was necessary to capture the context of certain phrases in their natural language. ${ }^{170}$ Recurrent words such as "beneficiaries," "target," and "poor urban neighborhoods" are not symbolic expressions. According to Wiedman, these recurrent words have a strategic impact on guiding future practices, becoming dynamic forces of culturally accepted behavior. ${ }^{171}$ Later on, in the second coding cycle, a "manual coding" of implicit themes was made explicit using definitional words and phrases that express specific latent and manifested meaning towards the identified themes. These findings are, later, triangulated with evidence from expert interviews, secondary sources and historical records, documenting the major themes in both

\footnotetext{
168 Ibid.

${ }^{169}$ Johnny Saldaña, The Coding Manual For Qualitative Researchers. SAGE, (2016), 119.

${ }^{170}$ Ibid., 91.

${ }^{171}$ Dennis Wiedman and Iveris L. Martinez, "Organizational Culture Theme Theory And Analysis Of Strategic Planning For A New Medical School,” Human Organization 76, no. 3 (2017): 265.
} 
strategic plans. That way, the study explored the significance of each finding and assessed the development of the organizational structure and operation management across both plans. After reviewing the word list and phrases, I conducted a "domain coding," grouping similar words and phrases together under a common code category—node. These nodes will later on form child nodes hierarchically falling under major categories — what is known in NVivo as "sub coding" into parent/child nodes. ${ }^{172}$ Once I finalized the categorization, themes emerged from the coded data, bringing meaning to recurrent patterns, capturing and unifying the dispersed information into a longitudinal coding of major themes. ${ }^{173}$ Through "matrices," the project examined the qualitative increase, decrease, constancy, and so on, within the qualitative data gathered. This method helped compare and generate inferences of change between both policy plans-if any. ${ }^{174175}$ Accordingly, this study used the previously established table below by Dr. Wiedman and Dr. Martinez that identifies six major categories portraying the Longitudinal Cultural Theme change over time.

\footnotetext{
172 Johnny Saldaña. The Coding Manual For Qualitative Researchers. Sage, (2015), 23.

${ }^{173}$ Ibid., 77.

${ }^{174}$ Ibid., 234.

${ }^{175} \mathrm{Ibid}, \mathrm{p} 266$.
} 
Table 1. Definitions of Longitudinal Cultural Theme Categories

\begin{tabular}{|c|c|c|}
\hline \# & Category & Definition \\
\hline 1. & Operational & Structures and personnel required for proper functioning of any organization \\
\hline & Continuous & Clearly and consistently articulated over time \\
\hline 3. & Elaborated & More detailed and specific using similar words within original meaning \\
\hline & Transforming & Contemporary words and concepts with similar meaning replace original words \\
\hline 5. & Diminishing & Original words used less frequently, deemphasized or absent \\
\hline 6. & New & Emphasis outside of original themes, meanings, or intentions \\
\hline
\end{tabular}

When evaluating and comparing both Crisis Response Plans, continuous, elaborated, or transforming themes demonstrated the efficacy and influence of the 2015 LCRP on the newly established 2017 Plan and the power of cultural themes. Meanwhile, diminishing themes would serve as evidence that some cultural themes created in the 2015 strategic plan were inconsistent and had little effect on the subsequent development of the 2017 organization of the LCRP. As for the new cultural themes, they served as evidence that new realities emerged and required innovative interpretations and strategies for action, diverging from the original themes established in $2015 .^{176}$

\subsection{Expert Interviews}

Many social science researches utilize qualitative semi-structured expert interviews, in which their process varies from case to case. ${ }^{177}$ These experts

\footnotetext{
${ }^{176}$ Dennis, Wiedman, and Iveris L. "Organizational Culture Theme Theory And Analysis Of Strategic Planning For A New Medical School." Human Organization 76, no. 3 (2017): 266.

177 Alexander Bogner, Littig Beate, and Menz Wolfgang. Interviewing The Elite-Interviewing Experts: Is There A Difference?." In Interviewing experts. Palgrave Macmillan, London, (2009): 98-139..
} 
represent their organization's views and mission goals. ${ }^{178}$ Experts are commonly knowledgeable about the topic they are interviewed on and are thus of essence to have a holistic view on the research topic. In the case of the Syrian crisis in Lebanon, this method was geared to understand how the interviewed experts perceive the LCRP, generating their respective organization's attitude towards the implications of the plan formulated on refugee (in)security in general, women specifically.

Knowing that the LCRP is the result of the collective effort of ninety-five partners, including government ministries, UN agencies, national organizations, and international NGOs, it was essential to conduct interviews with key practitioners and leading officials involved directly in the construction of the LCRP. After identifying all interviewee prospects through an online search, professional networks, and family acquaintances, I reached out to plausible candidates, scheduled interview appointments, and coordinated all the logistical requirements for conducting the interviews.

Five participants were chosen to conduct expert interviews. Starting with the Lebanese Ministry of Social Affairs - MOSA. The advisor of the minister for the refugee portfolio and general supervisor of the Lebanon Crisis Response Plan agreed to conduct the interview. He was involved in the LCRP since the beginning of the crisis. Regarding the UNHCR, the interagency coordinator officer and the

${ }^{178}$ Ibid. 
sexual gender-based violence- (SGBV) sector coordination team officer in the UNHCR agreed to conduct a conjoint interview. They were explicitly assigned to create the Crisis Response Plan in coordination with the Lebanese government. As for the regional NGOs, the Abaad organization that promotes “women's equality and participation through policy development, legal reform and gender mainstreaming" ${ }^{179}$ recommended their program and technical coordinator for the interview. Last but not least, the study chose Justice Without Borders, a local human rights association that works on providing free legal support to women and children who are victims of social violence, develops and promotes democratic reform and the rule of law to support human rights. Accordingly, its founder and director provided critical information regarding the Syrian refugees' legal status, specifically women. The conducted interview was highly informative, lasting approximately one hour.

All Interviewees were identified through their respective agencies and the depth of their involvement in the crisis response plan. The expert interviews were on average between 20 to 40 minutes and audio recorded. Having these experts as interviewees allowed the study to gather the many organization's attitudes towards both LCRP documents. From government officials-represented by MoSA-, international organizations - represented by UNHCR - , non-profits - represented by Abbad-, to local grassroots organizations - represented by Justice without

\footnotetext{
179 “ABAAD Resource Center For Gender Equality: About.” Daleel Madani. https://www.daleelmadani.org/civilsociety-directory/abaad-dimensions-resource-center-gender-equality/about
} 
Borders - a representative sample of crisis response planners gave the study validity. Each organization interviewee represented the perception of the various interest groups coordinating the crisis response plan. Although interviewees had different backgrounds, all interviews were conducted in English.

Interviewees faced minimal to no risk during and after the interview for all the questions were geared to their professional positions at work and not their personal lives or opinions. All questions were exploratory in nature and professionally geared to provide greater insights into the creation process of the LCRP policy. No answer provided within the study disclosed the anonymity of the interviewee's personal information. If there were any discomfort in discussing and expressing issues of refugee (in)security, interviewees had the opportunity to back out of their commitment and retract anything or everything they shared with the interviewer beforehand. Explaining the project and providing interviewees the list of questions before having them sign the written informed consent form was critical to have them feel more comfortable in participating in the project. Once the interview was over, the interviewees had ample time to provide an answer they deemed fit and, later, review them once the transcriptions were made.

Through those interviews, this study traced the creation and evolution of the Lebanon Crisis Response Plan and the participants' different positions from the security strategies developed for Syrian refugees, especially women. Being physically in the field helped me better communicate in person through one on one meetings and not just via telephone or email. The research provided open-ended 
questions, allowing some space for the interviewees to reflect on certain points they deem relevant. Key participants from the Lebanese government, UNHCR, and other NGOs involved in the final version of the LCRP gave this study a better grasp of the Syrian refugee crisis. ${ }^{180}$ The questions provided to the interviewees are listed below:

- How long have you been working in (Lebanese government/UNHCR/NGO)?

- How did your organization become involved in the LCRP?

- What was your role in this project?

- Can you briefly explain the policy process that went into the development of the LCRP?

- How was your overall experience in being part of it?

- What are the greatest weaknesses and/ or strengths in this policy?

- Does (Lebanese government/UNHCR/NGO) have a gender policy? Content?

- Do you believe that the Action Plan helps protect Women specifically?

- How could the plan improve a gender-sensitive approach to Syrian Women's Insecurity?

- What expectations do you have for the future of the LCRP?

- Is there anything else you want to share/anecdote/comment?

Tentative follow-up questions:

\footnotetext{
${ }^{180}$ Appendix A. (Advisor to the Minister for the Refugee Portfolio and General Supervisor of the LCRP in MoSA, UNHCR Interagency Coordinator Officer and SGBV Sector Coordinator, Director of Justice Without Borders, Abaad Technical Coordinator).
} 
- Do you feel that the inclusion of your organization into the LCRP helps or challenges the neutrality/credibility of UNHCR in aiding the Syrian Refugees?

- What about the different objectives/goals of other groups such as the Lebanese government? Do you believe that they conflict or accord with the UNHCR aim at protecting and alleviating the Syrian refugees?

- Do you think including in the Project Lebanese citizens limits or enhances the UNHCR goal in aiding Syrian refugees?

- How do you see the role of NGOs as partners in the application of the LCRP? (Essential or complimentary? Constructive or difficult? Agenda-setting or decisionmaking?)

- Is there a set of tools established within the LCRP for future follow up/enforcement mechanism?

This method proved to be beneficial for this research project which was geared to find out what the interviewees knew, did, and thought about the LCRP.

\subsubsection{Problems and Success}

The purpose of the expert interviews was informational conversations, exploring the implementation of the LCRP process while analyzing the different organizations' day-today practices of politics. My choice of experts' selection was directly related to the research interest in tracing the LCRP creation and processes. Except for Justice Without Borders' interview, all selected experts bore critical positions within their respective organizations having a critical role in the creation of the LCRP. 
One element that I could not control is that each expert was presented as an individual, a representative, and a strategist. ${ }^{181}$ The validity of the shared information gets problematized when the study is not able to discern the participants' private opinion from their official position within their respective organization, or strategic rhetoric aiming for personal political gains. That is why the questions were carefully selected, enhancing trustful engagement. Each question maximized the dialogical conversation, during the interview session, while at the same time minimizing the danger of the interview being instrumentalized for political gains. ${ }^{182}$ It is also worth mentioning that gender was a constitutive factor in the interviews and that gender-specific behavior influenced the way I conducted the interviews. ${ }^{183}$ I could not help but notice the gendered interaction that, ultimately, contributed to gaining information positively. In fact, being a foreign academic — not affiliated to any organization involved in the LCRP formulation and implementation, as well as a woman—whose opinion within the Lebanese community is generally seen as less influential than that of men, my position was not threatening to the interviewees' input of the LCRP plans within their respective organizations.

\footnotetext{
${ }^{181}$ Bogner, Alexander, Beate Littig, and Wolfgang Menz. Interviewing The Elite-Interviewing Experts: Is There A Difference?." In Interviewing experts. Palgrave Macmillan, London, (2009): 98-139.

${ }^{182}$ Ibid. p 140.

${ }^{183}$ Gabriele, Abels, and Maria Behrens. "Interviewing Experts In Political Science: A Reflection On Gender And Policy Effects Based On Secondary Analysis." In Interviewing Experts. Palgrave Macmillan, London, (2009): 140.
} 
Still, one must not ignore the limitations that came along with being a foreign female academic, as interviews create temporary relational spaces, varying from one interview to another, where different expectations affect the patterns of interactions. ${ }^{184}$ One example where I noticed such behavior was during the interview conducted with the MoSA representative. This interview was almost impossible to schedule nor conduct under the pretext of having more pressing issues on the Assistant Minister's schedule. Also, the interviewee, in the beginning, was distrustful, answering questions defensively by stating that all the information asked of him were in the LCRP document. Gendered dynamics were vividly present when at one point the interviewee switched the gear into bringing up questions if I, a 'female' researcher, am knowledgeable about the LCRP plan, offering me the latest version booklet in case I would like to be updated. This nonchalant approach, later, switched to a paternalistic trend, extending to the point of asking me questions that go beyond the scope of the interview. That particular interviewee took a protective approach, inquiring if I was able to successfully conduct fieldwork within informal Syrian refugee camps, thinking perhaps it would be harder on a female researcher to do it on her own. The interviewee also recommended websites and offices to reach out in order for me to get more informed about the situation and gain 'proper' access to the field. This standard paternalist behavior could also be connected to the interviewee being a Lebanese male expert providing input to a female university student, who is seeking knowledge about the ministry's official

${ }^{184}$ Ibid. 
position towards the LCRP. Still, this behavior was not found in the other interviews for most of the interviewees were females, except for one of the experts from the UNHCR - who identified himself as a foreigner on a brief mission in Lebanon.

\subsection{Photovoice}

An adapted version of Wang and Burris's participatory research method thickens the research's understanding of issues within their context. Having local participants providing a set of visual representations of certain local realities is deemed relevant to this study. As local participants, the co-researchers discussed the collected pictures, elaborating their own opinions and individual experiences with the Syrian refugees. Through group discussions, the research participants were able to disclose their personal views within a safe space confident that their utterances and diverse positions will not be judged and used against them later on. This approach aimed to enrich the research and give more insights into previously invisible Syrian refugee practices. In the case of Lebanon, this methodology provides a "culturally-grounded contextually-situated site for reflection and elaboration on visual images and associated meanings," by describing, understanding, and elaborating the complexities within, rather than predicting and controlling. ${ }^{185}$

185 Camille A Sutton-Brown, "Photovoice: A Methodological Guide." Photography And Culture. 7.2 (2014):169-185 
Including local participants, this study captured the intersectional Syrian refugee (in)securities through a relatively new participatory methodphotovoice-that brings different visual narratives from local contributors. According to Caroline Wang, photovoice helps the principal researcher engage a specific community in critical dialogue around what they perceive as (in)securities within their local realities. ${ }^{186}$ In that respect, Lebanese volunteers were locally situated, knowledgeable in the daily refugee anxieties within their respective communities. Having their input on local impact and power dynamics enriched the research with unforeseen micro-variables, usually missed when looking at the refugee situation from a top-down lens.

This study benefited from capturing multileveled concerns through an innovative approach that brings different visual narratives from the local population. Even though the participants were not refugees, the perception of engaged local volunteers brought this study closer to the local impact and realities of the Syrian refugee crisis in Lebanon. Including local participants was of importance when there is a need to display the contextually complex realities within certain communities that might be invisible to external investigators. At the same time, the participants projected their anxieties as Lebanese citizens towards the multiple local backlashes to contested refugee (in)security practices. Photovoice research participants were, thus, able to empathetically describe the various local

\footnotetext{
${ }^{186}$ Caroline C. Wang "Photovoice: A Participatory Action Research Strategy Applied To Women's Health." Journal of Women's health 8, no. 2 (1999): 185-192.
} 
(in)securities that Syrian refugees go through while still projecting the Lebanese anxieties to the Syrian crisis' repercussions on their communities. Hence, this section first discusses the benefit of visual narratives for this research. It, then, recounts this method's framework and the different steps taken throughout this process. Lastly, it reflects on the successes and complications encountered throughout the development and implementation of the field research.

\subsubsection{The Impact Of Visuals}

Inherently biased social inquiries should not disregard local pointers, where norms are multiple and complexly interrelated. ${ }^{187}$ Limited framings and deductive methods do not achieve comprehensive examination of policy practices such as refugee (in)security. Accordingly, conventional research approaches narrowly capture the contextual dynamics and emotions that shape the gendered refugees' realities. The example of Alan Kurdi's - a three-year-old Syrian boy of Kurdish ethnic background-picture, taken by Turkish journalist Nilüfer Demir, made global headlines after he drowned on September $2^{\text {nd }}, 2015$ on Turkish shores. ${ }^{188}$ Even if short-lived, this specific photo aimed for disruption and resistance to the current European refugee security policies, provoking temporary changes within

${ }^{187}$ John W. Creswell, Qualitative Inquiry And Research Design: Choosing Among Five Approaches, Sage (2007), 23.

${ }^{188}$ Bryan Walsh. "Alan Kurdi's Story: Behind The Most Heartbreaking Photo Of 2015," TIME Magazine, (December 29, 2015), http://time.com/4162306/alan-kurdi-syria-drowned-boy-refugee-crisis. 
their immigration policies and humanitarian aid. ${ }^{189}$ The photo personalized the Syrian refugee crisis with the image of a boy's tragic death, refocusing people and states' attention and securing millions of dollars of donations for refugee assistance and protection overnight. ${ }^{190}$

In that sense, visuals are not objective; they are political acts, dependent on their authors' perception of exposing what should be accounted within the politicized frame. ${ }^{191}$ They can be used as compelling alternative forms of accountabilities in global politics. Images have agency by actively illustrating certain scenarios, transforming them into what Brent Steele calls "scars of violence." ${ }^{192}$ A visually provocative photograph of gendered (in)security and silenced violence disrupts abstract policies that are considered convenient when dealing with faceless numbers of threats or victims. The impact of visuals prints a strong impression on readers' minds compared to mere words. ${ }^{193}$

\footnotetext{
${ }^{189}$ Werner Binder and Bernadette Nadya Jaworsky. "Refugees As Icons: Culture And Iconic Representation." Sociology Compass 12, no. 3 (2018): e12568.

${ }^{190}$ Jackie Northam. "For Syrian Refugees, Needs Are Growing And Aid Is Declining." National Public Radio. (September 14, 2015): https://www.npr.org/sections/parallels/2015/09/14/440280540/for-syrian-refugeesneeds-aregrowing-and-aid-is-declining

${ }^{191}$ Brent J. Steele, Alternative Accountabilities In Global Politics: The Scars Of Violence. Routledge, (2013), 36.

192 Ibid.

193 Caroline C. Wang and Yanique A. Redwood-Jones, "Photovoice Ethics: Perspectives From Flint Photovoice," Health Education \& Behavior 28, no. 5 (2001): 560-572.
} 
Still, photos can be deceitful as well, for they alone do not tell the entire story. ${ }^{194}$ As much as they are the product of their reality, the integrity of visual production is inherently contested. ${ }^{195}$ The timing and conditions of them being taken reflect their author's subjective experience. ${ }^{196}$ In fact, photographs cannot objectively translate different scenarios at hand, as images produce their own biased 'truths' and are also heavily dependent on the observer's interpretations. For this reason, accompanying visuals with written narratives played a major role in disclosing background stories and intentions. Complementary captions and written paragraphs were necessary for (re)constructing a specific scenario, having a stronger impact on the viewer's mind. ${ }^{197}$

\subsubsection{Photovoice Framework}

The Photovoice participatory visual method shifted the focus from the main researcher to the participants' perspectives. These local volunteers became coresearchers, depicting their grounded intake on certain refugees' lived realities. Through thoughtful discussion and reflection, the research participants co-created contextual knowledge of respective refugee insecurities, building local critical consciousness. The multiple views collected from the participants brought a

\footnotetext{
${ }^{194}$ Annabelle Cathryn Wilmott. "The Politics Of Photography: Visual Depictions Of Syrian Refugees In UK Online Media." Visual Communication Quarterly 24, no. 2 (2017): 67-82.

${ }^{195}$ Brent J. Steele, Alternative Accountabilities in Global Politics: The Scars of Violence. Routledge, (2013), 18.

196 Ibid.

197 Angela Naimou, "Double Vision: Refugee Crises And The Afterimages Of Endless War," College Literature 43, no. 1 (2016): 226-233.
} 
collaborative (re)construction of the multiple gendered realities of the Syrian crisis, projecting the participants' personal views and anxieties while depicting their perception of the various refugee (in)securities.

Due to the geographical and cultural proximity with the Syrian refugees, local volunteers were well positioned to address the local practices and challenges of refugee security policies. The local volunteers became the subjects of the study, showcasing the impact of specific policies on the (re)production of refugees' (in)securities within their communities. Through an inductive bottom-up approach, the trained participants took photographs, voiced out their concerns, and conversed about the significance of their respective and each other's photographs.

According to Alice McIntyre, this participatory action-oriented methodology lacks a definitive structure for designing, practicing, or implementing photovoice research. Therefore, there is room for certain flexibility within the general framework of the study, which overlaps with the theoretical and ideological perspective of the principal investigator. ${ }^{198}$ Voicing out what a person sees through photographs creates the agency to provoke a reaction - a new discourse that cannot be predicted. Adopting a feminist intersectional approach challenges the universalistic assumptions of a collective experience that all refugees endure, exploring the different research participants' perceptions of refugee agency and

${ }^{198}$ Alice McIntyre, Participatory Action Research. SAGE, vol. 52, (2007), xi. 
resilience, especially women. The photovoice process has various components illustrated according to the following framework:

a. Photovoice participants' recruitment.

b. Introductory group session.

c. Ethics of photography.

d. Informed consent.

e. Fieldwork.

f. Data collection.

g. Photo elicitation and analysis.

h. Future planning.

\section{a. Recruitment of Participants}

Having access to local networks and government officials puts me at an advantage, especially given that I am fluent in Arabic. The initial study intended to use photovoice with the marginalized refugee population. However, it was difficult to conduct this type of fieldwork on foreign soil without the university's Institutional Review Board approval (IRB), let alone gain access to members of the Syrian refugee population without being potentially harmful.

Other than the fear of igniting psychosocial and legal damages to Syrian refugees, the international setting of the research conducted would require extensive funding for local institutional support and time for fieldwork translation. Due to the sensitivity of interacting directly with the targeted vulnerable population, the photovoice process was used to identify nonpartisan Lebanese individuals and groups that work or volunteer with Syrian refugees. Dr. Guitta Hourani played a 
crucial role in the successful completion of the IRB procedure and recruitment efforts. She provided institutional support and academic referrals of potential participants to partake in the field research safely and ethically.

As clarified, the study opted for local Lebanese volunteers who expressed interest in innovative and flexible techniques to voice out their perceived local (in)securities. It helped identify the complex dynamics and (in)securities that Syrian refugees experience and project within different Lebanese communities. Acknowledging the diverse participants' personal views and positions towards the Syrian refugees was important and formed the central focus of the study. ${ }^{199}$ The findings did not aim to provide a general representation of refugee (in)securities in the Lebanese context. The goal here was indicative, identifying the context-specific trends that complement some of the other methods' findings.

Historical and social contingencies shape cultural identities differently, reflecting specific individual and collective security views, interests, and practices. The cultural proximity and contested sympathetic relationship between the Lebanese volunteers and Syrian refugees brought more insight into the complexities of the dynamics that one gets from policymakers, who are distant physically and socially from their policy implementation and practices. Even though the participants are not living in the refugee camps and experiencing the daily (in)securities that Syrians do, they are still affected by those security practices.

${ }^{199}$ Caroline Wang and Mary Ann Burris, "Photovoice: Concept, Methodology, And Use For Participatory Needs Assessment," Health Education \& Behavior 24, no. 3 (1997): 369-387. 
After all, the Syrian refugees' agency and responses do affect locals' social milieu (in)directly.

After completing the Institutional Review Board (IRB) protocol and gaining approval, the next step was to identify the right participants. I used purposeful sampling. Throughout the preliminary interviews with local (non)governmental agencies that work directly with Syrian refugees, the study took their referrals to recruit potential volunteers as participants. By using the snowball sampling method, the solicited study recruited future subjects from among their acquaintances. Having only four weeks left to conduct the fieldwork, the study aimed for a group size of seven participants, just in case some would withdraw from the project.

I met virtually and in person with several volunteers and college students referred by local networks, organizations, and Notre Dame University's faculty and friends. I introduced myself and informed the potential participants about the project and the overall aim of the study, inviting them to an introductory training session where I introduced the project's aim and method. The initial meeting comprised seven participants (Bechara, Hanan, Maria, Diana, Mazen, Yves, and Lina). The following five remained throughout the entire project:

1. Maria S. worked as a senior outreach and psychosocial support (PSS) worker under two UNICEF projects with the Makhzoumi Foundation: Child Protection and GenderBased Violence. Her tasks were to do psychosocial support to Syrian refugee women and children. She was referred to the project by common acquaintances from the Lebanese Red Cross. Her work experience motivated her 
to voice out the real conditions that Syrian refugees endure in different parts of Lebanon.

2. Diana $\mathrm{H}$. is a design practitioner by trade and a volunteer at the Kayany Foundation. The latter organization was founded in response to the growing needs of Syrian refugee children in Lebanon. Diana spent three months providing basic aid to some of the most vulnerable youth living in informal tented settlements scattered throughout hometown of Kefraya, Bekaa.

3. Bechara B. is an undergraduate engineering student at the American University of Beirut (AUB). His interest in social work started with the AUB Neighborhood Initiative promoting the neighborhood's livability and diversity through innovative outreach activities such as the "Civic Engagement and Community Service" (CCECS), teaching, in Hamra, Beirut, vulnerable Lebanese and local Syrian refugees English.

4. Mazen J. worked as the head of the Statistics department at a non-disclosed research company. When trying to expand my knowledge on the Syrian refugee situation in Lebanon, I made the first online contact with Mazen over Facebook. An initial meeting was set up over WhatsApp where I explained the research study and purpose. Mazen showed much interest in the project. He later volunteered, wanting to voice out the refugee insecurities within his hometown village in Bekka, Mansoura. This town is strategically located by one of the most important rivers in the area, the Litani river, hosting the biggest informal Syrian camps in Lebanon: Ghaze. 
5. Hanan A. was referred to the project by her close friend Mazen. She joined the team, showing much interest in the photovoice methodology, and wanted to partake in the fieldwork to highlight Syrian women and children are begging for money in the streets of Beirut. She also wanted to shed light on the reasons behind this phenomenon that, in her view, dehumanizes this vulnerable population.

The other participants' details will not be shared for I did not get their informed consent to share their information. As co-researchers, the five participants went through the following research steps, becoming co-producers of contextual refugee (in)security knowledge.

b. Primary Group Session

There are three main purposes from the primary group session: ${ }^{200}$

i. Introduce and establish relations between the participants

ii. Explain the Photovoice research processes

iii. Discuss the risks and responsibilities of being a participant and co-researcher.

The site of this session is the gendered space of my family's house in Lebanon, which gave me power over the potential participants in controlling the conversations. In the first part of the meeting, I introduced the project backed by a PowerPoint presentation explaining the goals, key components, and the ways to conduct participatory action research -(PAR). The PowerPoint was previously

200 Camille A Sutton-Brown, "Photovoice: A Methodological Guide." Photography And Culture. 7.2 (2014):169-185 
created during the IRB protocol to set the framework of the research. ${ }^{201}$ I explained to the potential participants that the study would enable them to record and reflect refugees' reality and concerns. I also explained that the project would promote critical dialogue and knowledge about the different issues that participants deem essential, providing a space for synthesis and empowering recommendations for a normative change in understanding refugee (in)security.

All participants welcomed the idea of becoming co-researchers, taking on the role of photographers. The session explained all the fieldwork responsibilities, such as capturing photographic evidence, setting research goals, data collection, and data analysis.

Starting with the first section on photography tips, I explained the following procedures:

Observe what is happening.

Analyze why that picture is important.

Act on how we can use this experience to recommend policy change.

c. Ethics of Photography

As it was necessary to protect all parties - the research participants, Syrian refugees, and the research as a whole; participants were to refrain from photographing any illegal activities. Instead, they were to suspend all photographic activities, warn of any unexpected situation, and retreat when there were risks.

${ }^{201}$ Check Appendix E. Photovoice PowerPoint Presentation 
Participants needed to also refrain from entering dangerous spaces or situations to complete the project. Having prior knowledge of the areas and different context helped evade dangerous positions. If they were ever put in any emergency or health situation that would inhibit the participants from continuing the project, they were expected to communicate it to the principal investigator.

Participants needed to protect the communities they are researching by abstaining from taking pictures that may harm people's reputation, safety, or individual liberty. ${ }^{202}$ Consequently, no pictures were taken in private settings or without the subject's consent. All photos included partial facial and body parts that do not identify a specific person or an illicit activity. As for the issue of false light, the participants were previously warned that it was necessary to make sure that the situations in the refugee communities are reflected accurately. Necessary steps were introduced in the first session to portray the community accurately and to avoid taking photographs and images that could be out of context.

Since all participants owned personal smartphones, there was no need to provide them with additional digital cameras to take meaningful pictures. After training the participants on how to take pictures safely and ethically, I outlined the suggestive vision for the project and welcomed their comments, recommendations, and concerns. All participants agreed on the logistics and the four-week timeframe.

\footnotetext{
202 Caroline C. Wang and Yanique A. Redwood-Jones, "Photovoice Ethics: Perspectives From Flint Photovoice," Health Education \& Behavior Sage Journals. 28, no. 5 (2001).
} 
Some even suggested the idea of having group field trips during the weekend, where, each Saturday, one of the participants would try to get permission, through institutional or personal connections, to visit some of the informal camps or locations deemed interesting and accessible.

\section{d. Informed Consent}

Obtaining an informed consent was mandatory, especially when participants examined sensitive issues. The consent came in two parts; The first written consent was distributed at the end of the first training session, explaining the goal of the research and the voluntary participation of all the participants. It was signed before the commencement of the study, indicating all the potential benefits and risks that may arise from the participants' involvement in the study. ${ }^{203}$ The second form of consent came after the participants conducted all field work and provided all photos and narratives. This form, when signed, ensured that the participants approved my choice to decide which pictures can be publicized within the study and in any future research.

e. Fieldwork

The field project established was short-term, spanning for four weeks. Adapting to the volunteers' availability and accommodating everyone's time, the study encouraged the participants to take photographs on their own whenever they encounter, work, and or volunteer with Syrian refugees. Two participants managed

203 Camille A Sutton-Brown, "Photovoice: A Methodological Guide." Photography And Culture. 7.2 (2014):169-185 
to get permissions for the entire group to conduct simultaneous field research on two different occasions inside a couple of informal Syrian settlements.

On both occasions, I visited the Syrian refugee informal camps with the group, under the role of the group supervisor. While the participants were busy taking photographs and engaging the refugee community, I was conducting a participant-observation and informal face-to-face discussions with Syrian refugees, mostly women passing complaints and personal requests. It seemed that they, initially, confused the research group with practitioners or activists coming on behalf of either the government, the United Nations High Commissioner for Refugees (UNHCR), or other non-governmental organizations (NGOs). When the refugees found out about the study project, they were eager to let the participants wander around and take photographs of the public spaces, wanting to share with the principal researcher their destitute and troubled stories of neglect and despair. The fieldwork ended with the distribution donations acquired before each visit to thank the local Syrian communities for hosting the participants.

\section{f. Data Collection and Analysis Processes}

After the field work was over, the participants agreed on a specific date to meet for a follow-up session to discuss the photographs. Meanwhile, they needed to share individual photographs with respective narratives, before initiating a critical group discussion in the final session. ${ }^{204}$ The interpretation of the photographs was critical

${ }^{204}$ Caroline C. Wang, "Photovoice: A Participatory Action Research Strategy Applied To Women's Health." Journal of Women's Health 8, no. 2 (1999). 
to the success of the project for the visual narratives were the ultimate objects of group reflection. All coresearchers agreed to create a shared google drive and upload their captioned photographs with annotated narratives answering the following five questions.

This research used the original Wang's and Burris technique termed as "SHOWeD" for the participants to follow while discussing each image. ${ }^{205}$ This technique's term is an acronym for different questions that the participants needed to answer while selecting the photographs. Thus, the participants posted each picture answering Wang and Burris' methods' main questions: ${ }^{206}$

1. What do you See here?

2. What is Happening here?

3. How does this relate to Our Lives?

4. Why does this situation, concern or strength exist?

5. What can we Do about it?

These questions would later engage group discussions and generate new findings of different experiences and reflections, creating new forward-thinking knowledge. Consequently, the participants became agents of change, shifting their role from being a silent group of local actors to a powerful complementary voice with unique perspectives on Syrian refugee (in)securities, women in specific.

205 Ibid.

${ }^{206}$ Caroline Wang and Mary Ann Burris, "Photovoice: Concept, Methodology, And Use For Participatory Needs Assessment," Health Education \& Behavior 24, no. 3 (1997): 369-387. 
Accordingly, the Photovoice participants shared their photos, discussing and reflecting on perceived presence and absence of insecurities within each photo. ${ }^{207}$ Even though images are worth a thousand words, the participant's expanded narratives accompanying each photo ignited interesting, sometimes heated, discussions regarding the local dynamics and their impact on Syrian refugee (in)securities. Since photovoice is an action-oriented research that encourages a critical dialogue, each participant shared their visuals and captions with the rest of the volunteers, while projecting their anxieties towards elements that are absent from common policy rhetoric of the complex Syrian refugee (in)securities. ${ }^{208}$ Once the second group and final session were scheduled, the group then discussed the appropriation of each photo and the emerging themes and correlating issuesPhoto elicitation - developed through the discussions.

\section{g. Photo-elicitation Process}

Photo-elicitation is a participant-directed analysis process. This session was also facilitated in my family's house, where both my personal and academic researcher's identities could have affected the responses of the five remaining voluntary participants. Still, the photo-elicitation process encouraged all the participants to participate while understanding that each image might generate different meanings and critiques. It guaranteed both personal storytelling and group discussions on

\footnotetext{
207 Ibid.

208 Camille A Sutton-Brown, "Photovoice: A Methodological Guide." Photography And Culture. 7.2 (2014):169-185
} 
what to highlight and reflect on each picture. The main goal from the photoelicitation session was to record the participants' views of each picture and engage in a discussion about the different responses to the images. Each participant ended up personalizing each photograph, attributing their social and personal values when explaining. Mixed emotions were elicited throughout the photo analysis. Discussions helped bridge the distinct views that each photo provided, providing insights into how alternative practices could better alleviate the daily refugee insecurities.

Even when there was no group consensus, the multiple views of different realities in each photograph enriched the project when collected. They brought a joint collaborative reconstruction of the multiple perceived gendered realities that Syrian refugees witness. They also reflected on the latter group's impact on their overall communities, critically analyzing plausible measures of empowerment to overcome their daily insecurities. The photovoice methodology brought the volunteers to take responsibility for exposing local realities and become agents of change. Since knowledge and training are the primary sources of change, the participants' input was original and necessary for this research to grasp the transformative information on local realities.

h. Future Planning

At the end of the process, the participants chose the top ten elected themes deduced from the group discussions. The corresponding photo-narratives found most relevant to this study were selected and coded. As co-researchers, all the participants signed a release form for their pictures and narratives to be handed to 
me, while still having access to the google-drive document in case anyone would like to review, edit, add or update any information within. The session ended with a unanimous recommendation for a follow-up meeting session once the research was done to plan future opportunities for the project.

\subsubsection{Problems and Success}

The group discussions and photo-analysis brought out a deeper understanding of the complex intersectional realities that Syrian refugees, especially women, endure "solely by virtue of belonging to a particular gender, a certain age group, or social status." ${ }^{209}$ By sharing individual and group intake of all the photos collected, this method challenged the narrow assumptions of a universal refugee's experience. A collaborative work in

discussing each visual and sharing narratives within a safe space brought to light significant considerations of what types of Syrian refugee insecurities exist, while still exhibiting the local participants' anxieties, hopes, and fears. As such, the participatory nature of the Photovoice methodology made the implicit explicit. It educated everyone who participated, including the principal investigator, on the complexity of relevant refugee insecurities when explored within a bottom-up socio-cultural gender approach.

There were various challenges in using this method. A closer examination of sensitive issues could cause negative feelings among the subjects of the study.

${ }^{209}$ ABAAD. “Annual report 2014”. https://www.abaadmena.org/documents/ebook.1476091396.pdf 
Using inductive research, I had little control over the participants' choice of subject matters for their analysis. Participants had the complete freedom to decide what to include or exclude in their photographs and respective narratives. These choices influenced the research findings and interpretation. Still, the aim of this study was not for a non-biased accurate representation of all the micro-dynamics of refugee (in)securities nor the principal researcher's sole perception. After all, the goal of this research was to promote visual ethnography methods for exploring the local impact of refugee (in)security and practices. Still, I was cautious that the visuals selected did not entrap the damaging responses leading to vicious cycles of negative coping-skills of resentment and violence, having all sides blame each other for their respective visual insecurities.

After all, this study was about Syrian women and their (in)security. However, rather than being able to do research 'with' these women, this study opted to research with Lebanese volunteers in observing, reading, listening and learning more about refugee (in)security on multiple levels of analysis. Moreover, through all the methods mentioned earlier, the various findings, when triangulated, provided rich and complementing knowledge on the intersectional gendered Syrian refugee insecurities in the case of Lebanon. 


\section{LEBANESE SYRIAN (IN)SECURITY PRACTICES}

With the growing international refugee crisis, geopolitics and biased social attitudes play an instrumental role in shaping refugee (in)security construction with gendered practices. The Middle East, specifically Lebanon, has a long history of political and sectarian conflicts that have not only altered the fabric of its communities, but also influenced its local attitudes, opinions, and policies towards hosting neighboring refugees. Several recent scholarships examined Lebanon's lack of commitment to international refugee law. ${ }^{210}$ Still, most scholarships have not longitudinally traced the political junctures that led to the nuanced variations within Lebanese securitization of the recent influx of Syrian asylum seekers. Lebanese perceptions of the Syrian refugee population and increasing social tensions between both communities depend upon historical and structural factors. In this regard, this chapter addresses this gap in the literature by first examining four significant political junctures in the gendered Lebanese Syrian relationship. Second, it explores Lebanon's sensitivities towards the term "refugee" and the current legitimization of its rejection of the 1951 Refugee Convention. Third, it analyzes Lebanon's securitized refugee management practices that ostracize Syrian refugees in general. Then, this chapter provides further detail on the systemic gender discrimination that the Lebanese polity already imposes on its citizens impacting the majority of registered Syrian refugee women with some analytical implications.

${ }^{210}$ Maja Janmyr, "Precarity In Exile: The Legal Status Of Syrian Refugees In Lebanon," Refugee Survey Quarterly 35, no. 4 (2016): 58-78. 


\section{Critical Junctures in the Lebanese Syrian Relations}

Historical-critical junctures are relatively short periods of time that lead to ideational changes within the policy fabric and organizational changes that generate "self-reinforcing path-dependent processes." 211 A wide range of scholarships refer to these instances as "turning point," "paradigm shift," "crisis," "unsettled times," among many others; in this analysis we will refer to them as "critical junctures." 212 Such crises developed due to "change agents" contesting the existing status quo and attempting to (re)design policies that were once upheld. ${ }^{213}$ These endogenous and/or exogenous changes triggered new path dependent processes that constrain future choices, which become qualitatively different from previous norms and interests, affecting policymaking. ${ }^{214}$ These changes would cocreate lasting effects on the "choices made during [those] critical junctures in history," closing off different paths during that timeframe. ${ }^{215}$

In the case of Lebanon, contemporary political history has been defined by many interrelated factors that molded not only its internal structure but also its role within the region. Religion, which is believed to be one of the cornerstones of the

\footnotetext{
${ }^{211}$ Giovanni Capoccia and R. Daniel Kelemen, "The Study of Critical Junctures: Theory, Narrative, and Counterfactuals in Historical Institutionalism," World Politics 59, no. 3 (2007): 341-369.

212 Ibid.

${ }^{213}$ David Nachmias and Chava Nachmias, "Content Analysis," in Research Methods in the Social Sciences, ed. Edward Arnold, London, England, (1976), 132-39.

${ }^{214}$ Edward Anthony Koning, "The Three Institutionalisms And Institutional Dynamics: Understanding Endogenous and Exogenous Change,” Journal of Public Policy 36, no. 4 (2016): 639-664.

215 Nils A. Butenschøn,. "Arab citizen and the Arab state: The "Arab Spring" as a critical juncture in contemporary Arab politics." Democracy and Security 11, no. 2 (2015): 111-128.
} 
country's fabric, played a significant role in shaping Lebanese dynamics, as different sects mainly Maronite, Sunni, Shiite, Druze, Greek Orthodox developed into the primary social organizations maintaining political security. Identity politics led, most importantly, to communal favoritism over individual rights, causing resentment and alienation within Lebanese society. Lebanon's sectarian stability depends on "the ability of communal elites to sustain the power-sharing agreement and maintain control" over their respective communities. ${ }^{216}$

Since its independence, Lebanon's eighteen religious sects gave room for a confessional power-sharing system that was further institutionalized under the Ta' if Accord after the end of the civil war, in $1989 .^{217}$ The Ta'if Accord-a regional summit brokered in the city of Ta'if, Saudi Arabia-incorporated in the Lebanese Constitution a more confessional (a system of government that is a de jure mix of religion and politics) distribution of political power among the main religious groups. The three dominant ethnoreligious sects (Maronite Christians, Sunni Muslims, and Shiite Muslims) took the leading positions, with the office of the President assigned to a Maronite, that of the Prime Minister to a Sunni Muslim, and the Speaker of the National Assembly to a Shiite Muslim. ${ }^{218}$

\footnotetext{
${ }^{216}$ Jaulin Thibaut, "Citizenship, Migration, And Confessional Democracy In Lebanon," Middle East Law and Governance 6, no. 3 (2014): 250-271.

${ }^{217}$ Rola, El-Husseini. "Pax Syriana." Elite Politics In Postwar Lebanon." Syracuse University Press (2012), 38.

218 Jaulin Thibaut, 250-271.
} 
Meanwhile, the legacy of the civil war and repeated foreign occupation, thus, kept the Lebanese polity deeply fragmented. ${ }^{219}$ During that time, both Israel and Syria had a heavy military presence within the country. Syrians controlling most eastern and western parts of the country. While, Israel held its ground in South Lebanon." ${ }^{220}$ The latter furthered local Lebanese resentment of and contempt toward the Syrian "brothers" for leaving the Lebanese government pathologically fragmented and too weak to stand against foreign occupations. ${ }^{221}$

In the meantime, it is a truism to say that while Syria has dominated Lebanon until this day, with no major Lebanese political decision made without the Asaad regime's blessing, Syrian refugees suffer from the Syrian regime's privileges over Lebanon. As long as the two countries do not officially demarcate their common border, legally Lebanon remains a hostage of Syria's geopolitical ambitions in which the Lebanese-Syrian gendered relationship can never reach equal terms. In effect, the failure to demarcate Lebanon's boundaries, Syria's domination of the Lebanese socio-political sphere remains unabated. It maintained a strong foothold along the eastern Mediterranean coast and a strategic role in Lebanon's protracted war with Israel. Then, as a reaction, most Lebanese public outcry and constituents' hostile attitudes towards Syrians taking refuge in their

\footnotetext{
${ }^{219}$ Rola El-Husseini, 38.

${ }^{220}$ Scott Preston, "The confessional model and sectarian politics: Lessons from Lebanon and the future of Iraq." (2013).

${ }^{221}$ Augustus Richard Norton, “Lebanon After Ta'if: Is the Civil War Over?,” Middle East Journal 45, no. 3 (1991): 457473.
} 
communities were only (en)gendered manifestations towards the unwanted presence of Syrians.

For this reason, historical-critical junctures such as these were points within a timeframe that led to policy and strategy changes within Lebanese factions that ultimately shaped the existing Lebanese-Syrian relation and residing Syrian refugees' status quo by re-designing the policies that Lebanon once upheld. The logic behind the critical junctures in Lebanese politics rests on interrelated shocks or aberrations domestically and within the region. In this respect, the following subsections trace four relevant critical junctures within Lebanese-Syrian relations that (in)directly led to today's changes in Lebanese policy practices towards Syrians residing within the country.

\section{Critical Junctures in the Lebanese Syrian Rapport}

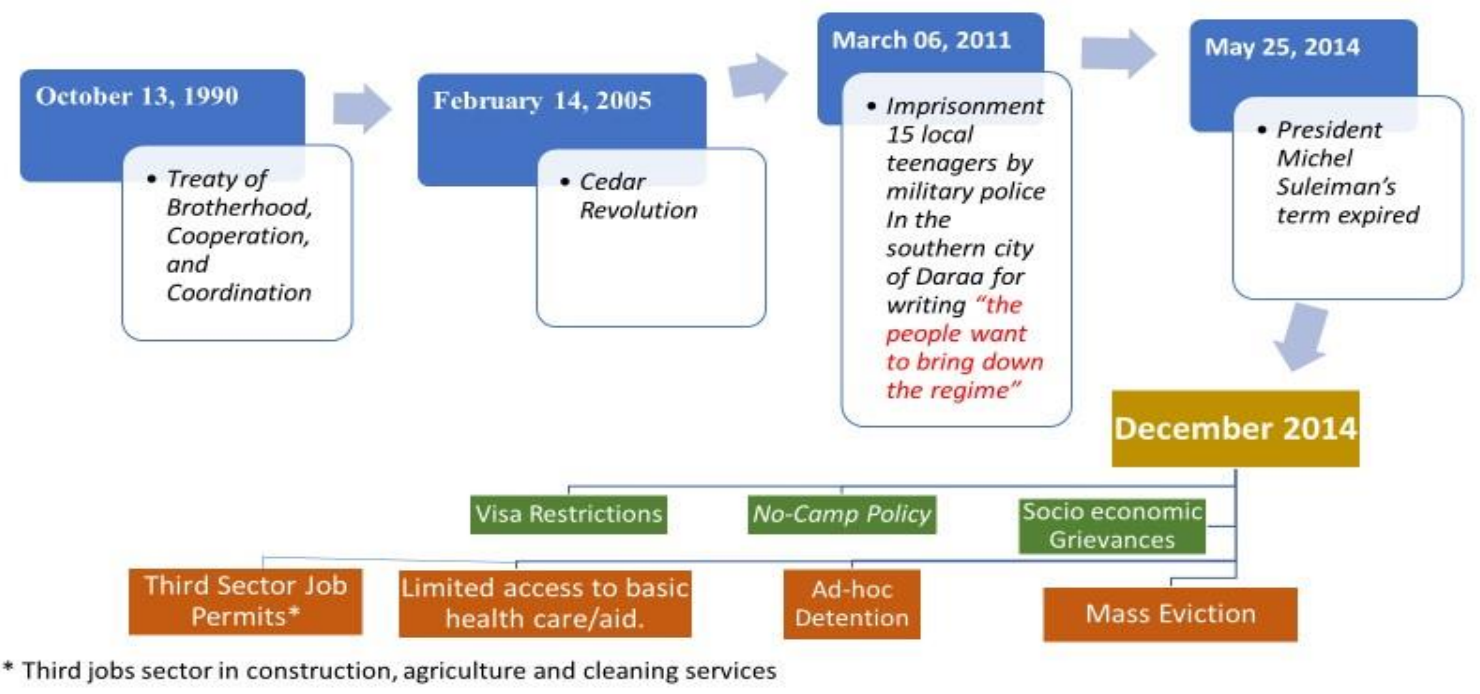

Figure 3. Lebanese-Syrian Relations and Syrian Refugee (In)Security Practices

The figure above provides a graphic representation of the following information intended to map out the critical junctures in the Lebanese-Syrian relation that led 
to today's Lebanese (in)security practices in relation to Syrians residing in the country. The information contained in the figure summarizes the following subsections of this chapter by providing visual information quickly and clearly.

1.1 First Juncture: $1990-2005$

On October 13, 1990, the Lebanese Civil War came to an end when favorable regional and international developments overlapped with the anguished internal parties' desires of a type of reconciliation. ${ }^{222}$ This political juncture guaranteed Syria's custodianship over Lebanon, as mandated by American and European authorities after the Lebanese Civil War, securing a free Syrian hand in internal Lebanese politics. ${ }^{223}$ It is crucial to note that the Ta'if Agreement of October 22, 1989, a result of a Saudi, US and Syrian agreement imposed on Lebanon, was the formal pact that ended the Lebanese civil war, establishing Syria's control over Lebanon. As a consequence, Lebanese-Syrian relation was cast in sibling terms: "brotherhood."224 This "special" relationship strengthened with its inclusion in the Ta'if Accord-"the roots of blood relationships, history, and joint fraternal interests" 225 — and was further institutionalized, later on, through a formal treaty in 1991 - the Treaty of Brotherhood, Cooperation, and Coordination

\footnotetext{
${ }^{222}$ Hassan, Krayem. "The Lebanese Civil War And The Taif Agreement." Conflict Rresolution In The Arab World: Selected Essays (1997): 411-435.

${ }^{223}$ Fawwaz Traboulsi, A History of Modern Lebanon. Pluto Press, (2007), 245.

${ }^{224}$ Marie-Joëlle, Zahar. "Peace By Unconventional Means: Lebanon's Ta’if agreement." Ending Civil Wars: The Implementation of Peace Agreements (2002): 567-597.

225 The English Translation of the Ta'if Accord can be retrieved from: https://www.un.int/lebanon/sites/www.un.int/files/Lebanon/ the_taif_agreement_english_version_.pdf.
} 
Between the Syrian Arab Republic and the Lebanese Republic. This treaty streamlined what could be perceived as a gendered relationship between both countries, in which Lebanese security and foreign policy objectives became dependent on Syria's wellbeing. Accordingly, Article 1 of the Brotherhood Pact engendered new mechanisms for further institutionalization of bilateral committees for common security, socio-economic, and foreign policies, stating that:

"The two States shall endeavor to achieve the highest degree of cooperation and coordination in the political, economic, security, cultural, scientific and other fields for the benefit of both fraternal countries within the framework of their individual sovereignty and independence and so as to enable the two countries to use their political, economic and security potential to provide for their prosperity and stability, protect their regional and national security and broaden and strengthen their joint interests in confirmation of their fraternal relations and as a pledge of their common destiny."226

Article 3 of this treaty interconnected Lebanese security with Syria's wellbeing, a matter that caused great concern to many Lebanese politicians at that time, as they feared that they would become hostage to Syrian maneuvers within the region:

"The interdependence of the security of the two countries shall require that

\footnotetext{
226 "Treaty Of Brotherhood, Cooperation, And Coordination Between The Syrian Arab Republic And The Lebanese Republic" United Nations Treaty Series; 154: https://peacemaker.un.org/sites/peacemaker.un.org/files $\quad$ /LY_910522-Treaty BrotherhoodCooperationCoordination.pdf.
} 
Lebanon shall not, under any circumstances, be made a source of threat to the security of Syria."227 This article called for wide-ranging cooperation between both countries security apparatus, exchanging any sensitive information that would eliminate what they deem as a threat with perceivable gendered effects. Syrian intelligence engendered structural security operations across Lebanese territories, legally entitling it to scrutinize any Lebanese resident for 'security reasons.' In practice, the Lebanese-Syrian relationship gendered most Lebanese citizens' experiences of (in)security. Syrian security agencies in Lebanon had a free hand virtually to pursue any masculinized perceivable threat or a critic of its regime, silencing the Lebanese population from the freedom of expressing concerns or opposition to Syria's control over Lebanon. ${ }^{228}$

Meanwhile, Article 4 set the timeline for Syria's slow withdrawal from Lebanon, stating that: "After the institution of political reforms in constitutional form in accordance with the provisions of the Lebanese National Charter and on the expiry of the time-limits prescribed in the Charter, the Syrian and Lebanese Governments shall decide on the redeployment of Syrian forces." ${ }^{229}$ Subsequently,

${ }^{227}$ Ibid.

${ }^{228}$ Erik Husem, "The Syrian Involvement In Lebanon: An Analysis Of The Role Of Lebanon In Syrian Regime Security, From Ta'if To The Death Of Hafiz al-Assad (1989-2000)," FORSVARETS FORSKNINGSINSTITUTT (FFI) Norwegian

Defence Research Establishment. (2002): https://admin.ffi.no/no/Rapporter/02-03005.pdf

229 "Treaty Of Brotherhood, Cooperation, And Coordination Between The Syrian Arab Republic And The Lebanese Republic” United Nations - Treaty Series; 154 , https://peacemaker.un.org/sites/peacemaker.un.org/files/LBSY_910522_TreatyBrotherhoodCooperationCoor dination.pdf. 
the Alawi regime in Syria subordinated the Lebanese polity by not allowing it selfgovernance. This "brother-sister" metaphor shown in the above articles extended beyond rhetoric, affecting relations between both states on political and social levels. ${ }^{230}$ With boots on the ground, Syria turned Lebanon into a police state, 'Dawlat al-Mukhabarat,' targeting any person or political group who resisted it. ${ }^{231}$ Syria acted as a colonial administrator in Lebanon, encouraging postwar proSyrian Lebanese political parties with political and financial rewards; thus these proSyrian parties had a stake in preserving the status quo. ${ }^{232}$ With Syrian blessings, the inability of Lebanese political fabric to recover from wartime practices hindered competitive politics. Anti-Syrian parties were banned, and top Lebanese positions were closely supervised and manipulated by Syrian agents. ${ }^{233}$ Several prominent Lebanese political figures either left the country, were imprisoned, or assassinated due to their anti-Syrian positions. ${ }^{234}$ Lebanon became dependent on the "big

\footnotetext{
${ }^{230}$ Diane Riskedahl, “The Sovereignty Of Kin: Political Discourse In Post-Ta'if Lebanon,” PoLAR: Political and Legal Anthropology Review 34, no. 2 (2011): 242.

${ }^{231}$ Marius Deeb. Syria's Terrorist War On Lebanon And The Peace Process. Springer, (2003), 4.

${ }^{232}$ Farid El Khazen, "Political Parties In Postwar Lebanon: Parties In Search Of Partisans," Middle East Journal 57, no. 4 (2003): 605-624.

${ }^{233}$ Dib Kamal, Warlords and Merchants: The Lebanese Business And Political Establishment (Ithaca Press, 2004). Erik

Husem, "The Syrian Involvement In Lebanon: An Analysis Of The Role Of Lebanon In Syrian Regime Security, From

Ta'if To The Death Of Hafiz al-Asad (1989-2000)," FORSVARETS FORSKNINGSINSTITUTT (FFI) Norwegian Defence Research Establishment. 2002, https://admin.ffi.no/no/Rapporter/02-03005.pdf.

${ }^{234}$ Farid El Khazen, "Political Parties In Postwar Lebanon: Parties In Search Of Partisans," Middle East Journal 57, no. 4 (2003): 605-624.
} 
brother," stuck in low-intensity conflict with Israel, and not able to conduct independent negotiations without Syria's "blessings." 235 From the widespread physical presence of Syrian soldiers' checkpoints to Syrian operated detention facilities in major Lebanese cities, the visible signs of Syrian dominion over Lebanon became visible in the majority of Lebanese's daily lives. ${ }^{236}$

On a socio-economic level, the Treaty of Brotherhood, Cooperation, and Coordination made Lebanon virtually subcontracted to the Syrian economy, where Syrians were able to work in Lebanon and, in turn, acquired significant remittances. ${ }^{237}$ A labor agreement was then made in 1994, legalizing the status of approximately 900,000 Syrian workers in Lebanon, which resulted in the capital flight of what could be considered as millions of dollars from Lebanon being added daily to the Syrian economy. ${ }^{238}$ The Syrian presence in Lebanon radically impacted the local environment, further magnified by arbitrary naturalization practices such as the "1994 naturalization decree that granted Lebanese citizenship" to hundreds of thousands of pro-Syria Arab foreigners residing in Lebanon. ${ }^{239}$ This

\footnotetext{
${ }^{235}$ Kail C. Ellis, “Lebanon: The Struggle Of A Small Country In A Regional Context.” Arab Studies Quarterly (1999): 5-25.

${ }^{236}$ Daniel Meier. "Lebanon: the refugee issue and the threat of a sectarian confrontation." Oriente moderno 94, no. 2 (November 18, 2014): 382-401.

${ }^{237}$ Daniel Meier. "Lebanon: the refugee issue and the threat of a sectarian confrontation." Oriente moderno 94, no. 2 (2014): 382-401.

${ }^{238}$ Volker Perthes. "From Front State To Backyard? Syria And The Risks Of Regional Peace," in Economic and Political Impediments to Middle East Peace. London, England: Palgrave Macmillan, (2000), 225-240.

239 Thibaut Jaulin, "Citizenship, Migration, And Confessional Democracy In Lebanon," Middle East Law and Governance 6, no. 3 (2014): 250-271.
} 
discretionary power over naturalization allowed pro-Syria political elites to distribute Lebanese citizenships to individuals deemed worthy, through which naturalization became an instrument to develop political clienteles. ${ }^{240}$

1.2 Second Juncture: $2005-2011$

The direct reign of Syria over Lebanon lasted till the anti-Syrian occupation movement - the Cedar Revolution of 2005 — called for the withdrawal of Syrian troops from the Lebanese territories. The Cedar Revolution came fifteen years after the end of the Lebanese civil war and almost five years after Israeli troops' withdrawal from southern Lebanon. This political juncture, triggered by the assassination of late Lebanese Prime Minister Rafic Hariri on February 14, 2005, was led by several anti-Syrian Lebanese factions blaming the Assad regime for his death. ${ }^{241}$ However, and even after the military withdrawal in 2005, Syrian oversight continued to influence Lebanese politics until this date through the presence of strong Lebanese allies within the country such as Hezbollah and the longstanding political, economic, and social ties constituted through a vast network of influence within Lebanese polities.

The void that the Syrian military withdrawal left triggered an increase in violence with several car bombs, explosions, and assassination attempts on a number of "anti-Syrian intellectuals and politicians," mostly blamed on the Syrian

\footnotetext{
${ }^{240}$ Ibid.

${ }^{241}$ Diane Riskedahl, "The Sovereignty Of Kin: Political Discourse in Post-Ta'if Lebanon," PoLAR: Political and Legal Anthropology Review 34, no. 2 (2011): 234.
} 
regime. ${ }^{242}$ Complex social organizations before 2005 , such as family ties and religious affinities, created double-edged attitudes between the two communities. This was coupled with submissive behaviors and continuous expectations from Syria to lead the country. ${ }^{243}$ Even after the 2005 withdrawal, Syria's political influence in Lebanon resisted the new realities of slowly constructing a viable independent country with a somewhat formal relationship with Syria - a move that was then substantiated by the establishment of the first Syrian embassy in the country in December 2008. ${ }^{244}$ Accordingly, Lebanon's president, Michel Suleiman, held the first state visit to Syria and forged the agreement to establish formal relations between both countries. ${ }^{245}$ This significant act hindered the days of undiluted Syrian hegemony over Lebanon, where Lebanon as a state became formally acknowledged by Syria sovereign on paper. In alteration, a variety of tactics ranging from diplomatic negotiations and persuasions between Lebanon and Syria increased. At the same time, informal intimidation tactics and assassination attempts were visibly recorded against local political and security adversaries but

\footnotetext{
${ }^{242}$ Daniel, Meier, "Lebanon: the refugee issue and the threat of a sectarian confrontation." Oriente moderno 94, no. 2 (2014): 382-401.

${ }^{243}$ Leila Tarazi. Fawaz. An Occasion For War: Civil Conflict In Lebanon And Damascus In 1860. University of California Press, (1994).

${ }^{244}$ Diane, Riskedahl. "The Sovereignty Of Kin: Political Discourse in Post-Ta'if Lebanon." PoLAR: Political and Legal Anthropology Review 34, no. 2 (2011): 233-250.236.

${ }^{245}$ Ian Black. "Syria and Lebanon To Establish Diplomatic Relations.” The Guardian. (October 14, 2008).

https://www.theguardian.com/world/2008/oct/14/syria-lebanon
} 
were inefficient in silencing anti-Syrian denunciations of its control over Lebanon. $^{246}$

Still, this new phase in Syrian-Lebanese relations needed time to adjust to the new reality of Syria's departure from Lebanon. Without the presence of a Syrian role in local politics, the political process was at a stalemate, characterized by unwillingness from the political elites to reach a shared vision of the future trajectory of Lebanon. ${ }^{247}$ Also, Israel's 33-day attack in July 2006 was more extensive, more lethal and reached deeper into northern Lebanon than any of its predecessors. The death and destruction in several Lebanese cities, towns, and villages empowered pro-Syrian Hezbollah to gain popularity within many Lebanese communities. By acquiring a reputation for being a legitimate political actor in Lebanon that successfully fought Israel with the aid of the Assad regime in Syria, Hezbollah gained direct control of most of the Lebanese intelligence infrastructure, which made sure anti-Syrian maneuvers were thwarted. ${ }^{248}$ Meanwhile, no real efforts were made between both states to officially delineate the borders between them, mostly due to the disputed issue of Shebaa farms-

${ }^{246}$ Samia Nakhoul. "Analysis: Killing Of Security Chief Raises Fears For Lebanon." Reuters. Beirut. (October 22, 2012). Retreived from: https://en.wikipedia.org/wiki/Wissam_al-Hassan\#cite_note-samia2212-19

${ }^{247}$ Alessandra Bajec, "Lebanon's Political Crisis Drags On As Politicians Agree to Extend Their Mandate A Third Time," Al-Araby News, (June 20, 2017), https://www.alaraby.co.uk/english/indepth/2017/6/20/lebanonspolitical-crisis-dragson-with-third-term-extension.

${ }^{248}$ Paul Salem. "The Future Of Lebanon." Foreign Affairs. 85, (2006). 13. 
which Israel claims is a Syrian land - and keeping Lebanon's struggle against Israeli occupation of what is practically a southern Lebanese territory. ${ }^{249}$

\subsection{Third Juncture: $2011-2014$}

On March 06, 2011, Syria was rocked by anti-regime demonstrations calling for Assad's impeachment, creating room for ongoing domestic turmoil in Syria. At the same time, four Syrian brothers and opposition activists in Lebanon vanished just after distributing flyers to demonstrate against the Syria's government in front of the Syrian embassy in Beirut. ${ }^{250}$ Human Rights Watch condemned the act, fearing that Lebanon was "back to doing Syria's dirty job." ${ }^{251}$ Meanwhile, at the onset of the 2011 crisis in Syria, Lebanon maintained an "open-door policy"-a policy of welcoming all refugees from Syria without exception. ${ }^{252}$ Then on June 11, 2012, the official Lebanese declaration called for establishing a policy of neutrality towards the Syrian conflict under the banner of a "dissociation policy seeking not to be involved in the Syrian conflict and maintaining neutrality in international institutions." 253 This course of action, albeit lauded by the international community

\footnotetext{
${ }^{249}$ Asher Kaufman. "Understanding the Shebaa Farms dispute: Roots of the anomaly and prospects of resolution." Palestine-Israel Journal of Politics, Economics, and Culture 11, no. 1 (2004): 37.

250 "Lebanon: Reveal Fate of Disappeared Syrians: Military Intelligence Detains Six Calling for Democratic Change In Their Country," Human Rights Watch, (March 9, 2011), https://www.hrw.org/news/2011/03/09/lebanon-reveal-fatedisappeared-syrians.

${ }^{251}$ Ibid.

252 “Amnesty International Annual Report 2015/2016." Releif Web: http://reliefweb.int/report/lebanon/amnestyinternational-regrets-lebanon-s-decision-overturn-its-open-borderpolicy.

${ }^{253}$ Maja Janmyr. "No Country of asylum: 'Legitimizing'Lebanon's rejection of the 1951 refugee convention." International Journal of Refugee Law 29, no. 3 (2017): 438-465.
} 
and various human rights organizations, did not stem from the Lebanese government's genuine willingness to practice its humanitarian obligations. ${ }^{254}$

In actuality, it was the lack of policy that resulted from an amalgam of deep divisions and conflicting opinions, that crippled the Lebanese political establishment during this period of deep political deadlock that did not translate this policy of dissociation into practice. ${ }^{255}$ Meanwhile, the renewal of a pro-Syrian president for a second term continued the polarized Lebanese political spectrum by keeping the Lebanese army and United Nations Interim Force In Lebanon (UNIFIL) away from safeguarding the blurry and porous Lebanese border with Syria. As a result, the Lebanese-Syrian responsive relation sustained until the end of his presidency. In 2011, the borders were left open to virtually any Syrian fleeing the war just because the Lebanese government was too divided to formulate an effective strategy to regulate the influx of refugees into the country, while the presidency remained loyal to previous agreements with the Syrian Assad regime. ${ }^{256}$ The rift between national political parties, those that are pro-Syrian regime and those opposing it, prevented Lebanon from responding earlier to the Syrian refugee

\footnotetext{
254 "U.S. Welcomes Lebanon Plan For Syrian Refugees," The Daily Star, (January 4, 2013), http://www.dailystar.com.lb/News/Politics/2013/Jan04/200934-us-welcomes-lebanon-plan-for-syrian-refugees.

${ }^{255}$ Maja Janmyr, "Precarity In Exile: The Legal Status Of Syrian Refugees In Lebanon," Refugee Survey Quarterly 35, no. 4 (2016): 58-78.

${ }^{256}$ Karim El Mufti. "Official Response To The Syrian Refugee Crisis In Lebanon: The Disastrous Policy Of No-Policy", Civil Society Knowledge Center, Lebanon Support, (January 10, 2014): http://civilsocietycentre.org/paper/officialresponse-syrian-refugee-crisis-lebanon-disastrous-policy-no-policy
} 
crisis. ${ }^{257}$ This inaction and the lack of strategic vision led to the fragmentation of the entire Syrian refugee-population across Lebanese territory. Accordingly, the geographical fragmentation of Syrians within Lebanon mostly followed a sectarian pattern, in which Sunnis mostly resided in heavily populated Sunni regions and the predominantly Christian and Shiite areas welcomed Syrian Christians and Alawites. ${ }^{258}$

Moreover, the Lebanese government failed to fight corruption and reach a consensus over a united foreign policy related to Hezbollah's military involvement in the Syrian war. ${ }^{259}$ Hassan Nasrallah declared, in April 2013, that Hezbollah would be giving Syria "a hand," stating that "Syria is the backbone of the resistance and we [Hezbollah] will not sit with our hands crossed." ${ }^{260}$ With the active participation of Hezbollah in the well-known clearing operation in al-Qusayr, this event marked the official start of Hezbollah's military intervention in the Syrian

\footnotetext{
${ }^{257}$ Kholoud Mansour. "UN Humanitarian Coordination In Lebanon The Consequences of Excluding Syrian actors International” Chatham House The Royal Institute of International Affairs. (March 2017).

258 "Too Close For Comfort: Syrians In Lebanon." The International Crisis Group (ICG) Middle East Report,(2013),9.

${ }^{259}$ Hezbollah-A Shiaa-based Lebanese paramilitary organization-offered unconditional support to the Assad Baath regime amid a regional Sunni-Shiaa antagonism within the whole Arab region. For them, a USSaudi initiative to topple the Assad regime only means a weakening of the Shiite Iranian Hezbollah influence within the region. This led to a lot of tension and resentment from the Lebanese Sunni public who are antiAssad regime and supporters of the Syrian resistance. They believe that the $90 \%$ of the Syrian populationSunnis - should have a say in their country's politics and not let the current regime- $8 \%$ Allawite pro-Shiiacontrol them. They heavily criticized and questioned Hezbollah's existence for it had no legal justification as a "Lebanese resistance" fighting other countries' wars.

260 Torie Rose DeGhett, “Is Syria About To Become Iran's New Vietnam?,” Vice News, (October 7, 2015), https://news.vice.com/article/is-syria-about-to-become-irans-vietnam.
} 
War. ${ }^{261}$ Since then, all other Lebanese political parties felt uncomfortable with Hezbollah sending an increasing number of its militants to Syria, complaining that the organization was putting Lebanon in danger by interfering in a foreign war. Still, the mainstream political climate in Lebanon positioned itself as pro-“opendoor policy" in solidarity with the Syrian refugee community, inconsistently advocating for aiding the "displaced" Syrians, in high hopes that the Assad regime would prevail, and displaced Syrians would soon be going back to their land. ${ }^{262}$

On a social level, many Lebanese, at that time, believed that the Syrian crisis was temporary, and the Assad reign would endure. ${ }^{263}$ Meanwhile, the Labor Agreement was still in a place through which Syrians were allowed to work and find jobs to the point of establishing and operating their own small businesses in Lebanon without any actual restrictions. ${ }^{264}$ While this has triggered an outcry among the Lebanese public complaining about the competition in the labor market as well as in business areas the Lebanese government still maintained a very permissive position toward Syrian refugees on its territory, merely because of

\footnotetext{
${ }^{261}$ Mirella Hodeib, “Hezbollah Fighters Find Nusra's Tactics in Qusair 'Irritatingly Familiar,"” Daily Star Lebanon, (May 31, 2013), http://www.dailystar.com.lb/News/Local-News/2013/May31/218984-hezbollahfighters-find-nusrastactics-in-qusair-irritatingly-familiar.ashx.

262 "Uncharted Waters: Thinking Through Syria's Dynamics, Middle East Briefing no. 31" International Crisis Group Damascus/Brussels (November 24, 2011).

263 "Syria's Civil War $\quad \begin{gathered}\text { Explained } \\ \text { http://www.aljazeera.com/news/2016/05/syria-civil-war-explained- }\end{gathered}$
AlJazeera,(2016), 160505084119966.html.

${ }^{264}$ Haytham Mahmoud, "Syrian Refugees Change The Lebanese Labor Scene," Al-Arabiya, (July 8, 2016), http://english.alarabiya.net/en/business/economy/2016/07/08/Syrian-refugees-change-the-Lebanese-laborscene.html.
} 
political paralysis. ${ }^{265}$ However, this sentiment towards the integration of the Syrian labor-force in Lebanon shifted in the following years.

1.4 Fourth Juncture: Post 2014

On May 25, 2014, pro-Syria President Michel Suleiman's term expired, and Lebanon had no president, creating a new political juncture. Consequently, a selfappointed parliament further exacerbated Lebanon's presidential stalemate, failing (for the 45th time) to elect a president in three consecutive years. ${ }^{266}$ As a result of this political paralysis, a security gap allowed hundreds of thousands of Syrians to enter the country without official supervision. It should be noted that presidential elections in Lebanon do not depend solely on domestic politics. Regional powers and several external factors, such as the Syrian crisis, critically influence local dynamics, thus creating a power vacuum. Still, these factors create space for new instabilities and opportunities to arise and galvanize different forces at work.

Moreover, without a strong Lebanese presidential figure to support the continuance of the Assad regime, the initial mood in the Lebanese public sphere which had called for a stance of solidarity with their Syrian "brothers" quickly shifted. ${ }^{267}$ On June 2014, the presidential elections in Syria occurred with president

\footnotetext{
${ }^{265}$ Maja Janmyr, "Precarity in Exile: The Legal Status Of Syrian Refugees In Lebanon," Refugee Survey Quarterly 35, no. 4 (2016): 58-78.

${ }^{266}$ Imad K. Harb, “The Hezbollah-Iran Pivot: The Controlling Agencies Behind Lebanon's Sectarian Politics.” Center for Security Studies, SAGE International Australia, (2016), 1.

267 Lamia Estatie, "Lebanon Detains Men Behind Assault On Syrian Refugee," BBC News, (July 19, 2017), http://www.bbc.com/news/blogs-trending-40653714.
} 
Bashar el-Assad winning with a landslide majority of $88 \%$ of the votes. ${ }^{268}$ This event led to tens of thousands of Syrians marching towards the Syrian embassy in Beirut chanting pro-regime slogans in solidarity with Bashar el-Assad. ${ }^{269}$ However, with the Syrian crisis increasing in intensity, turning into a full-fledged war, not only did domestic actors clash, but the Syrian crisis also resulted in (in)direct military interventions and political confrontations from Lebanese factions, competing in a protracted international war of proxies. ${ }^{270}$ Gruesome war methods, such as sieges, starvation, and chemical attacks, were criticized by various Lebanese factions who blamed local political groups such as Hezbollah for being too invested in the "external" Syrian armed struggle. ${ }^{271}$ The condemning attitudes concerning the Syrian conflict did not diminish with the continuous bloodshed and increased human suffering in Syria, which pushed millions of Syrians to forcibly leave the country in search for asylum."272 Alas, the once feeble number of 7,088 registered refugees in Lebanon in March 2012 skyrocketed to more than one million

\footnotetext{
268 “Syrian President Bashar Al-Assad Wins Third Term.” BBC NEWS, World, Middle East. (June 5, 2014). : http://www.bbc.com/news/world-middle-east-27706471

${ }^{269}$ Ruth Sherlock Yarzeh, "Expat Syrians Join the Crush To Support Assad In Parody Election,” Telegraph $U K$, (May 28, 2014).

270 Angela Stent, "Putin's Power Play in Syria: How To Respond To Russia's Intervention," Foreign Affairs 95 (2016): 106.

271 "World Report 2014 Events of $2013 \quad 2014$." Human Rights Watch, https://www.hrw.org/sites/ default/files/wr2014_web_0.pdf.

272 “"Unprecedented' 65 Million People Displaced by War And Persecution in 2015." UN News Centre, http://www.un.org/apps/news/story.asp?NewsID=54269 \#. WahMY8h96bg.
} 
refugees in March 2014, legitimizing local calls for securitizing the influx of Syrians to the country. ${ }^{273}$

The absorption of such an influx proved to be extremely strenuous for the Lebanese governmental institutions, which already suffered from shortages in delivering essential services to its domestic sphere. By the end of 2014, Lebanon, with an area of 10,452 square kilometers (4,036 sq. mi) and a population of roughly five million, hosted approximately 1.2 million registered displaced Syrians, almost one-third of the overall Lebanese population. ${ }^{274}$ And now, with the Syrian government's threats of confiscating millions of properties of Syrians who have fled if they fail to register them properly and on time, the odds of Syrians being "trapped" in Lebanon increased precariously with no viable way to return. In fact, a new decree introduced by the Assad regime called Law 10, also known as 'Absentees law', could be a means to reinforce the discriminatory gendered relations between the Syrian state and its outcasts, in which millions of refugees could lose their lands, legitimizing the government's seizure of such assets and threatening to change Syria's demographic. ${ }^{275276}$ Even though the Legislation is not yet in effect,

\footnotetext{
273 "Trapped in Lebanon: The Alarming Human Rights And Human Security Situation Of Syrian Refugees In Lebanon,"

ALEF, (May2016),https://alefliban.org/wp-content/uploads/2016/11/Trapped-In-Lebanon-_ALEF_PAX _May2016.pdf.

274 "Struggling To Survive: Slavery And Exploitation of Syrian Refugees In Lebanon," Freedom Fund, (April 12, 2016), http://freedomfund.org/wp-content/uploads/Lebanon-Report-FINAL-8April16.pdf.

${ }^{275}$ Arwa Ibrahim. Syria: 'Absentees Law' Could See Millions Of Refugees Lose Lands." Al-Jazeera News. (April 7, $\begin{array}{lll}276 & \text { ): } & \text { www.aljazeera.com/news/2018/04/syria-absentees-law-millions-refugees-lose- } \\ \text { lands180407073139495.html }\end{array}$
} 
it still allows the Baathist government to confiscate properties of millions of displaced Syrians unless they prove ownership with the Ministry of Local Administration within 30 days. This type of structural violence not only punishes the millions who have opposed the Assad government by denying them their rights to their land, but it also silences their claims as outcasts not able to ever go back to their lands, while rewarding mainly the Allawite and Christian pro-Assad communities in taking over the confiscated Sunni Muslims' properties. ${ }^{277}$

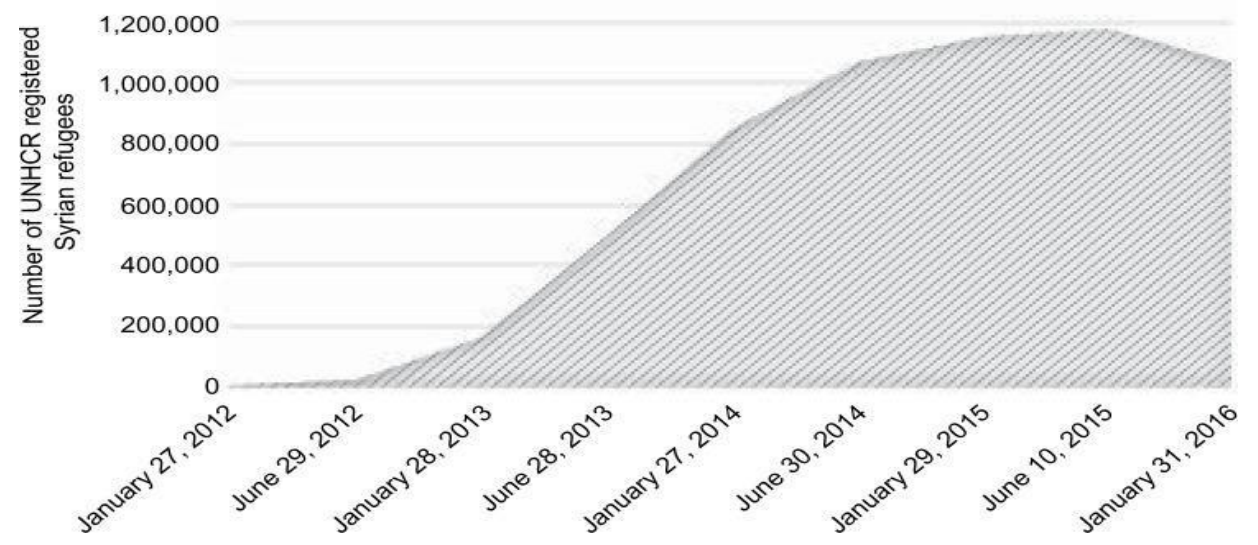

Figure 4. UNHCR Registered Syrian Refugees (2016)

Based on the above figure, the rapid increase of Syrians registering as refugees with the UNHCR (between 2013 and 2014) led to a shift in Lebanese attitudes towards the now perceived "refugee burden." As a reaction to previous Syrian aggressions when occupying Lebanon, the reevaluation of the "Brotherhood" relationship enshrined in the Treaty of Brotherhood, Cooperation, and Coordination between

\footnotetext{
277 "The Future of Syria: How A Victorious Bashar Al-Assad Is Changing Syria." The Economist, (June 28, 2018): https://www.economist.com/middle-east-and-africa/2018/06/28/how-a-victorious-bashar-al-assad-ischanging-syria
} 
Lebanon and Syria came under scrutiny. ${ }^{278}$ The perception of patriarchal kinship to Syria and its population turned to a perception of either a masculinized burden of a terrorist threat coupled with political instability or a feminized burden that would drown the country with socio-economic insecurities that it cannot afford, leaving all odds manifesting against Syrian refugees in Lebanon. According to one news article, the Lebanese Patriarch Bechara Boutros al-Rahi accused Syrian refugees of "snatching (the Lebanese people's) daily bread from their mouths, throwing them into a state of poverty and deprivation." ${ }^{279}$ In fact, his statement was an echo of the long-standing fear of hosting a big number of refugees, especially Syrian refugees who threaten Lebanon's security and burden its sluggish economy, taking jobs or straining Lebanon's straining public services. ${ }^{280}$ The following section explores Lebanon's history with forced migration and the reasons behind its distrust over hosting a large number of refugees, Syrians especially.

\section{Lebanon's Sensitivity Toward the Word "Refugee"}

Since Lebanon functions under a weak quasi-democracy in the Middle East, the constant influx of people into the country is one of its greatest concerns. ${ }^{281}$ From

\footnotetext{
${ }^{278}$ Filippo Dionigi, "Rethinking Borders: The Dynamics Of Syrian Displacement To Lebanon," Middle East Law And Governance 9, no. 3 (2017): 232-248.

279 "Patriarch al-Ra'i: "Syrian Refugees Threaten Lebanon Security." Orient News, (December 26, 2016): https://www.orient-news.net/en/news_show/129448/0/Patriarch-al-Rai-“Syrian-refugees-threaten-Lebanonsecurity

${ }^{280}$ Ellen Francis. "Hostility Grows Towards Syrian Refugees In Lebanon.” Reuters. (August 28, 2017): https://www.reuters.com/article/us-lebanon-refugees-tension-idUSKCN1B8128

${ }^{281}$ Marta Agosti, "The Nationality Law In Light Of The Refugee Crisis In Lebanon: Old Battles, New Consequences," Contemporary Levant 1, no. 2 (2016): 148-151.
} 
the day it took its independence, the history of the country is closely intertwined with forced migration and refugees. This section proceeds with the various empirical findings that highlight Lebanon's sovereignty practices of refugee exclusion. It revisits some crucial issues elaborated in the previous section that lead to the imposition of restrictive gendered policies on the entry, residence, and movement of Syrian refugees in Lebanon.

In effect, Lebanon never passed any national legislation pertaining to the status of refugees on its territories. According to the UNHCR, Lebanon hosts a lot of Iraqis, Syrians, and Palestinians. ${ }^{282}$ Some are considered as guests, others are viewed as a threat. Still, Lebanon does not have an official refugee law, so a big number of forced migrants are treated as economic migrants and temporary foreign visitors. ${ }^{283}$ Even though more than 145 states have ratified the Geneva Convention, Lebanon, like several other countries in the region, is neither a signatory of the 1951 Refugee Convention. In that respect, a sovereign state's exclusive control over its territory is well established in international law, securing its right to grant or deny asylum to foreign persons coming to its territory. ${ }^{284}$

\footnotetext{
282 5"UNHCR
http://www.al- Country Operation Profile: Lebanon." UNHCR, (2013), : monitor.com/pulse/ar/contents/articles/originals/2013/06/iraq-kurdistan-syrian-refugees-aid.html\# ${ }^{283}$ Sanyal, Romola. "A no-camp policy: Interrogating informal settlements in Lebanon." Geoforum 84 (2017): 117-125.

${ }^{284}$ Roman, Boed. "The State Of The Right Of Asylum In International Law." Duke J. Comp. \& Int'l L. 5 (1994): 1.
} 
Conventionally, universal obligations on states ensure that no asylum seeker loses their basic rights and benefits when fleeing persecution. However, no sovereign state, including Lebanon, seems to have a legally binding obligation to accept asylum seekers. It is rather non-binding humanitarian concerns that encourage sovereign states to host those in need of asylum. As a customary practice, issues relating to the concept of non-refoulement, such as residency permits and the right to work, are under the host state's discretion. Consequently, the reality of domestic exclusionary practices could be warranted for any masculine justifiable security basis by state authorities. Additionally, Lebanon's unimpressive human rights track-record on issues of prolonged detentions, arbitrary arrests, and forced deportations, fostered a favorable environment for political manipulation and legitimization of its exclusionary power practices. ${ }^{285}$ Accordingly, many loopholes and realpolitik encouraged overwhelmed Lebanon to securitize its borders, denying incoming refugees entry, threatening them with penalization and repatriation.

Still, once asylum seekers are inside Lebanese territory, Lebanon has a duty to treat those foreigners humanely without repatriating them to states in which they would face persecution. We find in the Constitution's Preamble that "Lebanon is a founding and active member of the United Nations Organization, committed to its Charter and the Universal Declaration of Human Rights," thus warranting

\footnotetext{
285 "Pushed To The Edge: Syrian Refugees Face Increased Restrictions In Lebanon." Amnesty International' (June 2015):

https://www.amnesty.org/en/documents/mde24/1785/2015/en/
} 
individual freedom of opinion, equality, right to access work, and own property. ${ }^{286}$ Lebanon's Constitution takes pride in the Lebanese forefather of the Declaration of Human Right, Charles Malek, stating that it embodies all human rights' principles without exception in any sector and scope. Lebanon is, additionally, a signatory of numerous human rights treaties and conventions that contain provisions relating to refugees' protection, including: “The International Covenant on Civil and Political Rights (ICCPR) (1966), the International Covenant on Economic, Social, and Cultural Rights (ICESCR) (1966), and the 1965 International Convention on the Elimination of All Forms of Racial Discrimination (ICERD)." ${ }^{290}$ Accordingly, nondiscrimination of refugees, access to education, work, and housing, are enshrined in most of the above treaties, which Lebanon already endorses. In this respect, Lebanon seems to be fully engaged in the social construct of collective sovereign states' efforts towards human rights, ratifying norms of previously agreed covenants that are deemed universally essential for human security, especially for prohibiting refoulement. 290 Consequently, the internationally guaranteed human rights — what became known as human security: "freedom from want" and "freedom from fear" that ranged from personal to socioeconomic and political security — ensured that Lebanon, as a sovereign state, secures a minimum

\footnotetext{
286 Maja Janmyr. "No Country Of Asylum: Legitimizing Lebanon's Rejection Of The 1951 Refugee Convention," International Journal of Refugee Law 29, no. 3 (2017): 438-465.
} 
of individual autonomy and preserves the right of foreign individuals residing within the country to be protected when fleeing their home state. ${ }^{287}$

In addition, once Lebanon as a host state accepts foreign citizen, it is theoretically required to provide that individual the basic rights that any other foreigner who is legally residing within the country is given legal rights and duties, including freedom of thought, of movement, and freedom from any degrading treatment towards a person's liberty. ${ }^{288}$ However, according to the expert interviewee from the Lebanese Ministry of Social Affairs,

"The only legal mandate you have is towards the Lebanese citizens. In relation to Syrian refugees you have some type of Sharia courts even in some informal settlements and informal groupings of Syrian refugees where they are also treating these cases: cases of divorce, cases of death; the issue of people of Syrians who are dying and getting buried in Lebanon, also this is another problem so also we have Dar Al-Fatwa because $90 \%$ of the Syrian refugee there are Sunnis and Dar AlFatwa is managing the religious aspect of the presence of them through the Cheikh." 289

This statement exemplifies how, in practice, Lebanon's intricate translation processes its commitment to the global discourse of human rights, in effect denies

\footnotetext{
${ }^{287}$ Gregor, Noll. "Securitizing Sovereignty? States, Refugees, And The Regionalization Of International Law," Refugees and Forced Displacement (2003): 277-305. 
de facto Syrian refugees from legally accessing adequate government assistance and protection. ${ }^{290}$ The official's misguided statement about Lebanon's mandate is legally wrong. It dodges Lebanon's international responsibility to provide refugees their basic right to security, liberty, and freedom of movement, by relinquishing the Lebanese government's duty towards non-citizens to unaccountable self-interested third parties with sectarian ambitions. In that respect, the issues and occurrences that Lebanon perceives as a security threat are subjective, a process of its social construction, dating back to historical events and the social makeup of the country. As discussed in the previous section, Lebanon suffers from a chronically unstable political system that it is gendered and path dependent. Founded on sensitive political, religious, and sectarian balances, Lebanon bases the Lebanese citizenship on one's communal identity, tribal loyalty as opposed to equality and individual rights. $^{291}$

Each refugee group is perceived differently according to the many criteria that enter the equation, including but not limited to their race, their social status, but mainly their religious affiliation. The discriminatory Lebanese nationality law and penal code reinforce the numerous personal status laws that engender longstanding sectarian patriarchal social norms. Lebanese authorities often promote this judicial pluralism as essential to protecting the sectarian diversity within the

\footnotetext{
${ }^{290}$ Maja Janmyr, "Precarity In Exile: The Legal Status Of Syrian Refugees In Lebanon," Refugee Survey Quarterly 35, no. 4 (2016): 58-78.

${ }^{291}$ Maja Janmyr, "Precarity In Exile: The Legal Status Of Syrian Refugees In Lebanon," Refugee Survey Quarterly 35, no.4 (2016): 58-78.
} 
confessional country. In practice, the multiplicity of laws deterred Lebanese citizens from intermingling across religious groups for fear of losing their religious identity or further complicating key aspects of their lives, such as marriage, divorce, and child custody.

The sectarian sensitivities present within the country created a space for refugee groups belonging to privileged sects to gain better treatment than others. For example, through history, Christian Armenian refugees in Lebanon fully integrated without having to assimilate. Other than Armenia, Lebanon is the only country that guarantees its Armenian community both parliamentary and ministerial representation. ${ }^{292}$ Armenians enjoy anomalous communal autonomy, preserving their identity, administering their private schools that are taught in Armenian, and regulating their personal status through their own religious courts. ${ }^{293}$ Christian Palestinians enjoy similar rights whereby Lebanese citizenship was given to most of them. ${ }^{294}$ However, when it came to the resettlement of Sunni Muslim Palestinian refugees, it was, and still is, a controversial issue. In fact, the perceived impact their settlement would have had on the sectarian balance of the country created a feeling of insecurity, even within the government, which resulted in barring Palestinian refugees from employment in the public sector, limiting them

\footnotetext{
${ }^{292}$ Scott Abramson, "Lebanese Armenians: A Distinctive Community In he Armenian Diaspora and in Lebanese Society," The Levantine Review 2, no. 2 (2013): 188-216.

293 Ibid.

${ }^{294}$ Simon Haddad. “The origins Of Popular Opposition To Palestinian Resettlement In Lebanon," International Migration Review, Vol 38, No.2, (2004), 484.
} 
from permits to work in the private sphere, or even buying properties. The Lebanese government, dominated then by Maronite Christians, justified its discriminatory laws and practices that would hegemonize the entire Palestinian refugee population as instigators of war, objectifying the Palestinian refugees' presence as a security threat of overcrowded, volatile,

ungoverned spaces. ${ }^{295}$ Meanwhile, Christian micro-communities enjoyed prosperity, political representation, and communal autonomy, while the Sunni Palestinians have languished as an underclass, abandoned to political and sectarian marginalization. ${ }^{296}$

\subsection{The Palestinian Refugee Case}

When it first started, the Palestinian refugee presence in Lebanon provoked deep communal, political, and ideological divisions. ${ }^{297}$ Still, official Lebanese statements have always rejected the permanent settlement, commonly known as 'tawteen,' of the Palestinians in Lebanon. ${ }^{298}$ The inherent fears related to refugees and their permanent residence in Lebanon, by both officials and citizens, was legally manifested in Lebanon's refusal to join the 1951 Refugee Convention.

\footnotetext{
${ }^{295}$ Bruce Riedel and Bilal Y. Saab, "Lessons For Lebanon From Nahr El-Bared.” Op-Ed, Brookings, (October 4, 2007).

${ }^{296}$ Farid El Khazen, "Permanent Settlement Of Palestinians In Lebanon: A Recipe For Conflict," Journal of Refugee Studies 10, no. 3 (1997): 275-293.

${ }^{297}$ Farid El Khazen, "Permanent Settlement Of Palestinians In Lebanon: A Recipe For Conflict," Journal of Refugee Studies 10, no. 3 (1997): 275-293.

298 Marta Agosti, "The Nationality Law In Light Of The Refugee Crisis In Lebanon: Old Battles, New Consequences," Contemporary Levant 1, no. 2 (2016): 148-151.
} 
Lebanon's attempt to shield itself from the prospects of permanently settling Palestinian refugees in Lebanon further justified these measures as a supportive move to the forcibly displaced Palestinians' "Right of Return."299 This advocacy was complemented with the denial of legal integration and assimilation of most Palestinians, not including Christian ones, within the Lebanese fabric. Even when the Civil War ended, all local factions supported the amended Lebanese Constitution of 21

September 1990 that introduced a new provision in the Preamble, Section I; "There shall be no segregation of the people on the basis of any type of belonging, and no fragmentation, partition, or settlement of non-Lebanese in Lebanon," ${ }^{300}$

Even though the above provision established a rule of no segregation, its vagueness still left room for interpretation, making sure that the only people not to be segregated were Lebanese, while clearly stating that non-Lebanese, such as the Palestinians residing within the country cannot settle within the country.

On another note, Lebanese mistrust of Palestinians residing within their country transcends sectarian fears. In 1969, the Lebanese skirmishes with the Palestinian Liberation Organization-(PLO) operating within the country ended with the Cairo agreement between Yasser Arafat heading the PLO, and General

${ }^{299}$ Ibid.

${ }^{300}$ Salah Dabbagh, George Deeb, Farid El-Khazen, and Maroun Kisirwani, “The Lebanese Constitution.” Arab Law Quarterly 12, no. 2 (1997): 224-261. 
Emile Bustani, the Lebanese military commander. ${ }^{301}$ In effect, this agreement legitimized the PLO's presence in Lebanon having the legal right to fight Israel from Lebanon. ${ }^{302}$ The primary objective behind Lebanon's endorsement was to sideline itself from the Arab-Israeli conflict, while still advocating for the Palestinian cause. However, this led to a failed attempt to establish a system of cooperation between both parties and could not prevent the PLO's threat to Lebanon's sovereignty. ${ }^{303}$ This agreement counterintuitively granted militant Palestinians the right to use the refugee camps on its territory as military bases, establishing autonomous regulatory institutions for Palestinians living inside formally acknowledged refugee camps. ${ }^{304}$ Consequently, this agreement created space for Palestinian institutions to develop in Lebanon, the outcome of which was called "a state within the state." The PLO's heavy presence in major strategic areas within Lebanon aggravated existing sectarian tensions between Lebanese factions. ${ }^{305}$ Historical accounts demonstrated the aggression and the taking up of arms by Palestinian refugees, targeting Lebanese nationals and political parties. ${ }^{306}$

\footnotetext{
301 “Did The PLO Die In Lebanon?" Al Jazeera, July 28, 2009. https://www.aljazeera.com/programmes/ plohistoryofrevolution/2009/07/200972855032594820.html

302 Franklin Lamb. "Will Hezbollah Support Right To Work For Palestinian Refugees?" The Palestine Chronicle. Beirut. May 10, (2010). http://www.palestinechronicle.com/will-hezbollah-support-right-to-workfor-palestinianrefugees/

303 Ibid.

${ }^{304}$ Sari Hanafi and Taylor Long. "Governance, governmentalities, and the state of exception in the Palestinian refugee camps of Lebanon." Journal of Refugee Studies 23, no. 2 (2010): 134-159.

305 Ibid.

306 Sarah Kenyon Lischer, Dangerous Sanctuaries: Refugee Camps, Civil War, and the Dilemmas of Humanitarian Aid. Ithaca, NY: Cornell University Press, (2015), 26.
} 
Taking over west Beirut, the PLO took part in the Lebanese Civil War, where "thousands of Palestinians became both victims and victimizers." ${ }^{307}$ As a result, till this day, Lebanon characterizes refugees, such as the Palestinians, as "ticking time bombs," and, ever since, Lebanese security and intelligence forces consistently targeted Palestinian refugee formal settlements within the country. ${ }^{308}$

\subsection{Memorandum of Understanding Between Lebanon and the UNHCR}

Advancing to September 2003, Lebanon signed a Memorandum of Understanding (MoU) with the UNHCR, defining each party's role concerning incoming refugees. Accordingly, the UNHCR's primary responsibility in Lebanon was to support Lebanon in registering incoming applicants, issuing them temporary residency permits, providing protection and assistance, until the UNHCR finds a durable solution for de facto refugees. ${ }^{309}$ Initially, Lebanon had maintained a gentleman's agreement with the UNHCR, relying on its operations within the Lebanese territory to adjudicate asylum applications, deciding who is eligible for protection, assistance as de facto refugees. ${ }^{310}$ The UNHCR strengthened its position within the

\footnotetext{
${ }^{307}$ Sari Hanafi and Taylor Long. "Governance, governmentalities, and the state of exception in the Palestinian refugee camps of Lebanon." Journal of Refugee Studies 23, no. 2 (2010): 134-159.

308 Ibid.

${ }^{309}$ UNHCR, “Country Operations Plan,” 2004, http://www.unhcr.org/3fd9c6a14.pdf.

310 Maja Janmyr, "UNHCR And The Syrian Refugee Response: Negotiating Status And Registration In Lebanon." The International Journal of Human Rights. 22:3, (2018): 393-419,
} 
country by taking over the responsibility of being the primary provider to Syrians refugees from the host state. ${ }^{311}$

On the one hand, this lenient approach provided space for a significant increase in refugees from different nationalities to enter and settle in Lebanon, triggering a series of local and international security concerns. On the other hand, The MoU contained some gendering structural measures that would shortly bring about its demise. The MoU clearly states that Lebanon is "no country of Asylum", rather a "transit country," due to its sociopolitical considerations and concerns. It goes as far as defining the term "asylum seeker" as a "person seeking asylum in a country other than Lebanon," making Lebanon a

transitionary state and not a permanent one. ${ }^{312}$ After all, the MoU was only utilized to shift refugee management responsibilities from the state, which is a primary duty bearer to the UN agency. ${ }^{313}$

The MoU stipulated that, as part of its responsibilities, the UNHCR is tasked with processing asylum applications for asylum seekers, granting refugee certificates valid for two years (eligible for renewal). Meanwhile, the Lebanese government was tasked with only tolerating de facto refugee presence temporarily

\footnotetext{
311 Ghida Frangieh. "Relations Between UNHCR And Arab Governments: Memoranda Of Understanding In Lebanon And Jordan." Middle East Centre Blog (2016).

312 Ghida Frangieh. "Relations Between UNHCR And Arab Governments: Memoranda Of Understanding In Lebanon And Jordan." Middle East Centre Blog (2016).

313 Ibid.
} 
while making sure that Lebanese citizens' rights are being protected. ${ }^{314}$ Simultaneously, the agreement allowed the UNHCR to secure short-term solutions by providing the registered de facto refugees basic assistance and protection while expecting that the UNHCR would resettle those registered to third countries within that period. ${ }^{315}$ Accordingly, the UN agency was compelled to formalize this compromised arrangement with the Lebanese government, struggling when attempting to regulate the main aspects of what is an obvious case of refugee protection with the lack of any encouraging national refugee law. ${ }^{316}$ In the case of permit expiration, Lebanese authorities had the legal right to take necessary action against any illegal resident, defeating, in the first place, the purpose of temporarilly hosting those fleeing their home country to seek protection. ${ }^{317}$ Although the international community criticized these shortcomings, the MoU between Lebanon and UNHCR was at first considered a positive preliminary step for protecting registered de facto refugees with the UNHCR. For the first time, the Lebanese government recognized those de facto refugees' semi-legal presence in

\footnotetext{
${ }^{314}$ Maja Janmyr, “No Country Of Asylum: Legitimizing Lebanon's Rejection Of The 1951 Refugee Convention," International Journal of Refugee Law 29, no. 3 (2017): 438-465.

315 UNHCR Regional Office In Lebanon, Country Operations Plan 1 (2004), http://www.unhcr.org/3fd9c6a14.pd

${ }^{316}$ Ghida Frangieh. "Relations Between UNHCR And Arab Governments: Memoranda Of Understanding In Lebanon And Jordan." Middle East Centre Blog (2016).

317 Maja Janmyr, "UNHCR And The Syrian Refugee Response: Negotiating Status And Registration In Lebanon," The International Journal of Human Rights 22, no. 3 (2018): 393-419.
} 
Lebanon by offering them temporary residency permits. ${ }^{318}$ Still, the MoU clearly stated that Lebanon was a 'transit country', mainly due to its socio-political considerations and concerns. Accordingly, the temporary legal residency permits introduced by the Lebanese government only curtailed UNHCR's capacity to continuously ensure that residing Syrians would register their detailed information, hence, preventing undocumented threats to public safety.

It is important to note that there were a few thousand asylum seekers in Lebanon when it passed its responsibility for managing refugees' registration, healthcare, education, and livelihood assistance to the UNHCR. The MoU was only considered as a first step, a basis in defining Lebanon's limited obligations concerning asylum seekers, with no solid national response strategy that could manage a large influx of refugees. The MoU's failure worsened the UNHCR's position where, as of 2014, the heavy Syrian presence in Lebanon forced the Lebanese government to shift its policy practices to reduce the number of Syrians within its territory. This move profoundly affected UNHCR's ability to implement its already compromised international protection mandate and placed its jurisdiction under the direct supervision of the Ministry of Social Affairs-(MoSA) whose justification was;

"What has been missing before is the absence of the state and the absence of true leadership from the part of the government as well from the lead ministry which is the ministry of social affairs. Now we have a totally different approach;

\footnotetext{
318 "Country Operations Plan." UNHCR Regional Office In Lebanon, (2004), :
http://www.unhcr.org/3fd9c6a14.pd
} 
the government has a unified approach toward the Syrian refugee crisis. The ministry of social affairs is the lead within the LCRP, and we are assuming our role and duties; All NGOs, all organizations, whether international regional or local partners, have to communicate with the Ministry of Social Affairs and get its approval before proceeding [with any action on Lebanese ground]."319

\subsection{The Syrian Refugee Case}

In 2014, with the Syrian crisis underway, the connotations of the word refugee worsened even more. When almost 30\% of Lebanon's population is made up of Syrian refugees, it is only normal that Lebanese constituents get concerned that the large Syrian presence within the country threatens its security and stability. This sudden overpopulation severely strained the country's stability, affecting nearly all Lebanese sectors: the security, infrastructure, economy, health, education, labor, and environment, ultimately endangering the already delicate Lebanese social fabric. ${ }^{320}$ Accordingly, refugee movements to Lebanon have been referred to by the Lebanese government as crises of displacement not to be governed by law, but by ad hoc security practices. ${ }^{321}$ These decisions were attempts to emphasize the fact that Syrian refugees are not recognized as such but rather as "temporary displaced persons" (a legally loaded term that is vaguely defined) who are expected either to resettle in third countries or return to their homeland as soon as the security and

\footnotetext{
${ }^{319}$ MoSa Expert Interview with author, (June 12, 2017).

${ }^{320}$ The UNHCR notes that although numbers of people from Syria applying for asylum in European countries is rising, that figure accounts for only $10 \%$ of all refugees from Syria. : http://data.unhcr.org/syrianrefugees/regional.php.

${ }^{321}$ Maja Janmyr, Precarity in Exile: The Legal Status Of Syrian Refugees In Lebanon, 35 Refugee Survey Quarterly. (2016): 58-59.
} 
political conditions there settle down. ${ }^{322}$ Even though the UNHCR experts were optimistic stating that:

“It is just semantics at this point. The applications' piece of paper and registration paper are the same, $[\ldots]$ There is a new minister created for displacement affairs. Well you know those are positive signs to see the language in general shifting to statements such as; before we could hear perhaps refugees were considered a burden, now we hear more they are an economic opportunity. So you know those are positive signs." ${ }^{323}$

Still, in practice, nothing tangible changed; Lebanese domestic attitudes and laws do not help displaced Syrians, let alone undocumented illegal residents, who are left with few legal recourses. ${ }^{324}$ The Lebanese public feared the creation of another space for Syrians that would engender a state within the state. ${ }^{325}$ Shared concerns of Syrian refugees exacerbating the deteriorating Lebanese economic, security, infrastructural, and social structures brought public outcry over residing Syrians being directly implicated in security threats in Lebanon. For example, numerous attacks against the Lebanese army and the bombings of several Lebanese

${ }^{322}$ Ibid.

${ }^{323}$ UNHCR Expert interview with author, (May 18, 2017).

${ }^{324}$ Benedetta Berti, "The Syrian Refugee Crisis: Regional And Human Security Implications," Strategic Assessment 17, no. 4 (2015): 41-53.

${ }^{325}$ Richard Hall, "Lebanon Doesn't Want Syrian Refugees Getting Too Comfortable, Even in Winter," Agence FrancePresse, (February 15, 2016), https://www.pri.org/stories/2016-02-15/lebanon-doesnt-want-syrianrefugees-getting-toocomfortable-even-winter. 
regions were planned and executed by radical Syrians posing as refugees. ${ }^{326}$ Accordingly, the attention and care the international organizations, especially the UNHCR, provided to Syrians generated local resentment towards perceived Syrian opportunists who are "living in better conditions than we do." 327 The feeling of anti-Syrian resentment was reinforced by earlier perceptions of who the incoming Syrians previously represented (the Assad regime). As former members of the Syrian regime, incoming Syrians could not escape the Lebanese collective bitterness towards them, dating back to the Syrian occupation with boots on the ground, came to life. ${ }^{328}$ Therefore, more problems, uncertainties, and dangers became correlated with the term "refugee," silencing most Syrians who have lost homes, jobs, and personal assets.

Moreover, different political actors in Lebanon have also focused on demonizing the Syrian refugee population, marginalizing them further in the pretext that these "Sunni" refugee masses pose a threat to Lebanese sectarian (im)balance. ${ }^{329}$ Therefore, hostile sentiments and aggressive attitudes towards the now unwanted displaced Syrians is no more than a symptom of the much deeper

\footnotetext{
${ }^{326}$ Ibid.

${ }^{327}$ Daniel Meier, "La Strategie Du Regime Assad Au Liban Entre 1970 Et2013. Du Pouvoir Symbolique A La Coercion." Revue EurOrient, n 41, (2013): 171-188. ebanon: The Refugee Issue and the Threat of a Sectarian Confrontation

${ }^{328}$ Ibid.

${ }^{329}$ Ellen Francis. "Hostility Grows Towards Syrian Refugees In Lebanon.” Reuters. (August 28, 2017): https://www.reuters.com/article/us-lebanon-refugees-tension-idUSKCN1B8128
} 
geopolitical sectarian relationship between the two countries. ${ }^{330}$ Moreover, with the appointment of President Michel Aoun in 2016, his tenure began by promising that "displaced Syrians would quickly return to their homeland and abstain from turning refugee camps into security hubs." ${ }^{331332}$ A recent statement made by Lebanon's Prime Minister Mr. Saad Hariri further exemplifies this argument. He stated: "Today if you go around most of the host communities, there is a huge tension between the Lebanese and the Syrians...I fear civil unrest." ${ }^{\text {333 }}$ In effect, a study shows that a $60 \%$ increase in crime in Beirut is directly related to the refugee population whereas, while as of $2016,26 \%$ of the prison population is of Syrian nationality. ${ }^{334}$ These growing negative perceptions of Syrian refugees in Lebanon facilitated Lebanon's General Security Officers' (GSO)—with questionable capacities and training in knowing how and when to identify justifiable humanitarian cases-abuse of power in vilifying Syrian refugees. Their mandate tends to focus on combating crimes and potential cases of terrorism, giving them

\footnotetext{
${ }^{330}$ Hassan Krayem, "The Lebanese Civil War And The Taif Agreement," Conflict Resolution in the Arab World: Selected Essays, ed. Paul Salem, Beirut, Lebanon: American University of Beirut, (1997), 411-436.

331 "Lebanon's President Aoun Calls For National Unity, Liberating Palestinian Territories," Albawaba, (November 1,

332 ), http://www. albawaba.com/news/lebanon's-president-aoun-calls-national-unity-liberating-palestinianterritories 899220 .

333 Tom Perry, “Lebanon Near 'Breaking Point' Over Syrian Refugee Crisis: PM Hariri,” Reuters, (March 31, 2017): http://www.reuters.com/article/us-mideast-crisis-syria-lebanon-idUSKBN1722JM.

334 "Syria's Good Neighbors: How Jordan And Lebanon Sheltered Millions Of Refugees," Washington Institute, (September 2015), http://www.washingtoninstitute.org/policy-analysis/view/syrias-good-neighborshow-jordan-andlebanon-sheltered-millions-of-refugees.
} 
room to verbally abuse potential refugee victims while interrogating, discriminating, and putting them in harm's way. ${ }^{335}$

\section{Sovereignty Through Exclusion}

Lebanon initially welcomed Syrian refugees without regulating their entry into the country, especially women and children. However, the increase in the number of refugees, and the subsequent challenges that arose led to a "re-ordering of national politics and relations visà-vis Syrians." ${ }^{336}$ As a result, the country securitized the influx of Syrians coming into Lebanon through the porous borders. ${ }^{337}$ The 'thin' boundaries that once separated these two neighboring countries eventually thickened by a series of border restrictions. These measures marked, for the first time in Lebanon's history, an extensive filtering system for Syrians entering Lebanese territories. With the Syrian regime busy fighting internal resistance, its influence on Lebanese policies diminished rapidly.

This situation led the Lebanese government to shift from a policy of "No Policy" to one of total control. ${ }^{338}$ Accordingly, Lebanese authorities and security agencies would ad hoc-ly legitimize their securitized practices under the guise of

\footnotetext{
${ }^{335}$ Ghida Frangieh, "Lebanon Places Discriminatory Entry Restrictions On Syrians," Legal Agenda 22, (2015), http://legal-agenda.com/en/article.php?id=679\&folder=articles\&lang=en.

${ }^{336}$ Are John Knudsen. "Syria's refugees in Lebanon: brothers, burden, and bone of contention." In Lebanon facing the Arab uprisings, pp. 135-154. Palgrave Pivot, London, 2017.

${ }^{337}$ Farid El Khazen, "Permanent Settlement Of Palestinians In Lebanon: A Recipe For Conflict," Journal of Refugee Studies 10, no. 3 (1997): 275-293.

${ }^{338}$ Daniel, Meier. "Lebanon: The Refugee Issue And The Threat Of A Sectarian Confrontation." Oriente moderno 94, no. 2 (2014): 382-401.
} 
fighting terrorism and preserving the Lebanese sectarian identity balance. They would use what would be seen as standard bureaucratic practices of approving which Syrian asylum requests are complete and feminized enough to be accepted and which requests are to be rejected under the pretext of them being insufficient and potentially violent, opportunists, aggressive threats. The previously commended lenient Lebanese open-door-policy approach was completely reversed, negatively affecting the functioning of the UNHCR to register future Syrian refugees in Lebanon and channel appropriate aid across the country. ${ }^{339,} 340$

In fact, Lebanon's strong reservations about acceding to the 1951 Refugee Convention already challenged the UNHCR's ability to execute its mandate. ${ }^{341}$ The UNHCR had to constantly adjust its international protection mandate to new forms of cooperation mechanisms that were difficult to maintain due to fluctuating complications unfavorable for refugee protection in the country. ${ }^{342}$ Since Lebanon does not extend automatic asylum to de facto Syrian refugees, many Syrian children and their families become objects of discriminatory domestic laws and (in)security practices for illegal entry and stay. Accordingly, international organizations, the

\footnotetext{
339 Yazan Al-Saadi. "The Diversion Strategy: Lebanese Racism, Classism, And The Refugees.” Al-Akhbar (June 10, 2014). Al-Akhbar. : https://english.al-akhbar.com/node/20121

340 “Amnesty International Regrets Lebanon's Decision To Overturn Its Open Border Policy Towards Refugees And

Refusal To Address Discrimination Against Women And Migrants," Amnesty International, (March 16, 2016), http://reliefweb.int/report/lebanon/amnesty-international-regrets-lebanon-s-decision-overturn-its-openborder-policy.

${ }^{341}$ Maja, Janmyr. "UNHCR And The Syrian Refugee Response: Negotiating Status And Registration In Lebanon.” The International Journal of Human Rights. 22:3 (2018): 393-419

342 Ibid.
} 
UNHCR particularly, are not capable of thereby easing their risk of harassment, xenophobic violence, detention, and forced deportation. These reactionary approaches, complemented by the UNHCR's limited role in crisis management of the Syrian refugee case, only worsened the already tragic situation of International aid, assistance, and refugee protection programs, aimed at alleviating refugees' insecurities in general, Syrians' in Lebanon specifically.

Despite the massive presence of foreigners within the country, Lebanese integration rhetoric religiously nationalized citizenship by privileging those who are perceived to belong to specific sects (such as Christians) for not threatening the overall sectarian balance that keeps Lebanon (dis)functional. ${ }^{343}$ The unparalleled refugee burden faced by hosting Lebanese communities rendered it impossible for the Lebanese government agencies to provide necessary services and aid assistance, which are subject to sectarian intra-Lebanese calculations and corruption, thus serving personal and partisan agendas. ${ }^{344}$ Accordingly, bargaining for aiding the vulnerable Lebanese communities and reforming Lebanon's infrastructure became paramount for Lebanon's outcries for the global community's participation in refugee burden-sharing efforts.

Consequently, ad hoc Lebanese securitized policies left the majority of Syrian refugees subject to discrimination and exploitation, while, at the same time

\footnotetext{
${ }^{343}$ Daniel, Meier. "Lebanon: The Refugee Issue And The Threat Of A Sectarian Confrontation." Oriente Moderno 94, no. 2 (2014): 382-401.

${ }^{344}$ Monika Borgmann and Lokman Slim, “Lebanon 2017/2018: Fewer Refugees More Refugeeism.” UMAM $D \& R$ Documentation and Research, (2018), https://umam-dr.org/en/home/projects/14/advancecontents/188/fewer-refugeesmore-refugeeism.
} 
pressuring the international community to take on the protection responsibilities in expanding aid assistance and community services across the country. ${ }^{345}$ As a matter of fact, UNHCR's Lebanon budget decupled between the beginning of the crisis and 2015, seeing an unprecedented increase, in which the agency found itself supporting public institutions and stuck negotiating the assistance terms with semifunctional government agencies and competing interests. In other words, international aid was no longer limited to UNHCR nor its operation to assist and protect Syrian de facto refugees. Instead, most of the international support went to finance Lebanese government spending — "budget support"-and a plethora of competing for issue-oriented non-governmental organizations whose missions came with the risk of corruption and fraud. ${ }^{346}$ This expansion led to a change in the refugee protection approach. Incremental protection tasks and social services were subcontracted to NGOs, competing with the UNHCR almost entirely for, voluntary contributions from member states, and international and regional organizations, as well as pooled funding mechanisms that include the self-interested private sector.

The main characteristics of the LCRP's budget support's section as a financing modality are threefold, focusing on the assigned country's development and poverty reduction, while, also working with the Lebanese government to tackle

\footnotetext{
${ }^{345}$ Richard Hall, “Lebanon Doesn't Want Syrian Refugees Getting Too Comfortable, Even in Winter," Agence FrancePresse, (February 15, 2016), https://www.pri.org/stories/2016-02-15/lebanon-doesnt-want-syrianrefugees-getting-toocomfortable-even-winter.

${ }^{346}$ Morgan Meaker. "When Aid Funds A Country — Not Its Refugees.” Devex News. (March 10, 2017):

https://www.devex.com/news/when-aid-funds-a-country-not-its-refugees-89744
} 
security and counter-terrorism inside the country, shoring up millions of dollars for border management. First, the majority of funds approved would be channeled directly to the Lebanese government. Second, those funds are to finance the government budget, not necessarily linked to specific refugee project activities. Finally, most funds donated need to be approved by the semi-functioning Lebanese authorities to make sure that the disbursement and procurement of funds do not jeopardize the country's security and interests. On the one hand, Lebanese public institutions were unwilling and not sufficiently trained to sensitively target the diverse groups that make up the Syrian refugee population. On the other hand, these male-controlled institutions would prioritize gender-blind projects deemed vital for their securitized interests of controlling Syrian presence within their communities over vital gender-related political or socio-economic projects. Accordingly, research shows that the Transparency International's 2016 Corruption Perceptions Index scored Lebanon with 28 over 100, labeling it as "plagued, untrustworthy and badly functioning." 347

Not having a clear, systematic channel of operation with lack of oversight over different non-governmental organizations' operations and institutional responsibilities, led to deepening the harmful aggressive behavior towards Syrian refugees, further engendering tensions between all members of society. As a sovereign state, a state has the legal right to secure its borders and control its territory. Thus, ad-hoc policies popped out across the country, tightening its border

${ }^{347}$ Ibid. 
policies towards Syrians, rejecting formal refugee settlements for Syrians, and limiting their mobility within the country - three sectors that will be developed in the following subsections. ${ }^{348}$

\subsection{Visa Restrictions and Border Control}

Lebanon's focus on reinforcing territorial boundaries, to uphold the fragile domestic status quo, shifted its border procedures with Syria. ${ }^{349}$ The Lebanese government started implementing a series of restrictions on Syrian entrance and residency in the country, making the acquisition of a visa increasingly challenging to obtain, and the time frame even shorter-ranging from one day to a year at most. ${ }^{350}$ Also, Lebanon's visa entry requirements and practices filtered the relatively financially privileged 'displaced' Syrians into Lebanon over the repudiated disadvantaged ones, depicting them as depoliticized, immobile, and passive.

The situation continued to deteriorate until 2015 when the Lebanese government took extreme measures when it comes to applying for or renewing residency permits. As such, on May 6, 2015, the male-dominated Lebanese government issued a ministerial policy paper demanding the suspension of official

\footnotetext{
348 Are John Knudsen. "Syria's refugees in Lebanon: brothers, burden, and bone of contention." In Lebanon facing the Arab uprisings, pp. 135-154. Palgrave Pivot, London, 2017.

${ }^{349}$ Sami Atallah and Dima Mahdi, "Law And Politics Of 'Safe Zones' And Forced Returns To Syria: Refugee Politics In Lebanon,” The Lebanese Center for Policy Studies 39 (2017): 36.

${ }^{350}$ Maja Janmyr, Precarity in Exile: The Legal Status Of Syrian Refugees In Lebanon, 35 Refugee Survey Quarterly. (2016): 58-59.
} 
registration of Syrian refugees. ${ }^{351}$ This decree hindered the majority of Syrian nationals, women, and children, from successfully applying for or renewing their residency permits, thus limiting their access to legal status, housing, employment, and protection. As stated by the MoSA, the policy established three primary objectives for managing the Syrian displacement into Lebanon, dictated by security concerns: ${ }^{352}$

1) Reduce the number of Syrians registered with the UNHCR as de facto refugees through border control.

2) Bolster security in the country to keep the displaced population under control.

3) Reinforce local stability by prioritizing Lebanese industries, vulnerable communities, and infrastructure.

According to the expert interviewee of MoSA this was an erroneous governmental approach;

"In January 2015 the [Lebanese government's] decision was made to stop the registration of Syrian refugees and close the [Lebanese-Syrian] borders except for humanitarian cases $[\ldots]$ This was the worst decision ever made; it was only about stopping the numbers at a certain exact number." 353

Surprisingly, the expert interviewee's opinion, highlighted above, echoed the humanitarian criticism towards the malfunctioning of the new refugee policies

\footnotetext{
${ }^{351}$ Filippo Dionigi, “The Syrian Refugee Crisis In Lebanon: State Fragility And Social Resilience." LSE Middle East Centre paper series, 15. London, UK. (2016).

352 "Trapped In Lebanon: The Alarming Human Rights And Human Security Situation Of Syrian Refugees In Lebanon.” ALEF, (May, 2016),18: https://alefliban.org/wp-content/uploads/2016/11/Trapped-In-Lebanon ALEF_PA X_May2016.pdf.

${ }^{353}$ MoSa Expert Interview with author, (June 12, 2017).
} 
introduced by the Lebanese government, imposing significant restrictions on the UNHCR's ability to properly manage Syrian refugees in Lebanon let alone successful integration. In fact, according to new rules, all Syrians registered with UNHCR have to sign a pledge that revokes their right to work in the country. ${ }^{354}$ Some refugees have even declared that they were asked to sign other legal documents stating that they are obliged to return to Syria as soon as their residency papers expire. ${ }^{355}$

Enshrined in Article 33 of the 1951 Convention, the principle of nonrefoulement is binding on state parties, constituting the cornerstone of international refugee protection;

"No Contracting State shall expel or return ("refouler") a refugee in any manner whatsoever to the frontiers of territories where his [or her] life or freedom would be threatened on account of his [or her] race, religion, nationality, membership of a particular social group or political opinion." 356

What should ostensibly be geared towards refugee protection measures—such as nonrefoulment - turned Lebanon, a nonsignatory state hosting large numbers of refugees, to gendered (re)production of refugee (in)securities through arbitrary arrests, torture, mass eviction, and de facto refoulment of perceived Syrian refugee

\footnotetext{
${ }^{354}$ Martin Armstrong, "Lebanon Resists Granting Work Permits To Syrian Refugees," Middle East Eye, (February 4, 2016), http://www.middleeasteye.net/news/lebanon-syria-refugees-jobs-554259285.

355 Ibid.

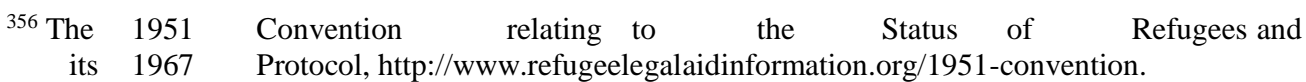


threats. ${ }^{357}$ We find that in a patriarchal system that perpetuates a male-dominated, clan-based political order, the majority of the Syrian permits and the right to work permits granted by the Lebanese government excluded Syrian refugees from any genuine participation.

A good illustration of aggressive governmental rhetoric justifying the exploitation of the Syrian refugee 'burden' came with the announcement of the Lebanese Minister of Social Affairs, Rashid Derbas, who stated that "the cessation of asylum is final because Lebanon can no longer bear anymore. [...] Lebanon does not deserve more burdens, and there are countries closer to them [Syrian refugees] to which they can resort to." 358 In that respect, the Lebanese government assured that the existing million or so displaced Syrians would regularly be examined by the concerned agencies to verify that their de facto refugee status criteria with the UNHCR are continuously met. If not, Syrian nationals would thus be subject to removal from the UNHCR's list and, consequently be liable to deportation. These bureaucratic procedures introduced were so "onerous and expensive that it became challenging for people to meet the requirements." ${ }^{359}$ For the first time in LebaneseSyrian relations, different entities dealing with refugees, whether the central state or local authorities, would be charged to take appropriate measures against any

\footnotetext{
357 “A Convoy of 300 Syrian Displaced Returned From The Town Of Arsal To The Syrian Town Isal al Ward", AnNahar, (July 12, 2017), https://www.annahar.com/article/617319F.

${ }^{358}$ Annahar News, (October 21, 2018): https://newspaper.annahar.com/article/181890.

359 "I Want A Safe Space: Refugee women from Syria uprooted and unprotected in Lebanon." Amnesty International, (February, 2016): https://www.alnap.org/system/files/content/resource/files/main/i-want-a-safeplace.pdf
} 
Syrian entering Lebanon without valid reasons or supporting documents, under the guise of law and order preservation.

Within the Lebanese structure, the Directorate for General Security (GS) is an intelligence agency that falls under the Ministry of Interior Affairs. The directorate has diverse functions, mainly including intelligence work and visa issuance, as well as managing state security regarding Syrian displacement. In fact, Article 17 of the 1962 law on the entry and exit of foreign nationals gives the General Security virtually unrestricted judicial police power to arrest, detain, and deport suspicious foreigners. ${ }^{360}$ This gendered law implies that immigration status within Lebanon gets processed through self-interested security personnel, with military uniforms, who seek to securitize the Syrian presence within the country rather than civil immigration employees. The General Security is responsible for controlling foreigners' legal status in the country, including Syrians' residency. Following a governmental decision, ${ }^{361}$ the GS issued several types of visas that allowed Syrians to lawfully acquire residency permits upon submission of official documents, such as passports, marriage and birth certificates. In other words, to be granted entry and residence in the country, Syrians must apply to one of the seven category visas: tourist, business, real estate ownership, student, transit, medical

${ }^{360}$ General Directorate Of General Security In Lebanon, http://www.general-security.gov.lb/en/posts/3.

361 "Lebanon Cabinet Votes To Stop Accepting Syrian Refugees," $\quad$ Daily Star, (October 23, 2014): www.dailystar.com.lb/News/Lebanon-News/2014/Oct-23/275075-refugee-crisis-topslebanoncabinetagenda.ashx. 
treatment, or legal sponsorship better known as Kafala. ${ }^{362}$ From all the previously mentioned reasons, two types of visas qualify most forcibly displaced Syrians to reside in Lebanon up to six months, eligible for renewal; these include the sponsorship-better known as the Kafala system and registration as de facto refugees with the UNHCR. Syrians over the age of 15 were thus obliged to renew their residency permit for 200 USD per person bi-annually.

Concurrently, these steps guaranteed GS officers control of Lebanese borders, identify Syrians' legal status, and make arbitrary decisions of revoking the residency of any Syrian that (re)enters Syria, thus disallowing them of any protective "privilege." 363 Issues such as increasing mobility restrictions imposed upon Syrians wishing to return for a quick visit could result in terminating their legal right to go back to Lebanon or preventing family reunions. ${ }^{364}$ Meanwhile, most Syrians fear filing any complaint against a Lebanese citizen, police officer, or security personnel for fear of losing their already limited legal status, which will be discussed in the following sub-sections, through vengeful threat measures such as pre-trial detention and biased interrogation practices. ${ }^{365}$

\footnotetext{
${ }^{362}$ Robert Rabil, The Syrian Refugee Crisis In Lebanon: The Double Tragedy of Refugees and Impacted Host Communities. Lexington Books, (2016), 20.

${ }^{363}$ Lebanon News, “UNHCR To Cross 5,500 Syrian Refugees: Derbas,” The Daily Star, (August 29, 2015):

https://www.dailystar.com.lb/News/LebanonNews/2015/Apr-29/296164-unhcr-to-cross-off-5500syrianrefugeesderbas.ashx.

${ }^{364}$ Rola Yasmine and Catherine Moughalian, "Systemic Violence Against Syrian Refugee Women And The Myth Of Effective Intrapersonal Interventions," Reproductive Health Matters, (2016).

${ }^{365}$ A 2015 Assessment By The Lebanese Institute For Democracy And Human Rights (LIFE).
} 


\subsubsection{Kafala System}

One dominant pathway for Syrians to reside in Lebanon is the Kafala system, constructed around the model of employer sponsorship of foreign labor. Like the Gulf countries, each foreigner who wishes to make a living in Lebanon must be guaranteed by a sponsor, who maintains the right to exert significant control over their employee's legal status, freedom of movement, as well as employment mobility. The makfoul-migrant worker-would become totally dependent on their kafeel-sponsor-to renew their residency and provide them income. This system is often criticized for being a disguised form of modern-day slavery, putting asylum seekers in a vulnerable position for all sorts of exploitation and abuse. The legal relationship that binds the employee to their employer appears most analogous to a modern-day slavery relationship." 366 The employee is dependent on their employer in their entry and residency rights in the country, giving them space to confiscate their passports as a way to limit their freedom of movement. $^{367}$

Even though the confiscation of employees' passports arguably violates Article 36 of the Lebanese Foreigner's Law, which stipulates that any foreigner found on Lebanese ground without valid proof of identity be subject to fines and imprisonment, the law itself encourages confiscation, as immigrants are the only

\footnotetext{
${ }^{366}$ Ray Jureidini, “An Exploratory Study of Psychoanalytic and Social Factors in the Abuse of Migrant Domestic Workers by Female Employers in Lebanon.” KAFA (enough) Violence \& Exploitation, (2011).

${ }^{367}$ Dina Mansour-Ille and Maegan Hendow, "From Exclusion To Resistance: Migrant Domestic Workers And The Evolution Of Agency In Lebanon,” Journal of Immigrant \& Refugee Studies (2018): 1-21.
} 
party to suffer from consequences in case the law was violated. Police, army, and General Security officers thus have the right to detain any foreigner who cannot prove that they are in the country legally, even if employers are the ones responsible for the missing documents. Detained non-citizens are systematically discriminated within over-crowded prison facilities with limited chances to not be deported. ${ }^{368}$ Consequently, under the Kafala system, a person becomes legally bound to an individual employer-kafeel — who would thus undertake all financial and legal responsibility for the migrant they sponsor. The migrant worker, thus, "cannot enter the country, transfer employment nor leave the country for any reason without first obtaining explicit written permission from the kafeel, who must report to the immigration authorities if the migrant worker leaves their employment, ensuring that their employee leaves the country after the contract ends."369

One could argue that, in the Lebanese context, such a system effectively became a status sought after by Syrians as the alternatives are much worse. Consequently, a new type of informal dynamics emerged, in which most Syrians would have to compensate Lebanese citizens to sponsor them and take them under their protection. ${ }^{370}$ In this case, the relatively privileged upper-class Syrian nationals that have Lebanese private citizens' connection and support, with

\footnotetext{
368 “Lebanon Immigration Detention Profile," Global Detention Project, (February 2018), https://www.global detentionproject.org/countries/middle-east/lebanon.

369 "Reform of the KAFALA (Sponsorship) System," Migrant Forum In Asia, Policy Brief No. 2, (July 3, 2013) : http://www.ilo.org/dyn/migpractice/docs/132/PB2.pdf.

370 OXFAM, Discussion Paper, "Lebanon: Looking Ahead In Times Of Crisis," (December 2015), https://www.oxfam.org/sites/www.oxfam.org/files/file_attachments/dp-lebanon-looking-ahead-time-crisis141215en_0.pdf.
} 
personal funds and (or) real estate in Lebanon, were often able to live a relatively decent life under the kafala system. Still, Syrians under this type of sponsorship face the same exploitative insecurities on a quid-pro-quo basis like any individual from any other nationality. ${ }^{371}$ In case their privilege went sour, the Lebanese sponsor has the power to confiscate or not renew a Syrian's kafala papers and, hence, deport them. However, this is not the case of most displaced Syrians who come from the middle to low class, work in low-skilled industries, and can barely afford the issuing and (or) renewal of their permits to remain lawfully employed in the country. ${ }^{372}$

\subsubsection{Syrian Refugees Registered Through the UNHCR}

Another form of a misused residency system that the majority of "displaced Syrians" undergo is the registration under the UNHCR, which provides them with a distinct set of rights and duties in Lebanon. Unlike the sponsored Syrians, those registered with the UNHCR can only have access to basic aid and health care, without being allowed to work legally. In fact, refugees can only register with the UNHCR and qualify for aid if they provide legal documentations confirming their residence and pledging not to take any job. ${ }^{373}$ Syrian refugees who wish to work can relinquish their registration with the UNHCR, not eligible then to receive

\footnotetext{
371 Katharine Jones. "Syrian Refugees In Lebanon Are Falling Into Slavery And Exploitation." The Conversation. (April 13, 2016), https://theconversation.com/syrian-refugees-in-lebanon-are-falling-intoslavery-and-exploitation-57521

${ }^{372}$ Ghida, Frangieh."Lebanon Places Discriminatory Entry Restrictions on Syrians." Legal Agenda 22 (2015).

373 Tine Gade, “Lebanon On The Brink," Norwegian Institute of International Affairs, Policy Brief 23. (2016), https://core.ac.uk/download/pdf/154676181.pdf.
} 
humanitarian aid, and acquire one of the three work visa permits; solid waste management, construction, and agribusiness sectors. ${ }^{374}$ In reality, most of these job types Syrians acquire are outside the formal job market, and most Lebanese employers do not register employees for visas nor report any legal transaction for fees evasion. It is important to note that the majority of displaced Syrians have always worked and resided in Lebanon under informal agreements, meaning that they were not required to provide any official documentation as proof of work or residency. With the relatively cheaper labor cost, unfair competition characterized the Lebanese job market, and many regular jobs were taken away from Lebanese and given to informal Syrian workers, thus jeopardizing the Lebanese labor force and further affecting working conditions of Syrians and increasing exploitation. ${ }^{375}$

Now, with the hardened Lebanese security measures, Syrians who fail to provide the required legal documentation are given a moratorium of up to ten days to secure it, after which their stay becomes illegal. It is crucial to note that all mandatory documents undergo lengthy bureaucratic processes, requiring municipal notarization and signatures from Lebanese officials, both of which are often challenging to acquire. The latter results in a time-consuming and expensive process that, based on UNHCR calculations, costs an average family around a thousand dollars per year. These costs are realistically unaffordable for most Syrian

\footnotetext{
374 “Syrians Who Obtain Work Permits in Lebanon Risk Losing Refugee Aid," Lebanon News, The Daily Star, (March 6, 2017): http://www.dailystar.com.lb/News/Lebanon-News/2017/Mar-06/396311-syrians-whoobtain-work-permits-inlebanon-risk-losing-refugee-status.ashx.

375 “The Syrian Refugee Crisis: Labour Market Implications In Jordan And Lebanon,” European Economy Discussion Paper, European Union. (2016), https://ec.europa.eu/info/sites/info/files/dp029_en.pdf.
} 
refugees, as a result, they are unable to meet registration requirements. ${ }^{376}$ Meanwhile, filing protracted lawsuits with legal and material assistance costs would drain the already limited financial ability of displaced Syrians to seek redress through Lebanese courts. Consequently, after seven years of displacement and without any significant income, many Syrians were forced to prioritize their basic needs over asserting legal rights through Lebanese courts.

Finally, the UNHCR's registration documents do not necessarily grant automatic residency permits but are subject to state approval through the GS. Consequently, refugees registered with the UNHCR before 2015 only obtain temporary legal status, depending on the GS's discretion, awaiting their final resettlement in a third country of destination. ${ }^{377}$ As for Syrians registered after 2015, The UNHCR does not share their information with the Lebanese government, barely guaranteeing them protection under the UNHCR with little legal aid or assistance. ${ }^{378}$ This lack of information-sharing increased hostilities between the Lebanese government and the UNHCR agencies operating within the country, resulting in increased restrictions from the Lebanese government upon UN

\footnotetext{
376 "Pushed to the Edge: Syrian Refugees Face Increased Restrictions in Lebanon," Amnesty International. (June 2015). www.amnesty.nl/sites/ default/files/public/pushed_to_the_edge_syrian _refugees_face_increased_restrictions_in_lebanon.pdf

377 Ibid.

378 "I Just Wanted to be Treated like a Person: How Lebanon's Residency Rules Facilitate Abuse of Syrian Refugees," Human Rights Watch, (January 12, 2016), https://www.hrw.org/report/2016/01/12/i-just-wantedbe-treated-person/howlebanons-residency-rules-facilitate-abuse.
} 
operations within the state. ${ }^{379}$ As a consequence, Syrian refugees are left in an ambiguous state of constant fear of arrest, apprehension or forced deportation.

\subsubsection{Undocumented Syrian Refugees}

A third category of relevance that the majority of Syrians fall under is illegal residency. Due to their sudden flight after the bombing and burning of their homes, the lack of identity proof or legal documents hinders many Syrians in Lebanon from obtaining official registration with the UNHCR, adding to the overall number of Syrians present in Lebanon. ${ }^{380}$ As for the ones who are fortunate to possess such documents, their registration as de facto refugees with the UNHCR is complemented with a pledge not to work, entirely reliant on the frequent interruption of humanitarian assistance to the affected populations due to lack of funding. ${ }^{381}$ As a matter of fact, due to a shortfall in funding, the UNHCR and other NGOs' assistance efforts are barely sufficient for immediate refugee needs, leaving them increasingly vulnerable to debt and poverty. Consequently, Syrian refugees become constrained from renewing their residency papers and are, thus, left without valid legal residency documents. The UNCHR estimated that the percentage of Syrian refugee households without valid residence permits rose from " $9 \%$ in

\footnotetext{
379 James Haines-Young, “Lebanon's Bassil Meets UNHCR to Defuse Refugee Row,” The National, (June 17, 2018), https://www.thenational.ae/world/mena/lebanon-s-bassil-meets-unhcr-to-defuse-refugee-row1.741039 .

380 "I Just Wanted to be Treated like a Person: How Lebanon's Residency Rules Facilitate Abuse of Syrian Refugees," Human Rights Watch, (January 12, 2016): https://www.hrw.org/report/2016/01/12/i-just-wantedbe-treated-person/howlebanons-residency-rules-facilitate-abuse.

381 "Refugees from Syria: Lebanon," UNHCR, (March 2015), 6: http://reliefweb.int/report/lebanon/refugeessyrialebanon-march-2015.
} 
January 2015 to $61 \%$ in July $2015 .{ }^{, 382}$ In fact, this number increased to $70 \%$, and approximately 700,000 Syrians are now undocumented and socially marginalized. ${ }^{383}$

Moreover, following the government's hyper-regulative decision of visa renewal, most Syrian refugees were unable to fulfill sufficient registration requirements. Accordingly, most newborn Syrian children also cannot be registered as the UNHCR only enrolls Syrian children if they are born in Lebanon having at least one of the parents already registered, and, most importantly, possessing a Lebanese birth certificate - a document that is bureaucratically almost impossible to acquire. ${ }^{384}$ Retrospectively, the nature of the Syrian Nationality Law is not far from the Lebanese one for it also presents enormous discriminatory obstacles for Syrian mothers. Syrian nationality regulations are predominately paternalistic - jus sanguinis for "anyone born inside or outside the country to a Syrian Arab father . . . shall be considered as Syrian Arabs ipso facto."385 The latter means that a child's citizenship can either be passed through a citizen father or if a citizen mother gives birth in Syria with no father establishing affiliation to the child. ${ }^{386}$ Therefore, most

\footnotetext{
382 "Protection Sector, Monthly Dashboard," UN Inter-Agency Coordination Lebanon, (July 2015), http://data.unhcr.org/ syrianrefugees/download.php?id=9508.

383 "I Just Wanted to be Treated like a Person: How Lebanon's Residency Rules Facilitate Abuse of Syrian Refugees," Human Rights Watch, (January 12, 2016), https://www.hrw.org/report/2016/01/12/i-just-wantedbe-treated-person/howlebanons-residency-rules-facilitate-abuse.

384 "Q\&A For Syrians Seeking Registration," United Nations, (July 15, 2017), https://www.refugeeslebanon.org/en/news/88/qa-for-syrians-seeking-registration.

385 Tim Schultz, "Combating Statelessness In The Wake Of The Syrian Conflict: A Right Without A Remedy," Notre Dame Journal of International \& Comparative Law 8, no. 2 (2018): 147.

386 Ibid, 132.
} 
Syrian children end up thus stateless-lacking a fundamental legal recognition of nationality $^{387}$ — violating the Convention of the Rights of the Child, that Lebanon endorses. $^{388}$

Even though Lebanese officials continuously reassure their commitment to the principle of "safe" returns of Syrians in Lebanon, the precarious Syrian refugees' legal status in the country is further complicated by the fact that different governmental agencies apply the rules at their discretion-not under a unified rule of law but rather following sporadic governmental decisions. ${ }^{389}$ Such actions allow the different local security agencies to revoke the expired residency documents and strip the now undocumented Syrian nationals of their fundamental rights. This latter leads to further marginalizing and facilitating refugee exploitation, under the pretext that their presence threatens national security. ${ }^{390}$

\subsection{A No-Camp Policy}

Another form of sovereignty through exclusion is the ban on formal refugee settlements. Through securitization measures, Syrian refugees were labeled as "displaced victims" who acquired limited governmental protection so they could

\footnotetext{
387 John Davison, "Redrawing The Middle East: A Generation Of Syrian Children Who Don't Count," Thompson Reuters, (May 3, 2016): http://www.reuters.com/investigates/special-report/syriarefugeesstateless/.

388 "Trapped in Lebanon: The Alarming Human Rights and Human Security Situation of Syrian Refugees in Lebanon." ALEF. (May 2016), 18, https://alefliban.org/wp-content/uploads/2016/11/Trapped-In-Lebanon_ALEF_PAX_May2016.pdf.

389 "Lebanon: New Entry Requirements For Syrians Likely To Block Would-Be Refugees," Amnesty
(January

${ }^{390}$ Maja Janmyr and Lama Mourad, "Modes Of Ordering: Labelling, Classification And Categorization In Lebanon's Refugee Response,” Journal of Refugee Studies (2017).
} 
become an existential threat to national security. Historically, Palestinian refugees were blamed for playing a primary role in igniting the devastating Lebanese Civil War that brought the country to the fragile state it finds itself in today. As a lesson from previous experiences with Palestinian refugees, the Lebanese government thus refused to build new refugee camps as primary settlements for the now "displaced" Syrians. One example was in 2013, where the Ikea Foundation's project "Better Shelters" donated easily transportable shelters that could be put up in four hours and had solar panels on the roof. ${ }^{391}$ However, the project was directly shut down by the Lebanese government authorities, and permanent shelters were banned, as local communities were worried that such initiatives might encourage Syrians to settle in their area indefinitely.

As a consequence, as of 2011 Informal Tented Settlements (ITS) started to emerge in Northern Lebanon and in the Bekaa Valley to accommodate the evergrowing number of Syrian refugees settling in Lebanon. As housing possibilities within the country were very limited, and the hosting government objected to the construction of official camps, refugees were scattered all over the country in all kinds of vacant facilities, thus occupying spaces such as rental apartments, garages, unfinished buildings, as well as living on the streets. ${ }^{392}$ Lebanese owners consider

\footnotetext{
${ }^{391}$ Richard Hall, “Lebanon Doesn't Want Syrian Refugees Getting Too Comfortable, Even in Winter," Agence FrancePresse, (February 15, 2016), https://www.pri.org/stories/2016-02-15/lebanon-doesnt-want-syrianrefugees-getting-toocomfortable-even-winter.

392 "VASyR 2017: Vulnerability Assessment of Syrian Refugees in Lebanon," World Food Program, United Nations Children's Fund (UNICEF), and UNHCR, (2016): http://documents.wfp.org/stellent/groups/public/documents/ena/ wfp289533.pdf.
} 
most Syrian refugee living on their private properties in Lebanon as essentially lesser private tenants, where contracts are based on informal negotiations and private agreements without any real governmental supervision.

Even though Lebanon has the sole authority to manage its constituents, the daily government practices of control, containment, and exclusion over displaced Syrians are done by property owners and local institutions, (re)producing new types of refugee insecurities. Instead of being supported by the government, any external assistance provided to refugees is in no way related to the government and comes mainly from humanitarian organizations or private enterprises, varying from being sufficient to severely limited and fragmented. Even though the condition of Syrian refugees living on private properties is, clearly, not enviable, it is considerably better than that of Syrian refugees living in ITS. According to the Lebanon Shelter Sector's Strategy, an ITS is defined as an:

"Unofficial group of temporary residential structures, often comprising of plasticsheeting and timber structures and can be of any size from one to several hundred tents." 393 Based on this definition, one could only imagine the unsafe and exploitative conditions in which those Syrian refugees live in, creating predictable inconveniences that would result from such a lifestyle.

Nevertheless, the ITS phenomenon existed even before the Syrian crisis, in most agricultural, rural, mountainous areas in Lebanon. In fact, several seasonal

${ }^{393}$ Romola Sanyal, “A No-Camp Policy: Interrogating Informal Settlements In Lebanon,” Geoforum 84 (2017): 117-125. 
tribal migrant workers and their extended families_locally known as "Bedouin el Arab" and to which the UNHCR refer to as "nomadic and border populations ${ }^{\text {"394 }}$ have always migrated from Syria to Lebanon every spring season until the end of the summer, residing at the outskirts of privately owned agricultural land. "Bedouin el Arab" linguistically relates to Badiya - desert. ${ }^{395}$ Historically, Bedouins are tribes' descendants of ancient Arab tribes of the Arabian Peninsula. Nowadays, Bedouin men cultivate the land and work on construction sites, whereas women and children from the age of five clean Lebanese households as well as collect fruit and vegetables during the week. ${ }^{396}$ Women and children would then, on weekends, roam different villages' plazas_-"Midan"-and restaurants selling toys, gum, and even reading people's fortune. At the end of the agribusiness season, most migrants would eventually go back to their respective towns across state borders, having collected enough money to move to a warmer, economically viable place, with work and school opportunities.

However, with the crisis dynamics unfolding in Syria, increasing numbers of Bedouins and their extended families were copelled to permanently reside in Lebanon out of fear of being persecuted or recruited for a war they do not want to

\footnotetext{
394 "Ensuring Birth Registration For The Prevention of Statelessness.” UNHCR. Ending Statelessness Within 10 Years.

(2017):https://www.unhcr.org/ke/wp-content/uploads/sites/2/2017/11/Good-Practices-Paper-on-EnsuringBirth Registration -for-the-Prevention-of-Statelessness.pdf

${ }^{395}$ Dawn Chatty, "Bedouin In Lebanon: The Transformation Of A Way Of Life Or An Attitude?," International Journal of Migration, Health and Social Care 6, no. 3 (2011): 21-30.

396 Dawn Chatty, Nisrine Mansour, and Nasser Yassin, "Statelessness And Tribal Identity On Lebanon's Eastern Borders,"Mediterranean Politics 18, no. 3 (2013): 411-426.
} 
partake in. In effect, the bedouins main sources of employment-construction and agricultural work - are mostly seasonal and unavailable in Lebanon during the winter season. ${ }^{397}$ Aside from being susceptible to extreme weather variations in the mountainous and arid open spaces during fall and winter times, Syrians now living in longer-term informal camps must live off their savings for part of the year, maintaining very low standards of living during the harsh winters of rural Lebanon. Their dependency on humanitarian aid and basic supplies of food and water was exacerbated with a lack of privacy and terrible sanitary conditions, among many other misfortunes, increasing social harassment and stigma for refugees.

With their presence becoming very noticeable to the host populace and municipalities, these informal spaces became "confining not only physically but also at the level of cognition, emotions, and temporality." ${ }^{398}$ The Lebanese Armed Forces (LAF) and other intelligence officers systematically raided several ITS with the aim of apprehending terrorist suspects and deterring potential threats. ${ }^{399}$ Accordingly, reports state that the LAF arrested Syrians for "alleged national security offenses, with human rights risks during pretrial detention and

\footnotetext{
397 "Self-Protection And Coping Strategies Of Refugees From Syria And Host Communities In Lebanon," OXFAM, (July, 2015):https://d1tn3vj7xz9fdh.cloudfront.net/s3fs-public/file_attachments/rr-lebanon-refugeesprotection-300616en.pdf.

398 Romola Sanyal, “A No-Camp Policy: Interrogating Informal Settlements In Lebanon,” Geoforum 84 (2017): 117125.

${ }^{399}$ Mona Fawaz, "Planning and the Refugee Crisis: Informality As A Framework of Analysis and Reflection," Planning Theory 16, no. 1 (2017): 99-115.
} 
interrogation." ${ }^{400}$ Military detention centers, including those that potentially house terrorists and other criminal suspects, are merged with other small crimes detainees in overcrowded spaces. Meanwhile, if any complaint against military conduct were to be voiced, the military penchant and court judgement trump civilian appeals. As a matter of fact, civilian victims, let alone Syrians, are not allowed to file a law suit nor produce evidence, let alone appeal, threatening any access to petition the judge's decision. This process is a clear violation of Article 13.3 of the International Convention on Civil and Political Rights (ICCPR). ${ }^{401}$ We find cases where military courts do not announce the justifications behind their declared judgements, giving space thus for unlawful military trials, ad hoc detention and negligent care. ${ }^{402}$

Consequently, the fear of being evicted, detained, and deported reinforces the fear of Syrian refugees and insecurity. ${ }^{403}$ As an effect, camps that were once part of the Bedouin culture ended up reproducing long-term physical restrictions on the now Syrian refugees disregarding them into a "state of anonymity and marginality that in itself is also confining." ${ }^{404}$ We find different interdependent

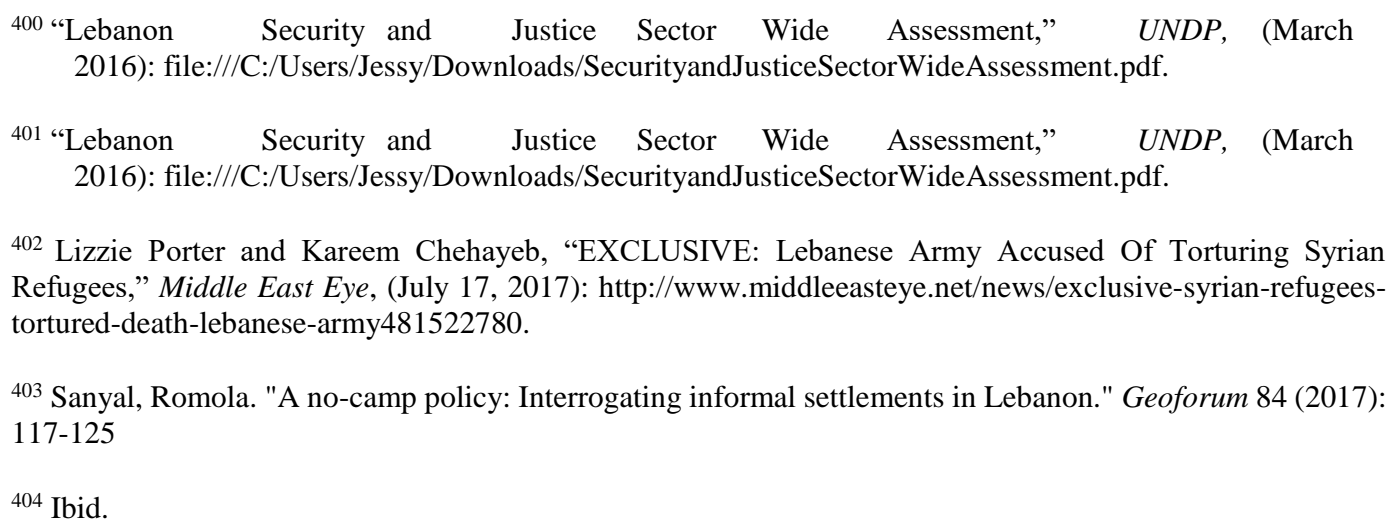


privileged bodies, such as municipalities, landowners, as well as the Syrian shawish - a masculine word used to refer to one man supervising an ITS — take the role of gatekeepers, controlling residing Syrian families with little to no security guarantees. In fact, the degrees of control in which "refugees are profiled, monitored, and disciplined, [mirrors] in many ways the conditionality of informal refugee camps. ${ }^{405}$

\subsection{Curfews and Checkpoints}

Most Syrian refugees who are coming to Lebanon experience a difficult process of assimilation due to conflicting socio-cultural attitude towards their presence within their country. While Sunni Muslims in Lebanon have been more tolerant toward the majority of Syrian refugees, other Lebanese sectarian communities especially the Shiites and the Christians do not share the same enthusiasm towards the majority of Syrian incomers (Sunnis). ${ }^{406}$ Due to the fragmented political deadlock, a lack of a coherent national strategy for addressing the Syrian influx has left different local bodies to take matters in their own hands. Municipalities were entrusted with managing and monitoring the refugee status quo by the Ministry of Interior and Municipalities (MoIM), counting refugees and managing both communities, a duty that played a key role in expanding the strategies of different municipalities in controlling the sudden refugee influx into their areas. As a direct result, most municipalities increased their municipal police taskforce, a body that

${ }^{405}$ Ibid.

${ }^{406}$ Hassan Krayem, "The Lebanese Civil War And The Taif Agreement," Conflict Resolution in the Arab World: Selected Essays (1997): 411-436. 
is not recognized by the central government as an "official" security service provider, to enforce curfews to control and supervise Syrian refugees. In fact, there are no standard operational policies for the Lebanese municipal police. Their accountability measures, and recruitment standards such as proof of clean criminal records are not certified nor based on professional police training before assuming duty and carrying firearms. ${ }^{407}$

Meanwhile, coordination with the central government security forces varies according to temporal and spatial dynamics. In fact, varying and contradictory responses implemented across the different municipalities led to different policies for Syrians, depending on specific areas of residence. Most of these policies were the fruits of not only local decision-makers but, also that of popular stances towards Syrian refugees, where some areas were more welcoming and others more hostile. The most antagonistic decision that is still, up to this date, condemned by the international community for its unethical element, was the decision of 252 out of 1108 municipalities to impose curfews as guidelines on Syrian de facto refugees after nightfall. ${ }^{408}$ It is crucial to note that under Article 12 of the ICCPR there is no legal basis for municipalities to impose curfews on a specific community while exempting others. ${ }^{409}$ In that respect, the biased policies of illegal curfews and

\footnotetext{
407 "Lebanon Security And Justice Sector Wide Assessment," UNDP, (March 2016), file:///C:/Users/Jessy/Downloads/ SecurityandJusticeSectorWideAssessment.pdf. 
evictions that certain Lebanese municipalities imposed on Syrian residents, reinforced the hostilities between both communities. ${ }^{410}$

\section{Systemic Discrimination of Syrian Women: A Double Tragedy}

Syrian women refugees are not isolated from the various types of insecurities mentioned in the previous section as they form most of the officially registered refugees in Lebanon. ${ }^{411}$

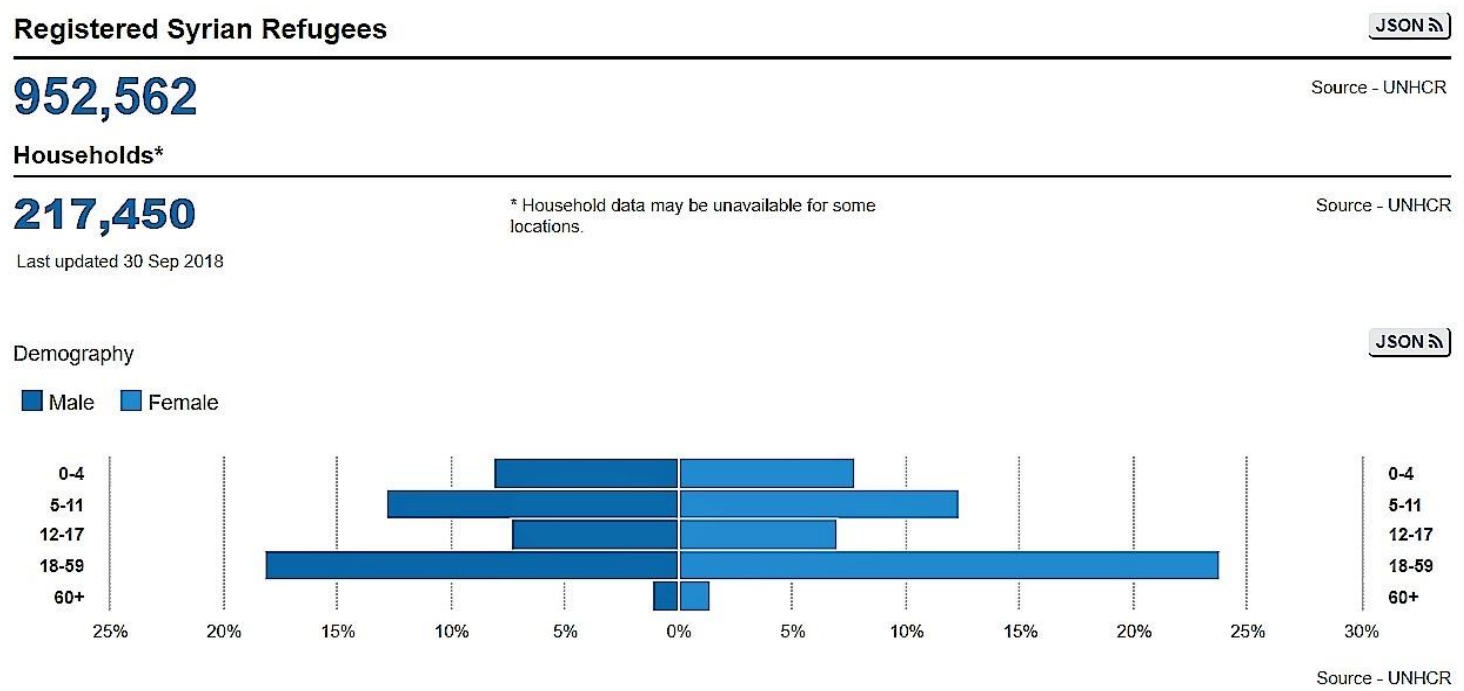

Figure 5. Registered Syrian refugees with the UNHCR by September 2018 412

According to the figure above, as of September 2018, of the 952,562 Syrian refugees registered with the UNHCR in Lebanon, $52.3 \%$ are female, with the

410 "Lebanon: At Least 45 Local Curfews Imposed On Syrian Refugees." Human Rights Watch. (October 3, 2014), https://www.hrw.org/news/2014/10/03/lebanon-least-45-local-curfews-imposed-syrian-refugees

${ }^{411}$ Rola, Yasmine, and Catherine, Moughalian, "Systemic Violence Against Syrian Refugee Women And The Myth Of Effective Intrapersonal Interventions," Reproductive Health Matters, (2016).

412 “SGBV Dashboard.” Interagency, Lebanon, January - August 2016, https://data2.unhcr.org/en/situations/ syria/ location/71. 
largest age group aged between 18 and 59, representing 23.8\% of all registered Syrians. The UN reports that females head $19 \%$ of Syrian refugee households. ${ }^{413}$ In fact, Syrian women heads of household live in Lebanon without a husband or other adult male relatives. Some of these women are either widows, divorced, ones whose husbands are missing, or whose husband is not registered, remained in Syria, died, vanished, or even sought asylum in other countries. ${ }^{414}$

Additionally, most registered Syrian males in Lebanon are children, with only $18.2 \%$ of registered males falling in the age group of $18-59$ and $1.2 \%$ over the age of 60 . Therefore, around $80 \%$ of refugees are either female or male dependents, most probably fall under the protection of their adults, thus adding new legal burdens upon their guardians. Therefore, it becomes evident that women's and children's legal stay in Lebanon and visa renewals fall upon the shoulders of their adult male guardians or adult female Syrian refugees heading their household.

Given the context where women have less social and legal status, they often also have insufficient capital, limited support, and bare legal backing to protect themselves. This alone implies that women are more likely than any other group to suffer the consequences of restrictive Lebanese policies. The Vulnerability Assessment of Syrian Refugees in Lebanon (VASyR) report jointly produced between the UNHCR, World Food Program, and UNICEF states that "female-

\footnotetext{
413 "VASyR 2017: Vulnerability Assessment of Syrian Refugees in Lebanon," UNHCR, World Food Program, and United Nations Children's Fund (UNICEF), (December, 2017), 4, https://data2.unhcr.org/fr/documents/download /61312.

${ }^{414}$ Amnesty International interviews with refugee women from Syria and with NGOs working with refugees, June and (October, 2015), Lebanon.
} 
headed households were less food secure, had worse diets, adopted severe coping strategies more often and had higher poverty levels [...] femaleheaded households were almost twice as likely as male-headed households to live in informal settlements, and were less likely to have legal residency." "415 The report adds that a good amount of female-headed households do not work with stringent support. ${ }^{416}$ This alone implies that Syrian women are more likely than any other group to suffer the consequences of restrictive policies imposed by the Lebanese government, even if those policies were gender-neutral and did not specifically target women. ${ }^{417}$ On the other hand, a news report made by Al Jazzera stated that Syrian women refugees who identify as widowed are not only fighting for survival, but they are also in constant conflict with their new communities. One Syrian widow named Fatima told the news agency that "Every time I voice my opinion on how to improve the aid distribution in the camp, the Syrian men in the village shut me up. Because I am a woman, I am being told my opinions are worthless even though I am more educated than most of them,[...] They say I am too open and too manly because I

\footnotetext{
415 "I Want A Safe Space: Refugee women from Syria uprooted and unprotected in Lebanon." Amnesty International, (February, 2016): https://www.alnap.org/system/files/content/resource/files/main/i-want-a-safeplace.pdf

416 United Nations Children's Fund (UNICEF), United Nations High Commissioner for Refugees (UNHCR), and the United Nations World Food Programme (WFP), Vulnerability Assessment of Syrian Refugees in Lebanon Report, VASyR-2017, 2017, https://data2.unhcr.org/fr/documents/download/61312.

${ }^{417}$ 0"Third Periodic Report of Lebanon, UN Doc," CEDAW, (July, 2006), $14-16$,

http://tbinternet.ohchr.org/_layouts/treatybodyexternal/Download.aspx?symbolno=CEDAW\%2fC\%2fLBN\% $2 \mathrm{f} 3 \&$ Lang=en.
} 
leave the house and speak out, even though my clothing has nothing to do with openness." 418

Therefore, with so much attention going towards national security concerns to assure state stability, the plight of Syrian women does not receive the necessary protection that they so desperately need. Reflecting on the context of the situation of Syrian refugees in Lebanon, gender and refugee status play a major role in contributing to the multiple forms of discrimination inflicted upon Syrian women refugees by both members of the host community as well as within their own communities. Traditionally stigmatized, Syrian women who leave their homes with their children in search of security get paradoxically subjected to double discrimination: one as refugees and another because of their gender. Accordingly, a deeper examination of the gendered Lebanese institutions that restrict women's access to justice, rights, and empowerment opportunities is important to highlight some of the forms of discrimination that Syrian women endure in association to their gender. When Lebanese women citizens endure such inequalities, it is natural to expect that Syrian women's agency and decision-making authority over their life choices would be similarly undermined, if not worse.

\subsection{Draconian Personal Status Laws}

The discriminatory Lebanese nationality law and penal code over the numerous personal status laws engender the long-standing sectarian patriarchal social norms

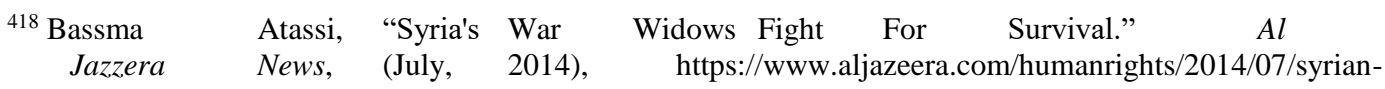
women-struggle-as-sole-providers-201478122435631439.html
} 
that generally hinder women's rights. Lebanon does not have a civil code to regulate issues such as divorce, property rights, or the care of children. Instead, different religious courts administer distinct personal status laws that often issue rulings that violate women's rights with little government oversight. Accordingly, on November 3, 2015, the Committee on the Elimination of Discrimination against Women expressed serious concerns in its concluding observations on Lebanon about Lebanon's delay in adopting relevant amendments. The Committee commented that the numerous different personal status laws could lead to various discriminations against women twice; within their respective religious sects and between the different religious denominations. ${ }^{419}$

Without a modern set of civil laws, social customs and the religious courts that rule on family matters treat women as inferior to men. As family guardians, men are in a position of power and rights over his wife-or wives in some instances — and children. ${ }^{420}$ They are responsible to care for children financially, health wise, travel, and consent for marriage. ${ }^{421}$ Lebanon has seen a consistent decline in the Global Gender Gap Index, ranking 135th out of 144, as of $2017 .^{422}$

\footnotetext{
419 "Concluding Observations On The Combined Fourth And Fifth Periodic Reports Of Lebanon." CEDAW. UN Doc. CEDAW/C/LBN/4-5, $\quad$ (November 2015 ): http://docstore.ohchr.org/SelfServices/FilesHandler.ashx?

${ }^{420}$ Amnesty International interviews with refugee women from Syria and with NGOs working with refugees, (June and October 2015), Lebanon.

421 "I Want A Safe Space: Refugee women from Syria uprooted and unprotected in Lebanon." Amnesty International, (February, 2016): https://www.alnap.org/system/files/content/resource/files/main/i-want-a-safeplace.pdf

422 "Briefing Note For Countries On The 2016 Human Development Report: Lebanon," United Nations Development Program (UNDP), (2016): http://hdr.undp.org/sites/all/themes/hdr_theme/countrynotes/JOR.pdf.
} 
After all, different sects possess different rights and duties, while influencing Lebanon's ranking position as a third to last in the Middle East and North Africa (MENA) region, with only Syria and Yemen behind. ${ }^{423}$

In Sunni Muslim gendered practice - which makes up most of the Syrian population residing in Lebanon-"guardianship in the absence of a child's father does not pass to its mother. Instead, custody is granted to another male member of the father's family." ${ }^{\prime 24}$ Meanwhile, all the unchecked patriarchal religious courts discriminate against Lebanese women, treating them as second-class citizens with insufficient oversight and accountability from the Lebanese government. Genderbased discrimination in inheritance, job opportunities, and education, are a few of the unfortunate events that Lebanese men would never have to deal with.

Meanwhile, the issue of state accountability is pivotal to a woman's freedom. Knowing the different legal institutions' responsibilities, and to whom these institutions answer, affect the way women's rights get translated into practice. Accordingly, Lebanese court procedures can have discriminatory effects, where a woman's case can be dismissed as a dubious emotional claim with a lack of evidence. ${ }^{425}$ Added to the fact, is that most women cannot afford legal or material

\footnotetext{
${ }^{423}$ William Avis, “Gender Equality And Women's Empowerment In Lebanon,” Helpdesk Report. University of Birmingham. (August 16, 2017): https://www.alnap.org/system/files/content/resource/files/main/175gender-equalityand-womens-empowerment-in-lebanon.pdf.

424 "Without Protection: Women's Rights under Lebanese Personal Status Laws." Human Rights Watch. (January, 2015).

425 “Roula Yaacoub's Husband Found Not Guilty After Beating Her To Death.” Beirut. (Novemeber 1, 2018), https://www.beirut.com/l/56670
} 
assistance during protracted legal proceedings, which makes them vulnerable to cases of child custody assured to the father, or, even worse, arrest without bail as punishment for defending themselves against their abusive husbands. Consequently, depending on their sect, officially registered Syrian women would have to abide by their respective discriminatory personal laws, making them particularly vulnerable to inadequate protection measures from all sorts of abuse, harassment, and exploitation due to their gender status of being second-class residents. The fact is that preserving the family's honor, and reputation is perceived as the responsibility of the head of the household, typically a man. In Arab culture, most men work the public space while women occupy the private sphere. ${ }^{426}$ Therefore, it is only natural that Arab men consider that it is in their right to control any public access of their female members of their family.

Meanwhile, landlords, security agents, faith-based officials, and community members, among many others, have opportunities to take advantage of Syrian women's position of being either widowed or unmarried with no male guardians to protect them. ${ }^{427}$ As for the ones who crossed the borders illegally, their status in the country is compromised. Consequently, their insecurities are far worse. Without a

\footnotetext{
${ }^{426}$ Elizabeth Thompson. "Public And Private In Middle Eastern Women's History." Journal of Women's History 15, no. 1 (2003): 52-69.

427 "Human Rights Watch Submission To The CEDAW Committee Of Lebanon's Periodic Report 62nd Session," Human

Rights Watch, (February, 2015), https://tbinternet.ohchr.org/Treaties/CEDAW/Shared\%20Documents/ LBN/INT_CEDAW_NGO_LBN_19385_E.pdf.
} 
residency permit, undocumented Syrians are threatened, potentially arrested with no consideration of their gendered insecurities. According to the expert from Justice without Borders, the Lebanese government's social service providers and the police do not provide immunity to illegal residents for immigration law violations. In that respect, Syrian refugee women who attempt to file a complaint and prosecute those accused of gender-based violence are subject to further abuse, harassment, detention, and potential deportation. ${ }^{428}$

\subsection{Citizenship Law}

The newly established Ministry of Women's Affairs, headed by a man named Jean Ogasapian, announced that November 4 would become the National Women's Day in Lebanon. ${ }^{429}$ This date was chosen because on November 4th, 1952, Lebanese women got the right to vote and give citizenship to their children, while their legislative rights in Lebanon barely existed. ${ }^{430}$ However, as of 1960, Lebanon's xenophobic and misogynistic laws stripped women's rights to give citizenship to their children in the case they were married to a "Palestinian" foreigner. In fact, the Lebanese Citizenship and Naturalization Law (1960) does not allow Lebanese

\footnotetext{
${ }^{428}$ Claire Harvey, Rosa Garwood, and Roula El-Masri, "Shifting Sands: Changing Gender Roles Among Refugees In Lebanon," Oxfam International, (2013): https://oxfam.qc.ca/sites/oxfam.qc.ca/files/rr-shiftingsands-lebanonsyriarefugees-gender-030913-en_0.pdf; Ghida Anani, 'Syria Crisis - Dimensions Of GenderBased Violence Against Syrian Refugees In Lebanon,' Forced Migration Review, No. 44. (2013): http://www.fmreview.org/en/detention/anani.pdf.

429 "Lebanon First Ever Womens Affairs Minister Man Jean Ogasapian Rights Equal." Independent. (December 19, 2016) :https://www.independent.co.uk/news/world/middle-east/lebanon-first-ever-womensaffairs-minister-man-jeanogasapian-rights-equal-a7484221.html

${ }^{430}$ Maya Mansour and Sarah Abou-Aad, "Women's Citizenship Rights In Lebanon." Research and PolicyMaking in the Arab World. (2012).
} 
women married to non-nationals to pass their citizenship to neither spouses nor children. ${ }^{431}$ Meanwhile, ad hoc official Lebanese executive orders scrambled to provide the very same passports to non-disclosed male foreigners who have enough status or funds to become Lebanese citizens. ${ }^{432}$ Article 7 of the Lebanese Constitution affirms gender equality and, in 1996, Lebanon also ratified the Convention on the Elimination of All Forms of Discrimination Against Women (CEDAW). ${ }^{433}$ Thus, on paper, Lebanon appears to be in a much more liberal and progressive position than any other Arab country.

In December 2012, Lebanon's Parliamentary Human Rights Committee published a National Plan for Human Rights 2013-2019, which aims to reform its laws and procedural measures to strengthen women's rights and gender equality in all fields and sectors. ${ }^{434}$ However, till this date, the plan is pending approval and adoption by the majority of the Lebanese Parliament. ${ }^{435}$ When looking closely, Lebanon has registered reservations towards specific articles within CEDAW, such as Article 9 regarding nationality, and Article 16 regarding marriage and family

${ }^{431}$ Ibid.

${ }^{432}$ Georgi Azar. "Lebanese President Draws Fire With Naturalization Decree.” Annahar News. (June 1, 2018): https://en.annahar.com/article/812753-lebanese-president-draws-fire-with-naturalization-decree

433 “Consideration Of Reports Submitted By States Parties Under Article 18 Of The Convention Fourth And Fifth Periodic Reports Of States Parties Due In 2014 Lebanon" United Nations (May 15, 2014): https://nclw.org.lb/wpcontent/uploads/2017/10/CEDAW-Fourth-and-Fifth-Periodic-Report-Lebanon.pdf

${ }^{434}$ Bachir Ayoub and Dima Mahdi, "Making Aid Work In Lebanon: Promoting Aid Effectiveness And Respect For Rights In Middle-Income Countries Affected By Mass Displacement” OXFAM, (2018).

435 "Female Refugees From Syria In Iraq, Jordan And Lebanon: Lebanon Gender Profile," United Nations Economic and Social Commission of Western Asia (ESCWA), E/ESCWA/ECW/2013/Technical paper 4, (2014), 15. 
life, that are among others central to the object and purpose of the Convention. By holding these reservations, Lebanon's contestation of these provisions negatively impacts CEDAW's mission in advocating women's basic rights "to ensure that women and men have equal ability to acquire, change, and retain their nationality and to confer their nationality to children and spouses." ${ }^{436}$ According to an interview conducted with a representative of Justice Without Borders, a Lebanese NGO that provides services to protect vulnerable women, including Syrian women refugees; "early marriage in Lebanon is not a crime because it is not mentioned in [Lebanon's] personal status law; but early marriage is an indicator of trafficking." Additionally, "when we refer to the national laws, there is no clear definition about what sexual violence is $[\ldots]$ There is no definition of what rape is [...] Moreover, when we talk about sexual violence in conflict, sexual violence could be investigated as genocide or a crime against humanity, but most of it is not mentioned [in Lebanese laws]. ${ }^{9437}$

Moreover, the Lebanese government insisted that all disputes over the interpretation or application of the Convention required prior approval of all involved parties before any referrals to the International Court of Justice (ICJ). ${ }^{438}$ Accordingly, the concept of sovereignty remains essential, entitling a sovereign

\footnotetext{
436 Tim Shultz, "Combating Statelessness In The Wake Of The Syrian Conflict: A Right without A Remedy," Notre Dame J. Int'l Comp. L. 8 (2018): 148.

${ }^{437}$ Justice Without Borders Expert Interview With author, (May 29, 2017).

${ }^{438}$ Lamia Rustum Shehadeh, “Gender-Relevant Legal Change In Lebanon,” Feminist Formations (2010): 210 228. ${ }^{442 ، T h e ~ C o n s e q u e n c e s ~ O f ~ L i m i t e d ~ L e g a l ~ S t a t u s ~ F o r ~ S y r i a n ~ R e f u g e e s ~ I n ~ L e b a n o n, " ~ N o r w e g i a n ~ R e f u g e e ~}$ Council, (December 2013), 27, https://reliefweb.int/sites/reliefweb.int/files/resources/9687105.pdf.
} 
state such as Lebanon to exercise prima facie exclusive jurisdiction over its territory and co-opt specific humanitarian measures and leave others behind. In that respect, Syrian women residing in Lebanon face many challenges as a consequence of their limited legal status. According to the official Lebanese birth registration procedures for non-Lebanese, Syrian women with limited to illegal status cannot complete the process of registering the births of their newborn babies without adopting a range of risky coping mechanisms such as bribery, forgery, and identity theft. ${ }^{442}$ According to the MoSA expert interviewee, "That is another big issue. [...]There is a sixstep process for them to be registered to have a paper from the UNHCR that says that these children practically exist. Most of them are not registered yet, you have many newborns that are not being added to the list we have, and this will create a huge problem in the long term." 439 The interviewee's statement echoed the "Good Practice Paper" published by the UNHCR, according to which the process usually involves several legal steps that usually involve paying fees, such as hospital birth notification letter, an official state's civil registry, or fines in case of any delinquency or late registration. ${ }^{440}$ Referring to the "Good Practice Paper," many Syrian parents are not well-informed or not capable of undergoing the whole six-steps process, affecting in the long term their child's eligibility to enroll in

\footnotetext{
${ }^{439}$ Abaad Expert interview with author, June 12, 2017.

440 "Ensuring Birth Registration For The Prevention Of Statelessness." UNHCR. Ending Statelessness Within 10 Years,

(2017):https://www.unhcr.org/ke/wp-content/uploads/sites/2/2017/11/Good-Practices-Paper-on-EnsuringBirthRegistration-for-the-Prevention-of-Statelessness.pdf
} 
school or try to access other state services. ${ }^{441}$ Consequently, it would be extremely challenging for any Syrian family to prove the identity of their newly born children and provide accredited parental links when eventually returning to Syria through official borders. Moreover, the MoSA expert reiterated that: "Unless the crisis ends. People [Syrians] will not go back there, and these people [non-registered Syrian children] do not exist," making it a double tragedy.

\subsection{Political Participation}

Structural hierarchies exclude women have from the top and sensitive political and judicial positions, such as the Constitutional Council and the Supreme Judicial Council. ${ }^{442}$ Men occupy the highest positions of public administration. At the level of the executive branch, there is a total absence of women ministers in Lebanon. ${ }^{443}$ One comprehensive strategy to address gender discrimination and promote gender equality is to increase women's political participation not because they can and should have the opportunity to do whatever male politicians do, but because excluding the voices outside of the gendered structural frameworks will produce limited knowledge and harmful practices. ${ }^{444}$ Research shows that only $3 \%$ of Lebanon's parliament members are female, most of whom are either the daughters,

${ }^{441}$ Ibid.

${ }^{442}$ Marguerite Helou, “Women's Political Participation In Lebanon: Gaps In Research And Approaches,” AlRaida Journal (2014): 74-84.

${ }^{443}$ Ibid.

${ }^{444}$ Marguerite Helou, "Lebanese Women and Politics: A Comparison Between Two Field Studies," Al-Raida Journal, (2001), 33-40. 
wives, or sisters of a renowned male politician. Their presence is the mere reflection of the political parties of their male counterparts who are either dead, assassinated, or cannot run for office themselves, the women legislators having little to no agency in the decision-making process. In fact, none of the female politicians actively ameliorated women's legal position in Lebanon while serving on parliamentary committees. The latest vow by the male Minister of Women's Affairs was to include a $30 \%$ quota for the last parliamentary election, a vow that tanked when only six women out of the 128 members won the 2017 parliamentary elections. ${ }^{445}$ The slight increase in female political officials does not reveal a positive change in the view of women's role, abilities, and status within Lebanese society. In fact, these female elites' arrival to parliamentary seats can be considered consecration of patriarchal electoral tradition rather than an indicator of transformation. ${ }^{446}$ The six female voices elected are not only part of the existing patriarchal institutions, but they also come from an elitist upper class, distinct from the vast majority of Lebanese women whose experiences and insecurities differ in practice. Consequently, their attention to fellow Syrian women residing in Lebanon can only project their fellow male politicians' homogenized stand towards the gendered

445 “Lebanon Elects Six Women To Parliament.” The Daily Star, (May 09, 2018): http://www.dailystar.com.lb /News/Lebanon-Elections/2018/May-09/448633-lebanon-elects-six-women-to-parliament.ashx

${ }^{446}$ Marguerite Helou, "Lebanese Women And Politics: A Comparison Between Two Field Studies," Al-Raida Journal (2001), 33-40. 
burden that all Syrians pose, objectifying Syrian women refugees with discriminatory practices.

\section{Analytical Implications}

This chapter provided the background of geopolitical and social attitudes toward Syrian refugees by highlighting important critical junctures (the end of Lebanese Civil War in 1990; the assassination of Prime Minister Rafic Hariri in 2005; the start of the Syrian civil war in 2011; the Syrian refugee drastic influx in Lebanon in 2014) in the Lebanese-Syrian relationship. This method builds from Lene Hansen's theoretical framework of exploring how and why specific issues, refugeeism, and subjects, Syrians, are constructed as a security threat to Lebanon's survival, paving the way for local governmental agencies to prioritize exclusionary ad hoc refugee policy practices that silence or even aggravate alternative threats being faced. While exploring the official Lebanese sensitivities toward the term "refugee," and published attitudes toward Syrians residing in Lebanon, this section analyzed the influence of Lebanese collective memory on the subjectivity of official Lebanese statements and practices of constructing perceived Syrian security threats. Even though several Sunni communities within Lebanon asymmetrically welcomed fellow Syrians Sunnis within, this chapter highlighted the (en)gendered concept of security through state sovereignty, where exclusionary practices — such as visa restrictions and border control, no camp policy, and curfews and checkpoints - explicitly and/or implicitly homogenize diverse groups of Syrians as another form of occupying threat. Accordingly, the hostile sentiments and 
attitudes towards Syrian refugee (in)security, translated into a range of ad hoc security mechanisms reproducing gender hierarchies and hegemonies between the Syrian refugees and Lebanese communities asymmetrically.

It is imperative for this study to take into consideration the intersectional power hierarchies and the way they asymmetrically (re)shape most Lebanese sectarian communities' political, cultural, religious, socioeconomic, attitudes to hosting Syrian refugees. The study finds that the predominantly Syrian refugees are homogenized, perceived as one masculine sectarian and/or economic threat to a big part of Lebanon's public, troubling the confessional consociationalism system of power-sharing that already breeds a lack of trust in the patriarchal relations that persist in both Lebanese societies and the political realm. ${ }^{447}$ With the Sunni ISIS faction threatening the northern Lebanese- Syrian border, the prospects of a spillover effect across Lebanon increased, especially in Christian and Shiite areas. In that respect, sectarianism plays an important role when exploring communities' struggle with socio-economic degradation. The study finds that the densely populated Sunni areas in Lebanon are subject to economic devastation and acute radicalization and extremism. ${ }^{448}$ Most notably, in the heavily Sunni-populated Ain el Helweh refugee camp in Sidon, terrorist cells mobilized and run by Bilal Badr,

\footnotetext{
${ }^{447}$ Marguerite, Helou. "Lebanese Women And Politics: A Comparison Between Two Field Studies." Al-Raida Journal. (2001), 33-40.

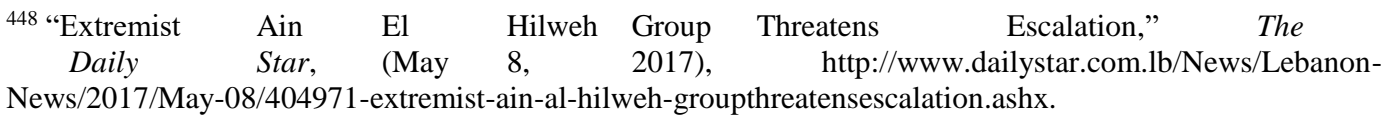


engaged in sporadic clashes with the Lebanese army and were involved in several terrorist activities across the country. ${ }^{449}$ As a reaction to terrorist Sunni turbulence, Lebanese Army Forces and General Security began issuing laws to evict and relocate some informal settlements, prohibiting any camp formation without prior official written consent. ${ }^{450}$

These types of practices, in turn, explain Lebanese measures leading to justified exceptional mechanisms of Syrian refugee deterrence with counterproductive consequences. We find cases when Lebanese government officials provided certain antagonistic non-Sunni Lebanese villages with buses to gather the unwelcome Syrian illegal threats there, sending the "unwanted" back to Syrian villages near the border to secure and preserve their communities' sectarian identity. ${ }^{451}$ The Lebanese invisibility of the majority of the "unwanted" Syrians women would generalize them all as a security threat requesting to send them all back to the same country that they, not long ago, suffered from his prolonged occupation of thirty years.

At the same time, gendered insecurities often involve an intimate interlinkage between the subject's intersectional identity, which rarely (re)produces

\footnotetext{
449 Ibid.

450 "Syrian Refugees In Lebanon," Syrian Civic Platform, (September 29, 2017), http://www.scplatform.net/en/syrianrefugees-in-lebanon/.

451 “A Convoy Of 300 Syrian Displaced Returned From The Town Of Arsal To The Syrian Town Isal AlWard”, AnNahar, (July 12, 2017), https://www.annahar.com/article/617319F.
} 
collective, selfcontained referential objects. ${ }^{452}$ Even though Syrian women and children's identities and agencies disappear in public discourses under one abstract number of a million and some Syrian intruders, posing a burden and threat to Lebanon's stability, Syrian women refugees are not isolated from all types of structural and relational insecurities. In fact, systemic discrimination against women in general within Lebanese polity create a double tragedy for the majority of Syrian refugees (women). Those domestic regulations and security practices possess a co-constitutive structural power of silencing and structurally objectifying Syrian women's insecurities. Due to the general perception that women hold a peripheral role in crisis situations, legal and economic strife, gender-based violence (GBV), and psychosocial scarring are some of the many insecurities that Syrian refugee women endure and brave to survive their new realities, which will be examined in Chapter V.

\footnotetext{
${ }^{452}$ Lene Hansen. "The Little Mermaid's Silent Security Dilemma And The Absence Of Gender In The Copenhagen School," Millennium 29, no. 2 (2000): 285-306.
} 


\section{V. (EN)GENDERING LEBANON CRISIS RESPONSE PLAN(S)}

This section explores the Lebanese government and UNHCR's level of coordination and cooperation in assessing and mediating the translation of refugee (in)security norms within the country. Contextual dynamics, tension, and resistance shape and are shaped by specific response plans between collaborating political institutions with distinct visions and goals of the Syrian refugee crisis in Lebanon. According to Dennis Wiedman, culture is a changing dynamic process that emanates from the various norms and values of interacting groups within a strategic plan. ${ }^{453}$ When interactions are initiated, a management culture surfaces, stimulating predictable practices that (in)directly impact stakeholders' interests and interactions. ${ }^{454}$ Accordingly, a longitudinal cultural theme analysis method highlights the norms and values that shape interacting agencies with varying interests competing over which policies are to be prioritized and how. A closer look into the evolution of the crisis response plans broadens our knowledge of how refugee management plans learn, adapt or adjust to new challenges and rapidly changing circumstances that force the incorporation, translation, and transformation of response strategies and target populations. Based on this line of thought, the cultural theme longitudinal analysis of the Lebanon Crisis Response

\footnotetext{
${ }^{453}$ Dennis Wiedman and Iveris L. Martinez, "Organizational Culture Theme Theory And Analysis Of Strategic Planning for A New Medical School,” Human Organization 76, no. 3 (2017). 264-274

${ }^{454}$ Ibid.
} 
Plan (LCRP) offers an empirical way of analyzing thematic changes within crisis response plans that (in)directly affect refugee management practices in Lebanon.

Therefore, the chapter first looks at the general background of the creation and evolution of the Syrian crisis response plans. Secondly, the chapter provides a thematic qualitative analysis of the cultural themes and patterns of the LCRP documents. It also highlights the evolution of specific cultural themes of the deteriorating situation, while underlining response strategies for how to manage the refugee crisis in Lebanon. Thirdly, the chapter analyzes the results of the longitudinal changes, highlighting the various sites of norm constructions, (re)definitions, and contestations. ${ }^{455}$ Finally, the chapter evaluates the "Operational," "Continuous," "Elaborated," “Transforming," "Diminishing," and "New" themes that emerged via the analysis. The cultural theme longitudinal analysis of the LCRP thus demonstrates the centrality of power politics and cultural influences in (re)shaping organizational culture change and crisis response plans.

\section{General Background:}

As elaborated in Chapter IV, 2014 saw a critical shift in the Lebanese paradigm, in which an extreme form of politicization of what became a Syrian refugee crisis enabled the Lebanese government and its organizations to push for specific policies, prioritizing security programs over others. In the name of national security and refugee protection, customized strategic plans emerged, setting a direction for

\footnotetext{
455 Susanne Zwingel, "How Do Norms Travel? Theorizing International Women's Rights In Transnational Perspective,” International Studies Quarterly 56, no. 1 (2012): 115-129.
} 
crisis management. By theoretically devising shared objectives and responsibilities, a Crisis Response Plan was first published on December 19, 2014 between the Lebanese government and its international and national partners, providing a general guide for the response to the Syrian refugee influx into Lebanon. However, in practice, as one expert from the UNHCR stated, it is done with the government; “ it is their plan." ${ }^{456}$ The initial two-year plan-2015-2016 aimed at identifying a range of short-term strategie and aid assistance to specific groups with targeted approaches, while boosting stabilization in Lebanon. Due to the temporal and spatial expansion of the Syrian crisis, rapid changes within the national and international context pushed for a revised plan aiming to adapt and (en)gender new local realities. Therefore, based on lessons learned, the initial LCRP laid the groundwork of a new elaborated version in 2017.457

Both response plans aim to tackle challenges holistically by delivering various intervention measures for reinforcing a humanitarian response and stabilizing the refugee crisis. However, as the UNHCR expert stated:

"Initially, there was a plan devised that was a pure refugee response plan. Obviously, [the] UN [was] taking the lead because of our mandate for refugees[...] as the crisis unfolded or the impact of Lebanon unfolded, and that numbers swelled, then the plan also became broader in scope, and it became the LCRP in 2014 if I am not mistaken. So we have been really involved, you know,

\footnotetext{
${ }^{456}$ UNHCR Expert Interview with author, (May 18, 2017).

457 “Government Of Lebanon And UNHCR, Lebanon Crisis Response Plan 2015-2016." UNHCR Portal (2015), 1, https://data2.unhcr.org/en/documents/download/44245.
} 
from the beginning, in the setup of it, in the conceptualization of it. From a refugee response plan to a broader plan that tries to assist vulnerable Lebanese and tries to build the institution and look at long term[..] Later on, as I said, it shifted. So, it went from pure humanitarian, to also integrated components of resilience[..] So this is why this year the LCRP is a four-year plan as well, to have a longer term in mind you know?"458

According to this statement, when looking closely at the two versions of the "same" crisis response plan, one would notice that the first was a short-phased twoyear plan (2015-2016), while the subsequent one is a medium four-year version (2017-2020). In fact, the second edition articulates an expanded long-term framework for assistance and partnerships that seek to ensure stabilization and progress towards sustainable development strategies, while maintaining an integrated humanitarian response through what is defined as "targeted assistance."

Analyzing the major themes longitudinally in both LCRP documents yields further insights into how strategic plans emerge, are elaborated, change, and are transformed based on their original intentions, thus reflecting contextual variances. ${ }^{459}$ It is crucial to note that both LCRPs constitute Lebanon's part of a greater 2015 Regional Refugee \& Resilience Plan, better known as the "3RP" a coherent regional strategy developed under the leadership of state authorities with

\footnotetext{
${ }^{458}$ UNHCR Expert interview with author, May 18, 2017.

${ }^{459}$ Dennis Wiedman and Iveris L. Martinez, "Organizational Culture Theme Theory And Analysis Of Strategic Planning For A New Medical School,” Human Organization 76, no. 3 (2017): 266.
} 
support from the UN and NGOs with the aim of providing an effective and coordinated response to the Syrian refugee crisis in the region. The $3 \mathrm{RP}$ process produced an overarching plan for the coordination, monitoring, and evaluation framework at a regional level of the immediate vulnerabilities and the mechanisms to tackle humanitarian aid, protection, and assistance throughout the MENA region. It focused primarily on Syria's neighboring host countries affected by the increasing refugee influx such as Lebanon, Turkey, Jordan, Iraq, and Egypt.

The Lebanese chapter of the 3RP grounded Lebanon's levels of commitment to the refugee protection regime. It determined, under the leadership of the national government, all aspects of humanitarian assistance provided to the most vulnerable groups who have been (in)directly affected by the plight of the Syrian war in Lebanon. Moreover, it is set to support all forms of progress towards sustainable long-term development plans and strategies, to alleviate human suffering and improve the overall quality of life of the plan's "beneficiaries." Numerous cooperation agreements complement the LCRP, such as the UN Strategic Framework, the World Bank Country Partnership, and the EU-Lebanon Partnership among many. The LCRP is also aligned with the strategies of the Lebanese government to be "neither a country of asylum nor a final destination for refugees, let alone a country of resettlement." ${ }^{461}$ At the same time, the LCRP seems to also be in compliance with the United Nations Strategic Framework (UNSF),

\footnotetext{
${ }^{460}$ Government of Lebanon and UNHCR, Lebanon Crisis Response Plan 2015-2016 (2015),14.

${ }^{461}$ Government of Lebanon and the United Nations, “Lebanon Crisis Response Plan 2015-2016” (2015),4.
} 
which provides the overall vision of the UN's engagement within Lebanese territories. $^{462}$

Both LCRP versions delineate the interplay and limbo between state-centric policy interests and international humanitarian values and principles. This latter could be best illustrated by looking into the LCRP vocabulary, as according to the UN, the forced migrants from Syria, characterized as "refugees," are eligible to enjoy international protective measures. However, the Lebanese government identifies all Syrian citizens who entered Lebanon after March 2011 as temporarily “displaced" individuals who must be subjected to Lebanese sovereign laws and jurisdiction. As a result, the LCRP has identified all people who have fled Syria and are unable to return as either "displaced Syrians," "persons displaced from Syria" or "persons registered as de facto refugees by UNHCR." 463

The fact that the LCRP does not recognize these masses as refugees with universally acknowledged rights exposes the gendered power struggle between the national government and the UNHCR in the clash of interests in deciding on legal status terminologies. Lebanese authorities discriminatorily label Syrians as "displaced" in an attempt to shield Lebanon from any potential obligations and responsibilities towards these homogenized refugee communities. In contrast, the UNHCR, with limited authority over domestic decisions, kept the categorical label of a "person registered as a refugee" in order to fit its humanitarian programs.

\footnotetext{
${ }^{462}$ Government of Lebanon and the United Nations, “Lebanon Crisis Response Plan 2017-2020” (2017), 20. ${ }^{463}$ Ibid, 4.
} 
LCRP 2015-2016

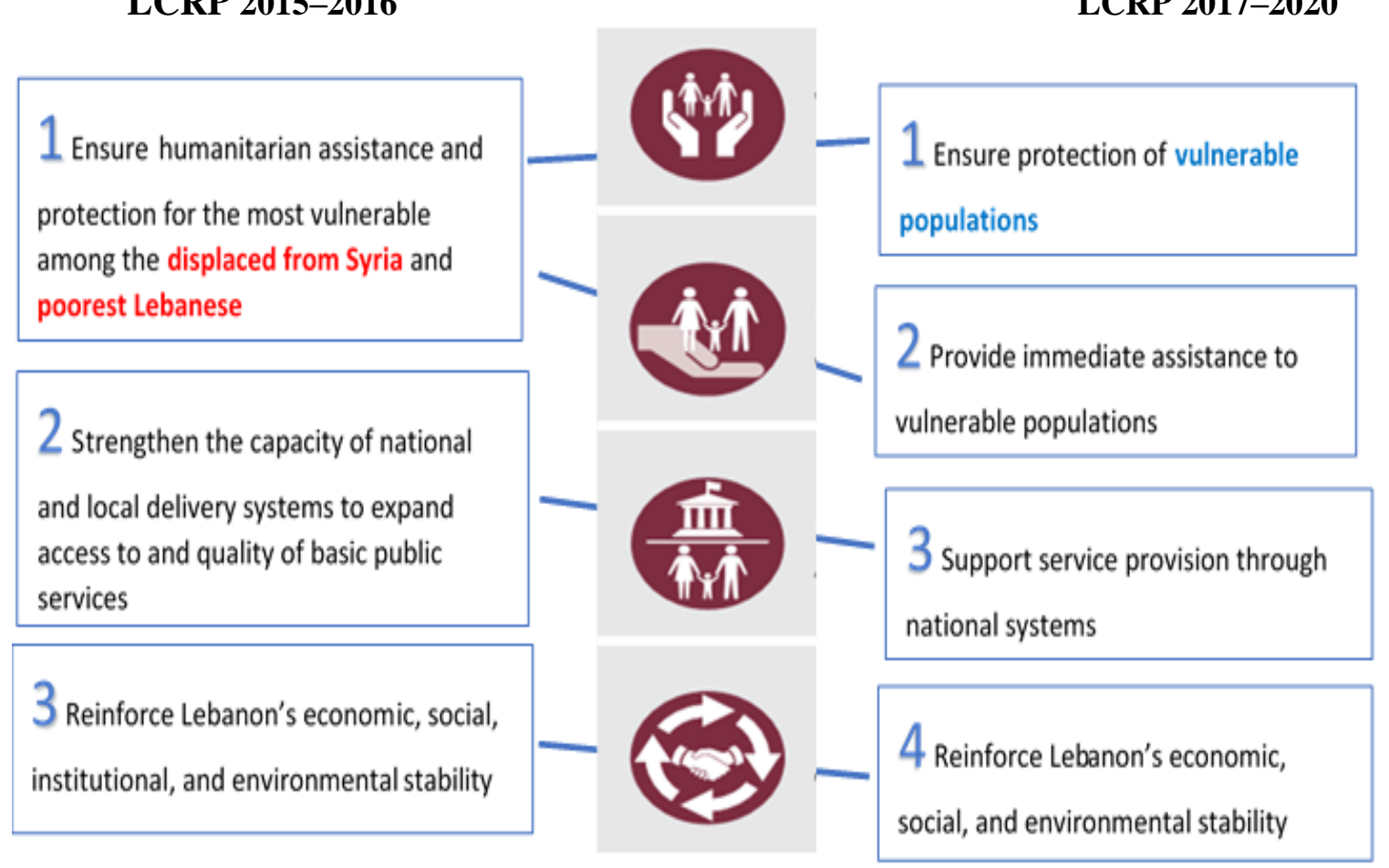

Figure 6. Comparative Figure of Both LCRPS'Response Strategies strategy as it encompasses diverse local vulnerable groups apart from the Syrian refugee communities. In fact, the first LCRP version included both 1.5 million "vulnerable Lebanese" and 1.5 million "displaced Syrians", attempting to expand the targeted vulnerable population in a 50-50 approach to burden sharing. ${ }^{464}$ However, as highlighted in the figure above, the Lebanese decision-making 
authorities imposed an organizational change to the original UNHCR mandate by including a wider range of "vulnerable populations" in the second version. This vague grouping of vulnerable population could cover other vulnerable groups of Iraqis, Somalis, and most importantly, the poor government estimate of 300,000 pre-existing Palestine refugees residing in Lebanon. ${ }^{465}$ Still, a recent "National Population and Housing Census of Palestinian Camps and Gatherings in Lebanon 2017" estimates the real number of Palestinian refugees in Lebanon is less of half of what Lebanese authorities claim. ${ }^{466}$ This vagueness of aid policy requests creates room for opportunistic divergent political groups to emphasize specific agendas and numbers of people, having no direct connection with the Syrian refugee crisis, making the most of the gendered "vulnerable populations" under the umbrella of humanitarian aid.

The 2015 version of the LCRP was a comprehensive response plan comprised of 77 various national and international organizations set to "respond to the specific needs of Lebanon and vulnerable populations" while the conflict in Syria continues. ${ }^{467}$ Based on Figure above, the 2015-16 LCRP's objective can be summarized into three main objectives: firstly, "ensure humanitarian assistance and protection" for displaced Syrians and vulnerable Lebanese constituents. Secondly,

\footnotetext{
${ }^{465}$ Ibid, 11, 48.

${ }^{466}$ Monika Borgmann and Lokman Slim, "Fewer Refugees More Refugeeism," UMAM D\&R Documentation and Research. (2018), https://umam-dr.org/en/home/projects/14/advance-contents/188/fewer-refugees-morerefugeeism.

${ }^{467}$ Government of Lebanon and UNHCR, Lebanon Crisis Response Plan 2015-2016 (2015), 5.
} 
"strengthen the capacities of national and local delivering systems." 468 Thirdly, reinforce national socio-economic, institutional stability.

By the end of 2016, the gradual worsening of opportunities for livelihood, the increased indebtedness and exacerbated negative coping mechanisms, as well as the continuation of the humanitarian situation for the refugee population, demanded the LCRP proposal in 2017 to further elaborate refugee security measures into four strategic objectives with the partnership of now $104 \mathrm{UN}$ and NGO partners. ${ }^{469}$ First, the second plan's goal became to ensure the protection of the now "vulnerable populations" access to laws and regulations, while anticipating the displaced from Syria's repatriation as a durable solution once the conditions allow for a safe return. Second, the LCRP 2017-2020 targeted immediate aid assistance to vulnerable populations living in substandard dwellings. Third, it aimed to support service provision by empowering national systems to provide adequate water, hygiene, health care, energy, and child education among many ${ }^{470}$ Fourth, it planned for the reinforcement of Lebanon's economic, social, and environmental stability that would expand livelihood opportunities and local resilience. These changes, even if subtle, show the complex dynamics between different agentic norm-entrepreneurs who were able to elaborate a short-term plan that had a relatively limited role and objectives to a more mature version with a

\footnotetext{
${ }^{468}$ Ibid.

${ }^{469}$ Government of Lebanon and UNHCR, Lebanon Crisis Response Plan 2017-2020 (2017), 15.

${ }^{470}$ Ibid.
} 
broader and more sustainable focus. It is this change that the following section focuses on, as it happened throughout two years and was affected by many dynamic factors.

\section{Longitudinal Cultural Theme Analysis Results}

For discussion purposes, the results of this research are displayed in two consecutive and interrelated sections. The content longitudinal theme analysis constitutes the first part of this section to reflect and compare the frequently used themes in the two time periods. However, producing a quantitative analysis of qualitative data, coded into explicit categories, tends to rely upon reductionism as it reduces the irreducibly complex constitutive mechanisms and their relationships. Subsequently, the second part of this chapter goes more in-depth by triangulating the findings within both plans with complementing evidence from primary news sources and expert interviews in order to develop a deeper understanding of the longitudinal theme analysis and situate relevant changes within contextual dynamics. 
2.1 Content Analysis.

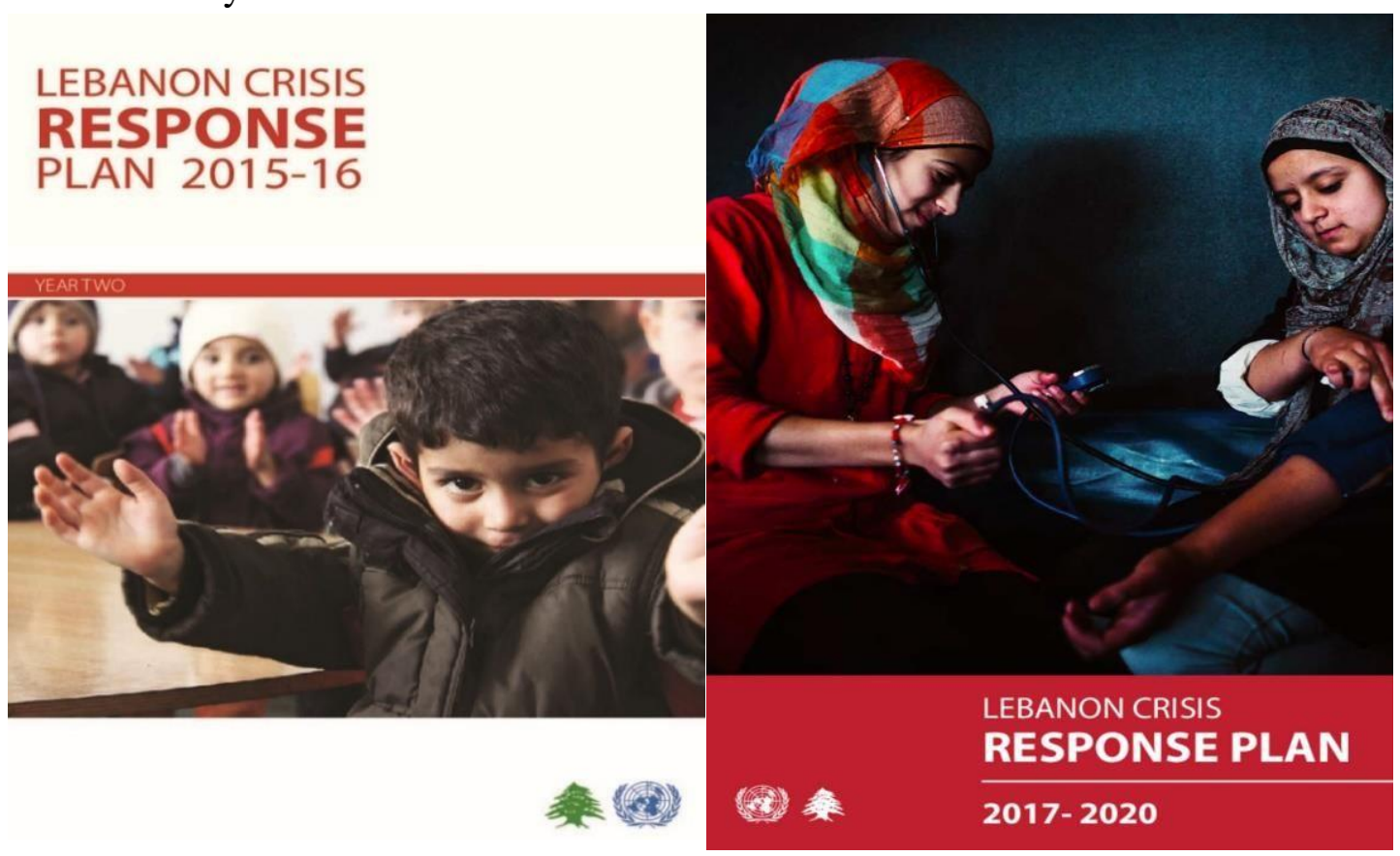

Figure 7. Cover images of Lebanon Crisis Response Plans

At first sight, the LCRP versions seem similar, tightly focused on proposing humanitarian assistance and protection to vulnerable populations, while at the same time targeting support for the Lebanese government in order to mitigate the effects of the Syria crisis. From the above cover images of the Lebanese Crisis Response Plans, we find both images of hope and resilience with no Syrian man present. Interestingly, these visual techniques do not portray the typical powerless, voiceless, helpless Syrian women and children as objects of humanitarian compassion that counterintuitively humiliate refugees but mobilize public support and gather more funds. Still, both feminization of women and children plays a vital role in the dialogical representation of Syrian refugees, where women and children are perceived as a lesser threat than the absent men, who are still under the scrutiny 
of being an imminent menace and less likely to entice funds. Both images seem to silence the diversity within the "vulnerable populations" they aim to target.

Moreover, the images that both plans portray do not help the targeted audience to understand the Syrian refugee crisis situation to respond closely. The Syrian situation in Lebanon is far from one child opening his arms in what looks like a classroom, nor two stereotyped women who seem to be comfortable, depicted as doctor and patient in what seems to be an safe indoor setting. The million and some Syrians residing in Lebanon challenge this view of a helpless child requesting a hug, or an optimistic woman working on a fellow woman in the field of medicine. In reality, most Syrians present in Lebanon and "vulnerable populations" are far from these portrayals. We find that the majority of Syrian children do not attend school, forced either to beg on the street or work in fields not by choice but to help their families pay rent and make ends meet. In addition, Syrian women are still legally unable to practice work, perhaps braving the huge risks of escaping Syria and oppressions in a neighboring country that come in every way, shape, or form. This visual construction contributes to the myth of a refugee identity, in which female refugees and children are portrayed as innocent, whereas men are absent, losing their identity status as productive members of the Lebanese community.

On another note, the exploratory coding phase, which focused on a word frequency query, enriches the study, through recording recurrent terms in both documents separately, highlighting the main common themes. This exploratory approach provides a visual comparison of the two texts. Such coding produced word clouds that portray, through quantitative ranking, the major themes within the 
treated document. In this respect, Figure 8 shows the word-cloud comparison of the 2015-2016 and 2017-2020 LCRP documents, in which the most frequent words are highlighted in the middle of the figure with larger fonts. From the first read, one notices that there is no considerable change in the organizational themes of both LCRPs. In both plans, the most frequent word was "Lebanon" with one hundred and seventy-two occurrences in the 2015-2016 plan versus ninety-three in 20172020. Nevertheless, when looking closely, the major secondary themes within each cloud seem to differ in context slightly.

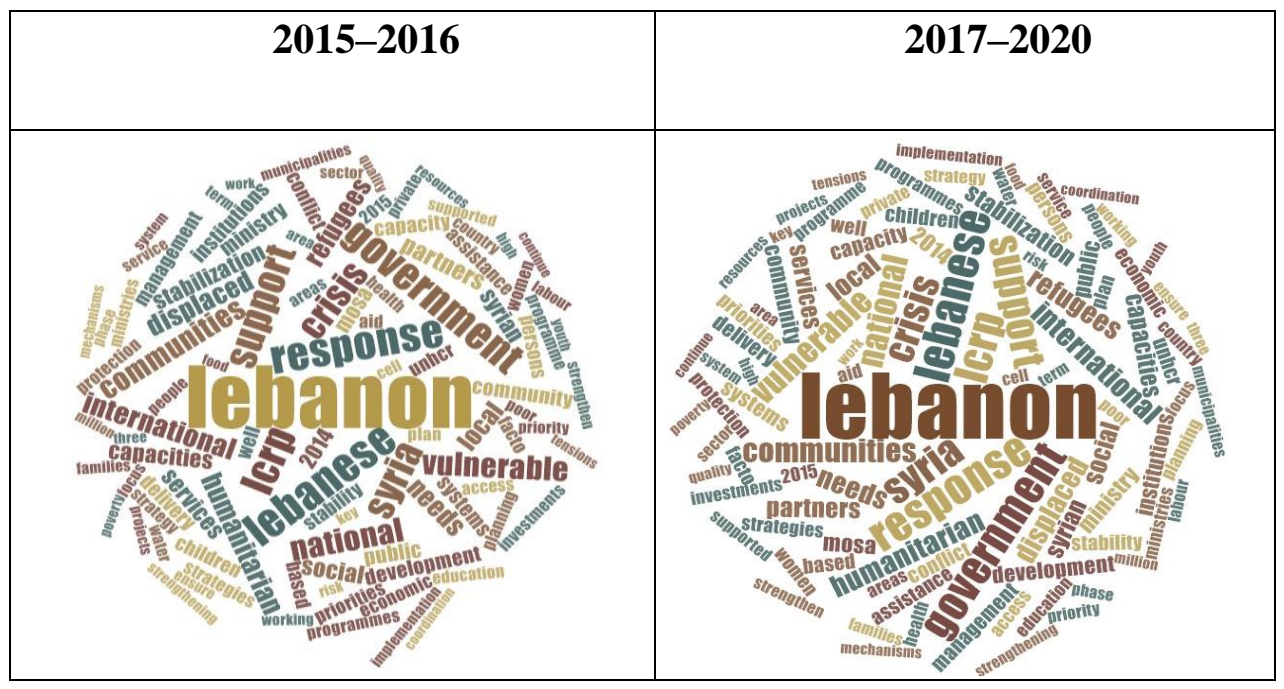

Figure 8. Word cloud comparison of most frequent words

In general, the top ten most frequent words in the 2015-2016 plan were "Lebanon," "Lebanese," "Response," "Government," "LCRP," "Support," "Syria," "Crisis," "National," and "Vulnerable." In the 2017-2020 LCRP document, the top ten most frequent words were "Lebanon," "LCRP," "Displaced," "Vulnerable," "Response," "Lebanese," "Needs," "Syria," "Crisis," and "Humanitarian." A meaningful phrase from the top mentioned words would be "Lebanon Crisis Response Plan" mentioned in both documents. 
Meanwhile, the word "refugee" diminished in count in the second version of the LCRP from fifty-four occurrences to thirty-three in the 2017-2020 crisis response plan. This decrease could be explained by the shift in the local perception of Syrians residing in Lebanon from "displaced" ${ }^{471}$ individuals who would soon go back to Syria — to long-term burden of "temporarily displaced individuals" 472 whose residence remains unclear- pressuring local emphasis on Syrians being "temporary displaced" in the second plan rather than long-term de facto refugees. The domestic wariness of Syrians becoming permanently resettled in Lebanon, fully integrated into Lebanese communities as potentially naturalized Lebanese citizens, pushed Lebanese authorities to increase its call for the viability of Syrians residents to return to "safe zones" within their homeland. ${ }^{473}$ The general resentment towards the Syrian presence in Lebanon would thus explain the official Lebanese calls for returning Syrian refugees to "safe zones" in Syria, even before a final political settlement is reached to end the civil war there. ${ }^{474}$ These official calls would justify a critical shift within the unequal power dynamics between both organizations.

Accordingly, the qualitative comparison of both crisis response plans provided subtle but interesting variations that highlighted the shift in response

\footnotetext{
${ }^{471}$ Government of Lebanon and UNHCR, Lebanon Crisis Response Plan 2015-2016 (2015), x.

${ }^{472}$ Government of Lebanon and UNHCR, Lebanon Crisis Response Plan 2017-2021 (2017), 4.

${ }^{473}$ Nour Shawaf and Francesca El Asmar, "We Are Not There Yet: Voices Of Refugees From Syria In Lebanon," OXFAM, (May, 2017), https://d1tn3vj7xz9fdh.cloudfront.net/s3fs-public/file_attachments/rrvoices-syria-lebanonrefugees-protection-310517-en.pdf

${ }^{474}$ Ellen Francis, “Hostility Grows Towards Syrian Refugees In Lebanon,” Reuters, (August 8, 2018).
} 
prioritizations. In the case below, Lebanon made a slight but major change between both plans that would tremendously diminish its commitment to international refugee law. Instead, this small change boosted its sovereign right to regulate the Syrian presence within the country according to its domestic laws and regulations. The qualitative comparison shows that in the 2015 LCRP document Lebanon "considers that it is being subject to a situation of mass influx and reserves the right to take measures aligning with international law and practice in such situations." ${ }^{.475}$ On the other hand, the 2017 LCRP document bears no mention of any alignment with international law nor its practice. Instead, Lebanon reinforced its sovereign right to (en)gender the legal status of Syrians residing within the country by considering that "it is subject to a situation of mass influx. It refers to individuals who fled from Syria into its territory after March 2011 as temporarily displaced individuals and reserves its sovereign right to determine their status according to Lebanese laws and regulations." ${ }^{476}$ This small but impactful claim increases the Lebanese government's upper hand in controlling the major issues in crisis response plan having legal impunity in discriminating the status of residing Syrian. Subsequently, this claim would further complicate the UNHCR's mandate to adequately protecting and assisting what they see as an obvious case of de facto refugees. Also, the volatile nature of international and regional politics enticed this unreceptive Lebanese handling to the now magnified Syrian presence, making

\footnotetext{
${ }^{475}$ Government of Lebanon and UNHCR, Lebanon Crisis Response Plan 2015-2016 (2015), x.

${ }^{476}$ Government of Lebanon and UNHCR, Lebanon Crisis Response Plan 2017-2021 (2017), 4.
} 
room for aggressive gendered behavior towards any unlawful incident that would involve Syrians residing in the country. ${ }^{477}$ As mentioned in the previous chapter, legal status is of the utmost importance to Syrians residing in Lebanon. Having their legal status stripped Syrian de facto refugees are subject to harassment, arrest, and potential deportation amongst many other issues.

Meanwhile, during the expert interview with the UNHCR, one of the two interviewees explained the LCRP funding mechanism stating that:

“Once the 2.75-billion-dollar appeal is made, there is no centralized bank account where that money comes in. We do not have a separate bank account that then gets it dispersed to sectors are partners. We say this is the amount we are asking for, that is broken down per sector of course, but then it is up to the agencies who have expressed an interest in being part of the implementation phase, they have to fundraise to donors, so that is also different. So there is no pool funding mechanism that gears the money, and then a centralized money system that then gets dispersed into sectors. So that is also the difference with other operations." ${ }^{\prime 78}$ That same expert added that:

"the 104 partners that this year said they want to be a part of the LCRP have to go with what they can.[..] They go and fundraise for whatever part they can contribute

\footnotetext{
477 Nabih Bulos, "In Lebanon, A Rape And Murder Galvanize Anti-Syrian Fervor," Los Angeles Times, (October 13, 2017), http://www.latimes.com/world/middleeast/la-fg-lebanon-syria-slaying-2017-story.html.

${ }^{478}$ UNHCR Expert interview with author, (May 18, 2017).
} 
according to the strategy they made together [..] But not controlled by us, because they go bilaterally to donors."

According to this expert, the lack of fund oversight and pledge enforcement measures are not monitored by the UNHCR, fueling a massive funding gap and engendering limited commitment from the Lebanese government's side. ${ }^{479}$ The lack of coordination and local efforts in alleviating Syrian refugees' suffering within the country hindered international financial commitment towards Lebanon's crisis, creating a serious case of donor fatigue. ${ }^{480}$ Also, the minimal transnational efforts of relocating Syrian refugees out of Lebanon further increased local suffering with billions of dollars in funding shortfall occurring. ${ }^{481}$ The MoSA expert interviewee reiterated that:

"Now that you have donor fatigue, we know all the resources are scarce so practically we will not be expecting to receive more funds than we have ever received so far, it is all going in totally different directions, so we have to manage in a better way which will allow us to have more resilience towards the response of the crisis and to shift from the mindset of crisis response towards more of a

${ }^{479}$ Marie McAuliffe, "Lebanon: Struggling On In The Face Of Donor Fatigue," The Interpreter, LOWY Institute, (May 18, 2016), https://www.lowyinstitute.org/the-interpreter/lebanon-struggling-face-donorfatigue.

${ }^{480}$ Jesse Marks, "Pushing Syrian Refugees To Return," Carnegie Middle East Center, March 1, 2018, http://carnegiemec.org/sada/75684.

${ }^{481}$ Ibid. 
developmental response in order to have longterm approach not just acting based on the crisis." 482

Obviously, the Ministry expert's call for a shift in approach is premature. For a country facing socio-economic collapse with an ongoing refugee crisis, donors not honoring their pledges toward the LCRP would provoke severe instability to the continually vulnerable targets who are still in need of the necessary assistance. Consequently, increasing local hostility towards most Syrians residing there would (re)produce a vicious cycle of socio-economic unrest. ${ }^{483}$ Thus, the study shows that the second version of the LCRP incorporated increasing calls for international support and aid appeals, which can be seen in the table below, in order to manage the new realities. As such, the table bellow summarizes the published figures and numbers by both LCRP documents, per sector-of the appealing partners, the financial requirements, the target population, as well as the gender markers - in order to better trace the changes between both plans.

${ }^{482}$ MoSA Expert Interview with author, (June 12, 2017).

${ }^{483}$ Marie McAuliffe, "Lebanon: Struggling On In The Face Of Donor Fatigue," The Interpreter, LOWY Institute, (May 18, 2016), https://www.lowyinstitute.org/the-interpreter/lebanon-struggling-face-donorfatigue. 
Table 2. Comparative Table of the 2015-2016 \& 2017-2020 Appealing Partners in Lebanon Crisis Response Plan ${ }^{484}$

\begin{tabular}{|c|c|c|c|c|c|c|c|c|c|c|c|c|}
\hline & LCRP & $\begin{array}{l}0 \\
0 \\
0 \\
0 \\
0 \\
0 \\
0\end{array}$ & 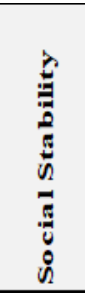 & 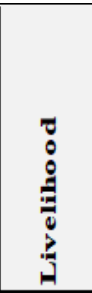 & $\begin{array}{l} \pm \\
\Xi \\
\mathbb{E}\end{array}$ & 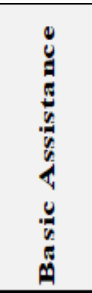 & $\frac{1}{2}$ & $\begin{array}{l}\hat{0} \\
0 \\
0 \\
0 \\
0\end{array}$ & 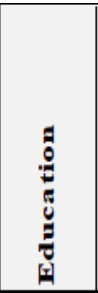 & $\begin{array}{l}0 \\
0 \\
0 \\
0 \\
0 \\
0 \\
\vdots \\
0 \\
0\end{array}$ & $\begin{array}{l}\dot{0} \\
\frac{0}{n}\end{array}$ & $\begin{array}{l}\overrightarrow{\tilde{H}} \\
\stackrel{0}{0} \\
\end{array}$ \\
\hline \multirow{4}{*}{ 2015-201 } & Partners & 33 & 27 & 27 & 24 & 29 & 33 & & 28 & 13 & 23 & 77 \\
\hline & Requirements (millions USS & $\$ 183.00$ & $\$ 157.30$ & $\$ 175.90$ & $\$ 249.20$ & $\$ 288.60$ & $\$ 391.20$ & & S 26.60 & $\$ 447.00$ & $\$ 147.20$ & $2,480.20$ \\
\hline & Target & 2185000 & 242 & 242536 & 204000 & 889500 & 2862291 & & 377000 & 1236976 & 1368255 & 2.9million \\
\hline & Gender Marker & $2 \mathrm{a}$ & 1 & $2 \mathrm{a}$ & 1 & 1 & 1 & & 1 & 1 & $2 \mathrm{a}$ & \\
\hline \multirow{4}{*}{ 2017-202 } & Partners & 61 & 51 & 47 & 43 & 42 & 37 & 13 & 32 & 30 & 28 & 104 \\
\hline & \begin{tabular}{|l} 
Requirements (millions USS \\
\end{tabular} & $\$ 163.80$ & $\$ 123.80$ & $\$ 195.70$ & $\$ 308.00$ & $\$ 571.50$ & $\$ 280.00$ & S 99.20 & $\$ 376.60$ & $\$ 507.20$ & $\$ 128.70$ & $2,750.50$ \\
\hline & Target & 1887502 & 2236299 & 65557 & 1535297 & 1276000 & 1959428 & 1119171 & 543616 & 961388 & 536002 & 2.8million \\
\hline & Gender Marker & $2 a$ & $2 a$ & $2 a$ & $2 a$ & $2 a$ & $2 \mathrm{a}$ & $2 a$ & 1 & $2 a$ & 0 & \\
\hline
\end{tabular}

According to above table, there are two trends: the first one is the overall increase in aid appeals and appealing partners, while the second is the slight decrease oin people targeted. Still, when looking closely, there are certain sectors in which the aid requirements and targeted groups diminished. The fields of protection and shelter mostly decreased in both funding required and people in need, due to the decrease in the overall number of Syrians legally registered as de facto refugees. Consequently, policy plans about terrorist-threat prevention, mainly due to geopolitics and lack of border control, shifted to sustainable initiatives, such as increasing assistance, livelihood, health, and education for residing Syrians post2015. Meanwhile, even though funding and the number of targeted people

\footnotetext{
${ }^{484}$ Government of Lebanon and UNHCR, Lebanon Crisis Response Plan 2015-2016 (2015), 5, Government of Lebanon and UNHCR, Lebanon Crisis Response Plan 2017-2020 (2017), 15.
} 
decreased, we find that the protection sector witnessed a dramatic increase from 33 in the LCRP 2015-2016 to 61 appealing agencies in the LCRP 2017-2020.

Interestingly, even though the targeted population and investment requirements do not reflect that increase, the protection sector gained attention and diversified, doubling the number of partner agencies and becoming one of the main four response strategies within the LCRP 2017-2020. Meanwhile, surprisingly, the appeals decreased from 183 million USD to 163.8 million USD. The amount needed to provide basic rights and access to services in the 2015-2016 plan was 54.4 million USD, while, in the 2017-2020 LCRP document, the number decreased to 31 million USD. Likewise, child protection from violence also witnessed a decrease in aid requirements from 43.4 million USD to 32.1 million USD. ${ }^{485}$ In the meantime, the social stability sector dramatically rose from 27 appealing agencies to 51. Also, the livelihood sector went up from 27 agencies to 47, reflecting the long-term investment in sustainable development programs. The health sector witnessed a rise in aid appeal, reflecting an increase in partner organizations from 24 to 43 , even when the targeted groups decreased from 2,040,00 to 1,535,297 people. Lastly, basic assistance went up from 29 to 42, doubling the aid requirements from 288.60 to 571.50 million USD.

In one interview conducted with a GBV expert at the UNHCR, the interviewee stated that:

${ }^{485}$ Government of Lebanon and UNHCR, Lebanon Crisis Response Plan 2015-2016 (2015), 5. 
"Each sector has as a gender marker. So, any code that is attributed to the sector is based on the international gender marker scoring that indicates to which level the sector is integrating gender analysis and responses that are gender oriented in the plan. So, there is a process, not just aesthetics or cosmetics either way. What happens is that in the planning process, we normally establish a pool of experts, normally this pool is mostly composed of people that are part of the GBV task force and have a gender background." ${ }^{\$ 46}$

According to this expert, the alterations of gender markers within the LCRP documents are the material interpretation, cultural expression, and written evidence of change in guiding future crisis response. With a gender marker included in both plans, it is crucial to note that this critical tool does not only score humanitarian projects on whether they provide enough aid and suport to different groups of men, women, girls, and boys with sustainable outcomes. ${ }^{487}$ It also tracks the level of funding they are getting allocated and if they actually promote greater reflection on gender issues and projects. Generally, during any project design, gender specialists from the Inter-Agency Standing Committee (IASC) support each sector team to code their cluster's projects. ${ }^{488}$ They would then "explore and gain an appreciation of how to integrate gender issues well in their projects." ${ }^{489}$ Theoretically, this

\footnotetext{
${ }^{486}$ UNHCR Expert interview with author, (May 18, 2017).

${ }^{487}$ Check Appendix A.

${ }^{488}$ Check Appendix A.

489 Ibid.
} 
technique would, therefore, benefit from all the feedback they can use to improve each sector's operational plan, implementation and monitoring system. Usually, the IASC provides three markers as a way to strengthen gender-sensitive humanitarian assistance ${ }^{490}$ However, according to the UNHCR's SGBV coordinator:

"We do not have like in Jordan a gender expert in Lebanon, but we have [an] SGBV task force which is acting for this role [...] What we currently have is partially related to gender but more focusing on the GBV. So, Lebanon is one of the countries that is being prioritized for the IASC, the role out of the interagency study committee GBV guidance released back in 2015 which will further enhance the inclusion of risk mitigation measures when it comes to GBV. So, it is a part of the overall gender coverage. It is not fully in terms of gender equality yet, but it covers one aspect of this."

This latter could be seen as one example of how the gender mainstreaming effort, beyond Sexual Gender Based Violence, is not a priority in all ten response sectors of the humanitarian crisis management mission in Lebanon. For the sake of a practical solution, there seems to be a tendency to dismiss or underestimate gender discrimination and inequality, deprioritizing them as secondary issues that do not require urgent attention but instead fall under future development or socialempowerment projects.

As for the gender marking process, the interviewee followed up by saying:

${ }^{490}$ Ibid. See also Government of Lebanon and the United Nations, Lebanon Crisis Response Plan 2017-2020 (2017). 
"What we do is that we work closely with the sectors and the sector-leads. We first discuss with them what are some of the components that they need to reflect their own strategy to make sure that assessments' design, implementation, and reporting are gender oriented and reflect the different dimensions when it comes to women, girls, men, and boys. So, there is the first phase of support and revision of the chapters of the LCRP; including strategy indicators reporting everything. So, we do a thorough revision and then based on that we assign a score. Now what happens is that clearly gender is mainstreamed through the sectors. Sectors differ in nature; in the way they apply their targeting and in the way they apply criteria. There is a difference between basic assistance and shelter. However, all of those have included some gender mainstreaming. So, each sector, in addition to being revised, the strategy gets evaluated from a gender perspective. There are also components, mentioned explicitly in the different mainstreaming efforts, we apply for gender visibility, where they have to explain how concretely they will proceed. We do try to have it not as a standard policy to say. We will look at the different needs, but we do try to reflect that concretely into their own strategies. So, if we know they are selecting a beneficiary through a certain process we would refer to this process and see how it would integrate[..] Establishing the gender marker in the plan formulation phase would be utmost efficient for all parties to question and learn what each initiative comprises of. Also, when all parties review the operations per sectors at the end of each year, the gender marker tool would provide further insights into how to better manage each sector in the next cycle." 
This detailed account of how gender markers come to be established within each sector helps this study understand how and why each marker was given. In that respect, the first marker " 0 " does not reflect any component of the sector response plan. This would mean that the plan risks the unintentional deepening of existing gender inequalities. As for the second marker " 1 ," it includes a gender analysis of identifying the targeted beneficiaries. This would lead to the third marker " $2 \mathrm{a}$ " of creating gender-responsive activities, which paves the way to the fourth marker " $2 b$ " of gender-sensitive outcomes that address diverse needs of vulnerable groups while advancing gender equality. ${ }^{491}$ What was coded in the LCRP 2015-2016 as the gender marker "1" meant that only one of the three components was met, making a limited contribution to gender equality.

Meanwhile, the " $2 a$ " gender marker signifies that a significant step forward was made in including gender analysis in the project's design and some of its activities, creating one or more gender mainstreamed outcomes. Still, the third gender marker " $2 \mathrm{~b}$ " was absent from both plans' evaluations, concluded by the relevant authorities' examination, which means that neither plan advances gender equality nor build gender-specific services. In fact, according to the codes assigned in the gender marker, none of the LCRP policies involved reaches the gender inclusivity required for their successful implementation.

\footnotetext{
${ }^{491}$ Siobhán Foran, Aisling Swaine, and Kate Burns, "Improving The Effectiveness Of Humanitarian Action: Progress In Implementing The Inter-Agency Standing Committee (IASC) Gender Marker," Gender \& Development 20, no. 2 (2012): 233-247.
} 
The comparative table above shows that some improvements were evident in the gender marker analysis or design within most sectors, considering the specific needs of women, girls, boys, and men, especially in SGBV prevention and response services. Positively enough, we find that most response efforts slightly increased their gender marker, showing improvement in including gender-sensitive response initiatives, except in one important sector: "Shelter." Looking closely, the LCRP 2015-2016 document had the shelter sector rated at "2a", while in the 2017-2020 plan, it dropped to 0 . This sharp drop should cause serious alarm for an external viewer who is contemplating funding the crisis response plan in general, and the shelter sector specifically. The only reasonable justification that could be given here is that the collaborating agencies did not properly assess this sector or "shelter" was not a priority that was sought anymore. Still, the LCRP document clearly states in the need assessment section for this sector that only $40 \%$ of the targeted funds were allocated to the shelter assistance, where "only 27 percent of the sector targets outside informal settlements were disproportionately reached." 492 Accordingly, almost $30 \%$ of female-headed households, compared to $15 \%$ of male-headed households, are forced to live in "non-residential spaces, such as garages or workshops, or in temporary, makeshift shelters" that are below standard, structurally dangerous, not appropriate for living conditions, and "inadequate especially for women and girls." 493 This critical example shows the complexity of

\footnotetext{
${ }^{492}$ Government of Lebanon and UNHCR, Lebanon Crisis Response Plan 2017-2020 (2017), 136.

${ }^{493}$ Government of Lebanon and UNHCR, Lebanon Crisis Response Plan 2017-2020 (2017), 137.
} 
the sector's response approach in which some sectors gain more attention to improving the needs and capacities of women, girls, men, and boys, than others deemed as necessary, such as shelter.

All in all, even with the few improvements that have been made, the study still shows that a gender-based analysis was not a priority feature to determine the needs of the different vulnerable groups that the LCRP 2017-2020 document sought to identify. Both plans fell short when prescribing adequate solutions, while continuously stereotyping women as victims, denying their agency. Recognizing the diversity among the vulnerable populations is imperative and needs further exploration. However, it seems that the plans' primary crisis response is still discriminatory, for neither plans seem to focus on advancing gender equality nor target women, girls, boys, and men according to their specific needs.

Still, one should not disregard the sporadic moments when gender differences were clearly acknowledged and targeted groups were clearly described, such as in the case of the protection sector that gained more attention than the shelter sector. Not surprisingly, both sectors' lead at that time in the government's Ministry of Social Affairs (MoSA) was

Dr. Aimee Karam, who holds a doctorate specialized in criminal justice from Walden University, and is currently working as a Child Protection Specialist at UNICEF Beirut. ${ }^{494}$ Still, even if having a leader in the ministry knowledgeable in

${ }^{494}$ Linkedin profile page: https://lb.linkedin.com/in/aimee-karam-ph-d-96760a29. 
gender inclusive urban planning or other related fields, the level of commitment to enhancing gender inclusive response plans could not threaten preexisting system of oppressions established within

Lebanon's confessional system. As seen in the previous chapter, women in Lebanon are expected to have a lesser status than their male counterparts. These women are objectified, heavily marginalized due to intersectional structural inequalities and a discriminatory legal system. That is why genuine gender mainstreaming efforts would take the back seat, depoliticized as administrative, long-term development goals that do not require imminent efforts.

On the one hand, the benevolent state's sole responsibility is to tolerate the problematic "temporary displaced individuals" and grant them securitized conditional asylum. On the other hand, non-governmental partners and altruistic aid-workers reinforce a false gender identity, in their "Needs Overview" section. The study shows that this latter' depiction of a feminized de facto refugee population as oppressed victims with no agency in "need of rescue, protection, assistance, activation, and reform" ${ }^{495}$ through humanitarian protection, assistance, and aid are mostly aimed at acquiring more funds rather than considering these individuals' complex dilemmas as serious issues that need to be tackled instantly through a crisis response plan.

495 Elisabeth Olivius, "Constructing Humanitarian Selves And Refugee Others: Gender Equality And The Global Governance Of Refugees," International Feminist Journal of Politics 18, no. 2 (2016): 270-290. 
While the LCRP commends the amelioration of the policy initiatives within its sustainable development programs, this enhancement is valued but still considered insufficient, not prioritizing enough the need to address gender inequality with clear-cut synergies. While a reasonable goal is to protect most Syrians residing in Lebanon, women, and girls are still disproportionately burdened by restricted access to legal, adequate, and affordable services. In many instances, the LCRP mechanisms that seek to promote de facto Syrian refugees' livelihood goals seem to undermine the gendered barriers to women's employment within the legally approved fields of construction, agribusiness, and sanitation. Consequently, using such approach without tackling the system gender hierarchies within Lebanese polities ends up (in)directly denying Syrian women refugees the fundamental right to find a decent job to procure food, water, and most importantly safety to live in a safe house and feel relatively protected. Given the Lebanese context, the cultural and legal discrimination against women working in mostly remote far from any form of palpable security or highly dense public spaces, high interaction with hostile Lebanese communities impedes their safety from any type of violence, such as sexual abuse, harassment, and exploitation. Most construction work and agribusiness jobs happen in inaccessible areas with a large number of men working in the fields. While cultural barriers impede women from working in sanitation labor, the traditionally all-male staff occupies this line of work that deals with corrupt waste management personnel and harmful and irritated Lebanese 
residents. ${ }^{496}$ In the meantime, the UNHCR practices seem stuck between the tendencies of developing and modernizing the perceived "backward" refugee society by calling for more livelihood initiatives, while, at the same time, no tangible initiative has been shown from their part to redress the harmful state laws and practices that challenge Syrian women's fundamental rights. Accordingly, Syrian female heads of households were forced to adapt and work, mostly informally, in domestic service (22\%) and agricultural labor (55\%), while many others ventured to work in small service businesses, such as clothing stores and restaurants, to provide for their families. ${ }^{497}$ These types of jobs are typically informal, leaving the majority of Syrian female-headed households economically challenged.

Consequently, without a gender-sensitive approach, these Syrian women are further marginalized, vulnerable to all types of violence due to a gendered crisis response plan that only allows three male-dominated low-income industriesconstruction, sanitation, and agribusiness and are destined to fail the majority of Syrian refugees women in providing sustainable refugee protection and livelihood. In effect, how both policy plans addressed the Syrian crisis in Lebanon had profound implications for who benefits from the livelihood programs and who suffers from the lack of gender commitment.

\footnotetext{
496 "VASyR 2017: Vulnerability Assessment of Syrian Refugees in Lebanon," World Food Program, United Nations Children's Fund (UNICEF), and UNHCR, (2016), http://documents.wfp.org/stellent/groups/public/documents/ ena/wfp289533.pdf.

${ }^{497}$ Ibid, 12.
} 
Meanwhile, the study's gender marker analysis demonstrates how gender equality initiatives were mostly used as lip service in a "Needs Overview" section with no power or concrete measures included to address the gendered asymmetries in Syrian refugee situations, (re)producing global hierarchies. As what the Abaad expert stated, the LCRP at the end is a funding appeal. The main target is donors. Accordingly,

"Gender is mainly addressed through the protection sector, but whenever we are doing the plan, like when we are doing each sector, we always have a gender marker. We have what we call the cross-cutting issues, and among those crosscutting issues you have visibility, gender, and I think, maybe, there was environment or another one." ${ }^{498}$

The portrayal of a vulnerable de facto refugee community narrowly focuses on the utility perspective of gender mainstreaming in garnering international support and funds. ${ }^{499}$ The study shows that the LCRP efforts to empower Syrian women and eradicate genderbased violence get complicated under the tradition of the feminized long-term development of women's issues. Without an all-encompassing gender-sensitive livelihood approach these Syrian women are silenced, part of a category of "male" job-seeking Syrian "temporary displaced individuals" who can legally work in only one of three fields: construction, agribusiness, and sanitation. So, the humanitarian crisis response plan failed to address the majority of the

${ }^{498}$ Abaad Expert interview with author, (June 20, 2017).

${ }^{499}$ R. Charli Carpenter, "Women, Children, and Other Vulnerable Groups: Gender, Strategic Frames, and the Protection of Civilians as a Transnational Issue," International Studies Quarterly 49, no. 2 (June, 2005): 295 355. 
Syrian refugee women's insecurities, disregarding the discriminations of the Lebanese patriarchal culture that isolates gender violence under the traditions of feminized "women's issues." 500

For instance, one case, in April 2016, that caught my attention when proposing this dissertation topic to my committee and shocked Lebanon with an unprecedented scandal, highlighting one of many realities of GBV, was the mediaexposed major prostitution and human trafficking rings operating in the country. ${ }^{501}$ In fact, one of these rings was found to have enslaved hundreds of Syrian women for periods of months, and even years, since the onset of the refugee crisis in $2011 .{ }^{502}$ What initially seemed to be a single prostitution ring turned out to be multiple rings, involving hundreds of helpless female victims that had been lured, captured and held against their will at several touristi locations. ${ }^{503}$ Within weeks, several arrests took place, and traffickers and brothel owners, such as in the case of Maurice Geagea, were placed in custody, just to be discharged a few months later..$^{504}$ Despite allegations to the contrary, these human trafficking and prostitution rings enjoyed protection from corrupt politicians and security officers, which allowed

\footnotetext{
${ }^{500}$ Joy L. Chia, "Piercing The Confucian Veil: Lenagan's Implications For East Asia And Human Rights," Am. UJ Gender Soc. Pol'y \& L. 21 (2012): 402.

501 Kareem Shaheen, "Lebanon Sex Trafficking: Syrian Woman Describes Nine-Month Ordeal," The Guardian, (August 1, 2016), https://www.theguardian.com/world/2016/aug/01/lebanon-sex-trafficking-syrianwoman-describes-ninemonth-ordeal.

502 Ibid.

${ }^{503}$ Ashley Gallagher, "Syrian Refugees Are Turning to Prostitution at Super Nightclubs," Vice News, (June 11, 2014), https://news.vice.com/article/syrian-refugees-are-turning-to-prostitution-at-super-nightclubs.

504 "Lebanon: Syrian Women At Risk Of Sex Trafficking," Human Rights Watch, (July 28, 2016), https://www.hrw.org/news/2016/07/28/lebanon-syrian-women-risk-sex-trafficking.
} 
them to escape extreme punitive measures they deserve under the rule of law. When Chez Maurice nightclub was raided, the owner Maurice Haddad already had criminal charges for trafficking women into forced prostitution. The police knew of his criminal background but left him free. ${ }^{505}$ The investigations and media coverage even stopped with the arrest of significant ring operators, failing to address the structural, legal and cultural factors that had permitted the perpetuation of such crimes in the first place.

Several observations are highly relevant in this context. First, all the female victims enslaved and exploited by these rings were Syrian girls and women, with a considerable number of them being under the age of 18 when they were first subjected to this systemic exploitation. ${ }^{506}$ Second, these women fell for human trafficking and prostitution rings in the context of an armed conflict in their country, but the humanitarian regime failed to protect them adequately. They were, in fact, victimized in a neighboring country where they were supposed to enjoy a minimal degree of protection in accordance with international and domestic laws. Third, several hundred of the women who were exploited by these rings were reluctant to seek protection from any state agent or humanitarian agency, even though the mechanisms that protect women against these atrocities were widely publicized. ${ }^{507}$

505 Ibid.

\footnotetext{
506 "Syrian Refugee Women Tell Stories About Sexual Exploitation In Lebanon," Naharnet Newsdesk, (August, 2014), http://www.naharnet.com/stories/ar/141494.

507 The Lebanese Internal Security Forces launched A National Awareness Campaign in 2014 and 2015 To Inform Women About The Availability of Hotline and the mechanisms through which women could seek Protection from Domestic Violence and other Violations.
} 
According to The Guardian interview with Rama, a 24-year-old Syrian sex trafficked woman who escaped with other captives from a local Lebanese brothel where they were held hostage, the deficiencies in Lebanon's human trafficking law co-exist with an already discriminatory prostitution law in the penal code, which treats female victims in prostitution rings as equivalent to their traffickers. Rama, a Syrian woman and a survivor of GBV, initially lost faith in her country when she crossed over to Lebanon. Once in the host country, she then claims to have lost faith in everyone, as she was forced to "have sex on average ten times a day and [was] imprisoned in a decrepit house without even a glimpse of sunlight." ${ }^{\text {"508 }}$ The case of Rama is a good example of how resilient Syrian women survivors were pushed to seek protection under informal networks as they had to go to local offices such as Hezbollah's , a Lebanese paramilitary, and dubious political organizations, rather than reaching out to the police or a renown humanitarian agency. ${ }^{509}$

Still, the shocking exposure of the prostitution rings did not significantly result to alleviating the insecurities that the majority of Syrian women residing in Lebanon face daily. On the contrary, official and non-official statements in the mainstream media and social media mainly focused on condemning the criminal acts, sometimes even faulting the victims for being in that position. Various statements highlighted the fact that Lebanon, as a state and as a nation, was treating

508 Kareem Shaheen, "Lebanon Sex Trafficking: Syrian Woman Describes Nine-Month Ordeal," The Guardian, (August 1, 2016), https://www.theguardian.com/world/2016/aug/01/lebanon-sex-trafficking-syrianwoman-describes-ninemonth-ordeal.

${ }^{509}$ Ibid. 
Syrian refugees in accordance with international standards despite the great burden of hosting a massive population of Syrian refugees. ${ }^{510}$ The entire issue of women's refugee rights and suffering was almost forgotten within weeks after exposing the prostitution rings. In the meantime, the UNHCR condemned such actions, stated that the LCRP plans provide a mechanism for Syrian women survivors to seek posttrauma emergency and life-saving services including medical services, as well as psychosocial, legal, shelter and livelihood support services.

On another note, two visual representations of project maps of the major themes within the LCRP 2015-2016 and 2017-2020 generated by the study are featured below, representing the thematic connections between the different initiatives, targeted groups, and designated targeted approaches in managing the Syrian refugee crisis in Lebanon.

510 “The 2015-16 Lebanon Crisis Response Plan.” UNHCR, (December 15, 2014),
http://www.alnap.org/resource/20702, 


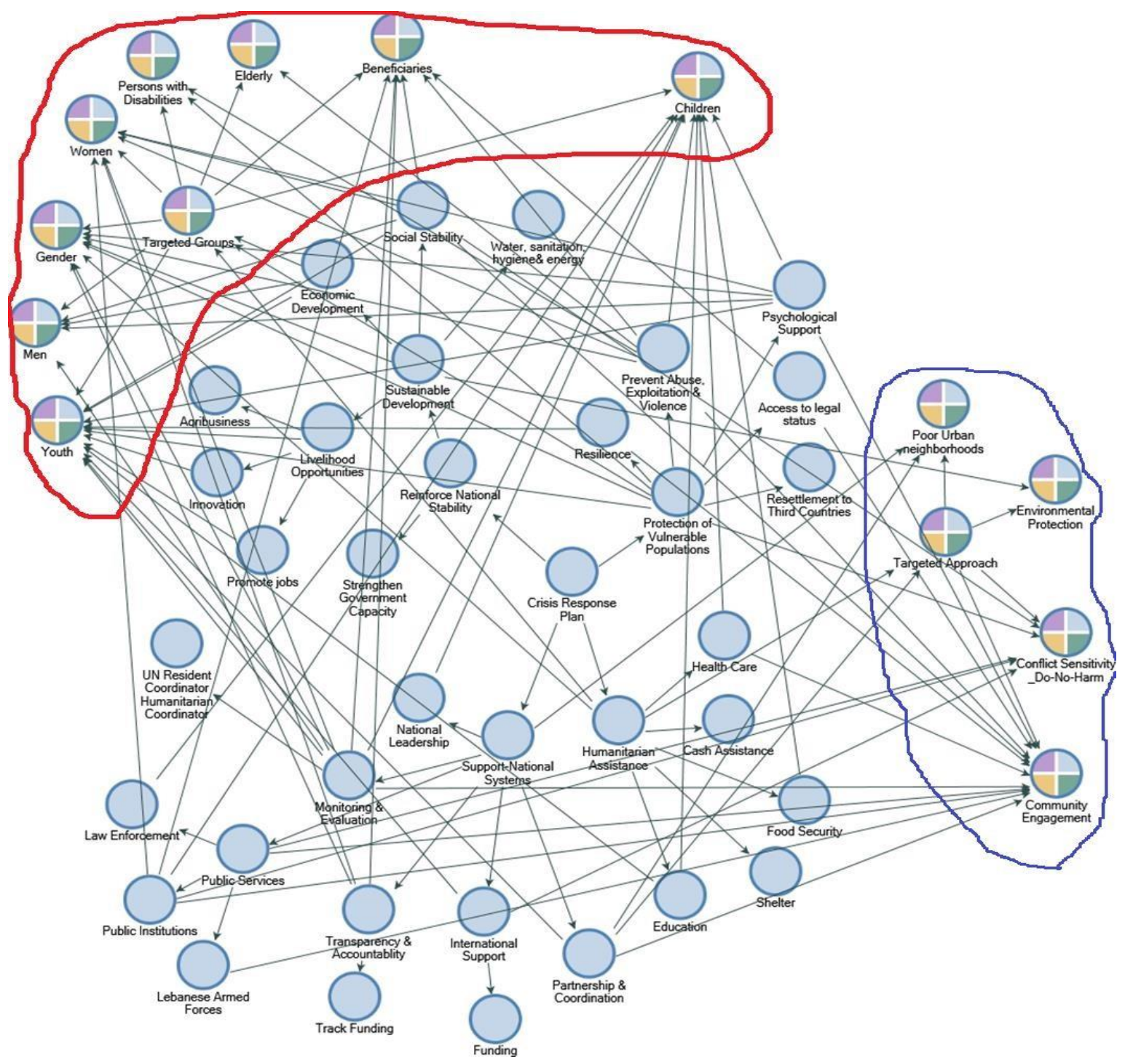

Figure 9. Crisis Response Plan Project Map

In the above Figure, the visual description of Code Mapping provides an overall image of thematical labels that emerged from comparing and sorting the main themes that I discovered within both LCRP documents. The figure documents how a list of selected codes get categorized and interconnect with each other throughout both documents, conceptualizing throughout the content analysis a complex web of interconnected networks. The simple nodes that are not encircled in the center represent the decreed LCRP response strategies to the current refugee crisis that 
Lebanon is facing. The nodes streaked and encircled in red represent the targeted groups that the response plans mentioned across the documents and focus on when proposing ways to respond to the refugee crisis in Lebanon. The nodes encircled in blue represent the type of approaches that the plans stated that they concentrated their efforts on. As for the arrows that flow from one node to another, they represent the thematic connections drawn between different response strategies towards the mentioned targeted groups and approaches. Those connections provide a visual understanding of both plans' focus when strategizing Syrian refugee management. In fact, the arrows provide a visualization of the degree of attention each targeted group got from the sectoral strategies that are supposed to materialize within the respective humanitarian assistance period.

Meanwhile, the below Figure depicts the refugee insecurities project map that both LCRP documents highlight in order to solicit support. 


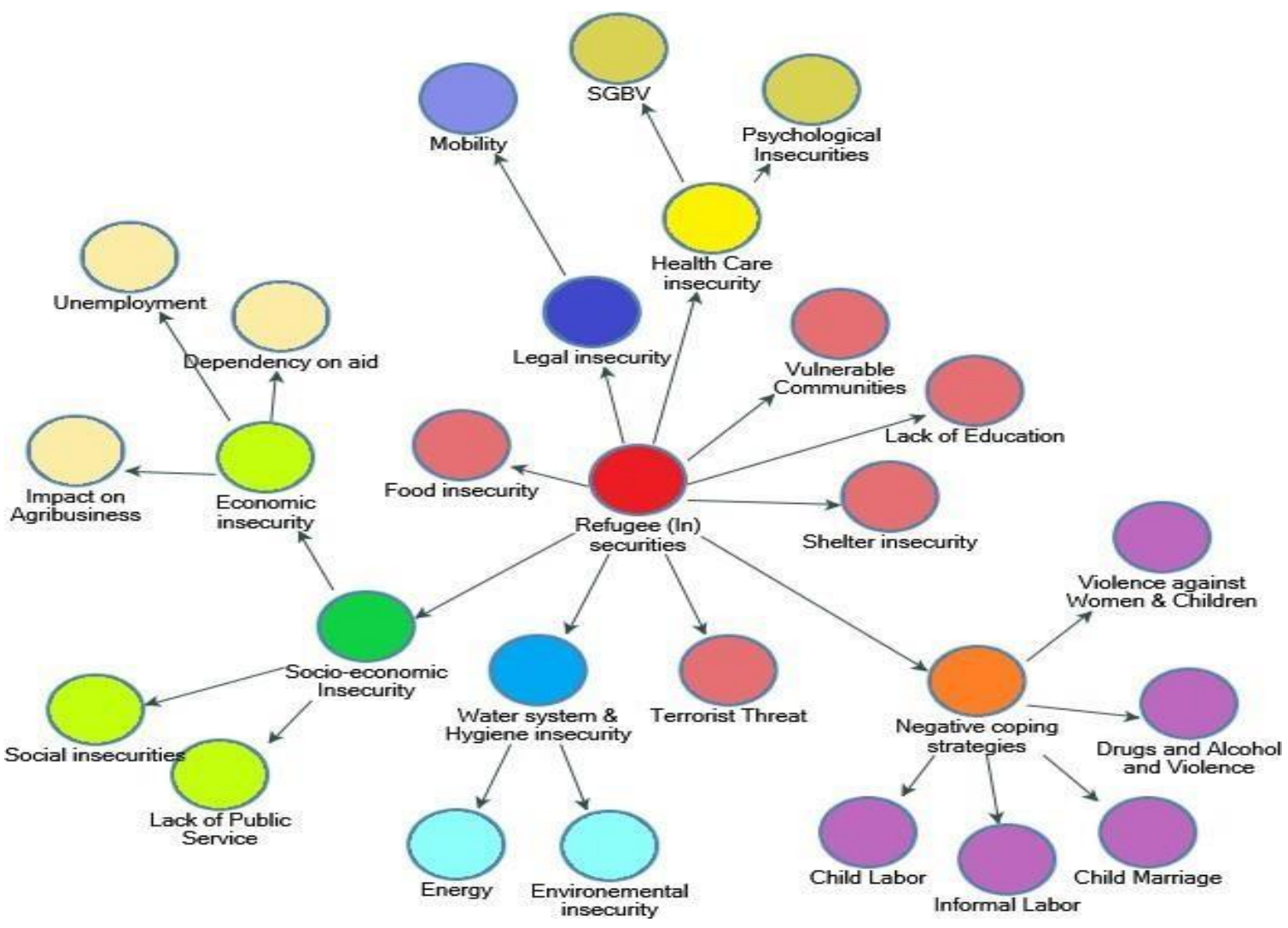

Figure 10. Refugee Insecurities Project Map

Based on both crisis response plans, the nodes in the map above visualize a network diagram of the overall refugee insecurities experienced in Lebanon. The automated network mapping illustrates performance degradation of deep insecurities and declared anxieties, creating a complex image of co-constructing local experiences that Syrian forced migration seems to have exacerbated in the Lebanese context. For the sake of a clearer visualization, the arrows do not represent a linear causeeffect type of image. As in practice, the different nodes are interconnected and affect each other in an interplay of self-reinforcing and co-dependent insecurities that the underprivileged but resilient people in Lebanon are facing through mostly negative coping strategies. 


\subsection{Cultural Theme Longitudinal Analysis}

The 2015-16 LCRP was formulated to tackle the sudden influx of Syrians that Lebanon witnessed after five years of the Syrian crisis. According to LCRP estimates, as of October 2015, Lebanon was hosting over 1.5 million Syrian refugees, from which approximately 1.07 million were recognized and registered by the UNHCR. The plan also declared that it hosted around 42,000 Palestinian refugees from Syria, 270,000 pre-existing Palestinian refugees, and 35,000 Lebanese returning from Syria. ${ }^{511}$ This latter implies that by 2015 , the population of Lebanon rose by 37 percent thereby resulting in one out of every three people in Lebanon being a Syrian. ${ }^{518}$ For that reason, the 2015-2016 LCRP aimed at controlling the refugee crisis by coming up with ways to eliminate challenges facing both the local population and refugees. In the meantime, the increasing number of displaced individuals from Syria to Lebanon amplified local vulnerabilities. ${ }^{512}$ While the international contributions were not sustainable enough-given that they only met half of the required funding-Lebanon witnessed an increase in Syrian refugees reliant on humanitarian assistance. ${ }^{513}$

\footnotetext{
${ }^{511}$ Government of Lebanon and UNHCR, Lebanon Crisis Response Plan 2015-2016 (2015), 3. ${ }^{518}$ Government of Lebanon and UNHCR, Lebanon Crisis Response Plan 2015-2016 (2015), 3.

512 Ibid.

513 "Bou Saab Continued With Lazarene Preparations For The Donor Conference And The IDP Education Plan,” Lebanonfiles Local News, (January 13, 2016), http://www.lebanonfiles.com/news/985407.
} 
3. Triangulation of Themes with Additional Evidence

The following is a table that outlines the continuation, diminishment,

transformation, and change of themes between both LCRP documents.

Table 3. Longitudinal Analysis of Major Cultural Themes From 2015 to 2017

Operational Themes: Structures and personnel required for proper functioning of Plan

National leadership: Supporting national leadership and ownership of the response

Partnership \& Coordination: Mechanisms to coordinate and help systematize assessment processes between different humanitarian partners and also to harmonize data collection and visualization tools.

Transparency and Accountability: Promote transparency and accountability

Monitoring \& Evaluation: Reinforced and objective monitoring and evaluation (M\&E) is critical to improving effectiveness and accountability

Track Funding: Improve tracking of funds

Energy: Increasing the level and quality of electricity supply

Continuous Themes: Clearly and consistently articulated

International Support \& Financing the LCRP: Initiatives funded by the wider international community \& donors

Refugee (In)securities: Deteriorating environmental, socio-economic, health, water, sanitation, and electric capacities

Negative coping Strategies: Resorting to unsustainable and damaging coping mechanisms

Public services: Equitable access to and quality of sustainable public services

Elaborated Themes: Detailed and specific with similar words and meanings

Protection: Aims to strengthen protection services and interventions

Vulnerable communities: The most vulnerable and deprived parts of the country

Livelihood Opportunities: Improve living conditions through job creation, increase market-based skills training and employability, apprenticeships, income-generation opportunities

Agribusiness: Promote sustainable farming and animal management practices

Food insecurity: Malnutrition due to inadequate diets and insanitary conditions

Targeted Assistance: Persons with Disabilities, Youth, Gender

Child Marriage, Labor \& Trafficking: Human rights violation

Violence against Women and Children: Human rights violation

Education: Expanding formal and non-formal education

Shelter: Promote affordable shelter and support for rental-related tenure security

Legal Status: Regularize residency in Lebanon and access to civil registration processes

UN Resident Coordinator/Humanitarian Coordinator:

Resilience: Resources and capacities that are needed to absorb, adapt and transform in the face risks

Transforming Themes: Contemporary words and phrases with similar meanings

Poor Urban Neighborhoods: Urban cadasters in concentrated poverty

Resettlement to Third countries.: Provide persons displaced from Syria humanitarian access to third countries

Diminishing Themes: De-emphasized, or absent

Institutional stability: Strengthening government, municipal, civic and community capacities to promote dialogue

Cash Assistance: Aid program targeting the poorest with cash transfers.

Beneficiaries: Persons who gain or benefit in some way from something 
Terrorist Threat: \& LAF: Militancy menace spreading from Syria provoking LAF and security personnel working to address multiple challenges

Law Enforcement: Enhancing the capacity of Lebanese law enforcement and justice systems

New Themes: Outside of the original themes, meanings, and intentions

Elderly: The accepted minimum chronological age of 65 years

Persons with disabilities: Any person who has a physical or mental impairment that substantially limits one or more major life activities

When explored through "Second Cycle Coding Methods," various considerable changes were introduced in the 2017-20 LCRP. ${ }^{514}$ One such change was the one related to the proposed budget and manner of spending between two plans with the same vision towards almost the same or a less targeted group of people. This change aimed at ensuring there is peace, stability, and security in Lebanon while ensuring that the most vulnerable communities are protected. In fact, the 2015-16 LCRP document proposed a US $\$ 2.14$ billion appeal plan that would be used to offer humanitarian assistance as well as protect a highly vulnerable population of over 3.3 million. ${ }^{515}$ The appeal plan targeted investment in services, institutions, and the general economy in order to reach the most vulnerable populations. On the other hand, the 2017-20 LCRP document proposed a US\$2.8 billion for providing humanitarian assistance to the same number of people in need, 3.3 million, divided into four categories. ${ }^{516}$ The first category is to offer protection to highly vulnerable individuals who are estimated to number over 1.9 million. The second category is to offer immediate assistance to the affected population of over 2.2 million

\footnotetext{
${ }^{514}$ Johnny Saldaña, The Coding Manual for Qualitative Researchers. SAGE, (2015), 207.

515 Government of Lebanon and UNHCR, Lebanon Crisis Response Plan 2015-2016 (2015), 3.

${ }^{516}$ Government of Lebanon and UNHCR, Lebanon Crisis Response Plan 2017-2020 (2017),10.
} 
individuals. The third category supports service provision through national systems, while the last one focuses on Lebanon's economy, infrastructure, and public institutions. ${ }^{517}$

The 10 percent difference in total budget between the 2015-16 LCRP and 2017-20 LCRP is not a consequence of an increase in the targeted population, but rather an outcome of the longer response period of, now, four years suggested for the lingering vulnerabilities across the population due to the protracted Syrian refugee crisis. It is important to note that as the Syrian crisis worsens, the repercussions in Lebanon become more profound. Subsequently, the 2017-20 strategic plan strengthens the ideals of the 2015 plan. It also highlights the challenges faced by refugees more holistically. After all, the 201516 LCRP is a transitional plan to the 2017-20 LCRP one, which expands on the stabilization and development efforts by enabling a transition from emergency immediate relief efforts to empowering local bodies, sustaining their livelihood, and empowering their resilience

efforts.

\subsection{Operational Themes}

The later 2017-2020 Response Plan is more of an operational plan than 2015-2016 LCRP as it offers greater details in the implementation schemes of the following areas: Lebanon holds the ultimate authority over the Lebanese crisis response plan's sectors. Through LCRP, all activities need to abide by Lebanese laws and

${ }^{517}$ Ibid. 
regulations as well as applicable international laws. ${ }^{518}$ MoSA is mandated by the Inter-Ministerial Committee (IMC) to monitor the LCRP dynamics in Lebanon. According to one expert interview with UNHCR representatives, the Minister at MoSA and the UN Resident/Humanitarian Coordinator co-chair the LCRP steering committee, whose position is further elaborated in the 2017-2020 version of the LCRP compared to the previous one. ${ }^{519}$ The following plan also expands on the role of the interconnected bodies that are invested in managing Syrians in Lebanon. Each sector steering committee communicate and facilitate the operation of partnering agencies' project implementations. ${ }^{520}$

The "Promotion of National Leadership" provides "an opportunity for the Lebanese government to strengthen its domestic control and stabilize its management of aid and protection." 521 As a first step, the LCRP steering committee oversees the "un-earmarked funding" and other resources within each sector." 522 The 2017-2020 LCRP proposed better planning and coordination with its international partners to expand aid coordination to promote transparency and effectiveness. ${ }^{523}$

This loosely used, broadly defined term of coordination is politicized by

\footnotetext{
${ }^{518}$ Government of Lebanon and UNHCR, Lebanon Crisis Response Plan 2017-2020 (2017), 22.

519 Ibid.

${ }^{520}$ UNHCR Expert interview with author, (May 18, 2017).

${ }^{521}$ Government of Lebanon and UNHCR, Lebanon Crisis Response Plan 2017-2020 (2017), 20.

${ }^{522}$ Ibid, 23.

${ }^{523}$ Government of Lebanon and UNHCR, Lebanon Crisis Response Plan 2017-2020 (2017),
} 
different partners with perceivably different interests. One instance of this can be seen in the condemnation by the Lebanese government of the UNHCR for concealing the actual number of Syrians registered with the UNHCR after $2015 .{ }^{524}$ While Lebanon ordered the cessation of Syrian registrations, the values of the agencies regarding the management of Syrian residents were not shared. In contestation, the UNHCR practice of recording Syrians, informally registering them, continued without official Lebanese oversight over the new registrations or updated number of Syrians residing in the country. ${ }^{525}$ These dayto-day response arrangements exposed a lack of strategic refugee crisis policy coordination between the Lebanese government and the UNHCR. Due to competing power relations and different political agendas sought by a wide range of actors within the humanitarian field, the broad conception of coordination in delivering a cohesive and effective response plan did not fully materialize. In practice, reports show a lack of transparency in sharing information about the different agencies' projects, funding, and timing. ${ }^{526}$ Another example of lack of adequate coordination can be examined under the education sector, where reports show the inconsistencies in targets and

\footnotetext{
524 “Lebanon Freezes UNHCR Staff Residency Applications In Row Over Syrian Refugees,” Reuters, (June 8, 2018): https://www.reuters.com/article/us-lebanon-syria-refugees-unhcr/lebanon-freezes-unhcr-staffresidency-applicationsin-row-over-syrian-refugees-idUSKCN1J41JE.

${ }^{525}$ Dionigi Filippo, “The Syrian Refugee Crisis In Lebanon: State Fragility And Social Resilience” LSE, Middle East Centre paper series, 15. UK (2016), 25.

526 "Following The Money Lack Of Transparency In Donor Funding For Syrian Refugee Education," Human Rights Watch, (September 14, 2017), https://www.hrw.org/report/2017/09/14/following-money/lacktransparency-donorfunding-syrian-refugee-education.
} 
goals between donors and Lebanese government. ${ }^{527}$ One critical example of lack of common vision and coordination between LCRP partners is found in a particular case dealing with the sector of education: one donor conference hosted in London announced that all participating agencies will "enroll all Syrian children by 2017." ${ }^{228}$ In parallel, the Lebanon publicly announced another plan that would go for five years at that same conference, leaving more than " 156,000 Syrian children out of public schools by $2021 .{ }^{.529}$

Alongside "Transparency and Accountability," established systems lack consistency, detail, and timely reporting, hindering genuine oversight over funded multiyear commitments towards all "vulnerable populations" they seem to target. ${ }^{530}$ The LCRP 2017-2020 did dwell on theoretically detailing the procedures on how implementing partners should engage and, in principle, report monthly to the relevant sector steering committee on their progress. ${ }^{531}$ Afterward, the sector steering committees would then pass all the collected information to the LCRP steering committee. ${ }^{52533}$ Still, as the Abaad expert interviewee stated:

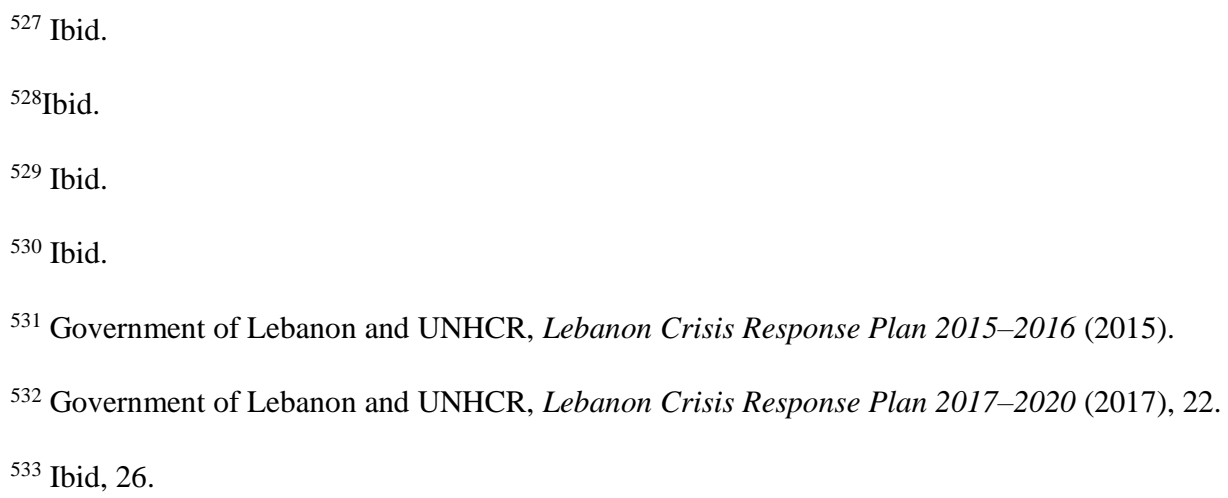


"Those people who are basically coordinating in each sector are not real public servants, so sometimes the decision-making process is not always that easy within the sector for the government because, for instance, their general directors have many other things to do so sometimes it can delay the process, again to the fact that it is very time-consuming., 534

According to the Abaad's expert statement, conflict of interest plays a huge role in shaping decision-making processes, where some policy plans are (mis)appropriated faster than others due to general directors' personal benefit from those actions when made in their official capacity. The Abaad NGO expert interviewee detailed that "the plan [LCRP] in itself is theoretically more or less good, the problem is more with its implementation because you are never able to fully implement it given the fact that you do not have all the necessary funds to implement it." 535

On another note, according to the interview with the UNHCR experts, from the beginning of the crisis response implementation period, all members of the steering committees agreed upon a certain type of format, content, and frequency of reports. We do find serious attempts by the major parties-the Lebanese government and UNHCR — to demand such mechanisms. Accordingly, the 20152016 LCRP original idea of information sharing and tracking through ActivityInfo increasingly developed in the 2017-2020 version as the latter reinforced objective monitoring and evaluations (M\&E) in order to "provide a multi-year framework for measuring progress in implementation, ensuring transparency, and facilitating

\footnotetext{
${ }^{534}$ Abaad Expert interview with author, (June 20, 2017).

${ }^{535}$ Abaad Expert interview with author, (June 20, 2017).
} 
strategic and programmatic adjustments." ${ }^{542}$ Theoretically then, the appealing partners are thus supposed to do a full report on funding through coordination and systematic and transparent reporting mechanisms. Still, in practice, the Abaad expert reiterated that:

"Every three months, if I am not mistaken, we are receiving an email from the intersector coordination asking us how much we received, for which period and from which donor. But it's self-reporting so that could be one of the weak issues as well of this financial reporting it all depends on the extent to which, organizations are committed, so we know that this reporting does not capture all the funding which is being received, but it gives you a good idea because it captures quite well what is being received by the UN agencies, by the big INGO's and by the national NGO'S."

The expert's statement recapped how financial self-reporting is not compulsory. Therefore, these measures are not prioritized as they should be for there are no enforcement mechanisms that would force aid agencies to report fully and on time. Funding and other resources received are left at the discretion of the appealing partners to handle benevolently, and their willingness to generate positive reports that are genuinely helping all groups of targeted vulnerable individuals inclusively without objectification make it harder for the LCRP steering committee to monitor their tasks, change, and hold them accountable.

Meanwhile, geopolitically, the high level of politicization of the Syrian crisis in Lebanon created space for non-traditional donors such as the Gulf Cooperation Council (GCC) countries and faith-based organizations to play a 
central role in refugee management. Reportedly, an increasing number of nontraditional donors make up to $12 \%$ of official humanitarian funds. ${ }^{536}$ Neither sharing the same values nor goals that the international community strives for, the politically, and ideologically motivated agencies would, consequently, undermine the need-driven aid policies, politicizing specific interests while excluding vulnerable non-member groups from accessing their support. In most Arab countries, women's dire legal status exacerbates gender stereotyping with a heavy emphasis on patriarchal norms of "who truly belongs to the nation and who does not." ${ }^{, 537}$ Consequently, a substantial block of non-traditional Arab states' assistance (in)directly marginalize and silence the most vulnerable groups of refugeesundervaluing women-specific needs - for the sake of their gendered agendas. Ultimately, these donors (en)gender asymmetrical types of humanitarian aid systems, where funding is given directly to unchecked local charities.

Meanwhile, it becomes difficult to oversee the non-traditional donors' work, let alone draw a clear picture of the type of funds, assistance, and aid distributions that target specific groups. One example shown in Sarah Hasselbarth's book Islamic charities states that:

"Dar al-Fatwa [a supreme religious authority in Lebanon responsible for all Islamic relief and humanitarian aid charities within the country] has no proper control over

\footnotetext{
${ }^{536}$ Dalya Mitri, "Challenges Of Aid Coordination In A Complex Crisis: An Overview Of Funding Policies And Conditions Regarding Aid Provision To Syrian Refugees In Lebanon," Civil Society Knowledge Center (2014): 15 .

${ }^{537}$ Batl Sadliwal. "Including Women, Excluding Migrants, And Reimagining National Belonging InTthe GCC," World Peace Foundation, (March 12, 2018), https://sites.tufts.edu/reinventingpeace/2018/03/12/including-women-excludingmigrants-and-reimaginingnational-belonging-in-the-gcc/.
} 
the expenditure of this money. This is a phenomenon taking place in Tripoli: decreasing Dar al-Fatwa's control of local charities in Tripoli makes those charities independent. In Tripoli, this increases the risk of advances by the Salafists or the Muslim Brotherhood.[...] not able to keep track with actual developments."538539 Sarah Hasselbarth states that the UNHCR views that independent, politically affiliated, extremist Islamic groups in Tripoli with hidden agendas, do not report their activities, becoming "stronger during the refugee crisis and might have taken over internal control or at least influence internal structures and procedures." ${ }^{, 540}$ This type of selective engagement in crises can be significant without being forced to report, let alone coordinate, their detailed activities with other agencies. Many political and patriarchically motivated religious groups are likely to allocate their funding directly to their constituents without further documentation within the ActivityInfo tracking system, leading to a poor exchange of gender-sensitive information. As one of the many impact translations, an investigation report recorded another case where hundreds of Syrian Muslims are converting to Christianity to either be better received by certain communities, benefit from aid distributed by Christian charities, that might also facilitate their approval to move to wealthy Western (Christian) countries. ${ }^{541}$

\footnotetext{
${ }^{538}$ Sarah Hasselbarth. Islamic Charities In The Syrian Context In Jordan And Lebanon. Friedrich-EbertStiftung (2014),

539 . https://library.fes.de/pdf-files/bueros/beirut/10620.pdf

${ }^{540}$ Ibid.

${ }^{541}$ Josie Ensor, “The Muslim Refugees Converting To Christianity To Find Safety,” The Telegraph, (January 30, 2017), https://www.telegraph.co.uk/news/2017/01/30/muslim-refugees-converting-christianity-findsafety.
} 


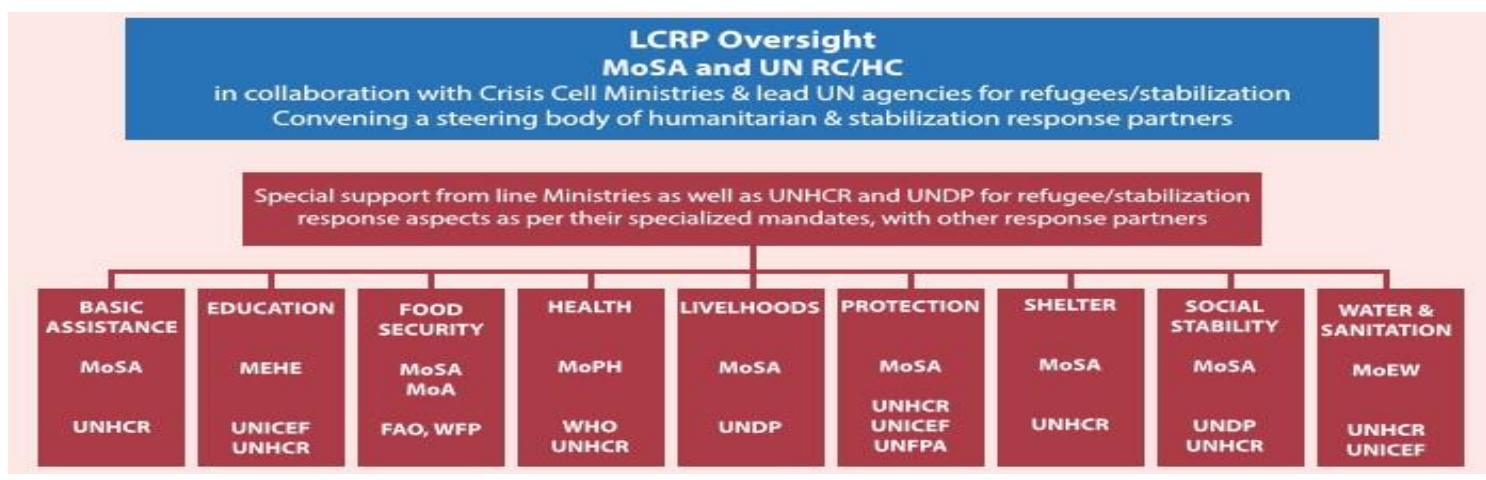

Figure 11. LCRP Sectors 2015-2016

542543

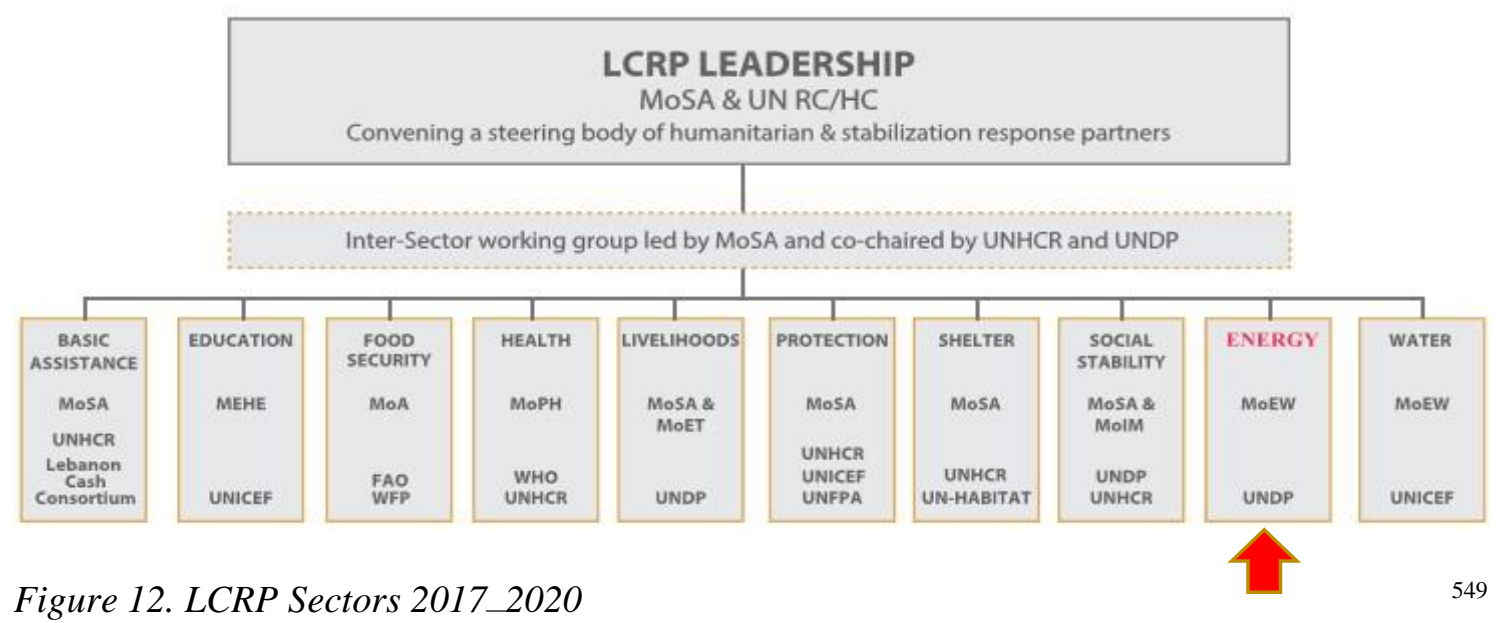

On another note, the two figures above are taken from both LCRP documents,

which the expert from UNHCR portrayed as "quite a layered process." 544

According to the Abaad expert interviewee, their [Abaad] involvement basically was to revise the sector chapters, discuss the accountability framework through core groups meetings to agree on everything. Afterward, "at the national level, there are [sector chapters] finalizing the plan within the core groups. So, for each working

${ }^{542}$ Government of Lebanon and UNHCR, Lebanon Crisis Response Plan 2015-2016 (2015), 32.

${ }^{543}$ Government of Lebanon and UNHCR, Lebanon Crisis Response Plan 2017-2020 (2017), 22.

${ }^{544}$ UNHCR Expert interview with author, (May 18, 2017). 
group, there is also a core group, which is a little more restricted to enable a little bit more effective work." ${ }^{545}$ As the chain moves upward, different groups get respectively filtered, until it reaches the LCRP governing steering committee that is made up of an official representing the Lebanese Ministry of Social Affairs, a UNHCR representative, and a UN Resident and Humanitarian Coordinator(RC/HC) guiding the overall humanitarian response efforts in Lebanon.

In that respect, a comparison between Figure 11 and Figure 12, representing the targeted sectors of collaborating national organizations within both LCRP plans, provides an interesting find. Problematic issues such as "Energy" increased in importance, forcing changes within the multi-sector response plans, becoming a stand-alone segment in the LCRP 2017-2020. According to the Lebanese Minister of Energy and Water, Cesar Abi Khalil, Syrian residents in Lebanon cause an additional burden on the already deteriorated electricity network as a result of increased demand. ${ }^{546}$ The severe electricity rationing forced Lebanese residents to take to the streets and publicly blame Syrians for engendering the shortages and straining the already limited government reserves. ${ }^{547}$ Meanwhile, Lebanese officials admit that there was a severe electricity shortage, tax evasions, and unpaid

${ }^{545}$ Abaad Expert interview with author, (June 20, 2017).

546 “Abu Khalil: Without The Syrian Crisis, Electricity Would Have Been 24/24," Lebanon News, LBC News, (February 21, 2017), www.lbcgroup.tv/news/d/lebanon/304003/24/24.

${ }^{547}$ Paula Astih, "Lebanon: Public Discontent Over Continuous Power Cuts," Asharq Al-Awsat Newspaper, (December 23, 2017), https://aawsat.com/english/home/article/1121661/lebanon-public-discontent-overcontinuous-powercuts?amp. 
electricity bills even before the Syrian crisis affected the total government revenues and that the "overburdened" government has still not agreed on any concrete resolutions for the near future. ${ }^{548}$ While problems such as lack of electricity are gender-neutral and provide equal impairment, they do not always result in equal outcomes due to the inherent need differences between both genders. Electricity rationing greatly hinders the domestic chores primarily managed by women. As patriarchal structures limit women's labor to the domestic sphere, the majority of Syrian women's labor "in-house chores such as cooking and washing clothes and dishes" ${ }^{549}$ depends on having electricity within the household.

The non-recognition of the essential impact electricity could have on Syrian women's livelihood leads to the LCRP's relative de-prioritization of the imminent provision of essential services for women's domestic work. Consequently, increasing electricity cuts restrict Syrian women from finding some sense of security.

\subsection{Continuous Themes}

There are no considerable changes regarding the planning principles of the two

\footnotetext{
${ }^{548}$ Osama Habib, “Tax Evasion Close To \$4.2B Annually: Economist,” The Daily Star News, (March 2, 2017), http://www.dailystar.com.lb/Business/Local/2017/Mar-02/395690-tax-evasion-close-to-42b-annuallyeconomist.ashx.

549 "Revisiting Inequalities in Lebanon, The case of the "Syrian refugee crisis" and gender dynamics." CivilSociety Review. Issue 1, January 1, (2015). https://civilsociety-centre.org/sites/default/files/resources/lscsrissue1-jan2015.pdf
} 
LCRPs. After all, both plans built a case to donors in the "Needs Overview" section, requesting from the international community "international support" and "financing." As one interviewee from the UNHCR stated, "It is a needs-driven process. However, donors are an important part of the process. So, we also try to get that component covered.

Moreover, again, of course, the government is leading it. So it has very much to do with the approval." 550

In fact, the 2017-2020 version "reaffirms the international community's commitment to support and reinforce the response capacity of national/local institutions and national/local humanitarian actors. [...] The calls for burden sharing continue through the development of a four-year plan that asks for an investment in Lebanon and supports to the population that Lebanon hosts." ${ }^{551}$ These repeated calls stem from the constant outcries over the shortfall of pledged funding which countries have yet to provide. ${ }^{552}$ According to Emirates News Agency, only $18 \%$ of the 4.6 billion USD of the 2017 interagency appeal were met, barely providing "targeted vulnerable groups" immediate humanitarian needs of Syrian refugees across the Middle East region. ${ }^{553}$

\footnotetext{
${ }^{550}$ UNHCR Expert interview with author, (May 18, 2017).

551 Government of Lebanon and UNHCR, Lebanon Crisis Response Plan 2017-2020 (2017), 22.

552 "Lebanon Between The Largest Displacement and the Least Aid," Emirates News Agency, (June 6, 2017), https://www.zawya.com/mena/en/story/Some_60000_Syrian_refugees_in_Lebanon__

Jordan_could_lose_assistance_warns_UNHCR-WAM20170606192048379.

${ }^{553}$ Ibid.
} 
The 2015-2016 document previously mentioned, emphasizes most of those humanitarian needs. Both plans call for innovative responses that could address the deteriorating refugee crisis within the country." ${ }^{" 554}$ Alas, the crisis has continued to deteriorate significantly ever since. The four-year plan that was put in place in 2017 continued its request for burden sharing, mostly through investment and local support for the vulnerable populations residing within the country. While warning of "increasing negative coping strategies" and "dependence on external aid," both plans seem to be appealing for further aid and collaboration in easing the chronic problems due to perceived lack of funding without recognizing the targeted vulnerable people's potential of being strategic partners in finding the right solutions. Accordingly, many grassroots initiatives were initiated outside the LCRP spectrum, while some of them still engender Syrian women's empowerment as strategic partners for non-gender sensitive goals that would counter-intuitively reinforce in the long run their limited status within the gendered hierarchical system in Lebanon. As such, the following Photovoice section provides more examples of these type of scenarios in which most of these humanitarian initiatives would correspondingly enable and empower the majority of "vulnerable targeted groups." Instead, most humanitarian initiatives tend to specifically exploit Syrian women's cultural place in the domestic sphere and their roles as free domestic laborers in

${ }^{554}$ Government of Lebanon and UNHCR, Lebanon Crisis Response Plan 2017-2020 (2017), 5. 
their own homes in order to garner their participation in aid programs that do not address specifically the problematic gendered (in)security structures.

Both LCRP documents highlight how Lebanon could undergo civil unrest and economic collapse if not enough funds are received. However, according to an Al Jazeera news article, the reality on the ground is much more complicated, emphasizing that the populist protectionist rhetoric and the ad hoc restrictions that Syrians are facing in Lebanon do not only affect the livelihood and resiliency of residing Syrians but they also diminish the chances of Lebanon adequately benifiting from potential Syrian contributions to the amelioration of their country. ${ }^{555}$ An average of $\$ 1.5$ bn every year has been allocated to Lebanon in aid funds. Still, these funds mainly target short term humanitarian projects that do not sustain. ${ }^{556}$ Counter-intuitively, a considerable ratio of those cash assistance funds neither support Syrian refugees' livelihood nor the host state's stability, nor generate gender sensitive jobs, nor promote social solidarity in the areas where displaced Syrians are living. Instead, due to the severity of refugee living conditions, most funds are limited to direct aid such as food, housing, education, and health services. According to the World Bank estimates, this phenomenon is costing Lebanon's economy 7.5 billion USD annually, in addition to a significant

555 Ibid.

${ }^{556}$ Jad Chaaban, "Should Lebanon Get More Funds For Hosting Refugees?,” Al Jazeera, (April 5, 2017), https://www.aljazeera.com/indepth/features/2017/04/lebanon-funds-hosting-refugees170405082414586.html. 
decline in trade and tourism, which is blamed on the ongoing Syrian crisis. ${ }^{557}$ In the meantime, according to Annahar newspaper, the consequences of Syrian poor living conditions are visible in the increase in chronic diseases, suicides, use of violence, and involvement in hard labor. ${ }^{558}$

Socio-economic, health, water, sanitation, and hygiene problems seem to be continuously at stake. In fact, studies show that the health care system in Lebanon is overwhelmed by the sudden spike in patients, mainly caused by the increase of population, affecting all groups of people residing in the area. ${ }^{559}$ Additionally, most registered Syrian refugees receive assistance from the UNHCR for payment of "basic" health services. However, the report states that Syrians would still need to cover the remaining $25 \%$ of "advanced" medical checkups and much needed health services that most pregnant women and nursing mothers undergo, which reflect conditions of gender discrimination. ${ }^{560}$ Most efforts to include measures to control disease outbreaks, hunger, and childbirth were not prioritized as part of the health sector initiatives, even though these are the most endemic types of health hazards that the majority of Syrian refugees women and children endure. Accordingly, the health sector's needs analysis was divided into two objectives objectifying the

\footnotetext{
${ }^{557}$ Dominic Evans, “Syria War, Refugees To Cost Lebanon \$7.5 Billion: World Bank," Reuters, (September 19, 2013), https://www.reuters.com/article/us-syria-crisis-lebanon-idUSBRE98I0T320130919.

${ }^{558}$ Rita Sfeir, "Migration Is Increasing And The 'Specter' Of Bosnia And Rwanda Present Any Repercussions of Russian Military Intervention On Asylum?" Annahar News,

(September 20, 2015), https://newspaper.annahar.com/article/276860-

${ }^{559}$ Government of Lebanon and UNHCR, Lebanon Crisis Response Plan 2015-2026 (2015).

${ }^{560}$ Ibid., 14.
} 
majority of Syrian de facto refugees in Lebanon: increase access to healthcare and strengthen health-care services to cater to the growing population in Lebanon. ${ }^{561}$

Meanwhile, except primary health care and life-threatening emergencies, genderspecific medical requirements are almost absent within both plans, even when $80 \%$ of vulnerable targets differ in health risks, conditions, and needs from those concerning men. ${ }^{562}$ On the one hand, different structural hierarchies and social barriers hinder Syrian women and girls from seeking adequate health assistance due to "stigma, fear of mistreatment or discrimination, lack of awareness, fear of reporting violence, and difficulties obtaining legal status." ${ }^{, 563}$ On the other hand, the availability and cost for seeking the already strained health services prevents most Syrian women and girls from accessing the needed reproductive diagnosis, and treatment, putting them at serious risk of avoidable mortality hazards. ${ }^{564}$ While the humanitarian response-needs prioritize essential items such as food, protection, water, and shelter to fulfill the Syrian refugees' related needs, the study shows that their provision of services related to reproductive, maternal and child health services are barely provided. One of the main reasons stated by

\footnotetext{
${ }^{561}$ Government of Lebanon and UNHCR, Lebanon Crisis Response Plan 2017-2020 (2017).

${ }^{562}$ Karl Blanchet, Fouad M. Fouad, and Tejendra Pherali, "Syrian Refugees In Lebanon: The Search For Universal Health Coverage," Conflict and Health 10 (2016): 12.

${ }^{563}$ Goleen Samari. “Syrian Refugee Women's Health In Lebanon, Turkey, And Jordan And Recommendations For

Improved Practice." World Med Health Policy. (June, 2017), https://www.ncbi.nlm.nih.gov/pmc/articles/PMC5642924/

${ }^{564}$ Karl Blanchet, Fouad M. Fouad, and Tejendra Pherali, "Syrian Refugees In Lebanon: The Search For Universal Health Coverage," Conflict and Health 10 (2016): 12.
} 
health experts is the ill-equipped Lebanese health care system, already established before the crisis, that does not provide gender inclusively subsidized or discounted health services to women in Lebanon. ${ }^{565}$ Even if the well-intentioned international agencies would want to provide these essential services to the majority of the Syrian refugee population Syrian women and children, they end up failing to empower and protect them.

Economically, in the last couple of years, the volume of products exported from Lebanon has been on the decline for the simple reason that the only land route used for export crosses through Syria. ${ }^{566}$ One study reported that Lebanese exporters who use Syria as a transit country suffered more than Jordanian exporter, meaning that Syria is more critical to Lebanon than to Jordan. ${ }^{567}$ Lebanese households are also experiencing a decrease in income and an increase in debts, forcing them to search for loans to meet their basic needs. According to the LCRP "Needs Overview" section, "public services are overwhelmed, economic growth has faltered, and unemployment is rising at record rates." ${ }^{, 568}$ There is a continuous need to enhance "service delivery and reduce the fiscal burden that the sector places

\footnotetext{
${ }^{565}$ Goleen Samari. “Syrian Refugee Women's Health In Lebanon, Turkey, And Jordan And Recommendations For

Improved Practice." World Med Health Policy. (June, 2017), https://www.ncbi.nlm.nih.gov/pmc/articles/PMC5642924/

566 Josh Wood, "Syrian War Deals Heavy Blow To Lebanon's Export Business," The National News, (September 26, 2015), https://www.thenational.ae/world/syrian-war-deals-heavy-blow-to-lebanon-s-exportbusiness-1.127856.

${ }^{567}$ Ibid.

568 Ibid.
} 
on public resources." ${ }^{569}$ The decrease in income and savings has been closely connected to increasing unemployment and high dependency on international aid. The plan states that "Syrian insecurities have been increasing, as savings are rapidly depleting, and the use of negative coping strategies is on the rise." 570

In turn, both plans call for the enhancement of "resilience" and "livelihoods" techniques to alleviate the suffering of the most vulnerable Lebanese and displaced persons from Syria, requiring individualized sector steering committees that would ensure there is proper alignment of funding to various initiatives. In both plans, the steering committees are responsible for guiding the allocation of resource funding among various sectors after conducting consultations with relevant stakeholders. According to the UNHCR, the 2015- 2016 LCRP shifted its mandate from pure humanitarian to long-term sustainable integrated components of refugee resilience. One example is the creation of "Livelihoods Sector Steering Committee" in the 2017-2020 LCRP plan, which was a step towards coordinated engagement in restoring and expanding economic and livelihood opportunities for refugees. Still, the government limitation of Syrian jobs within three permissible low skilled sectors-agriculture, construction, and sanitation - clearly limit the degree of how much these resilience plans can achieve, and which groups are to be excluded — women.

\footnotetext{
${ }^{569}$ Ibid, 14.

${ }^{570}$ Government of Lebanon and UNHCR, Lebanon Crisis Response Plan 2015-2026 (2015).
} 
The continuous call to "strengthen government ownership of investments made by supporting national planning and implementation, monitoring and management processes" highlight the scenario of power politics and agenda-based competition between the international community and the Lebanese government, among other actors. ${ }^{571}$ Even though all parties call for government oversight and a leadership role, in practice, most available humanitarian aid is not channeled through the Lebanese government but is given mostly to non-governmental organizations working on the ground, with no tangible means to control their operations. ${ }^{572}$ Accordingly, what initially seems like a similar schema what the international community and Lebanese government share, evidenced by their use of common appropriation of agenda initiatives and goals, a closer inspection highlights a more complex gendered story of both harmony and tension between both sides. While both parties genuinely aim for socio-economic stability and increase of government services and aid, the specific monitoring mechanisms and prioritization of targeted approaches seem to alter in practice, creating room for tension.

${ }^{571}$ Ibid.

572 Lina Fakhreddin, "Lebanon Between The Largest Displacement And The Least Aid," Assafir News, (January 6, 2015), http://assafir.com/Article/2/394120. 


\subsection{Elaborated Themes}

Both plans aim to provide "direct and targeted aid" to the "most vulnerable people" while ensuring complementarity across various sectors. ${ }^{573}$ Through a longitudinal analysis, we find the "protection" theme to be more elaborated in the 2017-2020 plan than the previous version. Local dynamics and the long-term nature of the second version pushed the planning partners to adapt to the multiple local adversities by splitting the 2015-2016's first strategy into two separate ones. When reading both strategic response plans, the targeted group also seems to have changed from the "most vulnerable among the displaced from Syria and poorest Lebanese" to an expanded group of "vulnerable populations" that would encompass Palestinians and Iraqi groups as well. ${ }^{574}$ That change aims to "reduce exposure to hunger, homelessness, health complications, disease outbreaks, violence, abuse, exploitation, as well as the worst effects of poverty." 575 Both plans request the continued "immediate and temporary service delivery in informal settlements, collective shelters, substandard dwellings, and gatherings," all while continuing to respond to emergency humanitarian needs as they arise from these interventions. ${ }^{582}$

\footnotetext{
${ }^{573}$ Government of Lebanon and UNHCR, Lebanon Crisis Response Plan 2015-2026 (2015), Government of Lebanon and UNHCR, Lebanon Crisis Response Plan 2017-2020 (2017).

${ }^{574}$ Government of Lebanon and UNHCR, Lebanon Crisis Response Plan 2015-2026 (2015), Government of Lebanon and UNHCR, Lebanon Crisis Response Plan 2017-2020 (2017).

575 Ibid.
} 
Due to the influx of refugees, there has been a competition over informal menial jobs, which caters to around $56 \%$ of employment positions in Lebanon. ${ }^{576}$ A majority of workers in such jobs are poor. A combination of words increased in intensity from one plan to the other when describing how vulnerable people are sinking deeper into debt and adopting "negative coping mechanisms." 577 Issues such as "legal status," "resilience" and "substandard shelters" are also elaborated as intersectional and mutually dependent. ${ }^{578}$ Legal protection is an essential prerequisite for improving the lives of refugees, especially women, as mentioned in the previous chapter. Having an ambiguous status could only lead to the detriment of refugee assistance and protection in accessing essential services.

Meanwhile, the categories that label the complex groups of people that came from Syria fail to provide adequate legal protection mechanisms due to multifaceted bureaucratic mechanisms at prohibitive costs. The vulnerability assessment of Syrian refugees in Lebanon estimates that the "level of illiteracy among female heads of households was more than double that of male heads of household (28\% and 12\% respectively)."579 Adding to that, Syrian women's limited

\footnotetext{
576 VASyR 2017: Vulnerability Assessment Of Syrian Refugees in Lebanon," World Food Program, United Nations Children's Fund (UNICEF), and UNHCR, (2016), 16. http://documents.wfp.org/stellent/groups/public /documents/ ena/wfp289533.pdf.

577 Government of Lebanon and UNHCR, Lebanon Crisis Response Plan 2015-2026 (2015), Government of Lebanon and UNHCR, Lebanon Crisis Response Plan 2017-2020 (2017).

578 Ibid.

579 "VASyR 2017: Vulnerability Assessment Of Syrian Refugees in Lebanon," World Food Program, United Nations Children's Fund (UNICEF), and UNHCR, (2016), http://documents.wfp.org/stellent/groups/public /documents/ ena/wfp289533.pdf.
} 
financial means, due to gendered policy plans and discriminatory government practices, would suffer the most. Most refugee (in)security approaches tend to homogenize all Syrian individuals' needs and objectify the agency of the marginalized majority of Syrian women, where justified ad hoc policies of exclusion would (en)gender counterintuitive negative coping strategies. This latter includes a reduction of food intake and expenditure on gaining education and health, coupled with an increase in debt, informal work, street begging, and prostitution, all potential conditions manifesting as part of their resilience efforts to overcome their inequitable experiences.

Not having legal access to work increases poverty and pushes marginalized populations away from proper resilience efforts. Consequently, "informal settlements, collective shelters, substandard dwellings and gatherings," "homelessness, hunger, disease outbreaks, violence, abuse, and exploitation are few of the many consequences that arise. $" 580$ The 2017 plan elaborates on these issues, discussing how the "resilience of the country's vulnerable communities is eroding as they run out of savings and struggle to access income," and emphasizing the dire need to facilitate access to legal documentation so that all registered refugees can access essential public services. ${ }^{581}$ Still, both plans do not tackle the double discrimination that Syrian women, specifically, undergo due to their residency status and gender.

\footnotetext{
${ }^{580}$ Government of Lebanon and UNHCR, Lebanon Crisis Response Plan 2017-2020 (2017), 17.

${ }^{581}$ Government of Lebanon and UNHCR, Lebanon Crisis Response Plan 2017-2020 (2017), (2017), 11.
} 
Another theme worth mentioning is "agribusiness." What seemed, at first, as a new theme in the 2017-2020 plan, was later viewed as an elaboration of the previous 20152016 plan. "Agribusiness" was introduced in the second plan as a sign of increasing knowledge of the local situation. According to the International Labor Organization (ILO), Syrians tend to maintain the same kind of jobs they used to have before the crisis: " $92 \%$ [of Syrians] have no work contract and over half work on a seasonal, weekly or daily basis." ${ }^{, 52}$ As workers, Syrians mainly engaged in agricultural work, domestic services, and construction. Due to their informal nature, in the case of Lebanon, these jobs provide little to no income protection and do not offer any social security benefits. Accordingly, the 2017-2020 plan promoted sustainable agriculture production through supporting vulnerable food producers and communities in the hopes of addressing Lebanon's preexisting labor market challenges, taking on a holistic and comprehensive approach to balance refugee assistance with the tacking the needs of vulnerable Lebanese communities. ${ }^{583}$ The elaborated plan also called for enhancing agricultural livelihood activities and social tension prevention within stressed communities. The document proposed strengthening the Lebanese institutional capacities and

\footnotetext{
582 “Assessment of The Impact of Syrian Refugees In Lebanon And Their Employment Profile.” International Labor Organization,(2013),https://www.ilo.org/wcmsp5/groups/public/---arabstates/---ro-beirut/documents/ publication/wems _240134.pdf.

583 "Two-Thirds Of Syrian Refugees In Lebanon 'Employed'," Almanar TV Archive, (March 4, 2014), http://archive.almanar.com.lb/english/article.php?id=144153.
} 
agribusiness owners in the hopes of promoting a legal labor market, in which working Syrians could enjoy some legal protection while residing in the country. ${ }^{584}$

Since most Syrian refugees lack legal status, access to housing became difficult. The increase of rent in most cities pushed the establishment of informal camps in agricultural areas. Most Syrian refugees are either working informally in Lebanese farms and factories, or on the streets. Higher rates of child labor are seen on the main highways and streets, where children sell tissue paper, beg, or shine shoes. According to an Al Jazeera news report, the Beqaa area, east of Lebanon, witnessed an increase in child labor. ${ }^{585}$ The report estimated that child labor is becoming increasingly common with an average of $65 \%$ of Syrian children put to work for little to no pay. ${ }^{586}$ Most of the jobs are coordinated through the shawisha man who takes charge of managing the informal camps that are set on a leased plot of land from a Lebanese owner. He then becomes the middleman between the refugee population and the local community and businesses, recruiting workers and making commissions. There, he supervises and supposedly protects the "most vulnerable, especially children and women, older persons and persons with

\footnotetext{
${ }^{584}$ LCRP 2017-2020

585 "Syrian Children In Lebanon Forced To Work: Report," Al Jazeera News, (April 12, 2016), https://www.aljazeera.com/news/2016/04/syrian-children-lebanon-forced-work-report160412051345859.html.

586 "Syrian Children In Lebanon Forced To Work: Report,” Al Jazeera News, $\quad$ (April 12, 2016), https://www.aljazeera.com/news/2016/04/syrian-children-lebanon-forced-work-report160412051345859.html.
} 
disabilities," taking the rent from them. ${ }^{587}$ The expert interviewee from MoSA stated:

"You have the structure within the Syrian refugees' committee where you have a Shawish that has access to all the people and households within a specific informal settlement that could communicate with them, communicate their needs, etc., coordinate with the rest of the NGO's, international NGOs and agencies to provide for their needs."

As such, the expert's assertion that a Syrian, most probably male, shawish can exercise power over other Syrian refugees residing in his informal settlements under some conditions does not signify that he does not suffer discrimination from other groups, such as the local authorities and NGOs. This signifies that the Syrian refugees' (en)gendered relations at the heart of our study are mutable and dynamic, socially and politically constructed.

On another note, one of the most considerable changes between the 2015-16 LCRP and the 2017-20 LCRP is about various cross-cutting issues concerning "gender," "youth," the "environment," "gender violence," and "legal" insecurities. The 2017-2020 plan further elaborates on the "vulnerable populations" by splitting and maximizing the variances between its members, with more emphasis on "elderly," "children," "persons with disability" and "youth," regarding work and education. Unlike the 2015-16 LCRP, the 2017-20 LCRP emphasizes and prioritizes youth programming as one of its major components within its various sectoral plans. In fact, the youth component in this LCRP plays a great role in

${ }^{587}$ Government of Lebanon and UNHCR, Lebanon Crisis Response Plan 2017-2020 (2017), 17. 
fostering youth resilience by empowering them socially, economically, and personally thereby increasing education, entrepreneurship, and civic engagement as well as other forms of participation. ${ }^{588}$ The 2015-16 LCRP built the youth agenda whereby various partners have expanded their focus to assist the targeted youth, considered as one of the most vulnerable and marginalized groups. The LCRP initiative aimed at motivating young refugees so that they could positively influence their communities. It focuses on expanding youth capacity through job creation, skills training, improving employability, and entrepreneurship programs as well as other income generating activities. The 2017-20 LCRP also focused on the education sector whereby it tackles various challenges by increasing access to education programs, and vocational training activities. ${ }^{589}$ Finally, this plan focuses on the protection sector by targeting youth who are likely to engage in risky behaviors and therefore ensuring that they are provided with proper psychosocial support. This section also covers the main place to tackle women and gender issues.

According to the Abaad expert, these types of topics are "mainly done through the protection sector; this discussion happens mainly through the protection sector. For ourselves, we would report it in a way, but this is really happening through the protection sector." ${ }^{, 590}$ Since the protection sector is more focused on gender-based

\footnotetext{
${ }^{588}$ Government of Lebanon and UNHCR, Lebanon Crisis Response Plan 2017-2020 (2017), 24.

589 Ibid.

${ }^{590}$ Abaad Expert interview with author, (June 20, 2017).
} 
violence problems and developing response mechanisms for girls and boys who are at risk, other types of inequalities and insecurities that are important for the success of the response plan seem to be non-existent.

Also, in practice, studies hsow that the targeted support to adolescents and youth aged 14 to 25 has been minimal in both plans. ${ }^{591}$ It is important to note that, while the 2017-2020 LCRP prioritizes "youth programming" within most sectors, gender seems to be absent in their formula. ${ }^{52}$ The primary goal of the 2017-20 LCRP youth engagement is to foster socio-economically youth resilience to "increase education, entrepreneurship, empowerment, participation and civic engagement of this generalized population. ${ }^{.593}$ Expanding the LCRP 2015-2016 agenda, the new initiatives aimed to motivate youth to and their respective communities fall short when girls are, still, being targeted for child marriages and sexual harassment, limiting their mobility in the public sphere. ${ }^{594}$ As such, youth programs proliferated mostly under the "livelihood sector" with an increase in education, income-generation opportunities, innovation, and entrepreneurship programs. Still, a recent study conducted with a group of 10-12 and 13-14-year-

\footnotetext{
${ }^{591}$ Carole Alsharabat and Jihad Nammour. "Survey on perceptions of Syrian refugees in Lebanon." Beirut: Institut des Sciences Poltiques, Universite Saint-Joseph (2015).

${ }^{592}$ Government of Lebanon and UNHCR, Lebanon Crisis Response Plan 2017-2020 (2017),

593 Ibid.

${ }^{594}$ Jocelyn DeJong, Farah Sbeity, Jennifer Schlecht, Manale Harfouche, Rouham Yamout, Fouad M. Fouad, Seema

Manohar, and Courtland Robinson, "Young Lives Disrupted: Gender And Well-Being Among Adolescent Syrian Refugees in Lebanon," Conflict and Health 11, no. 1 (2017): 29.
} 
old Syrian refugee adolescents in Barelias and Qabelias, Lebanon, called for much needed special attention to "gender differentials in factors encouraging enrolment and leading to drop-out, such as security concerns for girls." 595 The LCRP "education" sector increased youth access to "formal education, vocational training, and regulated non-formal education programs." ${ }^{596}$ Basic education is a right that should be enjoyed by all children between the age of 3 and 18 in Lebanon. However, $58 \%$ of displaced Syrian children are not attending school. Meanwhile, economically vulnerable Syrians attend public schools. ${ }^{597}$ The number of Syrians students surpassed the Lebanese counterparts in public schools, where they have to pay a relatively smaller fee to attend. ${ }^{598}$ Still many other barriers hinder Syrian children from attending school, such as unaffordable cost of transportation, unfamiliar language of instruction (such as French or English), lack of residency papers to properly enroll, early marriages and child labor to support families, insecurity concerns, and psychosocial concerns, such as harassment, bullying and, corporal punishment, amongst many other issues. ${ }^{599}$

\footnotetext{
595 Ibid.

${ }^{596}$ Government of Lebanon and UNHCR, Lebanon Crisis Response Plan 2017-2020 (2017).

597 Ibid.

598 "Syrian Refugees In Lebanon Surpass One Million," UNHCR, Press Releases, (April 3, 2014), http://www.unher.org/533c15179.html.

599 "Growing Up Without An Education: Barriers To Education For Syrian Refugee Children In Lebanon," Human Rights Watch, (July 19, 2016), https://www.hrw.org/report/2016/07/19/growing-withouteducation/barriers-education-syrianrefugee-children-lebanon.
} 
On the one hand, no Lebanese law entirely prohibits ten-year-old and up children from child labor, particularly in the agricultural sector. On the other hand, Syrian parents cannot afford to prioritize education over having their children bring income to support their family. ${ }^{600}$ As a result, "93 percent of refugee families resort to child labor since adults are restricted from accessing the labor market." ${ }^{601}$ In a Human Rights Watch interview with a Syrian refugee family, an interviewee stated, "We cannot afford to put them in school here. All my children were studying in Syria, but if I would put them in school here how would I live? We would have to buy them clothes and pay for transportation. Even if everything was free, the children could not go to school for they are the only ones that can work."602 Based on these facts, both LCRPs' goal is to ensure that both Syrian and Lebanese children have access to a good school environment by investing in the amelioration and expansion of schools premises. The reports advocate rehabilitation, expansion of existing premises and constructing new ones. That way, the education system becomes strengthened and able to cater to most children.

An elaboration on "targeted assistance" was necessary to include in the 2017 crisis response plan. We find a decent shift in "targeted approach" and

\footnotetext{
${ }^{600}$ Morgan Meaker, "Syrian Refugee Children Reduced To Selling On Beirut's Streets To Feed Their Families," The Guardian, (January 25, 2017), https:// www.theguardian.com/globaldevelopment/2017/jan/25/syrian-refugee-childrenselling-beirut-streets-lebanon-support-families.

601 “The Situation Of Human Rights In Lebanon.” ALEF, Annual Report 2017, (March, 2018), 11, https://alefliban.org/wp-content/uploads/2018/04/annual_report_2017_v03_-2.pdf.

602 "Growing Up Without An Education: Barriers To Education For Syrian Refugee Children In Lebanon," Human Rights Watch. (July 19, 2016), https://www.hrw.org/report/2016/07/19/growing-withouteducation/barriers-education-syrianrefugee-children-lebanon.
} 
"targeted groups," which provide adequate strategies that would not aggravate the social tensions between both populations. The 2017-20 LCRP tackles the issue of "gender" by denoting that one of the sustainable development goals (SDGs) is the achievement of gender equality and the elimination of gender-based violence.

In this regard, the efficient mainstreaming of gender requires an adequate assessment of how any planned action is likely to affect women, girls, men, and boys. Gender concerns need to be the integral dimension when designing, implementing, monitoring, and evaluating various programs and policies across different spheres. The 2017-18 LCRP recognizes that gender-based violence (GBV) is particularly challenging about various humanitarian contexts. Responding to GBV is a collective effort. Thus, the LCRP should ensure there is risk mitigation across all the intervention sectors.

When looking at the evolution of the LCRP plan from 2015 to 2017, from the first read, one notices that the texts barely mentions "women," homogenizing them as part of a growing list of vulnerable groups, with no clear plans to address their specific gendered insecurities. When mentioned, women are loosely associated with vulnerable groups in general, and no clear plans are addressing their specific gendered (in)securities. Forming the majority of registered refugees, Syrian "women" are mostly portrayed in both plans among the different "targeted groups" whose troubles get mentioned in a couple of paragraphs of a 186-page crisis response plan. Consequently, the gendering securitized crisis response plans marginalize the "78 percent of Syrians registered as refugees with UNHCR [that] 
are women and children." ${ }^{603}$ When a plan mentions "the estimated 1.5 million displaced Syrians, half of whom are women and children," one would expect that the responses suggested and the funds received would target them accordingly. ${ }^{604}$ Still, the study finds major anomalies within problematizing the whole humanitarian approach for conflating statistics of one single "vulnerable group" that would strip both women and children from any type of productive agency. Consequently, as the previous chapters show, Syrian women refugees get subjected to various types of intersectional discriminations ${ }^{605}$ According to the International Labor Organization (ILO), Syrian women residing in Lebanon are particularly vulnerable to unemployment: "over two-thirds of women looking for work in Lebanon were unable to find a job. Only two out of 10 working refugees were female, earning about 40 percent less on average than their male counterparts." The 2017-2020 plan elaborates the emphasis on increasing communal and institutional responsiveness to support the elaborated targeted groups, especially children and women, from armed violence, abuse, exploitation, and neglect. ${ }^{607}$ The

603 "VASyR 2017: Vulnerability Assessment of Syrian Refugees in Lebanon," World Food Program, United Nations Children's Fund (UNICEF), and UNHCR, (2016), http://documents.wfp.org/stellent/ groups/public/documents/ ena/wfp289533.pdf.

${ }^{604}$ Government of Lebanon and the United Nations, Lebanon Crisis Response Plan: 2017-2020, (2017), 11.

605 Yuval-Davis, Nira; Floya Anthias, and Eleonore Kofman, "Secure Borders And Safe Haven And The Gendered Politics of Belonging: Beyond Social Cohesion," Ethnic and Racial Studies 28, no. 3 (2005): 513535.

606 “Assessment Of The Impact Of Syrian Refugees In Lebanon And Their Employment Profile," International Labor Organization, (2013), https://www.ilo.org/wcmsp5/groups/public/---arabstates/---robeirut/documents/publication/wcms_240134. pdf.

${ }^{607}$ Government of Lebanon and the United Nations, Lebanon Crisis Response Plan: 2015-2016, (2015). 
plan also theoretically provides referrals and support to GBV survivors through robust interweaving mechanisms. Still, the 2017-2020 plan does not tackle in depth the unemployment predicament that the majority of the working-age refugee population suffers from. Existing socio-political gender hierarchies manipulate Syrian women's legal status and force them to adopt negative coping skills by working either informally under exploitative environments or remain free-ofcharge domestic laborers in the private sphere.

The study shows aid programs recognize women's issues as important to highlight but not enough to include them as reliable partners nor ensure adequate measures to deliver aid and protection, constructing an inferior identity for Syrian refugees in a power hierarchy vis-à-vis the relief providers, while at the same time preventing women refugees from seeking true empowerment. Even though there is an increased elaboration of the various targeted vulnerable groups, the constant marginalization of women as mere victims of abuse and violence is particularly seen in the case of unemployment noted in LCRP documents, furthering Syrian women refugees' daily (in)securities. Gender-specific policies for women are practically nonexistent outside of "eliminating sexual exploitation and sexual and gender-based violence." ${ }^{\prime 60}$ There is additionally a noticeable difference between the girls and boys in the "children" group. In fact, girls in refugee camps are at a higher risk of being subjected to "child marriage" because their parents are unable to cater their needs. According to the Women's Refugee Commission, armed

${ }^{608}$ Government of Lebanon and the United Nations, Lebanon Crisis Response Plan: 2017-2020, (2017), 24. 
conflicts have made young girls more vulnerable because they have no one to defend them. According to one study, their parents tend to marry them off immediately when they start menstruating. ${ }^{609}$ Humanitarian agencies often perceive child marriage as a negative coping response for parents who are struggling with poverty. Accordingly, their married daughters move to live with their husbands and inlaws, while in some cases parents also think that their daughters would be in a safer environment. ${ }^{610}$

The "environment" is also a priority sector where the second version of the LCRP made considerable changes from the previous 2015-16 LCRP. In the 201720 LCRP, the Ministry of Health, the government of Lebanon and other UN agencies including the UNDP, UNHCR, and OCHA formulated an environmental task force. ${ }^{611}$ The priority of this task force is to address major environmental impacts. To achieve this, the Ministry of Environment (MoE) is required to ensure there is mainstreaming environmental efforts mostly within emergency relief and stabilization projects. In turn, it would have the capacity to monitor the environmental impacts of the Syrian refugee crisis in Lebanon and guide plausible means for interventions. The MoE would also cooperate with the various sectors in the LCRP in order to identify and implement environmental interventions while

\footnotetext{
${ }^{609}$ Cherri Zeinab et al., "Early Marriage and Barriers to Contraception Among Syrian Refugee Women in Lebanon: A Qualitative Study," International Journal of Environmental Research and Public Health 14, vol. 8 (2017): 836.

610 "Childhood In The Shadow Of War: Voices Of Young Syrians," $\begin{array}{lll}\text { Save The Children, } & \text { (2015), } \\ \text { ://resourcecentre.savethechildren.se/sites/default/files/documents/childhood-in-the-shadow-of-war.pdf. }\end{array}$

${ }^{611}$ Ibid.
} 
exclusively focusing on the 2017 priority sectors including food security, social stability, water, and energy. The 2017-2020 LCRP aim is to expand its management of the deteriorating Lebanese environment through sustainable longterm development programs, with attention to water and waste management, use of energy-efficient products, and conservation of land use ecosystems.

Another notable change in the 2017-20 LCRP is on conflict sensitivity, which arises as a result of the complex social fabric of Lebanon as well as how the Syrian conflict has politically impacted the domestic scene. This LCRP fully incorporates the need for "social stability" by analyzing the potential adverse effects of maximizing the sector's contribution. There is no doubt that the "poor urban neighborhoods" were highly affected by the Syrian crisis given the challenge of hosting a big number of displaced Syrians. Therefore, the 2017-20 LCRP expanded on the 2015-16 neighborhood profiles by increasing its coverage of urban areas, while addressing the gaps by using a comprehensive and coordinated approach within a highlighted "Cross-Cutting Issues" section. ${ }^{612}$

\subsection{Transforming Themes}

Lebanon already suffers from "high levels of deprivation, inadequate access to basic services and social stability challenges." ${ }^{613}$ Subsequently, the Lebanese government required some transformations within the updated version of the LCRP to adapt and better control the refugee crisis at hand. The term "vulnerable

\footnotetext{
${ }^{612}$ Government of Lebanon and the United Nations, Lebanon Crisis Response Plan: 2017-2020, (2017), 24. 613 Ibid.
} 
localities" used in the 2015-2016 LCRP version became particularized to "Poor Urban Neighborhoods," a shift that had an important impact on the level of aid and assistance targeting displaced Syrians. The 2017-2020 LCRP elaborated on newly discovered situations where "vulnerable people are increasingly migrating towards poor urban areas where living conditions have significantly deteriorated." ${ }^{\prime 614}$ The plan calls for targeting its assistance efforts to "poor urban neighborhoods" through a coordinated and comprehensive approach.

As for the issue of "resettlement to third countries," the 2017-2020 plan changed the approach from stating that resettlement is a preferred solution to advocating for an actual mechanism to be put in place and provide "persons displaced from Syria humanitarian access to third countries." ${ }^{615}$ Still, to this date, with less than one percent of the global refugee population so far resettled, no thirdcountry has shown any interest in accommodating enough Syrian refugees to make a viable contribution to this plan. ${ }^{616}$ Therefore, stressing the need to resettle Syrians in third counties furthers unrealistic expectations about the degree to which resettlement measures can reach enough Syrian refugees in Lebanon, constituting a major setback for any durable solution proposed.

\footnotetext{
${ }^{614}$ Government of Lebanon and the United Nations, Lebanon Crisis Response Plan: 2017-2020, (2017),13.

${ }^{615}$ Government of Lebanon and the United Nations, Lebanon Crisis Response Plan: 2017-2020, (2017), 19.

616 "Global Trends: Forced Displacement in 2015" UNHCR (2016), retrieved from: https://www.unhcr.org/576408cd7
} 


\section{Diminishing Themes}

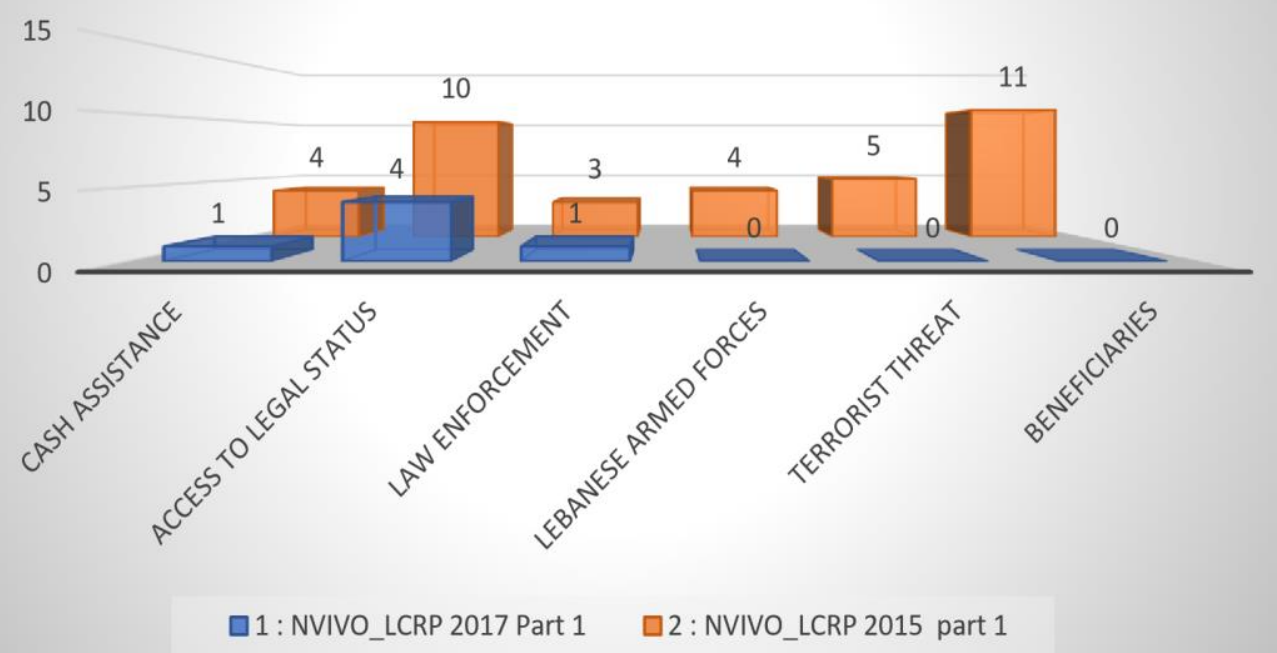

\section{Figure 13. Diminishing Themes}

As for the interrelated diminishing themes of "Law enforcement", "Lebanese armed forces", and "Terrorist threats", mentioned in the figure above, the study can shows that they are less visible in the 2017-2020 Plan. This latter could be due to the drastic weakening of ISIS and its retreat in the region and consequently the decrease of terrorist threats that were menacing Lebanon's stability during the creation of the 2015-2016 version of the plan. In fact, we find that during the terrorist attack/surge of ISIS in 2014, the 2015-2016 LCRP emphasized more on supporting the Lebanese armed forces in fighting the constant terrorist attack threatening the country's stability as Lebanon witnessed around 30 
terrorist attacks between 2013 and 2015 as seen in the table below. ${ }^{617}$ That number tremendously decreased to almost no successful attack in 2017.

On another note, as mentioned in the previous chapter, the hostility, violence, and hate crimes against Syrians have sharply risen. The negative impacts of Syrian refugees portrayed by most Lebanese outlets get exaggerated and misplaced, calling for their return.

Table 4. Summary of Attacks in Lebanon Post-Syrian Conflict

\begin{tabular}{|c|c|c|c|c|c|}
\hline Date & Area & Target & Method & Death & Injured \\
\hline Oct 19,2012 & Achrafieh, West Beirut & $\begin{array}{l}\text { Wissam Al Hassan, head of the intelligence } \\
\text { branch of the ISF }\end{array}$ & Massive car bomb & 8 & 128 \\
\hline July 9,2013 & Beir el-Abed, South Beirut & Popular street associated with Hezbollah & Car bomb & 0 & 50 \\
\hline Aug 15,2013 & Roueiss, South Beirut & Hezbollah stronghold & Car bomb & 27 & 300 \\
\hline Aug 23,2013 & Tripoli & Two mosques & Two car bombs & 42 & 400 \\
\hline Nov 19,2013 & Suburb, South Beirut & Iranian Cultural Center & $\begin{array}{l}\text { Car bomb and explosive } \\
\text { motorcycle }\end{array}$ & 22 & 146 \\
\hline $\operatorname{Dec} 3,2013$ & Beirut & $\begin{array}{l}\text { Hassan Lakkis, senior Hezbollah } \\
\text { commander }\end{array}$ & $\begin{array}{l}\text { Assassination by two } \\
\text { gunmen }\end{array}$ & 1 & 0 \\
\hline $\operatorname{Dec} 27,2013$ & Downtown, Beirut & Former Minister Mohamad Chatah & Car bomb & 6 & 70 \\
\hline Jan 2,2014 & Haret Hreik, South Beirut & Hezbollah Political Office & Car bomb & 4 & 77 \\
\hline Jan 16,2014 & Hermel & Bustling neighborhood & Car bomb & 5 & 42 \\
\hline $\operatorname{Jan} 21,2014$ & Haret Hreik, South Beirut & Bustling street & Suicide bomber & 4 & 46 \\
\hline Feb I, 2014 & Hermel & Petrol station & Car bomb & 4 & 23 \\
\hline Feb 3, 2014 & South Beirut & Van & Suicide bomber & 0 & 2 \\
\hline Feb 19,2014 & Suburb, South Beirut & Iranian Cultural Center & Two car bombs & 8 & 128 \\
\hline Feb 22,2014 & Hermel & Army Post & Car bomb & 5 & 17 \\
\hline March 29, 2014 & Arsal & Army soldiers & Car bomb & 3 & 4 \\
\hline June 20.2014 & Dahr Al Baidar & Police checkpoint & Suicide bomber & 1 & 32 \\
\hline June 24,2014 & Beirut & Military checkpoint & Car bomb & 0 & 12 \\
\hline June 27,2014 & Beirut & Hotel & Suicide bomber & 0 & 11 \\
\hline Aug 6, 2014 & Tripoli & Army checkpoint & Homemade bomb & 1 & 10 \\
\hline Sept 19,2014 & Arsal & Army & Bomb & 2 & 3 \\
\hline Sept 20, 2014 & Eastern Borders of Lebanon & Hezbollah checkpoint & Bomb & 2 & 0 \\
\hline Nov 14, 2014 & Arsal & Army & Bomb & 0 & 3 \\
\hline Dec 3, 2014 & Arsal & Army & Bomb & 1 & 2 \\
\hline Jan 10,2015 & Tripoli & Café & Suicide bomber & 9 & 30 \\
\hline $\operatorname{Jan} 26,2015$ & Zagharta & Ghassan Ajaj, ISF intelligence officer & Gunman & 1 & 0 \\
\hline March 2, 2015 & North Lebanon & Bader Eid, brother of Alawite leader Ali Eid & Gunman & 1 & 0 \\
\hline Nov 5,2015 & Arsal & Qalamoun Muslim Scholars Committee & Motorcycle bomb & 5 & 15 \\
\hline Nov 6, 2015 & Arsal & Army & Improvised explosive device & 0 & 5 \\
\hline \multirow[t]{2}{*}{ Nov 12, 2015} & Bourj el-Barajmeh, South Beirut & Hezbollah stronghold & Two suicide bombers & 43 & 240 \\
\hline & & & & 205 & 1796 \\
\hline
\end{tabular}

${ }^{617}$ Cherri Zeinab, Pedro Arcos González, and Rafael Castro Delgado, "The Lebanese-Syrian Crisis: Impact Of Influx Of Syrian Refugees To An Already Weak State," Risk Management and Healthcare Policy 9 (2016): 165. 
to their country. The cessation of new Syrian registrations and the impeding mechanisms to renew previous ones to obtain "Legal Status", required the diminishing of the theme to be mentioned less in the updated plan.

As for the last theme, when I first saw how the 2017-2020 plan evaded the mistake of portraying the receiving ends as "beneficiaries" I expected to find literature on what that means. Alas, to no surprise, not many justifications were made. In fact, when looking further into subsequent LCRP reports, the word "beneficiaries" popped out again. Still, to my "benefit" dwelling on what looks like a small anomaly helps this research highlight the needs for analyzing not only critically systemic changes but also language. Referring to refugees as "beneficiaries," language sensitivity becomes important for it matters how one chooses words. Labeling a Syrian "beneficiary" silences that person's agency of actively adapting, manipulating, and (re)defining complex humanitarian processes, attempting to access and gain the donors" "bene." When aid discourses inform aid practices across different institutions about Syrian refugees being part of a "beneficiaries" group, one would think that this creates an gendered discourse between the "benevolent" aid workers - benefactors - and "disempowered" refugees-beneficiaries_-seeking assistance, where power dynamics, gendered inequalities, and structural violence are reinforced. In this case, by labeling targeted groups as "beneficiaries," Syrian refugees get automatically stripped from being a distinct group that has international rights to seek aid and protection. Suddenly, these rights become benefits to certain Syrian who need to qualify to "gain" them. 
When the majority of Syrian refugees—women and children-can not renew or register, what would happen to their "beneficiary" status? Would they be viewed negatively by policy practitioners and involved aid workers as non-qualifying opportunists who might falsely claim assistance, taking advantage of the aid provided and/or trying to steal jobs away from residents? Also, this negative portrayal of the different vulnerable groups as beneficiaries due to the refugee crisis at hand increases local vindications of exclusionary practices that would worsen the mechanism of refugee aid and protection.

\section{New Themes}

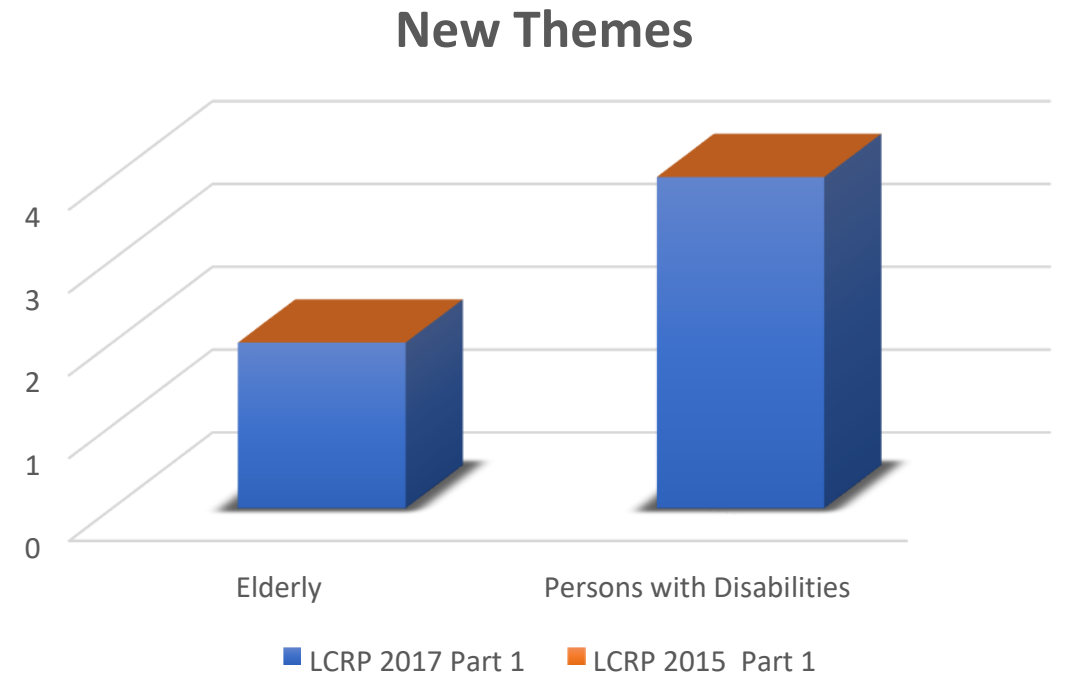

Figure 14. New Themes

As seen in the above figure, new terminologies such as "elderly" and "persons with disabilities" appeared in the 2017-2020 version of the crisis response plan. As a

618 Ibid. 
matter of fact, with the increased collaboration and humanitarian aid partners and the slight increase in gender marker, it becomes only predictable to find that the previously marginalized groups, whose (in)securities were mostly silenced in the earlier LCRP document, are now included in the 2017-2020 version. This latter should portray a positive move for the LCRP plans in elaborating on previously homogenized groups, while their agencies are still objectified. Instead, the study finds that the 2017-2020 LCRP document only expanded the crisis response needs assessment as part of a four-year term development plan that justifies the need for greater funding from potential donors. After all, most Syrian refugees are still in legal limbo, potentially deported, with limited mobility, unable to access basic safety nor emergency needs, among many other problems. Having all these elaborations within the newer LCRP version does not mean that their translation into concrete domestic policies with sensible response strategies that advance gender-equal treatment would be conceivable.

4. Analytical Implications

The purpose of this study was to highlight and compare the dominant cultural themes represented in the 2015-2016 and the 2017-2020 crisis response plans. This study showed how both crisis response plans are social constructions tied to the social fabric affected and affecting local realities. Adapting Dennis Wiedman's original work of organizational cultural theme longitudinal analysis to Susanne Zwingel's concept of norm internalization - the phase where the norm is implemented in domestic settings, this study helped the dissertation understand the dynamics between the main contributors - the Lebanese government and the 
UNHCR - better through the Continuous, Elaborated, New, Diminishing, and Transforming Themes that are dominant within both plans.

The study highlighted the organizational theme change from 2015 to 2017, broadly connecting it to the complex dynamics of norm translation practices that engage with their fluid environment. The study finds that many nodes and themes diminished such as "terrorist threats," "Lebanese armed forces" and security. This would mean that the specific security problems that are related to those themes were either successfully controlled or seized to be a major problem. At the same time, only two new themes_elderly and disabled persons - emerged in the 2017-2020 plan, which can be considered more of an expansion of targeted groups and protection techniques than utterly new approaches brought into the 2017-2020 crisis response plan, reflecting the host society's expanding its adoption of humanitarian norms within its crisis policy plans. Meanwhile, most cultural themes identified in the 2015-2016 LCRP are also recurring in the 2017-2020 LCRP through mundane bureaucratic practices and refugee management efforts that reinforce Bigo's concept of securitization and Sara Gibson's conditional hospitality. ${ }^{619620}$ Most challenges facing Syrian refugees in Lebanon addressed in 2015 are still mentioned in the 2017 plan, reflecting the host society's feeling of unease.

${ }^{619}$ Didier Bigo, "Security And Immigration: Toward A Critique Of The Governmentality Of Unease," Alternatives 27, no. 1 suppl (2002): 63-92.

${ }^{620}$ Sarah Gibson, “Abusing Our Hospitality: Inhospitableness And The Politics Of Deterrence," Mobilizing Hospitality: The Ethics of Social Relations in a Mobile World (2007): 159-177. 
Still, the discussed changes between both LCRPs create room for hope in the refugee crisis management approach, drawn from the setbacks of the first version, thereby coming up with innovative responses that could empower both Lebanese citizens as well as Syrian refugees. The second LCRP version seems more focused and inclusive to previously invisible and new realities- -energy" and persons with specific needs such as "elderly" and "persons with disabilities" and "youth." It builds on the 2015-16 LCRP version, generating various programming activities for eliminating issues such as genderbased violence. Other changes also imply that youths are now seen, hence motivated through job creation; The second version of the LCRP plan calls for enhanced employability and the youth access to both formal and informal education. The fact that the 2017-2020 LCRP has made more efforts in wanting to safeguard the environment also implies that its stabilization efforts in various sectors including water, energy, social welfare, and food security are desired. After all, there was a 10 percent increase in the budget from 2.48 billion USD in 2015-2016 to a longer-term project of 2.8 billion USD for 2017-2020 LCRP.

Still, in practice the second plan's development project for social stability did not match up to the continuing insecurities on the ground for the refugee crisis is still on emergency mode, not controlled yet, where Lebanese national interest measures justify exceptional mechanisms of refugee deterrence and exclusion. In all the interviews that I conducted, the experts' stated that the main weakness of the LCRP 2017 program is lack of funding and disproportionate deterioration of the refugee crisis situation. Even though the expert interviewees raised many 
continuing serious issue-such as limited participation, lack of transparency, and Legal discriminations that hinder most of their daily operations among manyfunding was the main theme of their complaints and not the root causes for the unsustainable status quo.

Although this analysis showed some improvement in addressing the challenges facing refugees in a sustainable contextual manner, still the stereotyped perception of Syrian refugees as both dependent and problematic, which both Lebanon and the international community buy into, mostly remains. Despite official declarations in favor of refugee protection in general, both states and international organizations have not accurately addressed Syrian women's insecurities, and in turn, their human rights, livelihoods, and resilience were often objectified and not prioritized. Other than momentarily mentioning women within specific refugees' protection measures such as sexual and gender-based violence or targets of psychological support and monitoring systems, within both crisis response plans, women have been absent from major response approaches with no gender-specific empowerment measures. ${ }^{621}$ Subsequently, limited refugee emergency relief can neither offer refugees' gender comprehensive aid protection, nor real prospects in the long term, especially in the context of a protracted crisis. ${ }^{62}$ This latter was highlighted in the gender marker change within both documents,

${ }^{621}$ Alison Gerard and Sharon Pickering, "Gender, Securitization and Transit: Refugee Women And The Journey To The EU,” Journal of Refugee Studies 27, no. 3 (2014): 338-359.

${ }^{622}$ Sue Lautze and John Hammock, "Saving Lives and Livelihoods: The Fundamentals Of A Livelihood Strategy.” Feinstein International Famine Center, Tufts University, (1997). 
where gendered security concerns are still often prioritized, commonly leading to a gap between stated gender empowerment intentions and the local refugee management practices that objectify the majority of Syrian refugee women's insecurities. According to both LCRP documents, Syrian women are still viewed as lacking both the legal status and local support within their gendered environment to have their concerns prioritized, including those that are directly linked to their personal security and survival.

While Syrian women residing in Lebanon are forced to engage the public sphere to secure their livelihood, the study finds that both LCRP plans do not provide them with the necessary tools to successfully navigate the public sphere as productive members. In effect, one of the most problematic issues within both plans' design is that they are both based on the assumption that the top managers of the crisis response plans have the moral capacity and exclusive role to save those de facto refugees along with the vulnerable Lebanese communities by doing for them rather than working with them to empower their selfreliance efforts. ${ }^{623}$ Consequently, the response strategies offered would hardly work in empowering Syrian women without involving them in the process. It is particularly important that these doubly discriminated women need to have a say in the LCRP for it is imperative to recognize their essential role as active agents and potential

${ }^{623}$ Elisabeth Olivius, "Constructing Humanitarian Selves And Refugee Others: Gender Equality And The Global Governance Of Refugees," International Feminist Journal of Politics 18, no. 2 (2016): 270-290. 
humanitarian actors who would want to be productive within their host communities.

On another note, the study shows that most alterations made between both plans do not seem to ease the Syrian presence in Lebanon. Dealing with such a critical humanitarian situation with an increasing collection of competing nongovernmental partners-104 appealing UN and NGO partners-brings up many challenges and criticisms from all parties. This latter creates room for misperception, where numbers have become essential to monitoring and evaluating the now feminized Syrian population as a burden: backward and dependent on aid assistance. The inaccurate statistics and numbers become necessary to convey as much human misery as possible as scientific truths and mobilize sufficient donor funds for one of the competing sustainable solutions offered within the crisis response plans. Consequently, as subjects of intense refugee protection practices, various groups of Syrian refugees become heavily dependent on sporadic protection measures and diminishing aid assistance. Standard operating procedures, regarding who gets what, when, and how, are spread among thousands of interested NGOs that do not necessarily partner with the LCRP plans and whose accountability is poorly managed by both the Lebanese government and UNHCR. ${ }^{624}$ Accordingly, resilience intervention programs through these agencies hardly empower refugees'

${ }^{624}$ Volker Turk and Elizabeth Eyster, "Strengthening Accountability In UNHCR," International Journal of Refugee Law 22, no. 2 (2010): 159-172. 
livelihood without the government's blessing, counterintuitively discriminating against the same refugees they are trying to protect.

In that respect, using a longitudinal organizational cultural theme analysis, this chapter was able to shed light on the dynamics of refugee management, aid assistance, and prevention of violence in an already fragile country. This study filled an empirical void on exploring the gendered power relations between a developing host country like Lebanon, which has a long history with the population seeking asylum, and a seasoned international humanitarian agency, such as the UNHCR. Both institutions had to adapt to a case of a protracted Syrian refugee crisis and cooperate in refugee management practices, showing elements of resistance, compromise, and (re)construction of gendered crisis response plans for the sake of refugee protection and national stability. As such, the altruistic crisis response plans assume that the providers and administrators of relief possess a mandate to save those who are oppressed and in need. These discourses emphasized the politicization of the refugee crisis while, at the same time, depoliticized the Syrian refugees, excluding them from the crisis response strategy formulation and practice. Simultaneously, the vulnerable otherness that the Syrian refugee represent is contested within Lebanese public discourse with the assumption that Syrian refugees are opportunistically what Elizabeth Olivius highlights; needy, helpless, and dependent on those who will help, save and modernize them. ${ }^{625}$ Consequently,

${ }^{625}$ Elisabeth Olivius, "Constructing Humanitarian Selves And Refugee Others: Gender Equality And The Global Governance Of Refugees," International Feminist Journal of Politics 18, no. 2 (2016): 270-290. 
these strategies would then objectify their insecurities, reinforcing and (re)producing local insecurities, where the Syrian refugee crisis in Lebanon is no longer sustainable. 


\section{ALTERNATIVE REFUGEE INSECURITY NARRATIVES}

This chapter explores how gender (in)security norms are applied on the ground with local repercussions. Through photovoice methodology, the goal was to enable local Lebanese volunteers to give visibility to Syrian refugees by recording and reflecting the volunteers' views of Syrian refugee insecurities through pictures and voice to reach normative policy change. In effect, the participants became co-researchers: collecting pictures, analyzing data in group form, discussing, elaborating, and sharing their findings, while, at the same time, recognizing their own anxieties as Lebanese citizens towards the Syrian refugee presence within their communities. This grounded approach enriched the contextual analysis of the gendered impact translation by highlighting the intersectionality of Syrian refugees' insecurities and resilience efforts, specifically those of Syrian women. Whereas keeping in mind, this relatively small sampled project is by no means representative of, nor appropriate to generalize all the Lebanese individuals'-with a plethora of intersecting gendered identities_-views of Syrian refugee presence in Lebanon.

Therefore, this chapter, first, discusses the motives behind this participatory action-oriented method by describing its novel approach and contributions to understanding the (en)gendering of Syrian refugee insecurities. It, then, highlights the views of local Lebanese volunteers when addressing the issue of Syrian refugee (in)security in the case of Lebanon. These participants discussed and analyzed the Syrian refugees' insecurities, which the study incorporates into three major themes titled as: Extreme Impoverishment and Devastating Living Conditions; Identity and Security; and Labor and Gender Roles. 
Thirdly, this chapter explores the research findings and implications of using the Photovoice method. The final section evaluates the (en)gendered local implications and discusses the deterioration of the Syrian refugee crisis in Lebanon.

\section{Motives}

As mentioned, the main purpose of PAR is to formulate alternative knowledge, produced by individuals closest to the problem that is under investigation. ${ }^{626} \mathrm{By}$ enabling local Lebanese volunteers to record through pictures Syrian refugees' realities within specific contexts, the research participants became co-researchers, reflecting on what they perceive as refugee insecurities in their local communities. This qualitative participatory action-oriented research facilitated increased insight into the volunteers' perceptions of the Syrian refugees' complex lived experiences and perceived (in)securities. The representation of Syrian refugees in Lebanon becomes a key component of how refugee policies — such as the LCRP — are written, interpreted, contested, and applied. PAR also acts as a conduit to look deeper into the research participants' position in the Syrian refugee crisis within Lebanon. The timing of taking pictures and accompanying narratives can only reflect their author's subjective "beliefs, feelings, and cultural experiences." ${ }^{627}$ By voicing out their own insecurities, the research participants (re)examine how refugees are represented and situated within Lebanese communities. Accordingly,

\footnotetext{
${ }^{626}$ Michelle Jarldon "Photovoice Handbook for Social Workers: Methods, Particularities and Possibilities For Social Change." Palgrave. (2019) 1-24.

${ }^{627}$ Lisa M. Given ed, The SAGE Encyclopedia of Qualitative Research Methods. SAGE, (2008), 844.
} 
the participants (in)directly discussed the projected Lebanese anxieties of the (in)visible Syrian refugees' agency and complex (in)securities they (re)produce within their host communities. By elaborating on the visuals during the photoelicitation session, the co-researchers contributed to alternative visual narratives expanding and deepening our understanding of the co-constructed community discourses that (en)gender Syrian refugee (in)security in the case of Lebanon.

\section{Thematic Analysis}

The participant-oriented analysis process - known as photo-elicitation-brought all participants to share their findings while acknowledging that each image might generate different meanings and critiques. The main purpose of photo-elicitation sessions was to record the participants' views of each picture. The co-researchers and I engaged in a group discussion and reflected on what was deemed important to contextualize within the pictures based on the discussants' background, professional knowledge, and field experiences. Together, we selected the pictures to be chosen for the project, created a caption for the selected ones, and elaborated on the inferences behind each image according to the SHOWeD model, which the study is keen to follow in the coming section. ${ }^{628}$ This process guaranteed both individual storytelling and group dialogue of each picture positioning their arguments within the greater refugee (in)security context. Even when there was no group consensus, the multiple inputs on each photograph discussed in the photo-

${ }^{628}$ Caroline Wang and Mary Ann Burris, "Photovoice: Concept, Methodology, And Use For Participatory Needs Assessment,"Health Education \& Behavior 24, no. 3 (1997): 369-387. 
elicitation process enriched this project. Participants ended up personalizing each picture, attributing their knowledge, social, and personal values to it when explaining their respective views of each photograph. Correspondingly, participants reflected on their individual interactions with different Syrian refugee groups, provided field knowledge of Syrian refugee (in)security practices and highlighted local repercussions.

The photo-elicitation process involved the co-identification of major themes among participants with deliberative, ongoing discussions about the meaning behind each summarized photograph finding. As a result, the general themes for this project depicted the scarcity of Syrian refugees' basic needs and the (re)production of (in)securities within the informal camps due to harmful policy practices. Accordingly, this exercise helps this study showcase how negotiated refugee (in)security norms and practice resonate in different contexts (re)producing sights of Syrian refugee adoptions, (re)constructions, (re)definitions, and contestations. In the meantime, those themes also revealed the relationality of Lebanese coworkers involved in refugee assistance efforts and knowledgeable of the refugee crisis situation. From the way they saw Syrian refugee (in)securities, the co-researchers would highlight a specific agency of Syrian refugees — such as child labor and working women—within Lebanese communities and elaborate on the background of certain aspects that might not be, obviously, portrayed within the chosen pictures. To that matter, each one of the three themes I created was an outcome of a collection of the subthemes captions that the participants collectively produced. 
Theme 1: Extreme Impoverishment and Devastating Living Conditions Twelve photos addressed the issues of extreme impoverishment and devastating living conditions that Syrian refugees in Lebanon endure in some of the approximately 2,000 informal settlements scattered in rural areas all over the country. These twelve photos were divided into the following four sub-themes, followed by a summary of the main points.

It is important to note that the captions, photos, and analysis provided below are based on the discussions that took place during the photo-elicitation process between the main researcher and all five participants. The following literature neither represents my sole observations nor each participant's individual opinion. Instead, it is a collection of a variety of opinions, highlighted during the process. 


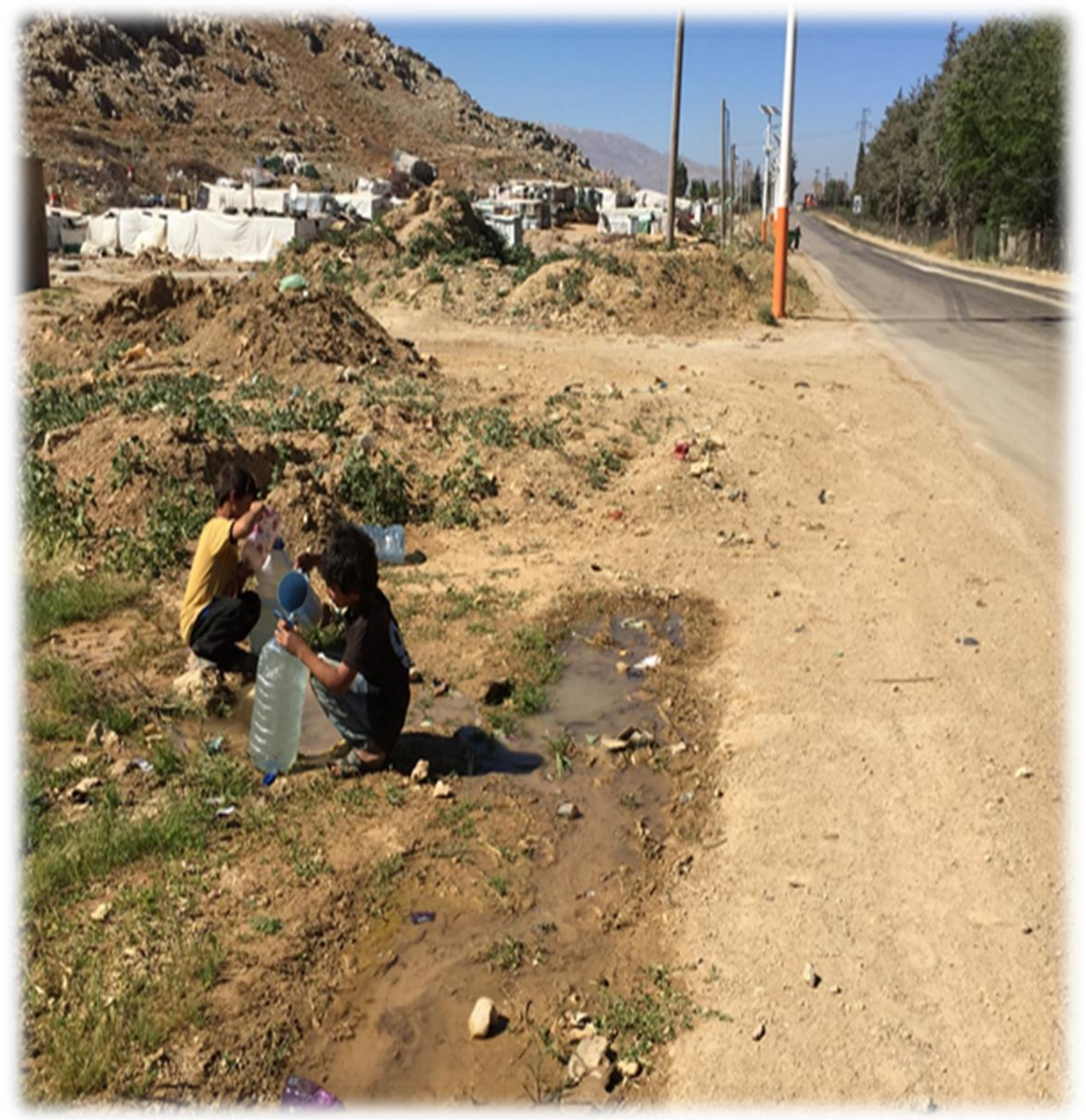

Figure 15. I am Thirsty!

In the photo above, two young children are trying to get water from a dirty puddle of water near the highway to fill two large empty plastic containers. According to one participant, these are not children playing in the mud. Instead, they were tasked to collect water for the household, and the muddy water is probably the nearest and only available source of water they can reach. According to all participants, this photo reflects a reality that is supposed to be shocking to the concept of the modern 
way of life in a developed country, the lowest acceptable standards of living, and human dignity. Not only are these children not supposed to be in this situation in the first place, but it was also ordinary to most participants to think of the unsanitary water, its lack of hygiene, and deadly bacteria and viruses present in it. According to most participants, this photo sums up the current situation of hundreds of thousands of Syrian refugee children, uprooted from their villages and towns, and forced to adapt to a neighboring country that already suffers a weak infrastructure, limited resources, and dwindling support from the international community.

All participants agreed that this problem has been a major issue in Lebanon before the refugee crisis and cannot be solved without understanding the political, social and cultural dynamics within the region. Some participants referred to accredited programs, such as Water Sanitation and Hygiene (WASH) that implemented specific projects to improve access to safe drinking. In that respect, the study concluded from an annual WASH result report that UNICEF provided that only $65 \%$ of 150,000 Syrians living in ITS receive a basic aid assistance and support, such as water, sanitation, and infrastructure. ${ }^{629}$ Knowing the inhospitable poor conditions of the informal settlements - makeshift tents lacking doors, proper toilets, electricity, and hygiene services - these children could die from preventable diseases.

Still, all participants acknowledged that the exponential increase in population and the poor measures for managing water made it more difficult to

629 “Annual Results Report. Water, Sanitation And Hygiene.” UNICEF. (2016), 41. 
enhance hygiene practices in most Lebanese communities, where women and children are adversely affected. As such, several participants distrusted the shortterm initiatives that are, currently, introducing clean water, basic toilets, and good hygiene practices, claiming they were either corrupt or insufficient. In their view, there is a need to develop adequate infrastructure or contingent solutions for bothlocal communities and Syrians residing in them-while ensuring financial transparency of resources acquired from the international community. Most participants agreed that a bulk of this problem could not be solved without a political arrangement — the ending of violence in Syria, and, consequently, Syrians' safe return to their homes.

The participants' portrayal of Syrian children getting water from a dirty puddle of water is an inherently demonstrative case of their agency. The above photo-elicitation brought to light how Syrian children seem to play a crucial part in household maintenance increasing their role within the domestic sphere that is typically framed as women's domain. Accordingly, the co-researchers' illustrations and analysis of the above image reinforce the research's aim in highlighting the fact that, Syrian residents are not passive recipients of the local humanitarian aid system. Instead, these Syrians appropriate, negotiate and modify their surroundings any way they can to survive. Therefore, the traditional relief model implemented in refugee crisis response plans fails, for it discounts these dimensions of normalcy and resilience that inherent in a people. Consequently, the dyadic linear depiction of Syrian refugees as passive recipients of aid assistance gets further complicated. 


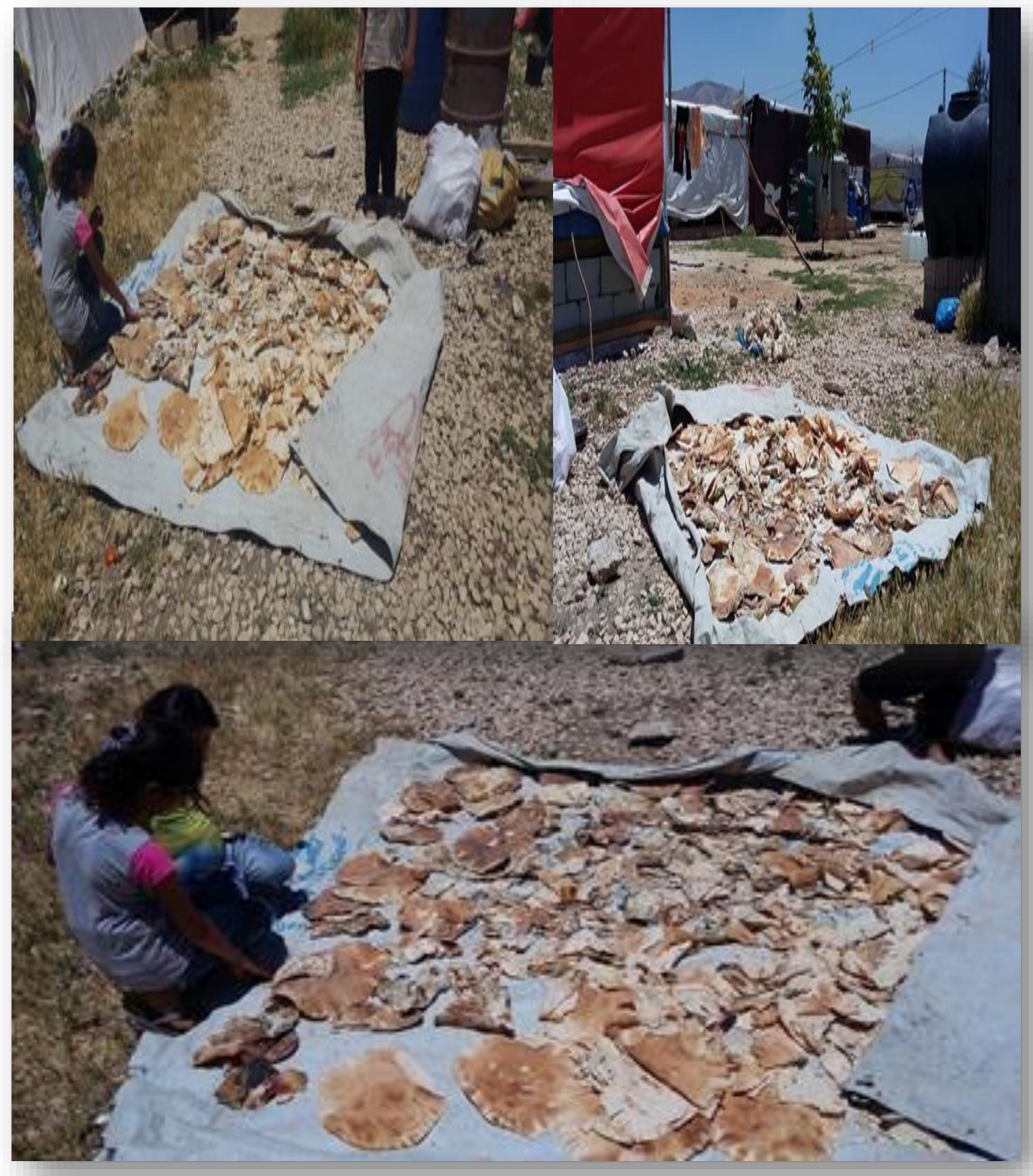

Figure 16. I Am Disinfecting Bread

In the photos above, Syrian children are seen drying up bread in the sun on a UNHCR-branded recycled tent. At first, this practice may seem to be part of preparing a traditional food of sorts. In reality, this is a process by which Syrian 
refugees disinfect and preserve bread in the sun for later consumption, mainly because bread, food supplies, and donations reach refugee populations on an irregular basis. Hence, some participants claimed that Syrian refugee women are forced to take unusual measures to prevent or disinfect stale bread to secure food availability for their families whenever supplies do not arrive on time.

This sub-theme was recurrent during the photo-elicitation discussion, illustrating the degradation of the quality of life for many Syrian refugees to the extent that it can no longer be compared to standard everyday life in Lebanon. Most participants associated this scenery with misery, usually depicted in films and novels, talking about the way of life during times of desperation. This image generated divisions between two main group perceptions. One group justified such a scenario as a natural result of forceful displacement, while the other normalized this behavior of unsanitary diets frequently performed by rural families as part of the Syrian-Bedouin tribal customs and practices. Accordingly, such photoelicitation produces the typical gendered case where Syrian women resiliently adapt new measures to curb hunger. ${ }^{630}$ In that respect, their views seem to complement one report of the gender situation and vulnerability of Syrian refugees. This report stated that Syrian women resort to harmful health cultural practices of cutting down on their own food intake so that "children and men in the household can eat....certain types of aid (specifically food vouchers) are insufficient; some

${ }^{630}$ Rola Yasmine and Catherine Moughalian. "Systemic Violence Against Syrian Refugee Women And The Myth Of Effective Intrapersonal Interventions," Reproductive Health Matters, (2016). 
respondents reported selling their [Syrian women] vouchers at lower than face value to get cash to pay rent or other expenses." ${ }^{\prime 631}$

All participants agreed that humanitarian aid and refugee relief systems that are set in place are inadequate and still suffer from underfunding, poor management, and corruption. Some participants discussed the available electronic food voucher (E-card system) that allows registered Syrian refugees to purchase food from hundreds of the World Food Program (WFP) contracted shops. Still, most participants believe that the E-card system creates a hierarchical space for opportunism, where often privileged men, more knowledgeable and adequate to handle transactions, take advantage of the unified system for cash transfers and control their extended family members' income. Accordingly, their photoelicitation provide a case of the masculinized impact of refugee insecurity. Where women are doubly discriminated; once by the availability of the aids and funds provided within through the E-card system, another by the gendered cultural norms and the aid mechanisms that limit them from avoiding or even accessing unpleasant and undignified shopping experiences at the scarce partner stores available in their area. On the one hand, the male-headed households are generally controlled by primary cash recipients - Syrian refugee men — who generally decide how money should be spent. On the other hand, female-headed Syrian refugees' households are according to one study excluded from receiving aid as cultural norms often prevent

${ }^{631}$ Claire Harvey, Rosa, Garwood, and Roula El-Masri.. "Shifting Sands: Changing Gender Roles Among Refugees In Lebanon.” Oxfam International. (2013), 4. 
most Syrian women from being able to register and follow up by themselves with the UNHCR's partner agencies. ${ }^{632}$

Some of the suggested solutions that the participants elaborated on were to find ways to ensure that food donations reach all targeted refugee populations immediately rather than subcontracting them through large organizations, often corrupted and too slow to deliver. Another suggestion made by all participants was to push the international community to be more involved in providing direct aid and awareness to refugees, not only by increasing support to the Lebanese government but also by improving the management, supervision, and efficiency of the one-on-one donation programs.

632 Ibid, 14. 


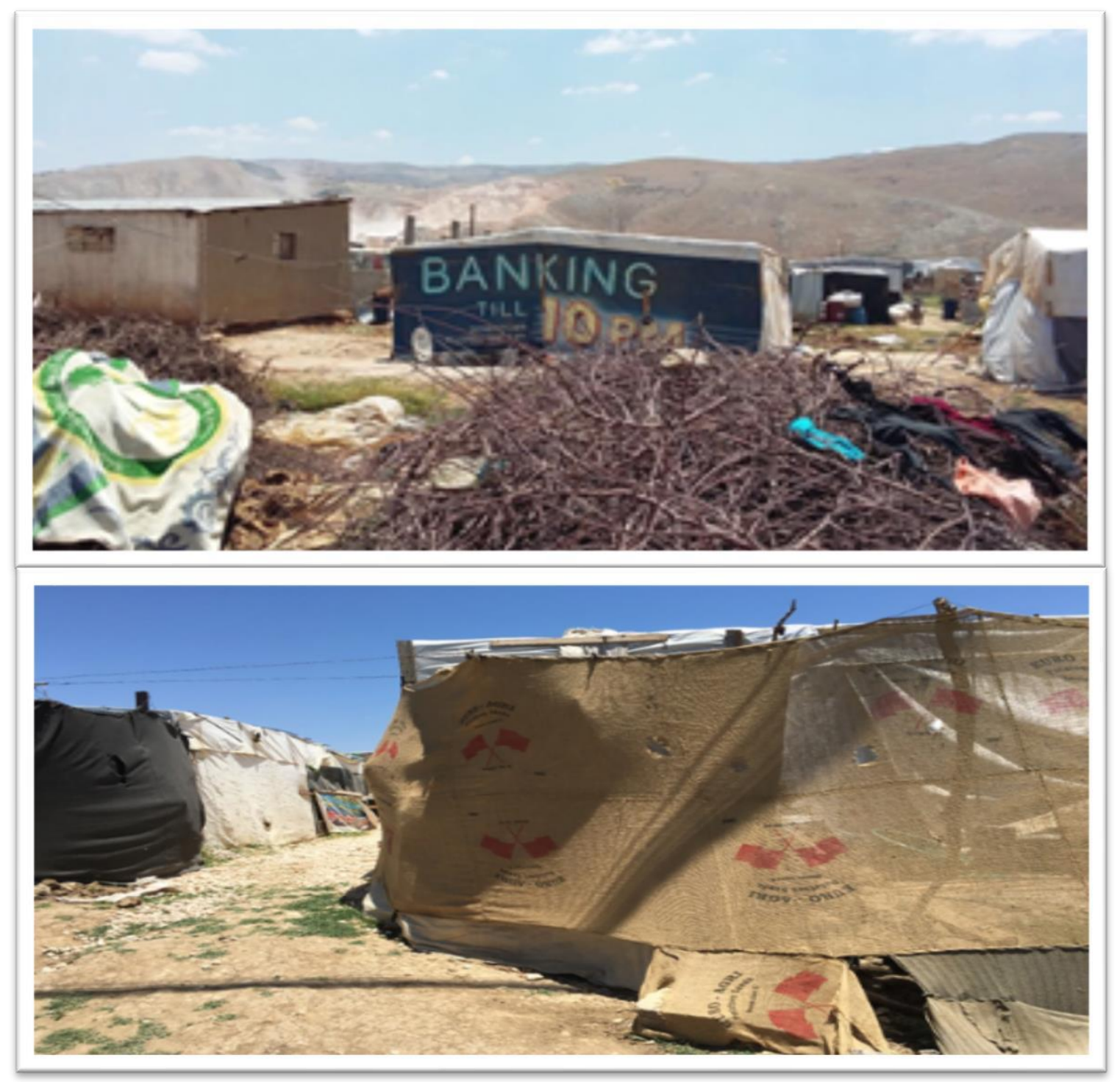

Figure 17. Scavengers

The above collection of photos depicts the exteriors of the tents and makeshift shelters that are typically seen in Syrian refugee shelter camps across Lebanese territories. One of the photos shows a collection of materials scavenged, outsourced, and even possibly stolen from everywhere, including tarps, cloth, cardboard, barrels, plastic containers, and metal sheets, among other accessible material—all to build a tent-like structure to shelter Syrian families. All participants 
agreed that these photos are perfect depictions of the common sites of desperation for survival by most Syrian informal campsite communities, deprived of adequate resources for resettlement. With no concrete plan to host the million and some Syrians, who, according to a few participants, "swarmed" into Lebanon between the year 2011 and 2015, illicit forms of Syrian refugee resilience were adapted; what the participants captioned as scavenging. This negative connotation, during the photo elicitation, on the Syrian presence provides one example of how some participants' perception is still affected by the hostile Lebanese attitude towards the inflow of Syrian refugees to Lebanon. Still, participants were keen to project their blame towards the Lebanese government's refusal to accommodate Syrians and provide viable shelters.

Even though most participants do not agree with creating official camps like the ones provided to the Palestinians, ensuring viable shelters would be a small effort in the right direction. Another part of the problem blamed by all participants is the failure of the international community, especially the United Nations, to take the necessary measures to manage the refugee crisis in Lebanon. As a result, some participants highlighted that much of the international organization's donations went to food, while very little went to shelter, which is considered by the participants to be the most pressing concern for most Syrian refugees, especially in areas of the country that know extreme weather conditions.

Accordingly, the participants viewed these tents as a sharp contrast to the most basic standards of living that one would expect in a village or a city. According to one participant, these shelters provide no privacy and no protection from 
intrusion or attacks, where Syrian women and children are vulnerable to any type of harassment, assault, or abduction.

Accordingly, the participants' statement that women and children are more vulnerable to assaults and attacks indirectly reinforces a justified dyadic view of refugees' identities and practices, where Syrian women and children are the weakest links having little to no agency in thwarting or even initiating such discriminatory attempts. One challenging question to the caption of the above picture is: if Syrian women and children comprise almost $80 \%$ of registered Syrian refugees in Lebanon, what is the probability of them being the scavengers? This is not to point fingers on their resilience efforts. As an alternative, it is an attempt to contest the gendered image of Syrian refugee women and children; passive victims. Instead, this "scavenger" image would represent one of the many ways refugee women brave through the worst humanitarian crisis by "shifting, changing, building, learning and moving on." 633

On another note, it is also important to point out that some participants correlated the scavenging situation with many Syrian experiences on the outskirts of urban areas, where a couple of participants criticized specific humanitarian programs. One example mentioned was the UN-Habitat that focused its effort on mostly liaising with landlords as focal points in their endeavor to identify new shelter units and rehabilitate existing ones. In their view, the informality of a renting

${ }^{633}$ Mariastella Pulvirenti, and Gail Mason, "Resilience And Survival: Refugee Women And Violence," Current Issues Criminal Justice.HeinOnline. 23 (2011): 37-52. 
agreement between a landlord and Syrian tenants further complicates the modality of what is called as "cash-per-task" basis programs, restraining direct access and assistance to refugee sites, having limited knowledge and monitoring mechanisms of distributed materials. There was unanimity on the issue of tackling corruption, especially when talking about aid programs that do not reach the people in need. Many participants echoed Syrian women's outcries towards the low quality of materials being provided if provided at all. All participants agreed that there are no immediate solutions to this problem without the inconceivable political decision of either accepting the build-up of formal refugee camps or guaranteeing the safe return of Syrian refugees to safe zones in Syria. Some participants' negative reaction to the formation of formal settlements brought to light their fear as Lebanese citizens of the great number of Syrians presents in Lebanon. In their view, formal Syrian refugee spaces could only lead to more Syrian concentration, (re)producing another dire threat to Lebanon's political stability, such as what previously happened with the Palestinian refugees' case.

Overall, the participants' depiction of Syrian refugees as scavengers is a great example of how Syrian refugees' resilience is a dynamic process relevant to the setting they are in. In effect, these contextualized actors-Syrian refugeesseem to be contesting the imposed gendered policies and harmful securitization practices to bounce back, (re)producing refugee (in)securities and creating disturbances within the status quo. As a result, this type of resilience efforts showcases how Syrian refugees retaliate to oppressive management by adopting negative coping strategies to overcome their experiences. 
Ultimately, these reactions would reinforce the contestation, resistance, and (re)construction of gendered inequalities, (re)producing an (in)security vicious cycle within the informal camps and respective host communities.

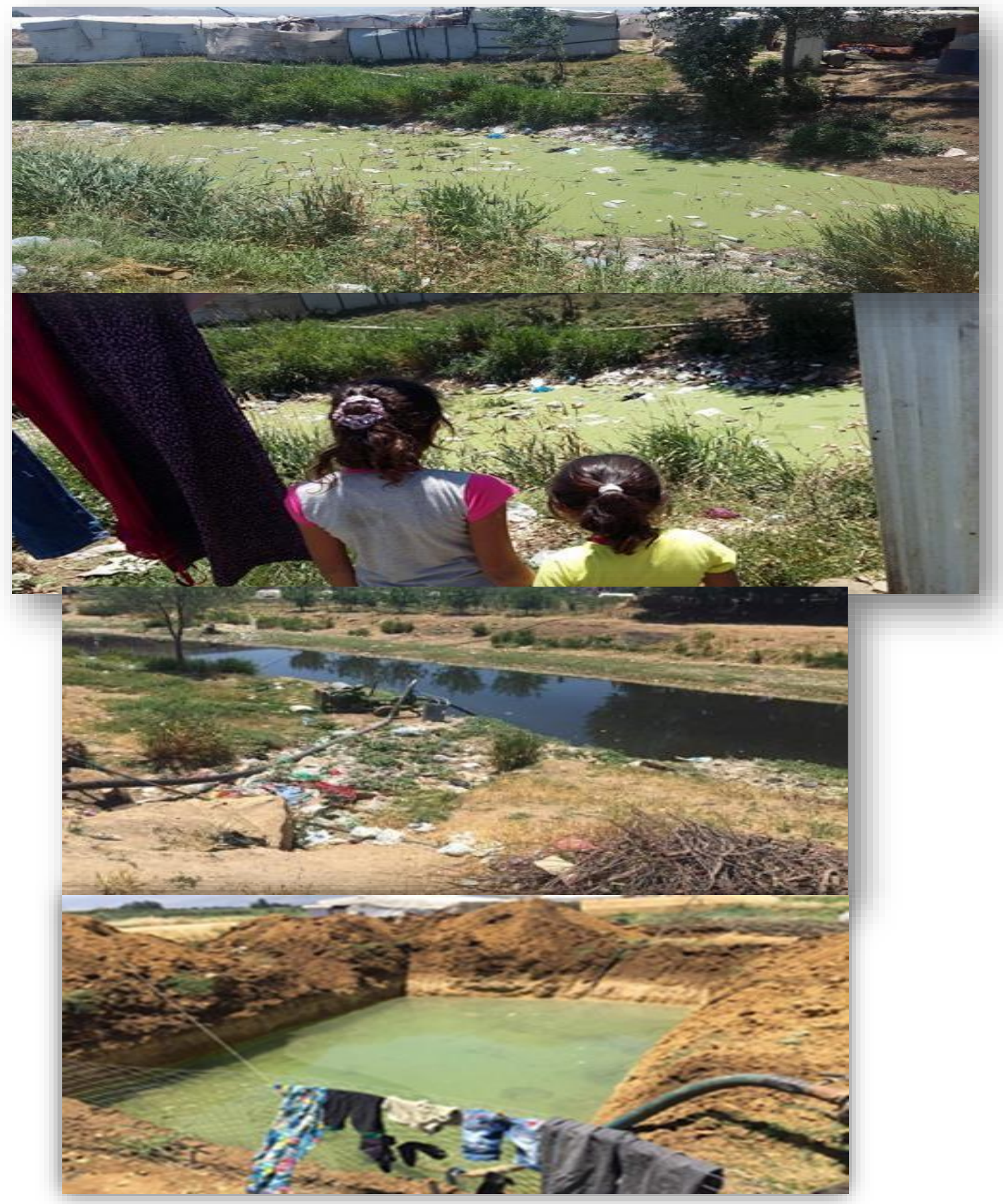

Figure 18. W.A.S.H. 
The above collection of photos shows the impact of refugee life on the Litany Riverside. Many refugee camps were erected near rivers simply because of the proximity to water sources. The first photo shows two young girls standing at the gate of a tin cottage watching a green patch nearby. In reality, participants stated that this is a pond of algae, which has formed as the water and garbage flowed down from the river and into the periphery of the refugee camp. Participants claimed that such a photo relates to their lives in several ways. First, these images are a reminder of the humanitarian catastrophe facing Lebanon with little effective intervention measures to bounce back from it. Participants chose these photos as a symbol of the deterioration of Lebanese infrastructure and waste management due to the Syrian influx to land already suffering from pollution. Secondly, these images show the severe nature of refugee life, where access to clean water is a luxury instead of being a fundamental right. These photos are also a reminder of the serious issues associated with the Syrian crisis that residents are facing in Lebanon, such as the strain on water supply, pollution, contaminated rivers and lands, and the spread of poverty-related problems.

Some of the photos above display pumps installed near the river and pipes carrying water to refugee settlements. The reality seen in these photos is the devastating impact of the sporadic informal settlements along Lebanese rivers, especially the excessive waste and pollution afflicting that area. Some participants, however, highlighted that the river water was polluted even before the outburst of the Syrian war and the arrival of Syrians to its land. According to participants, the primary cause of this unsanitary foul-smelling water infrastructure is the poor 
management and planning by the crisis response plan strategists - Lebanese government, the UNHCR, and donors-leaving wastewater, human excrement, industrial chemical overflow and residuals from quarries unattended. According to the participants, these organizations are aware of but mostly negligent about this longstanding water crisis. One of the main problems highlighted by the participants is the issue of ongoing corruption; unlicensed over-abstraction and illegal activities operating along Lebanon's main rivers such as the Litani. Some participants recapped the "You Stink" - Tul3it Rihetkun-movement protesting the garbage crisis and lack of trash collection in most municipalities due to tractor pull scandals over public waste management that Lebanon was and is still enduring. According to the participants, these demonstrations started when Lebanese communities were inundated with piled-up rubbish in the streets due to a shortage of garbage collection agencies and expiration of a dubious contract between the Lebanese government and the exploitative company Sukleen, among many other issues. All participants reiterated that there is a social distrust in the inconsistent public services that subcontract their managerial operations to monopolistic private businesses with dubious political connections and hiring personnel.

At the same time, most participants agreed that the Syrian presence in certain areas further deteriorated the water pollution, with refugees resorting to throwing their waste in the river instead of being proactive and disposing of it in corresponding garbage collection bins. Participants argued that the dirty river water is pumped directly to the informal settlements for consumption by Syrians who end up suffering from poor hygiene, sanitation issues, and various health problems. 
Still, one participant criticized the unavailability of collection bins near the informal settlements, justifying the negative coping strategies. Syrian residents utilize to adapt within their (in)accessible environment. Accordingly, the last photo in this collection shows a humanmade waterhole, intended to collect water for agricultural use, showing a pump and pipe, as well as wet clothes left to dry. All participants stated that most Syrians' health problems were related to a lack of clean water, proper sanitation, and hygiene. Although this water was intended for agriculture use, the nearby Syrian refugee settlement is accessing it for domestic use as well. Some participants elaborated on Syrian women's agency, where this infested water gets pumped out of the hole into the camp and is used for cooking, bathing, washing, laundry, and other household practices. Even though women play a key role in securing the household food and water resource management, some participants view that these women are still affected by their insufficient decisionmaking power within their household and community at large. This structural dynamic, highlighted by the photo-elicitation session, highlights the Syrian women's significant plights as inherently private, awaiting the male head of the household's approval and prevents these women from making the suitable choices in order to receive adequate care. Under those circumstances, the possible perils of Syrian women using this type of water supply not only jeopardizes Syrian lives within this camp, but also threatens the nearby health facilities, the continuity of overburdened service delivery, and weak local governance. Even though the problems in acquiring safe access to clean water differed slightly by shelter type, 
according to participants, this type of Syrian resilience prevents local health institutions from containing and preventing similar disease outbreaks.

All participants view additional refugee demands to the already neglected water resources has set the country on a self-destructive path. Participants' suggested solutions were twofold: immediate relocation of refugee settlements away from the polluted rivers to areas where supplies of clean water are available. In the meantime, participants reiterated the need to hold the Lebanese government accountable for improving its public services and addressing the issue of river pollution as a sustainable long-term goal for the sake of its own citizens. Most participants advised of the need to encourage water treatment and safe water container maintenance amongst refugee households, raising awareness on how to take care of national resource, as well as creating waste management initiatives through education, strict regulations, enforcement, and punishment. Some participants also highlighted the need to involve the international community in finding ways to incorporate Syrian refugees in hygiene promotion and treating Lebanon's water supplies.

Theme 2: Identity \& Insecurity

Five groups of photos were classified under the theme of identity and security. Both co-constituting themes were recurrent in the photo-elicitation process as participants viewed them as affecting not only Syrian refugees but also the hosting Lebanese communities. The participants' engagement in the gendered nature of refugee representation provided a critical assessment of the stereotypical simplistic division of roles of Syrian men as perpetrators and women as victims with no 
agency. Meanwhile, the coresearchers' projection of their positionality-as Lebanese citizens in search of local stability—was visibly highlighted when discussing the following pictures, (re)negotiating their position towards the Syrian presence in Lebanon.

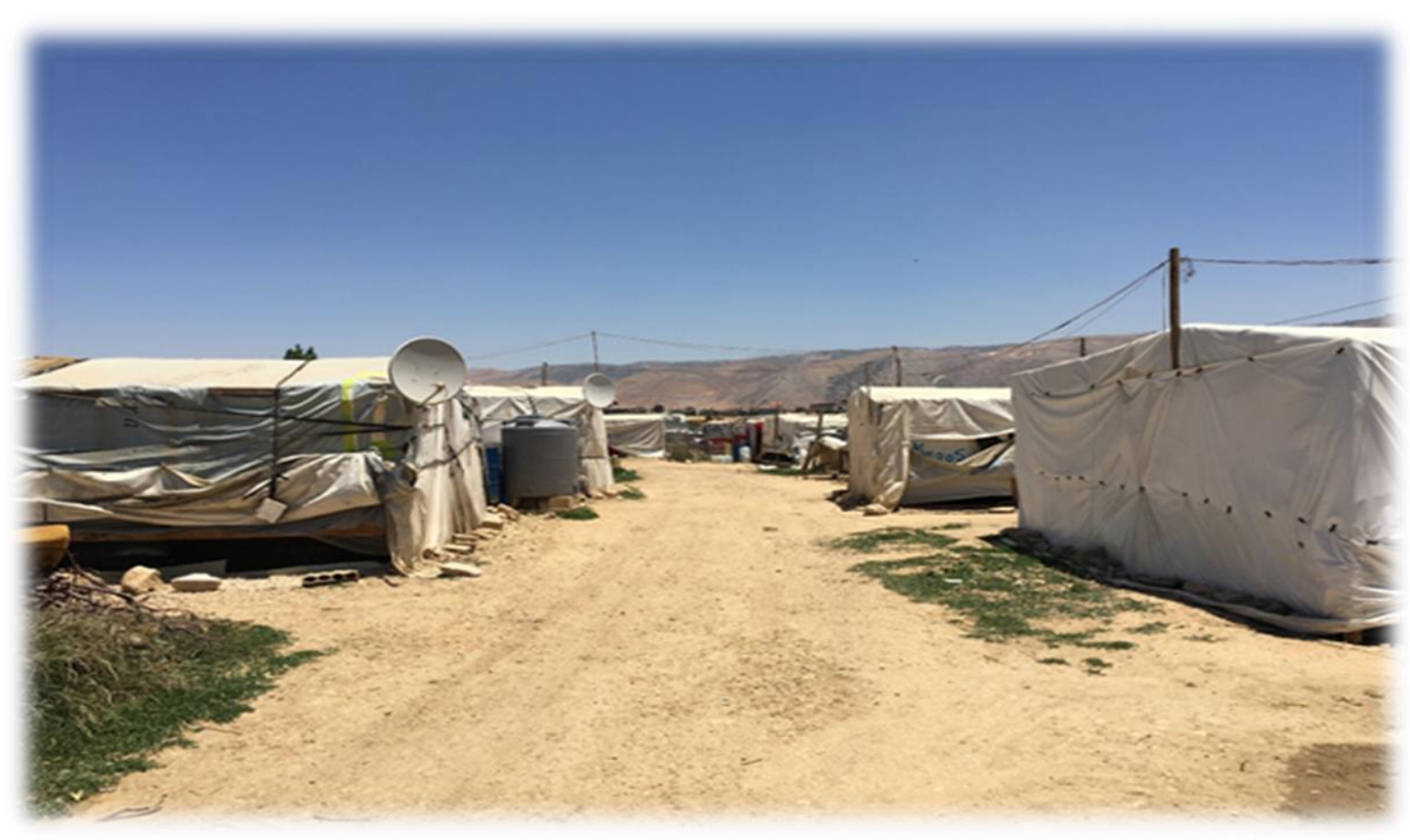

Figure 19. I Want, But I Do Not Need

The above photo portrays rundown tents in Syrian refugee settlements in Lebanon where electricity cables are hanging above some tents and satellite dishes are installed on top of others. According to participants, the contrast in this picture depicts the resilience and systemic privileges within the Syrian refugee communities - where the rundown tents represent poverty while hanging electricity cables represent resilience efforts and satellite dishes characterize some form of luxury. All participants stated that most informal settlements are built on privately owned lands, which Lebanese property owners are free to rent at any price. Some 
volunteers also stated that most Syrians, often within one camp, originate from the same region, sharing common socio-cultural and religious values. One participant criticized the fact that a shawish is always a man, who informally governs the Syrian settlements as its representative, affecting and excluding Syrian women from most decision-making processes. The fact that he is, often, the sole person who negotiates the settlement rental with the landlord, collects the rent, and the one who organizes the structure of the camp, gives him the public sphere decisionmaking privileges that citizenmen often hold and that other Syrians, especially women, do not enjoy. Several participants questioned the UN humanitarian relief system's reliance on shawishs as the interface between the aid programs and refugees themselves, privileging one (male) Syrian over others. According to some volunteers, this dynamic creates space for manipulation and unequal opportunities of having a dish on the top of some tents and not others. This photoelicitation generated by some participants helps the study illustrate the impact of the LCRP's approach to the Syrian crisis in Lebanon. It portrays a clear case of how refugee resilience can be interpreted in many ways; it can range from Syrian shawishs adapting to new realities as the de facto informal-settlements' supervisors and thrive by maintaining a securitized refugee system that guarantees their relative power over controlling most of the receiving aids, exploiting the relative vulnerability of other residing Syrian refugees.

According to one commentary made by the Century Foundation, Lebanon's treatment of Syrian refugees as a security problem (en)gendered a rise of "local Syrian strongmen known as the shawishs within Lebanese displacement 
camps" illustrating one of the many impacts of Lebanon's crisis response approach to the Syrian refugee crisis. ${ }^{634}$

Consequently, the commentary states that "the shawishs are a perversion in a system that is reinforced by State Security actors, ignored by the ministry of interior and local municipalities, convenient for landowners, and problematic for aid organizations and refugees." ${ }^{635}$ Positioned as the middlemen, most shawishs control the Syrians' livelihood and aid opportunities, using their given power to (re)negotiate their status with the landowner and aid organizations, barely serving the interests of Syrian refugees living in the camps.

On another note, most participants believed that images, like the one pictured above, are justified portrayals of the growing distrust and tensions between the Lebanese communities and Syrian refugees, as most Lebanese currently suffer from economic and social exhaustion, seeing Syrian refugees as a privileged burden and a source of insecurity rather than as people in need. The different sets of privileges stated within this photoelicitation lie in the fact that Lebanon suffers from a chronic electricity problem, where most towns get less than eight or twelve hours of power daily. ${ }^{636}$ The participants could not ignore the Lebanese society's

\footnotetext{
${ }^{634}$ Sima Ghaddar. "Lebanon Treats Refugees As A Security Problem-And It Doesn't Work." The Century Foundation.

(April 4, 2017), https://tcf.org/content/commentary/lebanon-treats-refugees-security-problem-doesntwork/?agreed $=1$

635 Ibid.

${ }^{636}$ Elie Bouri, and Joseph, el-Assad. "The Lebanese Electricity Woes: An Estimation Of The Economical Costs Of Power Interruptions.” MDPI Energies 9, no. 8 (2016): 583.
} 
anxieties and weariness that the informal refugee camps, as illustrated in the above picture, abuse and exploit their stay by extending illegally electricity cables and dishes. From their discussion, the co-researchers state that those in camps tend to get power and cable on a more regular basis than Lebanese residents at little to no cost. Their position here can be interpreted as empathetic with the poor Lebanese complaints that some "Syrian refugees receive more benefits than they do." ${ }^{\circ 637}$ As such, during photo-elicitation, participants justified several incidents of hostile attitudes toward Syrian refugees from local communities as a reaction to the illicit work committed by refugees in urban and rural areas. According to participants, this situation could be attributed to the fact that many refugee camps are informal, blaming the Lebanese political deadlock that (en)genders the susceptibility of these camps to harboring criminals and terrorist groups. Hence, pictures of satellite dishes and power lines triggered more questions among participants such as: what other kinds of luxuries do refugees "enjoy" inside their tents?

Meanwhile, one participant highlighted the fact that the Lebanese uproar against Syrians abusing electricity is out of place. It came with the fact that Syria's supply of electricity to Lebanon remained intact despite the raging war it is witnessing. This photoelicitation reinforced the participants' negative view of their government's ineptitude. It can be interpreted as the actual upheaval should be focused on the corrupted weak Lebanese system for causing severe electricity cuts,

${ }^{637}$ Anne, Barnard. “A Refugee Crisis In Lebanon Hides In Plain Sight.” New York Times. (November 12, 2015), https://www.nytimes.com/2015/11/13/world/middleeast/a-refugee-crisis-in-lebanon-hides-in-plainsight.html 
due to domestic political turmoil and personal gains. Even though the proposed solutions were limited, all participants blamed the Lebanese government, which was, still, expected to carefully manage these settlements and reduce them in scale so that they become secure to neighboring communities. Also, some participants echoed the Lebanese citizens' overburden and outcries for the return of many of these refugees to secure areas in Syria where fighting has ended. Without such solutions, participants ascertained violence to be inevitable between Syrian refugees and Lebanese communities, especially when tension arises.

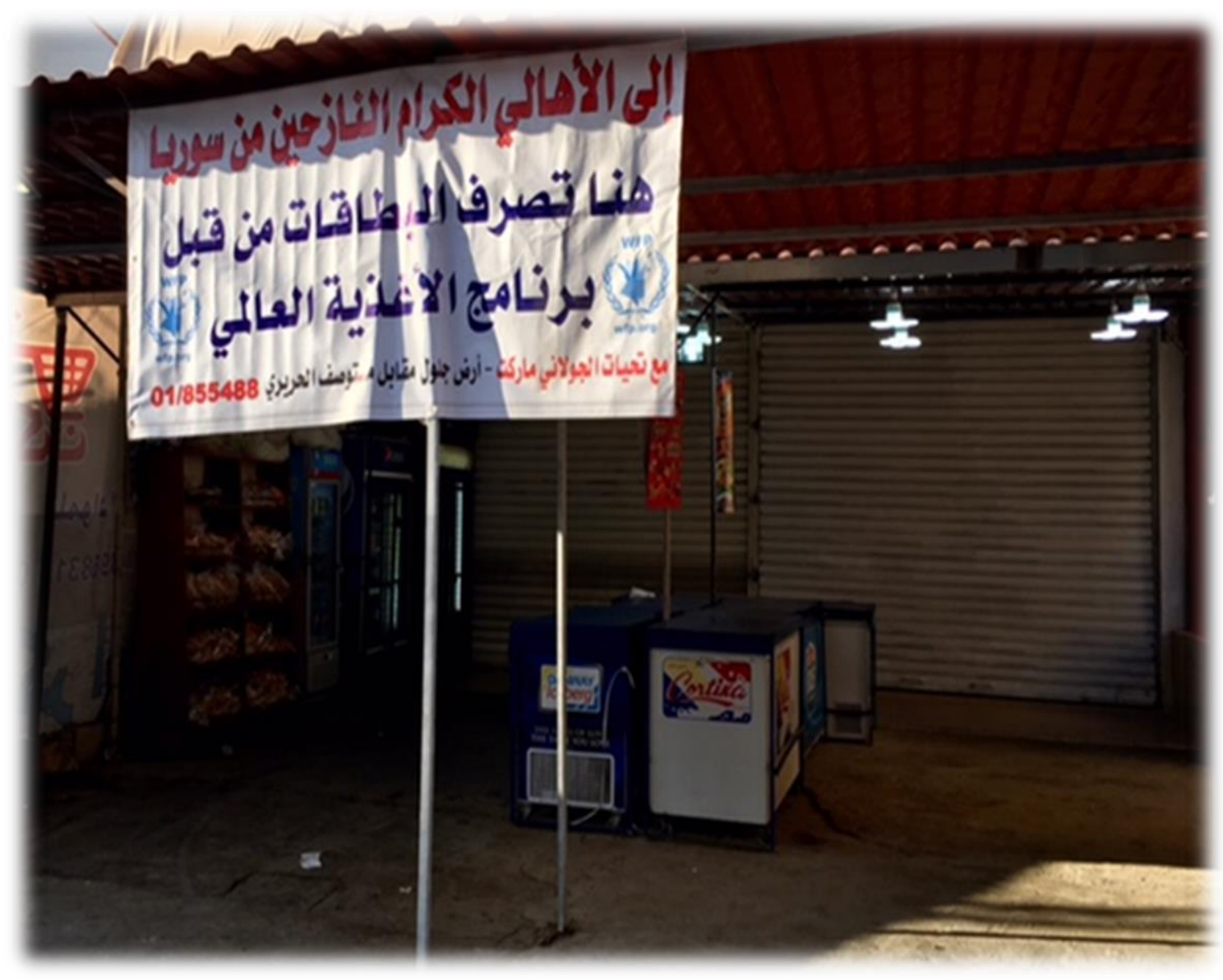

Figure 20. Refugee Food Assistance 
The above photo shows a store sign announcing that it is part of the food program organized by UNHCR. Participants explained that the current refugee aid system resulted in the monopoly of a limited number of stores where Syrian refugees could use the debit E-cards issued by the UNHCR to purchase food and supplies. Participants explained that this UNHCR program started to fight corruption, ensure the effective distribution of food supplies, and direct aid to Syrian families while empowering local businesses. In this case, the program seems to have failed Syrians where one participant highlighted an interesting aspect of this photo- the fact that the shop was closed. This fact triggered an interesting discussion among participants who justified the shop's closure either because of personal reasons, Ramadan (an important Muslim holy period), it ran out of supplies, or most Ecards ran out of debit.

Having a closed shop during the daytime meant to some participants the failure of the food and aid program to deliver the required assistance to vulnerable Syrians residing in an area where a local store owner has the privilege to deny Syrians assistance. One participant also highlighted the severe impact of the Syrian refugee crisis on local Lebanese businesses to the point that many stores in remote areas were no longer open since they have lost their begrudged Lebanese clients and, thus, became dependent on desperate Syrian clienteles. Overall, the photo above relates to the devastating impact of the Syrian refugee crisis on local businesses where gendered power relations complexly impact how aid assistance is translated in local context. Under those circumstances, a local store's provision or denial of aid products (en)genders local resilience efforts by both communities; 
Lebanese residents would boycott welcoming Syrian shops and residing Syrians adopting unhealthy food rationings strategies in order to survive. Participants claimed that many of the host communities initially welcomed Syrian refugees in their homes or on their properties. However, by 2014, the already economically embattled Lebanese began to show definite signs of exhaustion and tension toward Syrian residents, especially with the terrorist attacks of 2014 that overtook Lebanese cities and the Lebanese army. As a result, and according to the participants, most Lebanese blame Syrian refugees for almost every economic or social problem, as well as any threat to security.

Based on the photo-elicitation discussions, the participants persistently blamed the Lebanese government for failing to enforce local standards in regulating local businesses that leaves both populations vulnerable to illicit opportunistic business activities. Some argued that the situation is as such because the Lebanese government was politically corrupt giving business privileges to their devoted party members, while others pointed out the inconsistencies in foreign support and the failed outsourcing of humanitarian aid programs. One of the suggested solutions was to push for more direct aid and customized support for the different Syrian refugees, since this would attract more local businesses to participate in the program, creating competition, while reducing local pressure and corruption. Another suggested solution was to organize and regulate the presence of Syrian refugees in Lebanon, at least as far as the informal settlements are concerned for, they represent the primary source of economic instability and security threats. However, the only all-agreed upon solution was to find ways to help refugees safely 
return to their country because, after seven years of refuge, Syrians' living standards in areas such as these have deteriorated tremendously.

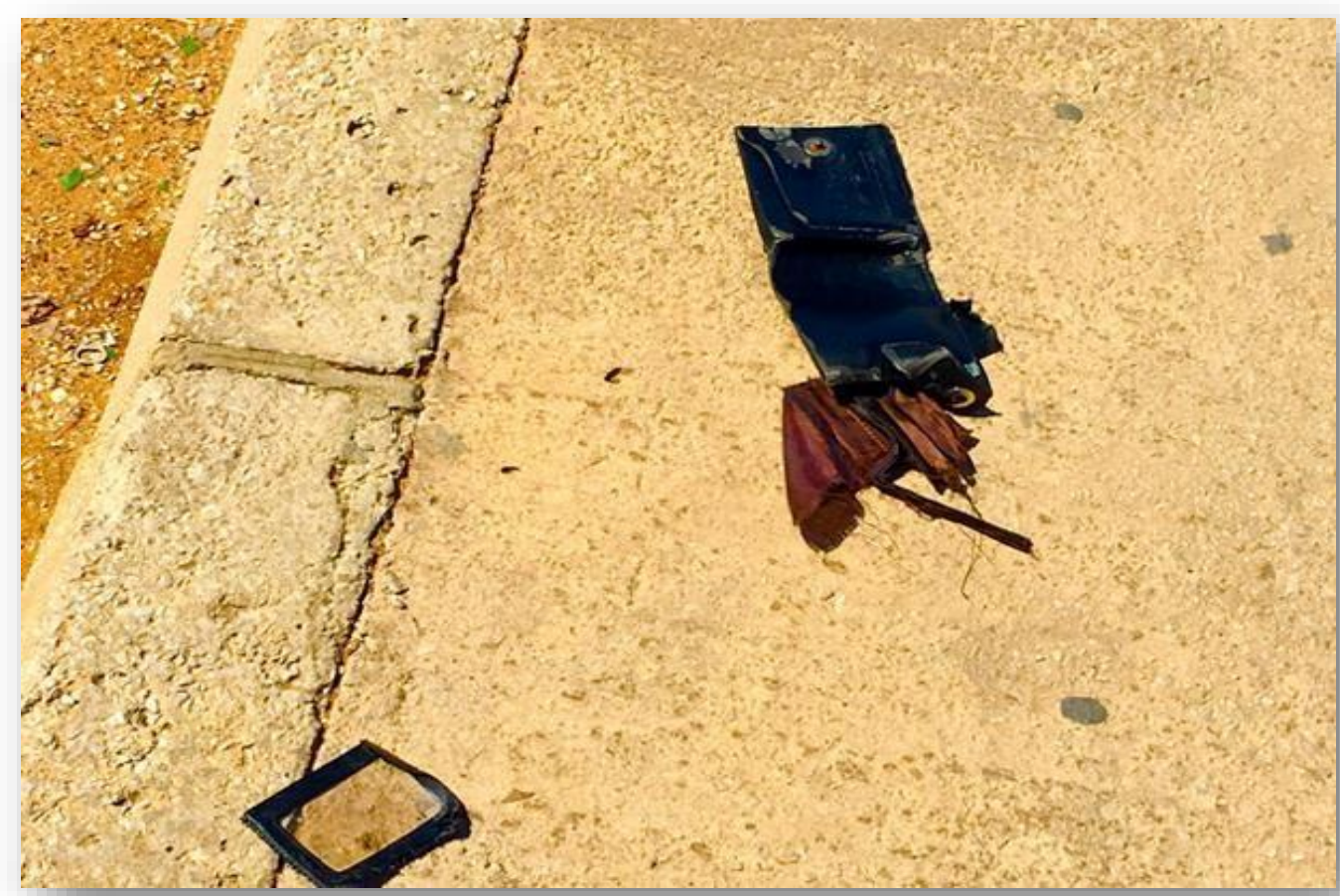

Figure 31. Lost Identity

The above photo shows a wallet discarded on the sidewalk. Interpretations were that it could have either fallen from someone or was stolen and then discarded. Participants argued that the valuables inside a wallet do not only include cash or credit cards but more importantly, identity cards. In a country where identity and identity politics prevail, and where refugees are classified and treated accordingly, one's self is often summed up in a plastic card issued by government officials. For a Lebanese citizen, losing their identity card would mean a real bureaucratic hassle and will lead to a colossal waste of time attempting to get a new one, if possible. For a Syrian refugee, losing their identity card means the possibility of going to jail, with dim to no hope of legitimately returning to Syria. 
According to some participants, this situation would lead Syrians to negatively adapt to their new realities using illegal measures to access socioeconomic gains, especially when many terrorists rely on stolen identity cards to facilitate their mobility within the country. Consequently, all participants agreed that Syrian women were the weaker link in this vicious cycle-having their identification cards managed by either their spouses or, even worse, the informal settlements' shawishs, who end up monopolizing most transactions within the public sphere. One participant echoed some of the Syrian women's lack of confidence in reporting incidents of abuse, exploitation, and harassment to local authorities due to lack of trust in the Lebanese authorities in taking action or, worse, the fear of reprisals by their abusers. ${ }^{638}$

Meanwhile, most participants approved of one suggested solution to develop more inclusive and stricter security measures. One example approved by some co-researchers was the automated system for issuing temporary identification cards by the UNHCR using biometrics that would be officially acknowledged by Lebanese authorities as a way for refugees to be legally visible by local authorities. However, a couple of participants were hesitant of using such intrusive measures that would end up surveilling the Syrian's daily activities and potentially sharing their information with third-party interest groups, thus stripping away their privacy. This commended recommendation of issuing legal identification cards to Syrians

${ }^{638}$ Lorraine Charles, Kate Denman. "Syrian And Palestinian Syrian Refugees In Lebanon: The Plight Of Women And Children.” Journal of International Women's Studies. (2013);14(5):96 
residents simultaneously came with some of the discriminatory fears of Syrian legal permanent presence within the participants' country. It seems as if their altruistic inclinations could not overpass the fears and enshrined vindications of Syrian (Sunni) hyper-masculine domination over Lebanon. Still, we do find some empathy from some of the participants' or perhaps a self-projection of their own collective fear over an intrusive state that uses notoriously intelligence services (Mukhabarat) in order to track, terrorize, and eliminate individuals who pose a threat or are just undesirable. 

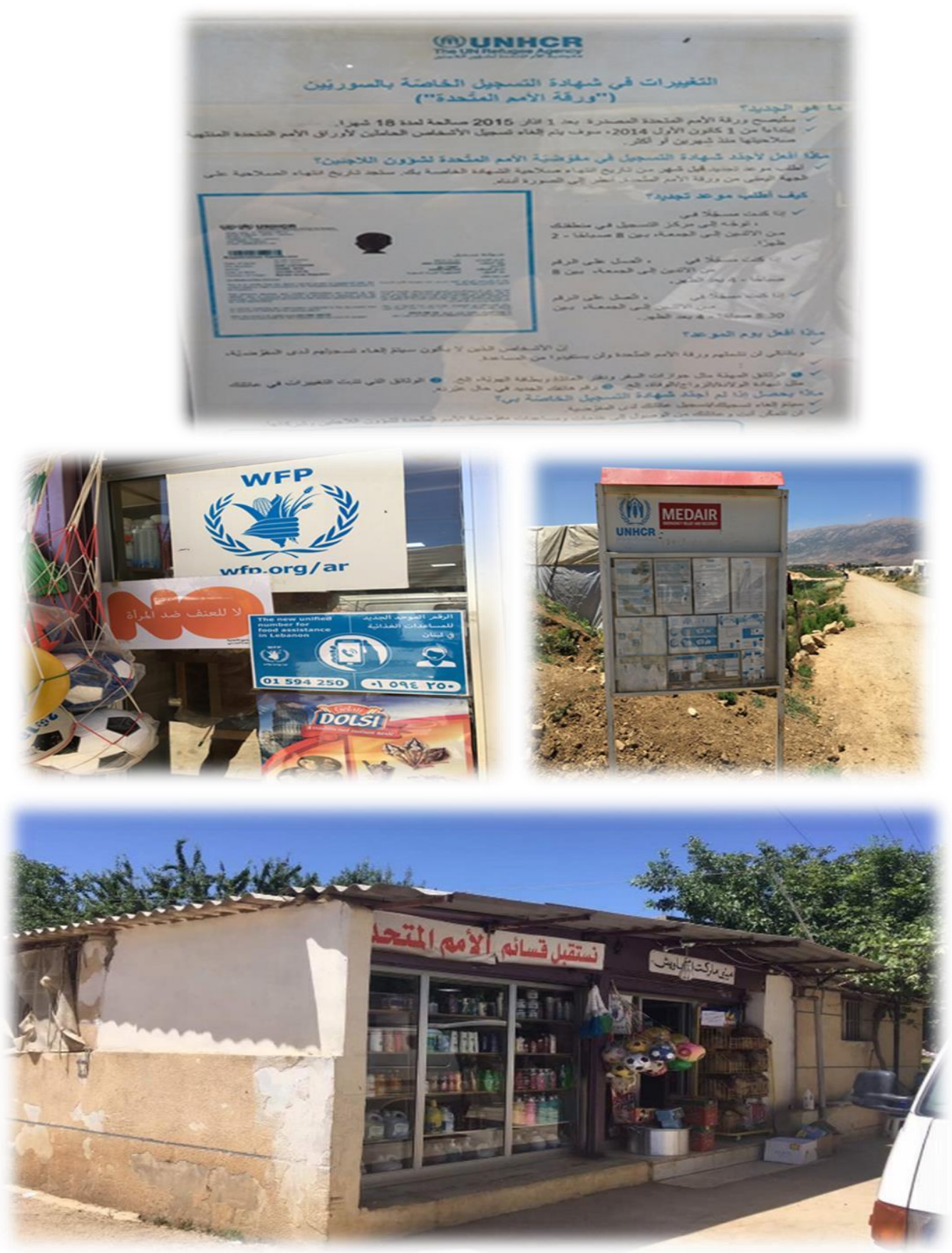

Figure 22. Raising Awareness

The collection of photos above shows some of the published literature and large posters issued by the UNHCR and other humanitarian programs involved in aiding Syrian refugees in Lebanon. The posters are seen on the walls of a store 
behind a pile of balls or on boards installed in a remote area near refugee camps. These photos appear to reflect part of the efforts to create awareness among Syrian refugees and Lebanese citizens on issues about the refugee crisis. However, most photos reveal more technical problems rather than easy solutions. One participant explained that the poster on the wall of the store could be barely seen, as it is (un)intentionally hidden by merchandise. Similarly, the pamphlets on the roads are difficult to recognize from a distance. This is not to mention that the posters are in remote locations that are difficult to reach by pedestrians or by someone commuting on public transportation. Other participants reiterated that low literacy among many Syrians makes these posters of limited use. In fact, the majority of the refugees in those informal settlements are children and young women from poor upbringings, mostly reserved in the private sphere, which, according to all participants, explains their lack of the necessary tools to successfully navigate the public sphere.

According to all participants, these posters exist because the UNHCR and governmental agencies find many difficulties in reaching out to Syrian refugees and communicating with them on an individual basis. Even with printed banners with animation about the preferred processes on how to acquire security and support, many participants agreed that refugees distrust the Lebanese government and international organizations, fearing that registration or submitting their personal information could, still, get them in trouble with the Lebanese law. Similarly, some participants added that neither the Lebanese government nor the relief agencies have the resources and capability to cover all the informal settlements because of the chaotic way these camps are scattered. 
With the lack of trust and the obstacles related to logistics, the most effective solution suggested by most participants was to resort to social and mass media. Educational and informative programs on media such as TV and radio can always reach larger populations of Syrians who get most of their information through these outlets. At the same time, all participants agreed that the UNHCR and other humanitarian organizations already use the WhatsApp application to reach Syrian refugees, sharing information and updates from respective agencies, which makes posters obsolete.

Still, some participants criticized this information gap as a significant barrier to most Syrians in accessing relevant news of Syrian conflict, forging crossboundary networks, and, most importantly, recognizing available aid programs. According to one participant, Syrian women are not the primary news bearers, vulnerable to inadequate, sporadic, and random misinformation. Most of these women do not have access to cellphones, impeded from accessing real-time information that would help them navigate safely within the public sphere. Most of the older Syrian women that the volunteers worked with either struggle to learn how to navigate the different types of communication devices or the younger females have their cellphones confiscated by their male counterparts. This information precarity is further exacerbated with the limited and costly network coverage that isolates most Syrian women, who have little control over the nuanced or inaccurate news circulated about them, becoming dependent on versions of stories. According to one participant, this situation created a new dynamism of female-lead Syrian initiatives to rebuff those inaccuracies by forging external 
alliances through media outlets. Online platforms, such as the Facebook group "I am a Syrian in Lebanon," were utilized as viable outlets to voice out their realities, while at the same time crafting alternative Syrian stories and seeking adequate assistance and support from fellow Syrians.

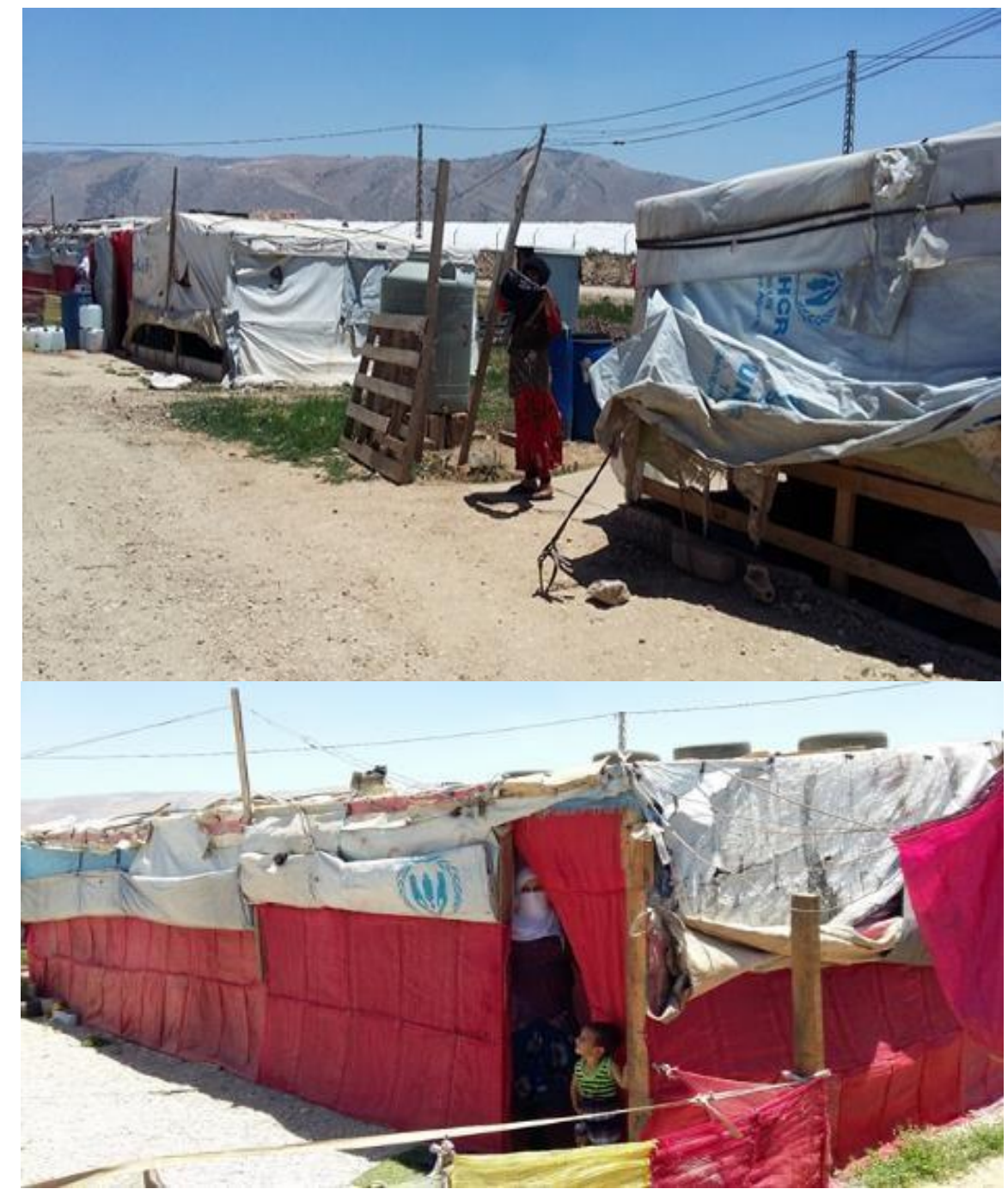

Figure 23. Fear Of The Other

This title includes two photos of tents inside an informal Syrian settlement. The tents are viewed as vulnerable and exposed, and yet appear as if they are aggressively hiding whatever is inside, with small entrances. The photos show the reality of life inside informal refugee camps at the edge of towns, roadsides, near 
rivers, or agricultural lands. Interestingly, on the exterior of the tents, the UNHCR logo can be seen, depicting their ineffective presence within the occupied space in providing refugees with some form of safety and protection from visiting outsiders. The half-built open tents, the scavenged pallets, and the hazardous extended cables shown are nothing like what the UNHCR promoted for refugee assistance and protection. One participant believed that Syrian adults and children living inside the tents can barely enjoy any security or privacy and are subject to voyeurism. Also, the participant highlighted that most informal camps are isolated from nearby communities, both by physical and invisible cultural barriers.

The volunteers chose these photos as a depiction of how most Syrian women refugees suffer from minimal privacy protection, especially those who live in ITS, relatively far from any town center, as they are vulnerable for anyone to just drive by and terrorize them. ${ }^{639}$ Street vigilantes, local police, and soldiers raid the informal tents, in the guise of checking permits, only to harass the women residing there. ${ }^{640}$ This dramatically increases the exposure to GBV, as in a patriarchal social context, the female body is a central subject of gazing, and Syrian women are perceived as sexual beings, especially in the case of younger women, having not developed sufficient experience in dealing with sexuality. ${ }^{641}$

\footnotetext{
${ }^{639}$ Ruth Sherlock, "In Lebanon, Syrian Refugees Met With Harassment And Hostility," NPR, (September 2, 2017), https://www.npr.org/sections/parallels/2017/09/02/547906231/in-lebanon-syrian-refugees-met-withharassment-andhostility?t=1532003561503.

${ }^{640}$ Ibid.

641 "Syria Regional Refugee Response, Information Portal," United Nations High Commissioner for Refugees (UNHCR), http://data.unhcr.org/syrianrefugees/country.php?id=122.
} 
On another note, all participants agreed that most Syrian inhabitants are apprehensive to intruders asking all sorts of questions. According to some participants, there were many times that they witnessed the same unfriendliness in some of their visits. Syrians residing in the camps, especially women, are anxious and angry about being exploited by newcomers whose sole purpose is to get a success story out of their misery.

Some participants stated that Syrians were mostly reluctant from journalists' visits, researchers, and agency representatives, where most external visit purposes aimed to get interesting photographs while twisting Syrian refugees' stories in order to gain enough attention. Rightfully, this could be described as "research fatigue" where alternative privileged individuals come up to refugees in order to rush questions with no tangible positive change for the refugees. This photo argument made me reassess at that moment my position in all this photo-elicitation, for the person most (in)directly benefitting from these participants' work is me so far. That is why, we all agreed at that moment that once the dissertation is finished, we would hold another (non)virtual session for future planning.

The participants, later, elaborated on the notion of special interest where some agencies' goals and interests do not necessarily correspond to the messages that the Syrians wanted to spread. As a result, the participants' portrayal of how Syrians distrust external visitors with an external agenda resonates with the study's aim of debunking the tendencies of reports, policies, and studies misusing an essentialist image of Syrian refugees - as either potential masculine threats that need to be controlled or feminized victims in dire need to be protected-for 
personal benefit. Both projected images silence the complex Syrian realities and forcibly strip away their agency. According to one participant, these ill-equipped intruders ask questions, take a photograph and, eventually, go back to the comfort of their homes, leaving the depicted Syrians in the same conundrum. Other participants responded that many other refugees seize the moment of foreigners coming to showcase impoverishment and request assistance. In fact, during both our visits the shawish, assisted by several women and a dozen children, gave us a tour around their informal camp highlighting all sorts of problems that many resident Syrians face. One example is when the shawish presented us with a couple of Syrian families and introduced them as illegal, having not acquired their UNHCR registration documents yet, not wanting to leave the camp out of fear of apprehension. Others joined in and complained about their health problems and lack of medication or even hospitalization and requesting aid to pay for these procedures. Even though these examples contradicted the first impression that the participant wanted to highlight, still, a common theme within both is the refugee's agency and resilience in either wanting to voice out their insecurities or shut all communication efforts down not wanting to be exploited.

The participants' suggested solution to end this situation is difficult and costly. One example is to provide an information outlet for these refugees to craft their own stories and be able to express their perceptions and feelings about their own realities publicly. At the same time, all participants viewed that the ultimate solution requires some political agreement and a strong will by the Lebanese government to allow refugees to access secure housing until their safe return to 
their homeland. According to participants, this problem can only be solved with the latter solution for most Syrians will continue to be exploited if there is news to "sell." In the meantime, all participants agree that the terrible living conditions Syrians endure in Lebanon will not change, and if these types of news stories continue, neighboring Lebanese communities will feel more tension and apprehension about the weight and cost of the continued Syrian refugee presence within their neighborhoods.

Theme 3: Labor \& Gender Roles

Three sub-themes are identified under this thematic category, addressing the issues of labor among refugees, especially among children, as well as the participants' view of the shifting and changing gender roles that seem imposed on many Syrian women as a result of the impact of the war. 


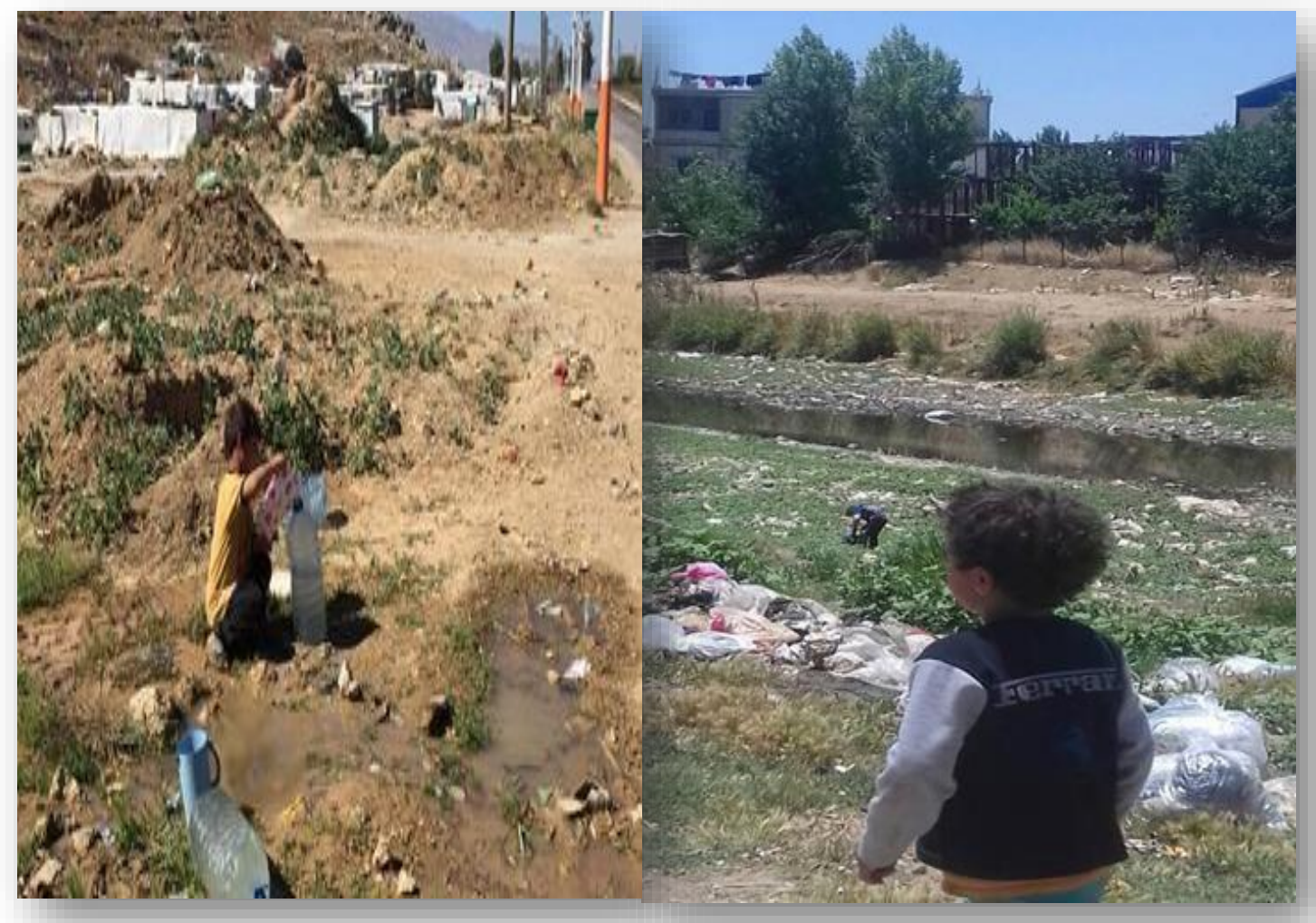

Figure24. Child Labor

One of the two photos above shows a child filling water in a bottle out of a muddy hole while the other shows a young child watching a sibling work in a vegetable field next to a dirty river filled with garbage. On the one hand, these photos speak of extreme poverty, unacceptable suffering, and despair combined with survival. On the other hand, they reflect issues of child labor as a result of the Syrian refugee crisis. The photos were taken during the holy month of Ramadan when most adults were fasting and sleeping during the day, while the children, who do not have to fast, worked. However, even during other months of the year, participants were used to seeing young children working, whereas mothers are more likely to stay inside the camps and fathers or adult males barely seen. 
These photos tell the stories of refugee children striving to survive under inhuman conditions. What makes their suffering worse is the combination of cultural values and traditions that are not equipped for times of war. All participants agreed that most of these children were born as refugees, inside the informal settlements in the absence of adequate family planning, and strong drive among refugees to beget more children for religious or cultural reasons. Either way, the participants stated that birth rates of Syrian refugees are growing exponentially, imposing a much more significant burden on the international community that is unable to offer enough aid, and on the Lebanese government and society that are suffering, mostly, from overpopulation.

In addition to the massive Syrian population residing in specific Lebanese communities, the limited capabilities of the Lebanese state, and the weak efforts of the UNHCR, the problem is caused and exacerbated by cultural factors, among many.

According to one participant, many Syrians reiterated an ill-informed, birthencouraging, Arabic cultural saying to them when asked about the reasons for childbearing: "Child's livelihood comes with his birth—Al walad rizkhou ya'ti ma3aho." Many of the refugees believe that they must continue begetting children despite the crisis and lack of resources, partly for traditional reasons that have to do with the practice of raising children to help in generating more possibilities of livelihood and expanding family status, and therefore strength.

In addition, it is important to note that there is also a lack of legal protection for refugee children that allows their parents, shawishs, or others to exploit them in 
labor and different fields such as becoming beggars or even thieves on the streets, where they are subject to all kinds of verbal, emotional, physical and sexual abuse. Interestingly, the Labor

Code in Lebanon states that no child under eight years old is allowed to work. Still, Lebanese laws do not extend to foreign residents, leaving Syrian children unchecked. ${ }^{642}$ Swapping one form of danger for another-sexual harassment and verbal abuse — one Syrian child recounts: "It was very hostile—people used to call me the 'Syrian dog' and other things [...] I would get really hurt, sometimes I would just sit and cry. It was humiliating.,"643

On one end, we find that with all the efforts made by both LCRP initiatives to ameliorate and expand the current education system, Lebanese schools barely accommodate 100,000 of the 300,000 Syrian children. ${ }^{644}$ With not enough teachers qualified to cover this sudden increase in student registrations, "some schools send Lebanese children home after half a day and then teach Syrians in the second half." 645 On the other end, child labor threatens the healthy growth and

\footnotetext{
${ }^{642}$ Lebanon News, "Lebanon Witnesses Rise In Syrian Refugee Child Labor Over Past Year," The Daily Star, (June 14, 2018), http://www.dailystar.com.lb/News/Lebanon-News/2018/Jun-14/453154-lebanon-witnessesrise-in-syrianrefugee-child-labor-over-past-year.ashx.

643 Ibid.

${ }^{644}$ Julia Craig Romano, "Humanitarian Crisis: Impact Of Syrian Refugees In Lebanon,” Middle East Program Wilson Center, (October 29, 2013): https://www.wilsoncenter.org/event/humanitarian-crisis-impact-syrianrefugees-lebanon.

${ }^{645}$ Patricia Mouamar, "Viewpoints: Impact Of Syrian Refugees On Host Countries," BBC News, (August 24, 2013), https://www.bbc.com/news/world-23813975.
} 
development of any child by restricting them from the necessary educational programs. ${ }^{646}$

Furthermore, all participants believe that most refugee children born in Lebanon have no documents and are not registered, which raises many serious questions about their stateless future when they choose to stay, return home, or even seek asylum in third countries. According to one participant, the only recourse the impoverished Syrian families are unable to undertake is a costly and complex legal process to register their children, failing to prove family ties when legally crossing state borders. Most participants agree that roughly half a million Syrian children born in Lebanon lack legal documentation. These children are, thus, unable to enroll in public schools for they are legally nonexistent and lack proof of their age.

Ideally, the participants' projected solutions would be to educate, inform, and create awareness about family planning to motivate Syrian refugees to avoid giving birth on a large scale. However, some participants viewed this as extremely difficult when there are very few resources to provide Syrians their most basic needs, let alone finding enough resources for education and awareness. In addition to this, it is impossible to persuade Syrians not to carry on with their lives, avoid getting married, or to have children, when they have already spent seven years in Lebanon with no hope that the war in their country will come to an end shortly. Thus, most participants acknowledged the presence of few initiatives in certain

\footnotetext{
646 "Growing Up Without An Education: Barriers To Education For Syrian Refugee Children In Lebanon," Human Rights Watch, (July, 2016), https://www.hrw.org/report/2016/07/19/growing-withouteducation/barriers-education-syrianrefugee-children-lebanon.
} 
hospitals and clinics to ease Syrian birth registration rules providing birth certificates in hopes of reinstating some legal presence. All participants agreed that the only viable solution left is to create a low-cost legal mechanism to register the oppressed Syrian children to access safety, education, and avoid informal labor at all costs.

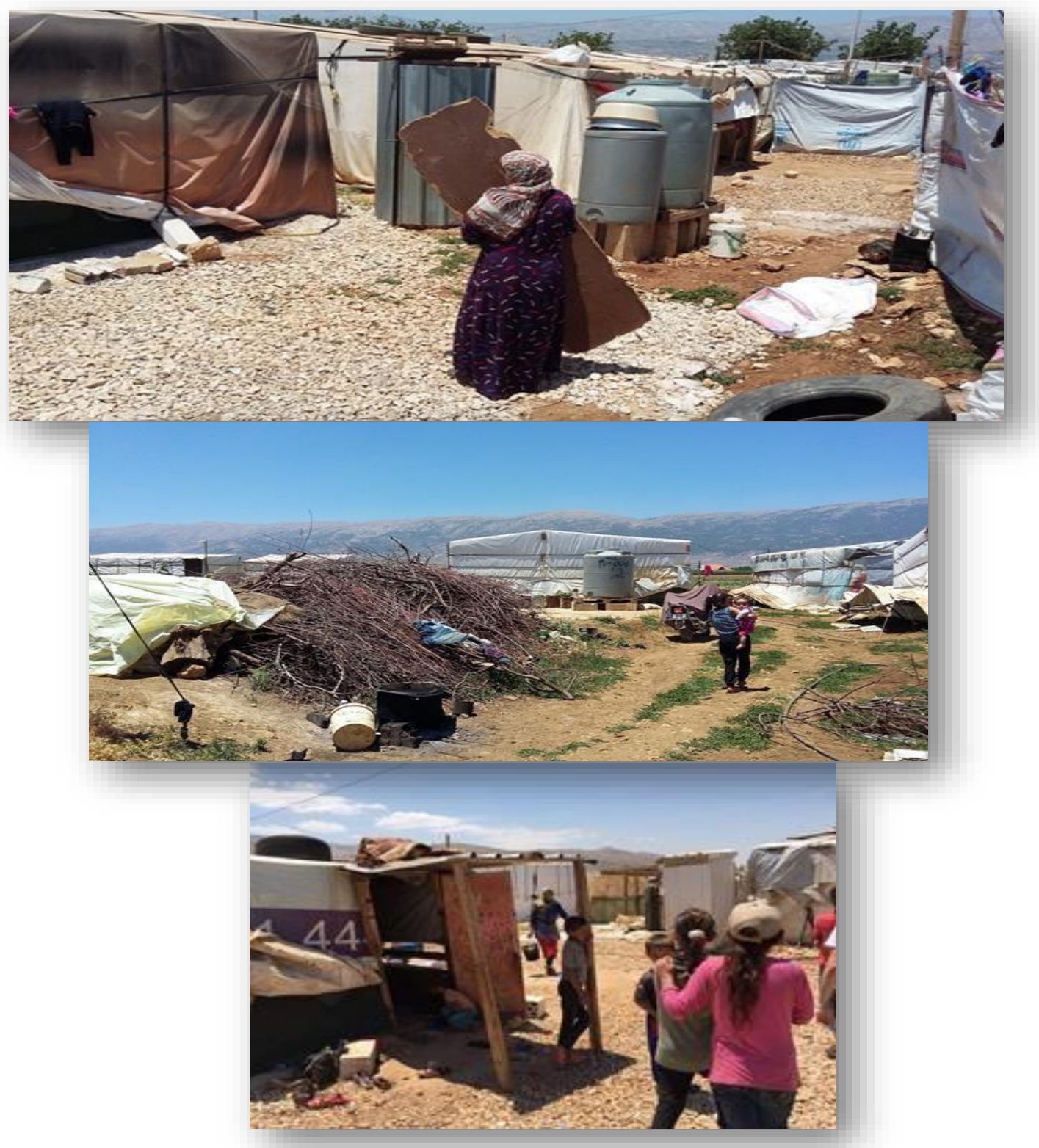

Figure 25. Shift Of Gender Roles 
The three photos above show the extent to which the participants showcase Syrian women's agency and what seemed to them as a shift of gender roles among Syrian refugees in Lebanon. One photo shows a woman carrying a bucket throughout the camp. The second photo shows a young girl carrying a child, and the third shows a woman lifting a wooden plank. The most striking reality in these photos is the absence of men in all three situations. This does not come as a surprise to the participants since few adult men are usually to be seen within the informal settlements. According to one participant, most men are either away during the day or resting during Ramadan season inside the tents. As a result, Syrian women and girls had to take on their responsibilities in managing the camp by conducting their daily chores within the open camp's public spaces without proper protection.

As Syrian women take on more responsibility and autonomy, for many of them these opportunities and increasing responsibilities do not mean equality nor security. All participants agreed that the significant number of females and children inside the refugee camps compared to adult men has severe implications for both Syrians and Lebanese residing there. Many Syrian women complained to some of the participants that the sense of security is barely felt at the camps, and even more so outside the camps, where women and children must occasionally venture to get supplies, get documents processed, or work informally to earn additional income. According to some participants, many Syrian women, as young as fifteen years of age, witnessed a dramatic increase of gender-based violence, as they were often seen as easy and desperate targets for sexual assault, rape, and other forms of intimidation. 
One volunteer stated that young boys have not been spared, especially as many are sent by their designated shawish on the streets to work, beg, or steal from the age of five.$^{647}$ According to that participant, a boy at the age of 13 is a man and is thus eligible to be a breadwinner, which means that he comes under more pressure to generate income with any means available, considering the possibility of starting his own family within few years. One participant highlighted the fact that most children under seven years were born in Lebanon; not knowing any life other than being refugees means that within a few years this population will be growing at explosive rates, worsening the Syrians' standard of living. As far as the Lebanese are concerned, all participants view that this not only represents a significant social or economic problem, particularly with the added strain on the already weak and limited resources of the country, but it is also a problem of basic security. One participant commented that theft, violence, crime, and rape became way too common in these areas, and in many cases, Lebanese citizens are the primary targets. As a result, simmering tensions between the communities and increased harassment and violence against refugees by the security apparatuses in the country became more blatant and somewhat justified.

Most participants highlighted the fact that there were several initiatives that focus on training women facing adversity to develop enough skills to engage in a

${ }^{647}$ Sima Ghaddar. "Lebanon Treats Refugees As A Security Problem-And It Doesn't Work." The Century Foundation.

(April 4, 2017), https://tcf.org/content/commentary/lebanon-treats-refugees-security-problem-doesntwork/?agreed $=1$ 
number of socio-economically viable and productive activities. According to one participant, her nonprofit organization helps Syrian women develop ways to market and sell their products in the local economy. By providing Syrian women with adequate skills and training in the production of goods, marketing, distribution, and sale, the organization hosts several funded projects to empower Syrian women by encouraging them to communicate, exchange experiences, share issues, and support each other at work. ${ }^{648}$ Still, most participants agreed that the available initiatives were insufficient, deeply affected by discriminatory personal laws that inhibit most of these women to thrive in a Lebanese context. According to some participants, most projects that focus on women's empowerment tend to be somewhat encouraging and not challenging the main problem - structural patriarchal system established within the Lebanese context. Some examples mentioned by participants cover vocational training; most either offer computer lessons or language courses or instruct them in gendered skills such as culinary activities, hair and make-up, and embroidery. Although these programs do help Syrian women in generating some safe income, one participant still criticized these programs of stereotyping women's division of labor that does not seem to promote nor achieve gender equality nor legally empower Syrian women. In fact, the Kafala system exploits Syrian women's position by tying their work visas to individual sponsors who have the sole authority in terminating their employment. All participants agreed that the

\footnotetext{
648 "Syrian Women Rise Above Differences And Forge A Statement Of Unity," UN Women News, (May 23, 2016), http://www.unwomen.org/en/news/stories/2016/5/syrian-women-rise-above-differences-and-forge-astatement-ofunity.
} 
only viable solution is to end the refugee and gender stigma towards many Syrian women residing in Lebanon by calling for more gender-inclusive initiatives that would truly benefit these women.

On the one hand, the co-researchers' photo-elicitation of Syrian women's agency challenges the essentialist views of Syrian women refugees as a helpless and indistinguishable mass. On the other hand, the participants' depiction of the disproportionate types of resilience activities - which most Syrian women must adopt in order to survive within a discriminatory gendering environmentresonates with the study's aim: To explore how the agencies involved consider and address these inequalities within their response and to highlight and understand the intersectional gendered differences in the situation of Syrian refugees in Lebanon.

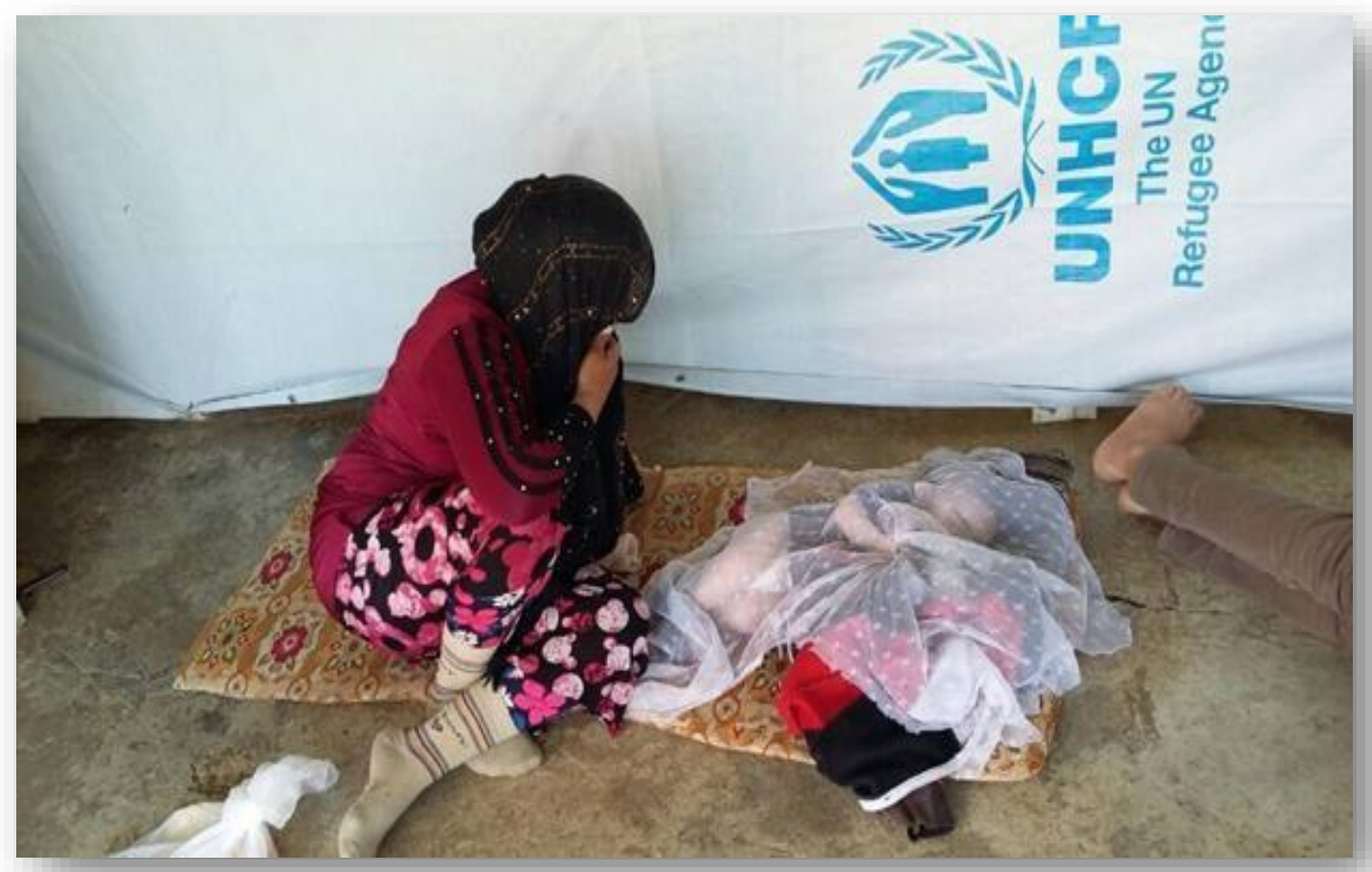

Figure 26. The Future 
According to all participants, the photo above depicts the overall tragedy of the Syrian crisis in Lebanon. A woman is sitting on the floor of her bare tent, attending to her sick child, covered in laced cloth to protect her from flies and mosquitoes. On the one hand, all participants claimed that these scenes are recurrent within most camps. Participants elaborated that Syrian children, living in unsanitary conditions, are often at risk of terminal illness inside informal settlements, where access to appropriate health care is costly and difficult to reach. This latter is especially the case if the parents or child lack documentation; in this situation, the participants believe that the process of acquiring adequate health care becomes almost impossible.

On the other hand, some participants reiterated that many photos like this are seen in skewed Lebanese media on a regular basis. At the beginning of the Syrian crisis, many reported that newly published victimizing images of cases such as these were shocking, compelling many Lebanese officials and citizens to take immediate action to help refugees financially. However, some participants critiqued that over the years, this warm support has faded away with the increase of cases like these and, especially, after witnessing much Syrian involvement in crimes and terrorist acts in Lebanon. Today, photos such as the ones above do not reach the media, since they are considered part of the normal experience of having so many refugees for so long in an overburdened developing country. All participants criticized that the previous rush of sympathy is gone, especially with the fact that official Lebanese rhetoric blames Syrian refugees for many of the health problems within the country. Meanwhile, one participant highlighted the fact 
that previous types of financial support dwindled, and many Syrian women complained to them that the aid provided by the UNHCR, whose logo appears in the photo on the back wall of the tent, became irregular and scarce.

Some participants claimed that the lack of legal protection, the absence of humanitarian assistance, and the sense of insecurity made women's and children's condition much worse. Ignoring this problem or pretending that it does not exist does not help, because cases such as these will continue to evolve until they become a serious humanitarian disaster that will affect the entire region and not only Lebanon. All participants agreed that there should be an immediate effort by specialized agencies to assess probable illnesses, provide basic medical supplies, and raise awareness among susceptible Syrians. Some participants suggested that a more sustainable solution needs to involve effort from multiple parties to provide enough resources to ease the Syrians' struggle and to provide safety, security, and resources to the most vulnerable populations, especially women and children.

\section{Photovoice Results and General Findings}

Due to the reflexivity of the process, the photo-elicitation session reproduced the participants' actual views and explanations of perceived policies' impact on Syrian refugees' insecurities. The analysis part was, thus, useful to reflect on the photos' visual representation of the complex and challenging social attitudes that can contextualize local practices. This exercise yielded greater nuanced meanings to the study's conception of Syrian refugee (in)securities in specific Lebanese localities. 
Mixed emotions were elicited throughout the photo analysis session, where discussions bridged the distinct views each photo triggered and increased knowledge production. While the participants held multiple and often competing, perspectives on how to define Syrian refugee (in)security, there was a strong consensus about the systemic gendered violence and exploitation that Syrian refugees endure, especially women. Some participants focused on blaming the inadequate funding that barely reaches Syrian women to empower them properly. Others complained that the inadequate legal loopholes and corrupt Lebanese bureaucratic agencies would naturally discriminate against these women even when properly funded. Still, most participant's recommendations projected some of the politicized rhetorical fears of continuing Syrian presence within a country that is often perceived as corrupt and unreceptive. On several occasions, the study shows the participants recommending that Syrian refugees are better off going back to Syria than remaining in a country that outlaws their assimilation, justifying their claim on humanitarian grounds. These statements brought me back again to one concept in social justice in which oppression is both a state and a process. ${ }^{649}$ One finds relational experiences of oppression and fear between two oppressed groups, where one is perceivably less privileged than the other with distinct inequalities, trying to survive an (en)gendered vicious cycle of violence.

${ }^{649}$ E. J. R David and Annie O. Derthick. "What Is Internalized Oppression, And So What." Internalized Oppression: The Psychology of Marginalized Groups (2014): 1-30. 
The major difference between foreign volunteers and local ones is that foreign volunteers have more time to contemplate and choose the degree and time of the aid and assistance they would like to allocate to help refugees in peripheral spaces. Meanwhile, local volunteers are not as privileged due to the proximity of the refugee crisis to their environment. Consequently, volunteers' choices are immediately performed. They have an interest in making sure to alleviate the (in)tangible human sufferings within their communities. At the same time, the participants aimed to project their own high value within the Lebanese context, where, unfortunately, their primordial instincts of providing aid and (en)gendering a support network of like-minded humanitarian people is something normalized during the many times of war. Most volunteers stated that they find satisfaction of being needed and doing meaningful work in a country they love but do not respect for it neither includes them nor appreciate their presence. As a matter of fact, several participants reported that they either contemplated, tried to leave, or wished to leave Lebanon to a country that would appreciate their humanity, skills, contributions, and most importantly a country that provides them a real sense of security. Their desire to wanting to do something good and make a difference prompted them to engage their new Syrian 'guests,' not leaving them in destitute, and a chance to be part of an admirable contributing community. At the same time, due to the daily discriminatory rhetoric that fuels their collective memory of fear of protracted Syrian presence within their country, most participants seem to have also internalized some of the public xenophobic paranoia of any type of legitimate 
Syrian integration in a country who is on the brink of a socio-economic, political, and most importantly sectarian collapse.

This exercise brought a fruitful dialogical reconstruction of the multiple gendered realities that the Syrian crisis (re)produced in Lebanon. The relational experiences between the research participants and Syrian refugees enrich the project in highlighting the multiple discriminations and collective fears that both communities are resiliently braving. The different critiques made by the participants of the needs and possible measures to overcome these insecurities seem to echo both Lebanese and Syrian refugees' complaints to them. All participants were aware that our work is framed by, and often unintentionally complicit with, the very power relations that we sought to dissect. After all, all participants knew that their views were subjective and non-representative of the overall situation of Syrians within the Lebanese context. The study shows that there were several instances where dominant ideologies influenced their perception of residing Syrian refugees. From the many photos assessed, participants chose the ones that would portray selling themes of destitute that we all wanted to focus on. Even though all participants agreed that photos of refugees in camps are by no means representative, they all believed that framing them in that context would better highlight their insecurities. In that regard, the participants were right for, according to the UN, around $85 \%$ of Syrian refugees do not reside in ITS. ${ }^{650}$ Most Syrian refugees are

\footnotetext{
650 “Syria Regional Refugee Response.” UNHCR. (August 11, 2018): http://data.unhcr.org /syrianrefugees /regional.php.
} 
scattered in urban and rural areas, very well integrated within the Lebanese communities and hard to locate let alone let one take pictures of their private settings. An article posted on the New York Times described how Lebanon had absorbed most Syrians, which the author labeled as "A Refugee Crisis in Lebanon Hides in Plain Sight. ${ }^{, 651}$ Even though most pictures are accepted to be biased, still, the co-researchers and I believed that the photo-elicitation session helped enhance the pictures' framing by expanding our knowledge of the different legal, economic, social, and personal (in)securities deemed important to share when reporting the different Syrian refugees' daily (in)securities.

Several themes were exposed such as lack of food, shelter, sanitation, and legal desperation. Meanwhile, participants' differing interpretation of each photo reflected the diverging norms and values that each participant held prior to the group session and highlighted Syrian refugees' agency by reflecting on the (re)production of (in)direct (in)securities that these diverse groups of people, legally labeled as displaced, pose on their host communities. Some examples brought up by the participants included waste management, child labor, development of informal economies, (re)enforcing the vicious insecurity cycle to all parties. The majority of the themes expressed during the photoelicitation process brought interesting criticism of the inefficiently gendered bureaucratic

${ }^{651}$ Anne Barnard. “A Refugee Crisis In Lebanon Hides In Plain Sight.” New York Times. (November 12, 2015), https://www.nytimes.com/2015/11/13/world/middleeast/a-refugee-crisis-in-lebanon-hides-in-plain-sight.html 
prioritization and stratification of crisis response management, which post-colonial feminist scholars often highlighted.

All participants agreed that Lebanon's refugee security strategies, networks, and discourses were ineffective in securing both populations from the burdens and threats they were facing daily. In fact, all participants agreed with this research's aim — that those policies labeling Syrians as either "displaced" or "refugees" fail at protecting the residing Syrians from all sorts of harm. We find cases where Syrian women registered through the UNHCR are not allowed to work. Whereas those who choose to acquire a work visa under the kafala system are rarely qualified for one of the three work permits - sanitation work, construction, or agribusiness-as they are not culturally viable for Arab women who mostly work in feminized occupational trades such as secretarial work and school instructors. Consequently, to sustain their own and families' livelihoods, Syrian women increasingly opt for informal work - one that comes with a great deal of intimidation and manipulation. Entering this illegal job market, makes Syrian women an easy target for genderbased violence, as they are legally powerless and could thus easily be coerced into providing sexual services to avoid harassment. ${ }^{652}$

Furthermore, early and forced marriages have reportedly increased among Syrian refugees in host countries, such as Lebanon, mainly because it is perceived as a significant resilience coping strategy. Early marriages are perceived to be a

${ }^{652}$ Geneviève Colas, Secours Catholique-Caritas France, and Olivier, Peyroux, "Trafficking In Human Beings," Caritas, (2016), http://www.caritas.eu/sites/default/files/report_-_trafficking_in_conflict_and_postconflict_situations_en.pdf. 
deterrent and a form of protection of adolescent girls from future instances of rape or kidnapping, under the pretext that by getting married a woman will come under the protection of her husband. Also, due to financial strains from which Syrian households suffer-with $70 \%$ of Syrian refugees living below the poverty line at the end of 2015 - the practice of child marriage is culturally accepted within patriarchal social contexts. ${ }^{653}{ }^{654}$ This could be attributed to two major reasons: as on the one hand, in patriarchal social contexts in which male providers feel young daughters are perceived as a high liability that is not only financial, which relates to "fewer mouths to feed," but also social and personal as marriage is the ultimate way of protecting women and their honor.

On the other hand, some studies show that it is not unusual for early marriages to be a form of exploitation through disguised prostitution in patriarchal contexts. ${ }^{655}$ In fact, some families tend to pragmatically wed off a young daughter to the highest bidder especially when there are times of financial and economic hardship and crisis. ${ }^{656}$ Accordingly, early marriage may be an indicator of forced prostitution and a precursor to GBV, where Syrian refugee girls in Lebanon are

\footnotetext{
653 "Syrian Refugee Women in Lebanon Face Abuse, Exploitation." Agence France Press, The Straits Times, (February 2, 2016), https://www.straitstimes.com/world/middle-east/syrian-refugee-women-in-lebanon-faceabuse-exploitation.

654 "Are We Listening? Acting on Our Commitments to Women and Girls Affected by the Syrian Conflict," International Rescue Committee, IRC. (2014), 15.

${ }^{655}$ Geneviève Colas, Secours Catholique-Caritas France, and Olivier Peyroux, "Trafficking In Human Beings," Caritas, (2016), http://www.caritas.eu/sites/default/files/report_-_trafficking_in_conflict_and_postconflict_situations_en.pdf.

656 Clarissa Ward, "Syrian Refugees Sell Daughters In Bid to Survive," CBS News, (May 15, 2013), http://www.cbsnews.com/news/syrian-refugees-sell-daughters-in-bid-to-survive/.
} 
being exploited by forcibly being married in exchange for legal support—getting a Lebanese residency when wedded to a Lebanese man - and economic support, which their low-income families sorely need. This practice is often justified by religious groups as lawfully constituting protection for vulnerable girls who just became women — adult enough to carry a family due to hitting puberty — even if they were below the age of $14 .{ }^{657}$

Meanwhile, it is very tough for the legal system to separate child sex trafficking and early marriage. According to the expert from Justice Without Borders, "when there are cases where they find the families sell their daughter to get some money from it, also it is legally not applicable to say that that is trafficking because, within the culture, they "take money for their daughter." 658 Accordingly, this expert expanded the idea by stating:

"As I say, when you talk about a penal issue, you consider the intention. If they got the money because this is what is mentioned in Sharia, and it is Muslim, it is ok. However, if their [family] intention is to get money to live better knowing what future awaits their daughter, then yes. This is a crime.[...] and sometimes the family is based in Syria. Therefore, we cannot do many things." ${ }^{659}$

This illustration adds to previous feminist critics of how the practice of perpetuating unequal relations co-constitute systemic social, historical, and

\footnotetext{
657 "Identifying the Legislative Gaps that Need to Be Filled for the Application of Security Council Resolution 1325." United Nations Economic and Social Commission For Western Asia-(ESCWA). (2000) on Women, Peace and Security in Selected Arab States." E/ESCWA/ECW/2015/Technical Paper.8, (March 17, 2015), women-peace-securitylegisislative-gaps-resolution-1325-english.pdf.

${ }^{658}$ Justice Without Borders Expert interview with author, (May 29, 2017).

659 Ibid.
} 
material forms of oppression that are grounded and continually reformulated, elevating Syrian women's insecurities and imposed gendered roles. As such, several cases were brought up in newspapers and media, where women, forced to adapt to their new realities, provide sexual favors to bargain for food, shelter, and other needs to secure themselves and their undocumented children. ${ }^{660}$ Meanwhile, most participants viewed their government's painful policies as mechanisms that (re)produce more insecurities within Lebanese communities. As a matter of fact, $60 \%$ of the increase in crime in Beirut is in some way directly related to the refugee population where 26 percent of the prison population is of Syrian nationality. ${ }^{661}$ Even with this entire maneuver, a large number of Syrians were still left without proper residency papers; unable to officially register the births of their offspring in Lebanon. ${ }^{662}$ A legal expert working with Justice without Borders — a Lebanese NGO that promotes human rights - echoed one Lebanese newspaper reporting that International organizations involved in the issue of Syrian refugees in Lebanon have submitted reports that of the 1.6 million refugees there are around 300,000

\footnotetext{
${ }^{660}$ Kareem Shaheen, "Dozens Of Syrians Forced Into Sexual Slavery In Derelict Lebanese House," The Guardian, (April 30, 2016), https://www.theguardian.com/world/2016/apr/30/syrians-forced-sexual-slaverylebanon.

661 “Refugee Children Resorting To 'Survival Sex' To Pay People Smugglers Says UN," International Business Times, (October, 2015), http://www. ibtimes.co.uk/refugee-children-resorting-survival-sex-pay-peoplesmugglers-says-un1525534.

662 USJ Rport
} 
Syrian women who gave birth in $2017 .{ }^{663}$ During the interview, the legal expert from Justice Without Borders stated that:

"There are maybe around 200,000 or more children who are not registered. Concerning the Lebanese law, after the first year of birth, [Syrian infants] who get one year old require a decision from court to prove the parental lineage. Such a procedure is costly as they would have to perform a DNA exam on the kid and the parents, costing around US $\$ 150$ per person. This sum is to be added to the cost paid to the court, the lawyer, and the clerk. [...] Syrian refugees do not have access to justice. They do not know that their children are stateless. They will have problems in the future. They will not be able to return to their country. They could be arrested because they do not have any ID.” 664

Even though the expert's analysis of the legal implications that the number of births of Syrians carries additional negative consequences on both Syrian and Lebanese communities, the number is exaggerated, not reflective of the estimated data collected by the involved agencies. The Minister of State for Refugee Affairs, Mouin Merehbi, the UN refugee agency spokesman in Lebanon, Khaled Kabara, and Medical Coordinator for Doctors Without Borders, Mounia Amrani, quickly debunked this viral news stating that such a number was impossible, fake news, and

\footnotetext{
663 “300 Thousand Syrian Women Pregnant Will Give Birth In Lebanon In 2017,” Addiyar News, (March 3, 2017), https://www.addiyar.com/article/1359928-300-2017.

${ }^{664}$ Justice Without Borders Expert interview with author, (May 29, 2017).
} 
part of a xenophobic anti-Syrian refugee agenda in Lebanon. ${ }^{665}$ Still, there is no doubt that an accurate number of Syrian births is impossible to provide. After all, Syrian presence in Lebanon is not limited to those officially registered in the state records nor with the UNHCR. Ultimately, even though the numbers are not as high as portrayed, the increasing annual rate of stateless births can only pose a bigger demographic threat to both Lebanese institutions and Syrian refugees' livelihoods, justifying local and international anxieties over civil unrest between Lebanese and Syrians in many host communities. ${ }^{666}$

Meanwhile, it is also crucial to note that there are severe gaps in general awareness on matters relating to reproductive and sexual health for both men and women who come from modest backgrounds with no literacy, nor sex education. These knowledge gaps have resulted in high birth rates and an increase in infant mortality and deformity percentages. ${ }^{667}$ This reality along with the overall financial shortages and economic hardships has only resulted in a vicious spiral of poverty and desperation for both Lebanese and countless Syrian refugees, where womenheaded households are the most vulnerable groups. At the end of 2015, the UN had only received $57 \%$ of the funds it requested for its work in supporting refugees in

\footnotetext{
${ }^{665}$ Mohamed Alloush, "What Is The Truth About The Presence Of 300,000 Pregnant Syrian Women In Lebanon?," ElNashra News, (May 3, 2017): https://www.alaraby.co.uk/english/news/2017/5/5/debunked-300000-syrian-refugees-arenot-pregnant-in-lebanon.

666 Ibid.

667 "Women And The Refugee Crisis: A News Update From Lebanon," Global Fund For Woman, (2015): https://www.globalfundforwomen.org/news-update-refugee-crisis/\#.WVovCoiGPIU.
} 
Lebanon. ${ }^{668}$ The severe shortage of funds resulted in the reduction of monthly payment to Syrian refugees — from US $\$ 27.70$ to US\$13.50 per person per month. ${ }^{669}$

As a consequence, the UN warned of an increase in Syrian refugees resorting to negative coping strategies such as a reduction of food intake and expenditure on education and health, coupled with an increase in debt, informal work and street begging. ${ }^{670}$ Such actions would result in various negative consequences on the already burdened Lebanese infrastructure. In some areas, the population has doubled, putting much pressure on the already dire Lebanese infrastructure, housing, health services, and educational services. Overpopulation and waste management strategies were mismanaged, posing a threat to most residents, violating their right to public health. As a result, trash could be seen all over the country, and dumping in public spaces and burning became the norm across the country. According to one research conducted by experts from the American University of Beirut, "77 percent of Lebanon's waste is either openly dumped or landfilled even though they estimate that only 10 to 12 percent cannot be composted or recycled." 671

\footnotetext{
668 "Regional Refugee and Resilience Plan (3RP), Funding Requirements: Lebanon." United Nations. (December 29, 2015): http://data.unhcr.org/syrianrefugees/country.php?id=122

669 "Food Security Sector, Monthly Dashboard," UN Inter-Agency Coordination Lebanon, (July, 2015), http://data.unhcr.org/syrianrefugees/download.php?id=9506.

670 "Syria Crisis Response, Situation Report." World Food Programme, Lebanon, (September, 2015), http://data.unhcr.org /syrianrefugees/download.php?id=9670. USJ REPORT

671 "Lebanon: Waste Crisis Posing Health Risks," Human Rights Watch, (December 1, 2017), https://www.hrw. org/news/2017/12/01/lebanon-waste-crisis-posing-health-risks.
} 
In this respect, this photovoice method helped this research highlight that topbottom production of a stereotypical gendered image of "displaced" Syrians brings counterintuitive results. It adds to previous feminist literature's critiques that overgeneralized refugee management policies end up ignoring the intersectionality of complex agencies within the refugee population. Thus, most participants agreed that while the intent of photographic depictions of Syrian refugees may very well be to humanize its subjects and show their agency, the resulted photos cannot capture the whole scenario of Syrian refugee insecurities in Lebanese context. Still, they believe these pictures do a better job in capturing Syrian destitute and agency when compared to most media visual depictions that often creates distance between the privileged spectator and the object of his gaze; dehumanized Syrian refugees. Most news images objectify Syrian women and children refugees as innocent victims, lacking protection and agency, and Syrian men posing security threats to Lebanon's security and identity. Also, the top-down physical marginalization of informal Syrian settlements pushed most Syrian women and their families to live in hazardous unsanitary habitats. Still, this exercise brought more information to the Syrians' situation than it may appear in general rhetoric.

In fact, the participants highlighted that the geographic settings and the refugees' social background affect Syrians' position of power over others within different contexts.

The degree of agency that Syrian women are legally allowed, due to their precarious legal status and due to their gender, affects their limited opportunities and 
expectations. Most participants agreed that the problematic generalization and misrepresentation of the Syrian refugees led to discriminatory policies and exclusionary practices that silence the already marginalized voices of Syrian women, enticing societal acceptance of intersectional violence to occur towards the diverse groups of Syrian women residing in Lebanon. However, through adaptation, and by using various means, most participants believe that Syrians (re)negotiate their way out of the different vulnerabilities. Several pictures portrayed this agency and resilience that seem to vanish under media practices and public discourse.

Moreover, some participants suggested that loopholes within security practices get used and abused by opportunistic agencies and Syrians as well, pushing special interests at the expense of the general communities' wellbeing. As long as gender-biased laws and security practices emerge, generate, or perpetuate, a cycle of victimhood persists, and any sustainable solution for the Syrian crisis would remain unabated. Despite the many efforts' refugees make to escape the horrors of war, governments, international agencies, and nongovernmental organizations seem to provide little to no relief to most of those refugees when looked at from a top-down lens. According to the participants, the shawish phenomenon is living proof of the erection of uncontrollable complex resilience effort that tends to (re)enforce hierarchies of power relations and discrimination within the local context.

Meanwhile, all participants blamed the Lebanese government officials and humanitarian aid initiatives for the inadequate policies and mixed messages. 
Instead of providing refugees with secure shelters, as mentioned in the policy planning, Syrians are still discarded in mediocre living conditions on the outskirts of towns, open to all sorts of discriminations. In that case, some participants perceive that most aid techniques are complicated, time-consuming, and mostly sporadic, unreachable by most Syrians. Consequently, many Syrians get pushed into homelessness, sickness, or any other type of vulnerability. As seen before, generalizing gendered vulnerabilities creates discriminatory social norms, exclusionary practices and, in some cases, structural violence against refugees with a constitutive power to reinforce, even (re)produce, local anxieties. All participants agreed that reinforcing current misperceptions of residing Syrians as a potential threat or a burden pushes most Syrian women not to report sexual abuse, provide survival sex, beg, and work informally for exploitative wages to survive. ${ }^{672}$ Therefore, echoing another feminist argument, all participants believed that without adopting a nuanced approach, considering the different socio-political sensitivities, refugee management policies become problematic, pushing Syrians' resilience efforts into silence. In effect, Syrian women refugees had to switch gender roles to adapt to the new realities, suffering the brunt and most devastating implications of discriminative securitized practices.

As such, the findings from this project helped this dissertation expand its understandings about the different systems of oppression within the visuals

${ }^{672}$ Claire Harvey, Rosa Garwood, and Roula El-Masri, "Shifting Sands: Changing Gender Roles Among Refugees In Lebanon," Oxfam International, (2013). 
collected and discussed by the research participants. On the one hand, discussing the many negative consequences that come out of these generalized policy processes produced increased empathy and appreciation towards most Syrian refugees - women and children. On the other hand, several participants felt the need to emphasize some positive stories and initiatives, which crucially needed to be expanded on, amid what is an extreme negative bias in the coverage of the refugee crisis in Lebanon. In times of hostile refugee political attitudes and practices, all participants felt the need to disseminate accurate stories that have the potential to empower the people whose voice is silenced by channeling the right humanitarian approach. Participants view that Lebanese citizens must get involved as much as Syrian residents should in order to relate more to the individual Syrian insecurities. Consequently, their effort to connect on an individual level would humanize the previously portrayed faceless numbers of refugees, generating sensible questions and, potentially, common sustainable solutions for both communities.

To solve the problematic issues with emergency relief, there is a need to reassess the underlying assumptions and approaches towards working with the diverse Syrian population and empower them rather than save them and fix them. Thereupon, this project helped disrupt some of the stereotypes and inaccuracies that prevail in the mainstream representations of Syrians refugee insecurities in Lebanon, particularly the victim and threat narratives that flatten and objectify Syrians' issues, especially women. In that sense, the photovoice project was conceived as a deliberately transnational project — between an external academic and local refugee workers and volunteers regarding the topic of a transnational 
Syrian population - aimed at challenging the stereotype of Syrians as a foreign nuisance, a threat, or vulnerable victimized population in the hopes of promoting self-reliance initiatives for refugees. By thinking through images about the political ramifications of Syrian refugee insecurities, all participants supported the critical engagement of dissecting the problematic issues that the Syrian crisis protracted in the Lebanese context. Meanwhile, it is essential to state that the appropriation and generalization of the research findings, applying them to all Syrian refugees in Lebanon, is a practice that this dissertation is keen to avoid.

The findings of this study contest the idea that Syrian refugee (in)security is a zero-sum game where aid assistance and protection services are either available or not. Contextual dynamics and critical variables complicate the Syrian refugee response mechanisms that continually exacerbate their insecurities with the humanitarian, socioeconomic, political, and security dynamics at hand. Consequently, their agency and resilience efforts would (re)produce further local insecurities (re)impacting Lebanon's economy, social fabric, and national stability. 


\section{A VICIOUS CYCLE OF SYRIAN REFUGEE INSECURITIES}

As seen throughout this dissertation, forced displacement due to warfare is one of the most traumatic types of human experience, where its depth and breadth pose significant challenges to asylum seekers, neighboring host states, and nongovernmental entities involved with managing crises. Exploring the case of Syrian refugees in neighboring Lebanon, a nation populated by roughly four million people, the dissertation investigated the securitization-refugee protection nexus as it permeates a South-South forced migration case of Syrian refugees in Lebanon. This concluding chapter incorporates the interweaving feminist scholarships on security studies and refugee governance to critically investigate what seems to be a vicious cycle of multifaceted predicaments across the construction, management, and impact of Syrian refugee (in)security, wherein Lebanon is undergoing a massive demographic transformation.

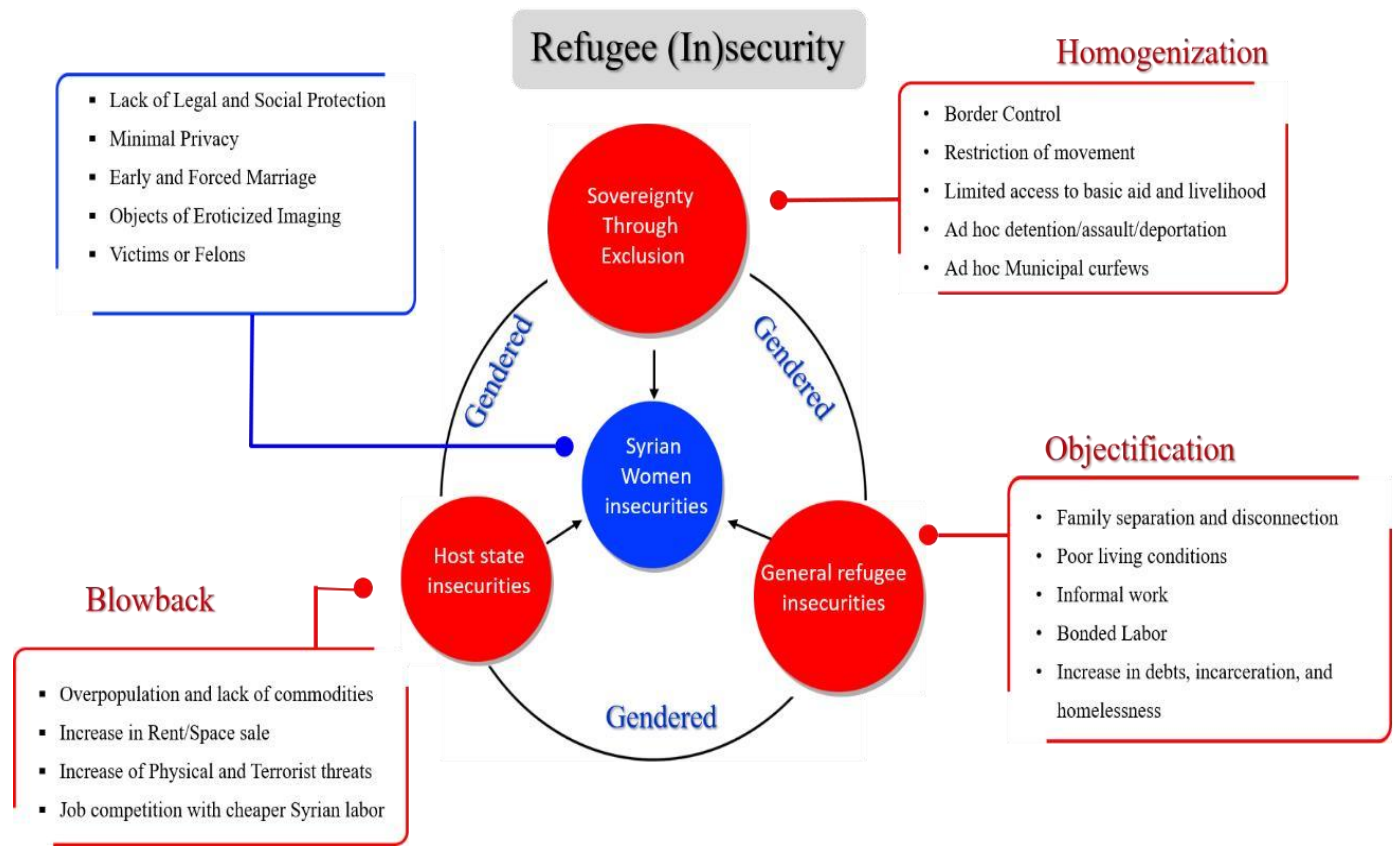

Figure 27. The Vicious Cycle Of Refugee (In)security 
In effect, the figure above synthesizes how different political and socio-economic elements influence a securitized translation of refugee protection norms in the case of Syrians in Lebanon. It gave visibility to the various relational processes across numerous spaces, where refugee insecurities are constantly (re)negotiated and translated, (re)impacting their surroundings. This figure highlights how involved bodies-host communities, Lebanese government officials, and humanitarian agents-silence Syrian refugees through multiple systems of oppression. By examining the critical gaps within the Lebanese politics of Syrian forced migration, this interdisciplinary study shows how securitized refugee management practices had intersectional effects on Syrian people who occupy marginalized identities, such as class, ethnicity, and gender. As a matter of fact, Syrian refugee governance policies seem to have affected both Lebanese insecurities and Syrian refugees' livelihoods and self-determination, making the latter's survival increasingly precarious, especially Syrian women's. ${ }^{673}$ For the most part, processes of homogenization and practices of objectification play a dominant role in (re)positioning some Syrian refugees at an advantage over others, creating a 'blowback' - “a metaphor to denote unintended negative consequences" 674 of securitized operations - that would (re)affect

\footnotetext{
${ }^{673}$ Richard Hall, “After Trump's Ban, Lebanon Renews Calls To Send Back Syrian Refugees,” Public Radio International, (February 6, 2017), www.pri.org/stories/2017-02-06/after-trump-s-ban-lebanon-renews-callssend-backsyrian-refugees.

${ }^{674}$ Sara Meger, “The Fetishization Of Sexual Violence In International Security," International Studies Quarterly 60, no. 1 (2016): 149-159.
} 
Syrian refugees' relations with the local population.

Therein, this final section is divided into three different sections, borrowing Sara Meger's theoretical framework regarding securitization, where Meger detects; a non-linear chain of processes of homogenization, objectification, and 'blowback. ${ }^{675}$ Accordingly, this section explicitly assesses the implications of this vicious cycle from the research findings, while also integrating them with the study's theoretical background and relevant literature findings.

\section{Homogenization}

As detailed in Chapter IV, geopolitics and biased social attitudes influence the domestic translation and application of universal refugee protection norms. Tracing different critical junctures in Lebanese Syrian rapport, the study finds that local relations between Lebanese communities and Syrian residents have significantly deteriorated in recent years. While Lebanon has shamed developed Western countries by hosting a million and some of the Syrian refugees at a time when most of them closed their borders, the research finds that Syrian refugee insecurities were (en)gendered with distressing consequences. Even if the main bodies that manage the Syrian crisis in Lebanon are gender neutral, they seem to exacerbate a gap between gender-sensitive policies theoretically advertised on paper and their

${ }^{675}$ Sara, Meger. "The fetishization of sexual violence in international security." International Studies Quarterly 60, no. 1 (2016): 149-159. 
securitized practices in the field. ${ }^{676}$ Here gender, as an essential organizing principle, consistently maintained the unequal Lebanese-Syrian relationship, where, Lebanese rhetoric homogenizes Syrian de facto refugees as threatening, reigniting a collective memory of an oppressive Assad regime that would want to further Syrian influence on Lebanon's fragile sectarian balance.

On the one hand, like many host countries, Lebanon legitimizes its sovereign right to refuse asylum seekers' requests to enter and remain regardless of eligibility. ${ }^{677}$ Subsequently, Lebanese law does not extend residency rights to foreigners living in the country except under very limited circumstances, restricting their access to public health care, education, jobs, among many. ${ }^{678}$ As highlighted in chapter IV, with such measures in place, refugee insecurities in the case of Lebanon were pushed away from being a national governance problem of a weak, severely divided, and overwhelmed state to become heavily dependent on exclusionary (in)security practices. ${ }^{679}$

On the other hand, while the Lebanese government and people have welcomed more Syrian refugees than any other country, the presence of so many

\footnotetext{
${ }^{676}$ Julie Mertus, "Sovereignty, Gender, And Displacement," in Newman, Edward, and Joanne Van Selm, Refugees and Forced Displacement. International Security, Human Vulnerability And The State. Tokyo United Nations University Press, (2003), 252.

${ }^{677}$ Susan M. Akram, Sarah Bidinger, Aaron Lang, Danielle Hites, Yoana Kuzmova, and Elena Noureddine, "Protecting Syrian Refugees: Laws, Policies, And Global Responsibility Sharing," Middle East Law and Governance 7, no. 3 (2015): 287-318.

${ }^{678}$ Ruth Pollard. "Lebanese Citizenship Law Strips Women Of Identity And Property." Reuters. (May 25, 2016), https://www.reuters.com/article/us-lebanon-women-property-rights/lebanese-citizenship-law-stripswomen-of-identityand-property-idUSKCNOYH03O

${ }^{679}$ Filippo Dionigi, “The Syrian Refugee Crisis In Lebanon: State Fragility And Social Resilience,” LSE Middle East Centre paper series, 15. Middle East Centre, LSE, London, UK. (2016).
} 
Syrians became a controversial intersecting political, economic, social and religious issue for most Lebanese constituents. For instance, numerous Lebanese individuals perceive the presence of Syrians within the country as the cause of their worsened (in)securities and access to work, even though, according to a survey, only $9 \%$ said they or their family members have actually been direct victims of Syrian led assault. ${ }^{680}$ In fact, as of 2017, $50 \%$ of registered Syrians operate in construction work and agribusiness-jobs that are traditionally filled by Syrians in Lebanon, even before the refugee crisis. ${ }^{681}$ The (mis)perceptions of Syrians in Lebanon are thus the result of inflammatory sectarian public discourse against the 95\% of those registered with the UNHCR agency (Sunnis) and not factual occurrences. According to chapter IV, Lebanese concerns were furthered by sporadic (in)security incidences of terrorist attacks and lone crimes such as theft, murders, and gender-based violence led by Syrians within the country.

This situation increased the Syrian women refugees' insecurities. As stated in Chapter IV, between 1976 and 2005, Syria dominated Lebanon both politically and militarily. Thousands of Lebanese were murdered, kidnapped or imprisoned by the Syrian authorities, and until this day, thousands remain missing. ${ }^{682}$ The crisis in Syria has reversed the power dynamic between the two nations, and while the

\footnotetext{
${ }^{680}$ Carole Alsharabati and Jihad Nammour, "Survey On Perceptions Of Syrian Refugees In Lebanon," Université Saint Joseph, (August, 2015), 33-34.

681 "VASyR: Vulnerability Assessment of Syrian Refugees in Lebanon," World Food Program, UNICEF, and UNHCR, (December, 2017): https://reliefweb.int/report/lebanon/vasyr-2017-vulnerability-assessment-syrianrefugeeslebanon.

${ }^{682}$ Nisan Mordechai, "The Syrian Occupation Of Lebanon," Coalition for Responsible Peace in the Middle East, (2000).
} 
Lebanese government has welcomed over 1 million and some Syrian refugees, hostility toward them is not uncommon because of historic and deeply rooted animosity, highlighted in chapter IV.

According to a Syrian woman called Leila residing in the Bekaa Valley, Lebanon: "Before, Syrians in Lebanon had dignity. Now, after the crisis, all Syrians just walk with our heads down." ${ }^{683}$ In politicized contexts such as this one, it is not uncommon for the women of the

"other" group to become the objects of eroticized imaging, a process that was well documented, for instance, in the context of North Korean refugees residing in South Korea. ${ }^{684}$ This comes in line with the objectification of women and transformation into targets of GBV during political conflicts. Although, the situation in Lebanon is not like the atrocities of mass rapes committed in many other wars, there are nonetheless some similarities in the manifestation of hostility toward the women of the enemy. ${ }^{685}$

Still, several Lebanese performative contestations towards Syrian presence within the country are not only tied to a xenophobic collective memory of Lebanon's subordination to the Syrian Assad regime. These tactics are also the product of a refugee host community's fatigue towards a protracted massive Syrian

\footnotetext{
${ }^{683}$ Amnesty International Focus Group Discussion, (October 6, 2015), Saadnyal, Bekaa Valley.

${ }^{684}$ Kim Mikyoung, "Securitization Of Human Rights: North Korean Refugees in East Asia," ABC-CLIO, (2012):73.

685 Sara Meger, “The Fetishization Of Sexual Violence In International Security," International Studies Quarterly 60, no. 1 (2016): 149-159.
} 
refugee crisis as well as donor fatigue with a decline in aid funds. Notably, as international funding fell short, the Syrian refugee crisis proved to be very expensive for the Lebanese public with an estimated cost of $\$ 7.5$ billion just in 2015. ${ }^{686}$ A decrease in GDP, an increase in unemployment rates, and a surge of poverty levels resulted in the gradual regression of the economy and the overall living standards of Lebanese citizens. According to Chapter V, severe cuts of international grants and funding - a reaction to the official decision taken by the Lebanese government to close the borders to Syrian refugees-were also a factor that did not help. ${ }^{687}$

The LCRP 2017-2020 mentions that in 2016, "only 56\% of the total appeal for Lebanon's funding requirements" was covered, primarily due to instances of mistrust between several donor communities and governmental agencies. ${ }^{68}$ In effect, short-term solutions addressed the protracted Syrian refugee crisis and basic needs of impoverished host communities, reducing any prospects for long term socio-economic stability. ${ }^{689}$

\footnotetext{
686 "Lebanon: Economic and Social Impact Assessment of the Syrian Conflict." World Bank Report, available at: http://documents.worldbank.org/curated/ en/2013/09/18292074/lebanon-economic-social-impactassessment-syrianconflict.

687 "Lebanon and Jordan Close Their Borders To Syrian Refugees," The Chronicle, (December 22, 2014), https://chronicle.fanack.com/refugees/lebanon-and-jordan-close-their-borders-to-syrian-refugees/.

688 "Following the Money: Lack Of Transparency In Donor Funding For Syrian Refugee Education," Human Rights Watch, (September 14, 2017), https://www.hrw.org/report/2017/09/14/following-money/lacktransparency-donorfunding-syrian-refugee-education.

689 “UNHCR 2016 Regional Refugee \& Resilience Plan - Funding Snapshot As Of End Of 2016." UNHCR, (December 31, 2016), https://alefliban.org/wp-content/uploads/2017/03/ALEF_AnnualReport_2016.pdf
} 
To this end, Lebanese politicians threatened the international community that the shortfall in funding could launch another massive wave of Syrian migrants to Europe, adding to the enduring burden of refugee inflow a few years back. ${ }^{690}$ Correspondingly, the Foreign Minister Gebran Bassil severely urged the international community "to quit lecturing Lebanon on humanity and to stop encouraging Syrians to stay in Lebanon." 691

The latter statement triggered aggressive policy measures ensue, reducing all incentives for Syrian refugees to stay in Lebanon, wanting them to return to Syria as soon as possible.

Based on Lene Hansen's definition of "security as silence," 692 chapter V highlighted a range of securitized mechanisms that the Lebanese government normalized when managing Syrian refugees, reproducing gender hierarchies and hegemonies, affecting residing Syrians asymmetrically. Imprudently, these securitized behaviors became anchoring objectifying practices on how to manage a homogenized refugee crisis. In effect, several practices, highlighted in the above figure, homogenized Syrian refugee insecurities, (en)gendering exclusionary refugee (in)security practices - such as visa restrictions and border control, a no camp policy, curfews, and checkpoints, among many-despite the Syrians clear

\footnotetext{
690 "International Plea For Syrian Refugee Jobs Sparks Anger In Lebanon,” Arab News, (June 24, 2018), http://www.arabnews.com/node/1292241/middle-east.

691 “International Plea For Syrian Refugee Jobs Sparks Anger In Lebanon,” Arab News, (June 24, 2018), http://www.arabnews.com/node/1292241/middle-east.

692 Ibid.
} 
vulnerabilities. Accordingly, this study supports Emanuel Adler and Vincent Pouliot's argument that practices are "socially meaningful patterns of action." ${ }^{\text {" } 93}$ It seems that the Lebanese government's exclusionary measures possess coconstitutive securitized practices, where only two forms of durable solutions were available for the UNHCR to sustain the legal determination of Syrian refugees in Lebanon; resettlement and repatriation, which both are arduous, somewhat unrealistic, options for the one million and some registered Syrian population. Meanwhile, Lebanon's attempt to find temporary solutions to the mass influx of Syrian refugees within the country, encompassed a wide range of violation to its human rights obligations - such as limited access to aid and livelihood, and ad hoc detention, assault, and deportation, limiting humanitarian agencies such as the UNHCR from accurately addressing Syrian refugees' needs.

\section{Objectification}

As seen in the above figure, Chapter $\mathrm{V}$ investigated the contextual changes that shape and are shaped by specific refugee crisis response plans between two political institutions with distinct interests and competing goals. The organizational cultural theme analysis teased out how a variety of interests clash between protecting Syrian refugees and protecting the host state's national interests. The focus of the study was on two core institutions with seemingly different knowledge claims and approaches to managing the Syrian crisis: the Lebanese government and the UNHCR. Chapter V highlighted how both interested bodies decontextualized the

\footnotetext{
${ }^{693}$ Emanuel, Adler, and Vincent Pouliot. "International practices." International Theory 3, no. 1 (2011): 1-36.
} 
majority of Syrian refugees' specific needs, homogenizing the diverse Syrian groups as both dependent and problematic. Thus, similar to what Elizabeth Olivius's work captured, both LCRP documents objectified the many Syrian insecurities through extensive procedural measures of refugee management practices that would hinder a viable translation of global refugee norms into meaningful actions. ${ }^{694}$ As highlighted in the figure above, numerous cases of discriminatory tactics, justifying the host society's conduct of unease, counterproductively enticed exclusionary refugee management practices that would further bonded and informal labor exploitation, poor living conditions, debts, and homelessness, and incarceration and deportation due police and municipal harassment, among many.

In that respect, the UNHCR's struggle to adapt their internationally recognized gender-sensitive norms to local policies distorted their refugee protection and humanitarian assistance goals when translating them into the Lebanese context. Even if the well-intentioned humanitarian agency would want to provide these essential services to the majority of the Syrian refugee populationSyrian women and children - they end up objectifying their needs under overgeneralized targeted approaches, failing to empower and protect the majority of the 'vulnerable' population. Chapter V traced how humanitarian policies' principles are still short in practice when not enabling and empowering almost $80 \%$

\footnotetext{
${ }^{694}$ Elisabeth, Olivius. "(Un) Governable Subjects: The Limits of Refugee Participation in the Promotion of Gender
}

Equality in Humanitarian Aid." Journal of Refugee Studies 27, no. 1 (2013): 42-61 
of the registered refugee population - women and children - and their resilience capabilities. By tracing the significant organizational cultural themes of the two consecutive LCRP documents and their development, the study showed what the expert from Abaad pointed to: "all those response plan mechanisms are mainly designed for the international humanitarian community [and not Syrian refugees themselves]." ${ }^{695}$ Instead of involving these targeted groups in crisis response planning, the plan's strategy focused on appealing for more funds for the various projects dependent on donors voluntarily choosing who, what, where, and when to fund.

Consequently, the elaborations, transformations, and changes made between the plans do not advance the necessary protection and assistance that targeted vulnerable groups desperately need. What initially seemed like a similar schema that the humanitarian community and Lebanese government share, evidenced by their use of common appropriation of agenda initiatives and goals, a closer inspection highlights a more complex gendered story of both harmony and tension between both sides. While both parties genuinely aim for socio-economic stability and increase of government services and aid, the selective prioritization of gendered projects, such as targeted approaches, the specific monitoring mechanisms, and the lack of transparency, seemed to affect the management of the Syrian the refugee crisis negatively. As such, the study showed that even the second

${ }^{695}$ Abaad Expert interview with author, (June 20, 2017). 
LCRP version failed to provide basic humanitarian services to the majority of the Syrian refugees, Syrian women.

The humanitarian approach seen in both LCRP documents mostly reinforces an image of Syrian refugees as a burden: disempowered, passive and helpless. Accordingly, the organizational cultural theme longitudinal analysis reinforces Heather Johnson's visual construction argument of the myth of a refugee identity, where female refugees are portrayed as depoliticized legally, socially, and economically for the success of humanitarian missions. ${ }^{696}$ These Syrian women are heavily dependent on the framing of the UNHCR, not capable to fully capitalize on their own skills as self-help mechanisms. Chapter V exposed that the elaboration and transformation of the crisis response plan(s) led to a minimal change of approach, where little prioritization of gender-sensitive assistance was made. This latter, thus, increased the gap between theory and actual mitigation of genderrelated political or socio-economic problems regarding the homogenized and objectified refugee population.

Due to several compromises persisting within both Lebanese crisis response plans, neither LCRP document fully ensured Syrian refugee safety nor selfsufficiency. In that regard, the given compromise that persists within both plans furthered the deteriorating Syrian refugees' insecurities when residing in Lebanon, especially for Syrian women. In that respect, the dominant governing humanitarian

${ }^{696}$ Heather L. Johnson. "Click to Donate: visual images, constructing victims and imagining the female refugee." Third World Quarterly 32, no. 6 (2011): 1015-1037. 
projects counterproductively dehumanized Syrian refugees as part of a larger targeted group of vulnerable people, highlighting their overwhelming numbers and insecurities' statistics that pose a threat to Lebanon's fragile stability, in order to ensure a good amount of aid and funds for their projects. Accordingly, the study found that refugee participation in the planning, implementation, or management of the LCRP operations was absent, increasing the gap between policy management and actual mitigation of gendered political and socioeconomic problems, especially for Syrian women refugees. The UNHCR's refugee crisis responses between 2014 and 2018 increasingly institutionalized Syrian refugees' insecurities through standard operating procedures (SOP) for intervention and control in the interests of nationalist donor states, devoid of genuine concerns regarding the multifaceted needs and risks refugee women experience in their daily lives. Meticulous exercises of counting, calculating, and coding refugees through census and surveys reinforced the inefficient gender-neutral methods of "knowing" the refugees. Thus, their perceptive needs end up contrasting and contradicting the LCRP mission's idea of enhancing gender mainstreaming through protection and assistance that were meant to alleviate various targeted groups from their daily insecurities. ${ }^{697}$

The lack of taking the experiences of the majority of Syrian refugeeswomen - seriously forces gender sensitive issues to be silenced, in favor of more overgeneralized accounts that group all refugee insecurities into one single unit. One study finds that most Syrian women in Lebanon face institutionalized multi-

${ }^{697}$ Ibid. 
systemic violence that are often silenced due to reductive (in)security measures that homogenize them under an abstract gender-neutral Syrian community ${ }^{698}$. Before the crisis, Syria had one of the highest rates of educated women in the Middle East. However, in the case of Syrian women, UNESCO's estimates show that Syrian girls are twice more likely than boys to be kept from attending school in Lebanon due to family fears of being victims of gender-based violence. ${ }^{699}$ In effect, Syrian women refugees took the hardest toll from sexual exploitation to gender based violence, raids, arbitrary arrests, and numerous apprehensions that continue to be common practice and everyday reality in Lebanon. According to a study conducted by the "Institut Des Sciences Politique," 73\% of Syrian-women refugees reported feeling insecure in moving any time of the day or night, resulting in different types of insecurities. ${ }^{700}$ Adding to that, the lack of valid residence permits is one of the main reasons Syrian women are unable to seek redress from local authorities or even move around safely. With children to take care of, adult female Syrian refugees heading their household's responsibilities expand beyond domestic activities, while still hindering them from gaining full access to the public sphere. ${ }^{701}$

\footnotetext{
${ }^{698}$ Rola Yasmine \& Catherine Moughalian

${ }^{699}$ Janice G. Raymond, "Pity The Nations: Women Refugees In Lebanon.” Coalition Against Trafficking in Women Report, (December 6, 2017), http://www.catwinternational.org/Home/Article/727-pity-the-nationswomen-refugees-inlebanon.

${ }^{700}$ Institut Des Sciences Politiques USJ, Survey On Perceptions Of Syrian Refugees In Lebanon, (March, 2015), http://www.sciences-po.usj.edu.lb/ pdf/Executive\%20Summary.pdf

${ }^{701}$ Rola Yasmine and Catherine Moughalian, "Systemic Violence Against Syrian Refugee Women And The Myth Of
}

Effective Intrapersonal Interventions," Reproductive Health Matters 24, no. 47, https://www.tandfonline.com/doi/pdf/10.1016/j.rhm.2016.04.008. 
Meanwhile, without gender inclusive protection measures, thousands of Syrian women of various ages suffer from an extremely precarious administrative and legal status that makes them vulnerable to arrest and deportation. While, some progress was made in providing social protection services for women against gender-based violence (GBV) in Lebanon, such as the new domestic violence legislation and the availability of a 24-hour hotline for reporting. Still, the study showed that these services are barely implemented and are generally limited to Lebanese women. $^{702}$

Although there is a multitude of private networks' efforts that respond to the immediate needs of refugee, without legal guarantee, they were unable to fulfill the minimum requirement for an adequate refugee reception. Evidently, these women are in much worse conditions than those who are registered and suffer thus from much heavier economic burdens than any other refugee group in the country. Because of their intersectional identity as both Syrian refugees and women within exclusionary Lebanese refugee securitized practices, their interests and experiences are frequently marginalized and further complicated depending on gender, class, religion, age, and ethnicity, among many interlinking identieis. ${ }^{703}$ According to the representative of Justice Without Borders:

\footnotetext{
702 “Lebanon Annual Report 2014 Highlights,” KAFA, (2014): http://www.kafa.org.lb/StudiesPublicationPDF/ PRpdf82-635689245975040950.pdf.

${ }^{703}$ Abaad Report 2014
} 
"Sexual violence is a national crime, but when you check the national laws, there is no clear definition of what sexual violence is. There is no definition of what rape is. Rape marriage is clear, but there many other kinds of sexual violence that are not mentioned. Moreover, when we talk about sexual violence in conflict, the sexual violence could be investigated as a genocide, as a crime against humanity, and as a war crime, but most of the gender-based crimes in neighboring states are not mentioned." 704

The expert interviewee's statement echoed this study's argument that, under Lebanese laws, single, divorced, or widowed Syrian women are not viewed as qualified independent women capable of managing their immediate families. As such, they become easy target for men who find out that they do not have any male support. ${ }^{705}$ As highlighted in Chapter V, public spaces become more dangerous for Syrian women, especially when they are without a male companion. Moreover, while issues related to Lebanese civilians generally involve security forces (e.g., the police), those related to Syrian refugees are managed by a different category of security apparatuses such as the Lebanese military intelligence, the General Security Directorate, and the Lebanese Information Division. These intelligence entities are rather focused on combating terrorism and dealing with serious state security threats and are not specifically trained to deal with gender-sensitive

\footnotetext{
${ }^{704}$ Justice Without Borders Expert interview with author, (May 29, 2017).

705 "I Want a Safe Place: Refugee Women From Syria Uprooted and Unprotected in Lebanon," Amnesty International, (2015): https://www.amnesty.org/download/Documents/MDE2417852015ENGLISH.PDF.
} 
procedures on how to protect women from daily local threats. ${ }^{706}$ Meanwhile, under the guise of fighting terrorism, humanitarian bodies, such as the UNHCR, share the registered refugee's information through information sharing programs between all partner agencies. $^{707}$

In this case, cultural choices may be, explicitly or implicitly, made by local authorities who sense that they can have impunity or realize that the target of their gender violence is powerless and with little or no protection. According to Amnesty International's report on Lebanon, one Syrian woman stated: “After a while, the police would pass by our house or would call us and ask us to go out with them. [...] Because we do not have legal [residence] permits, the officers threatened us. They said that they would imprison us if we did not go out with them." ${ }^{\text {,08 }}$ This statement reiterates the study's evidence that, for example, victims of prostitution and humantrafficking rings do not usually report their predicament or seek help from local authorities even when they may have the opportunity to do so. ${ }^{709}$ As a result, the intersection of refugee (in)security practices and sexist Lebanese domestic laws diminish the ability of humanitarian gender-sensitive programs to change the various

\footnotetext{
706 “Lebanon Annual Report 2014 Highlights," KAFA, (2014): http://www.kafa.org.lb/StudiesPublicationPDF/ PRpdf82-635689245975040950.pdf.

${ }^{707}$ Jennifer Hyndman, Managing Displacement: Refugees And The Politics Of Humanitarianism. University of Minnesota Press, (2000), 61.

708 "I Want a Safe Place: Refugee Women From Syria Uprooted and Unprotected in Lebanon," Amnesty International, (2015), https://www.amnesty.org/download/Documents/MDE2417852015ENGLISH.PDF.

709 Kareem Shaheen, "Lebanon Sex Trafficking: Syrian Woman Describes Nine-Month Ordeal," The Guardian, (August 1, 2016), https://www.theguardian.com/world/2016/aug/01/lebanon-sex-trafficking-syrianwoman-describes-ninemonth-ordeal.
} 
discriminations that Syrian women experience in Lebanon. This latter leads to a series of Syrian resilience efforts to cope with their new status quo, selling back those insecurities to the local Lebanese population, and creating a "blowback" that would affect the Syrian relations with the local population-such as negative coping skills, resistance, and contempt.

\section{Blowback}

The structural subordination of the status of Syrian refugees, in general, and Syrian women, specifically, leads to the invisibilisation of their agency, (re)enforcing their disproportionate shouldering of their precarious situation through objectified negative coping mechanisms and increased local (in)securities. As demonstrated in Figure 12, exclusionary possesses of Syrian refugee (in)security homogenization and objectification co-constitute securitized practices that (re)produce social anxieties over the increasing local vulnerabilities. Accordingly, Chapter VI borrowed Susanne Zwingel's term “impact translation” to shed light on the gendered local repercussions and contextual resilience efforts of Syrian refugees, where the intersectionality of gender, class, and ethnicity play an instrumental role. We find that most Syrian refugees, especially women, adopted new coping strategies, (re)impacting their new realities, in turn, Lebanon's (in)security.

In this sense, Chapter VI of the dissertation traced the gendered impact translation of securitized Syrian refugee management practices through the method of Photovoice. This participatory grassroots methodology provided a "culturallygrounded contextually situated site for reflection on visual images and associated 
meanings," describing, understanding, and elaborating Syrian resilience efforts within certain communities. ${ }^{710}$ Evidently, the study showed how the intersectionality of Syrian refugees' insecurities was reinforced through exclusionary settings. Consequently, various resilience practices of refugees, particularly women, appropriate, negotiate and modify the little legal provisions they have for personal goals, while, "further complicating issues of agency, ownership and humanitarian gender equality interventions." 711 Other instances, such as the shawish phenomenon, are living proof of the erection of intersectional systems of oppression and resilience efforts that further (re)enforce hierarchies of relational power and discrimination within specific contexts. These facts of gender bias and structural inequalities, thus, created a loop of aggression and exclusion that culminated in the deterioration of local resilience and interactions, completing the vicious cycle in the figure above, making it virtually impossible for Syrian refugees to weight productive options.

Several themes were exposed in Chapter VI, such as extreme impoverishment, lack of food, inadequate shelters, legal desperation, and shift of gender roles. As shown above, despite all these hardships that the participants highlighted, most Syrians adapted and were determined in doing their best to support themselves and their respective families. Having lost family members,

\footnotetext{
710 Camille A Sutton-Brown, "Photovoice: A Methodological Guide." Photography And Culture. 7.2 (2014):169-185

${ }^{711}$ Elisabeth Olivius, "Constructing Humanitarian Selves And Refugee Others: Gender Equality And The Global Governance Of Refugees,” International Feminist Journal of Politics 18, no. 2 (2016): 270-290.
} 
homes, and legal status, the study found that Syrians adopted different types of coping mechanisms to brave through their hostile environments. A mesolevel of resistance becomes particularly significant to inspect in the case of Lebanon, where Syrians, generally, "are forbidden from forming or joining formal unions" having little to no access to formal institutional protection. ${ }^{712}$ Syrians would thus build support networks, and through agency actants build a sustainable resilience system that would relatively enhance their human conditions, thwarting future shocks.

Consequently, the counterintuitive Lebanese approaches towards Syrian refugees would then create blowbacks, seen in Chapter VI, with unintended negative consequences on major Lebanese communities. ${ }^{713}$ The research participants underscored several themes such as scavenging informal economies, child labor, excessive waste and pollution that agonized all residing communities on several levels. Another occurring theme that was not mentioned but is important to highlight and add to the list is unlawful black-market activities, such as theft, smuggling, human trafficking, prostitution, and drug dealing. ${ }^{714}$ In that respect, refugees who are not fortunate enough, stealing other people's documents is perceived as their only viable solution to acquire freedom of mobility. Small petty crimes become the gateway to larger felonies that Syrians would coopt in their daily

\footnotetext{
712 Amrita Pande. "From "balcony talk" and "practical prayers" to illegal collectives: Migrant domestic workers and meso-level resistances in Lebanon." Gender \& Society 26, no. 3 (2012): 382-405.

713 Ibid.

${ }^{714}$ Lebanon News, "Small Drug Cartel Operating In Dora, Jounieh Arrested," The Daily Star, (April 5, 2018), http://www.dailystar.com.lb/News/Lebanon-News/2018/Apr-05/444244-small-drug-cartel-operating-in-dorajounieharrested.ashx.
} 
(in)security practices. As for the Syrians with a relatively privileged socioeconomic background opt for silent crimes in collaboration with the government that include bribing local authorities for falsifying residency papers and forging legal identity documentations from Syria, which increase the tendencies of local authorities to be corrupted. The latter would affect not only the functioning of concerned Lebanese institution but the entire Lebanese social fabric. ${ }^{715}$ With dire financial standing, Lebanese complain that they cannot find jobs, that local rents are rising, and that wages are falling. ${ }^{716}$ Both population groups would resort to short-term solutions such as buying or lending money for cheaper or lower quality food for lack of finances, igniting long-term health problems. As seen, in the previous chapter, these harsh economic situations have in several instances obliged Syrians to withdraw their children from schools in order to work and become an additional means to contribute to the household income. Meanwhile, Syrianwomen and girls end up working under exploitative low wages, engaging in dangerous and potentially hazardous work conditions, seeking marriage with Lebanese men, or merely begging on the streets, increasing local anxieties and gendered discriminations.

Thus, political actors and false media-dissemination would lobby for Syrian refugee repatriation, fearing their permanent presence. These anti-Syrian

\footnotetext{
${ }^{715}$ Conflict Analysis Report, "The Burden Of Scarce Opportunities: The Social Stability Context In Central And West Bekaa," UN Development Program, (March, 2017), https://reliefweb.int/report/lebanon/burdenscarce-opportunitiessocial-stability-context-central-and-west-bekaa-conflict.

716 "Syrians Entering Lebanon Face New Restrictions." BBC News. (January 5, 2015): https://www.bbc.com/news/worldmiddle-east-30657003
} 
presence's sentiments were increasingly evident within the participants' arguments during the photoelicitation session. As discussed previously, local attitudes towards hosting Syrians are linked to continuing grievances over past Lebanese-Syrian relationship, increasing tensions between both communities. Syrian refugees end up negatively coping with their lack of legal status not able to access their basic human needs, particularly Syrian women. Because of their intersectional identity as both Syrian refugees and women within exclusionary securitized practices, their interests and experiences are even more marginalized.

The variety of Syrian women's resilience processes challenge established gendered dichotomies between what is a public and what is a private sphere. As seen in Chapter VI, living in a discriminatory and overwhelmed Lebanese system led these Syrian women to increasingly depend upon sporadic emergency aid and adopt negative coping mechanisms such as illicit work, child labor, child marriage, begging, and prostitution. Some research participants blamed the inadequate humanitarian funding that does not empower individuals in need. Others complained that the legal loopholes and corrupt Lebanese bureaucratic agencies would naturally discriminate against disadvantaged individuals even when adequately funded.

Most participants suggested a drastic change need to be made in the underlying assumptions and approaches to Syrian presence in order to work with the diverse Syrian population and empower them rather than save them or fix them. Until then, a vicious cycle of (in)securities is (re)produced with a series of practices of mistrust and aggression between Lebanese constituents and Syrian refugees. For these facts 
of gender bias and structural inequality create a loop of aggression and exclusion that culminates in the deterioration of local resilience and interactions, widening the xenophobic Lebanese rhetoric towards Syrians, making it virtually impossible for any Syrian refugee to weight productive options.

\section{Significance Of The Study}

This project involved bodies-Lebanese citizens, Lebanese government official, and humanitarian agents - whose heterogeneity would otherwise be silenced and marginalized through homogenization and macro decontextualized practices. That is why, by involving local "bodies"-Lebanese citizens as research subjects, this step would create an encouraging space for Lebanese subjects who typically do not get a voice, and whose voices are often ascribed to them, to be involved as coresearchers in the exploration of Syrian refugee (in)security. This exercise brought a fruitful dialogical reconstruction of some of the multiple gendered realities that the Syrian crisis (re)produced in Lebanon. As such, the study drew on primary sources, grey literature, human subjects, and visual materials to gain in-depth interdisciplinary knowledge of the Syrian refugee crisis in Lebanon. It utilized multiple tools such as expert interviews, in-depth longitudinal cultural theme analysis, and a participatory method named Photovoice to understand the multilevel challenges where refugee (in)security is (en)gendered and experienced. Thus, this dissertation provides an original approach to the IR field by discussing the gender dynamics within the critical scholarship of security studies and refugee governance. 
All things considered; this dissertation is by no means attempting to produce a comprehensive understanding of refugee (in)security. It aims to develop new and more inclusive approaches to gain in-depth knowledge of a compelling case of Syrian refugee (in)security in Lebanon. Accordingly, this transnational feminist research considerably filled an empirical and methodological void in IR scholarship where the gendering of refugee (in)security is multilayered, continually shifting through processes of construction, interpretation, and application that span an array of political, humanitarian, socioeconomic, and security complications. This type of research enabled me to explore multi-leveled sites and processes of Syrian refugee insecurity construction, policy translation, and highlight some of the negative impacts in the local context, which play an instrumental role in informing how refugee (in)security is (re)produced. The growing anti-Syrian sentiments and refugee sensitivities frequently fuel xenophobic public discourse on the exaggerated impact of the Syrian refugees on host communities. The study highlighted several cases of how the essentialized refugee "crisis" is projected through dubious overstated numbers, such as Syrian annual births that further threaten Lebanon's demography, security, socioeconomic stability. Consequently, efforts to help the different people escaping persecution in Syria get complicated and harder to achieve tangible results.

Without trying to overcome the inherent relational or even structural differences, Syrian refugee management practices seem to further gender both communities' social fabric, economic stability, and security. Therefore, this dissertation highlights the benefit of an interdisciplinary research in IR scholarship, 
examining the importance of situating gender within critical scholarship in the field of security studies and refugee protection regimes, as a strategy to integrate insights across disciplines, furthering our knowledge of a significant social phenomenon: the (en)gendering of refugee (in)security. The use of multidisciplinary methods and data add to the existing feminist literature on securitized refugee governance and expand their visibility by providing a sophisticated understanding of the various spaces where refugee (in)security constructions, management practices, and local experiences materialize. It echoes their argument that refugee management practices need to acknowledge contextual differences, thus avoid pathologizing and further stigmatizing the diverse groups that make up the refugee population. ${ }^{717}$

The insurance of holistic Syrian refugees' protection from gendered violence requires both the Lebanese government and non-governmental organizations need to understand better the diverse groups they are trying to manage and coordinate with them in order to find common ground. This radical shift would then open up new opportunities for all groups involved to equally adjust to the current challenges, going beyond the securitized host government practices and the sometimes-counterproductive humanitarian agendas of service providers. By joining forces, these efforts would be a first step in destabilizing the existing power relations previously appropriated and used to limit any form of normative social change. Instead of viewing refugee women's insecurities as secondary to the

${ }^{717}$ Elisabeth Olivius, "Governing Refugees Through Gender Equality: Care, Control, Emancipation" PhD dissertation., Umeå Universitet, (2014), 8. 
host state interests and refugee governance in general, refugee women, such as in the Syrian case in Lebanon, need to be prioritized and empowered. Their issues need to be mainstreamed and dealt with accordingly.

As such, further work and research on Syrian refugee agency and resilience practices could help improve the current efforts in planning, coordination, innovation, funding, and partnerships by (re)shaping organizational cultures within refugee governance programs. Gender comprehensive research and policy planning should not just examine refugee politics as a rights-based system for they tend to disregard local traditions and practices that, till this date, regulate women's rights within the private sphere and not by legal regulations as other parts of the social life. After all, universal rights do not automatically translate domestically by excluding silenced voices. Instead, per Susanne Zwingel's argument, transnational networks of norm entrepreneurs are encouraged to not clash with the local sphere, establishing meaningful connections with the targeted communities through continual long-term processes of (re)negotiation and (re)interpretation. ${ }^{718}$ As such, these approaches would serve as an adaptation strategy of refugee empowerment, paying more attention to explore host state's communities and their needs, understand the domestic settings and practices, and involve the marginalized groups of displaced people as purposive subjects with agency rather than categorizing them based on their vulnerability and special status. Only by doing

\footnotetext{
718 Susanne Zwingel. “Translating International Women's Rights.” Palgrave Macmillan UK, 2016. p 32.
} 
that can crises be turned into opportunities of (re)constructing favorable conditions for all the affected communities to be empowered and adequately bounce back.

As such, this project seeks to expand the IR field by reaching a wider audience as a result of interdisciplinary research. It equips both academics and practitioners with the necessary tools to understand multilayered social phenomena and meaningfully contribute to both theory refinement and policy implementation, while also questioning existing paradigms and global structures that tend to homogenize, objectify, and discriminate women. The feminist theories that are relevant to this study emphasized the importance of a multi-layered approach and the richness of bottom-up perspectives when analyzing the experienced Syrian refugee insecurities, specifically women. By conducting a longitudinal cultural theme analysis of crisis response plans, developed by several interest groups with competing goals, future studies could explore the emergence, elaboration, and transformation of their management processes across time. Such studies would, thus, tease out relevant changes and assess these plans' continued engagement with and contribution to empowering their targets. As for the human centric Photovoice approach, including both host communities and Syrian refugees, especially women, this study was able to capture the similarities and differences of perceptions of what constitute a refugee crisis and resilience programs. This approach would assist future projects in highlighting the interlocking systems of oppression and celebrating the gender-inclusive stories of both host communities and people fleeing persecution in their home country. This method would then bridge the present exclusionary practices in refugee crisis response plans and perceived 
dichotomy of interests between host state security and refugee protection mechanism. Therefore, this type of approach enhances further dialogue over local anxieties and refugee best practices, turning crises into opportunities. That way, future projects could look beyond copious statistics to the extraordinary everyday experiences of the millions of individuals who are involved and entangled in what is labeled as a 'refugee crisis.' These projects would be better equipped in opening up new context-specific opportunities that challenge the currently securitized refugee status-quo and go beyond decontextualized humanitarian agendas. After all, when all refugees are seen the same, each one of them is different. 


\section{REFERENCES:}

Abels, Gabriele, and Behrens, Maria. "Interviewing Experts In Political Science: A Reflection On Gender And Policy Effects Based On Secondary Analysis." In Interviewing Experts. Palgrave Macmillan, London, (2009): 140.

Abramson, Scott. "Lebanese Armenians: A Distinctive Community In he Armenian Diaspora and in Lebanese Society," The Levantine Review 2, no. 2 (2013): 188216.

Acharya, Amitav. "The Limitations of Mainstream International Relations Theories for

Understanding the Politics of Forced Migration" (lecture, Centre for International Studies, Oxford University, (October 2008), 27.

Adler, Emanuel and Pouliot, Vincent, "International Practices," International Theory 3, no. 1 (2011): 1-36.

Adler, Emanuel and Pouliot, Vincent. "The Practice Turn In International Relations: Introduction and Framework." In International Studies Association 49th Annual Convention, San Francisco. (2008): 26-29.

Agosti, Marta. "The Nationality Law In Light Of The Refugee Crisis In Lebanon: Old Battles, New Consequences," Contemporary Levant 1, no. 2 (2016): 148-151.

Akram, Susan M., Bidinger, Sarah, Lang, Aaron, Hites, Danielle, Kuzmova, Yoana, and Noureddine, Elena. "Protecting Syrian Refugees: Laws, Policies, And Global Responsibility Sharing," Middle East Law and Governance 7, no. 3 (2015): 287318.

Alexander, Bogner, Littig, Beate and Menz, Wolfgang. Interviewing The EliteInterviewing Experts: Is There A Difference?." In Interviewing experts. Palgrave Macmillan, London, (2009): 98-139.

Alexievich, Svetlana. The Unwomanly Face of War: An Oral History of Women in World War II (New York: Random House, 2017).

Alsharabati, Carole and Nammour, Jihad. "Survey On Perceptions Of Syrian Refugees In Lebanon," Université Saint Joseph, (August, 2015), 33-34.

Anani, Ghida. 'Syria Crisis - Dimensions Of Gender-Based Violence Against Syrian

Refugees In Lebanon,' Forced Migration Review,

No. 44. (2013): http://www.fmreview.org/en/detention/anani.pdf. 
Anderson, Benedict. “Imagined Communities: Reflections On The Origin And Spread Of Nationalism Verso. London. (2006).

Arendt, Hannah. The Origins Of Totalitarianism, vol. 244. Houghton Mifflin Harcourt, (1973), 464.

Armstrong, Martin. "Lebanon Resists Granting Work Permits To Syrian Refugees," Middle East Eye, (February 4, 2016), http://www.middleeasteye.net/news/lebanonsyria-refugees-jobs-554259285.

Atallah, Sami, and Mahdi, Dima. "Law And Politics Of 'Safe Zones' And Forced Returns To Syria: Refugee Politics In Lebanon," The Lebanese Center for Policy Studies 39 (2017): 36.

Avis, William. "Gender Equality And Women's Empowerment In Lebanon," Helpdesk

Report. University of Birmingham. (August 16, 2017):

https://www.alnap.org/system/files/content/resource/files/main/175-genderequalityand-womens-empowerment-in-lebanon.pdf.

Ayoub, Bachir and Mahdi, Dima. "Making Aid Work In Lebanon: Promoting Aid Effectiveness And Respect For Rights In Middle-Income Countries Affected By Mass Displacement" OXFAM, (2018).

Bach, Hedy. "Composing A Visual Narrative Inquiry," in Handbook of Narrative Inquiry Mapping a Methodology, ed. Jean Clandinin. SAGE, (2006).

Baines, Erin K. Vulnerable Bodies: Gender, the UN and the Global Refugee Crisis (London, England: Routledge, 2017).

Baldwin, David. "The Concept Of Security." Review of International Studies, no. 23 (1997): 5-26.

Balzacq, Thierry. Constructivism And Securitization Studies. The Routledge Handbook of Security Studies (2010): 56-72.

Barnett, Laura. "Global Governance And The Evolution Of The International Refugee Regime," International Journal of Refugee Law 14, no. 2/3 (2002): 238-262.

Barnett, Michael. "Humanitarianism Transformed," Perspectives On Politics 3, no. 4 (2005): 723-740.

Bergold, Jarg, Thomas, Stefan. "Particpatory Research Methods: A Methodological Approach In Motion.” Forum Qualitative Social Research, Volume 13, January (2012). 
Berti, Benedetta. "The Syrian Refugee Crisis: Regional And Human Security Implications," Strategic Assessment 17, no. 4 (2015): 41-53.

Betts, Alexander. Forced Migration and Global Politics (New York, NY: John Wiley \& Sons, 2009).

Bigo, Didier. "Security And Immigration: Toward A Critique Of The Governmentality Of Unease," Alternatives 27, no. 1 suppl (2002): 63-92.

Binder, Werner, and Jaworsky, Bernadette Nadya. "Refugees As Icons: Culture And Iconic Representation." Sociology Compass 12, no. 3 (2018): e12568.

Blanchet, Karl Fouad M. Fouad, and Pherali, Tejendra. "Syrian Refugees In Lebanon: The Search For Universal Health Coverage," Conflict and Health 10 (2016): 12.

Boed, Roman. "The State Of The Right Of Asylum In International Law." Duke J. Comp. \& Int'l L. 5 (1994).

Bogner, Alexander, Beate Littig, and Wolfgang Menz. Interviewing The EliteInterviewing Experts: Is There A Difference?." In Interviewing experts. Palgrave Macmillan, London, (2009): 98-139.

Borgmann, Monika and Slim, Lokman. "Fewer Refugees More Refugeeism," $U M A M$

$D \& R$ Documentation and Research. (2018),

https://umamdr.org/en/home/projects/14/advance-contents/188/fewerrefugees-more-refugeeism.

Bourbeau, Philippe. "The Practice Approach In Global Politics." Journal of Global Security Studies 2, no. 2 (2017): 170-182.

Bourbeau, Philippe. "Migration And Security: Securitization Theory And Its Refinement," in Annual Meeting Of The International Studies Association, Town \& Country Resort and Convention Center, San Diego, California, USA. 2006.

Bourbeau, Philippe. "Resiliencism: Premises And Promises In Securitisation Research," Resilience Journal, no.1 Taylor \& Francis. (2013): 3-17.

Bouri, Elie, and El-Assad, Joseph. "The Lebanese Electricity Woes: An Estimation Of The Economical Costs Of Power Interruptions." MDPI Energies 9, no. 8 (2016): 583

Bryson, John M. Strategic Planning for Public and Nonprofit Organizations: A Guide To

Strengthening And Sustaining Organizational Achievement. Hoboken, NJ: John Wiley \& Sons, (2018). 
Butler, Judith, and Spivak, Gayatri Chakravorty. Who Sings The Nation-State?: Language, Politics, Belonging (London, England: Seagull Books, 2007).

Butler, Judith. Gender Trouble: Feminism and the Subversion of Identity. New York: Routledge, (1990).

Buzan, Barry, Wæver, Ole, and De Wilde, Jaap. Security: A New framework for Analysis. Lynne Rienner Publishers, Harvard. (1998).

Buzan, Barry. "Peace, Power And Security: Contending Concepts in the Study of International Relations," Journal of Peace Research, 21 (1984): 109-25.

Buzan, Barry. People. States \& Fear: An Agenda for International Security Studies in the Post-Cold War Era (Colchester, England: ECPR Press, 2008).

Byman, Daniel and Speakman, Sloane. "The Syrian Refugee Crisis: Bad and Worse Options," The Washington Quarterly 39, no. 2 (2016).

Capoccia, Giovanni and Kelemen, R. Daniel. "The Study Of Critical Junctures: Theory, Narrative, and Counterfactuals in Historical Institutionalism," World Politics 59, no. 3 (2007): 341-369..

Carpenter, R. Charli. "Women, Children, And Other Vulnerable Groups: Gender, Strategic Frames, And The Protection Of Civilians As A Transnational Issue," International Studies Quarterly 49, no. 2 (June 2005): 295-355.

Chandler, David and Hynek, Nik eds. Critical Perspectives On Human Security: Rethinking Emancipation and Power in International Relations. Routledge, (2010).

Charles, Lorraine, Denman, Kate. "Syrian And Palestinian Syrian Refugees In Lebanon: The Plight Of Women And Children." Journal of International Women's Studies. (2013);14(5):96

Chatty, Dawn, Mansour, Nisrine, and Yassin, Nasser. "Statelessness And Tribal Identity On Lebanon's Eastern Borders," Mediterranean Politics 18, no. 3 (2013): 411-426.

Chatty, Dawn. "Bedouin In Lebanon: The Transformation Of A Way Of Life Or An Attitude?," International Journal of Migration, Health and Social Care 6, no. 3 (2011): 21-30.

Chia, Joy L. "Piercing The Confucian Veil: Lenagan's Implications For East Asia And Human Rights," Am. UJ Gender Soc. Pol'y \& L. 21 (2012).

Cho, Sumi, Crenshaw, Kimberlé Williams, and McCall, Leslie. "Toward A Field Of 
Intersectionality Studies: Theory, Applications, And Praxis," Signs: Journal of Women in Culture and Society 38, no. 4 (2013): 785-810.

Cox, Robert W. "Social Forces, States And World Orders: Beyond International Relations Theory," Millennium 10, no. 2 (1981): 126-155.

Creswell, John W. Qualitative Inquiry And Research Design: Choosing Among Five Approaches, Sage (2007).

Culbertson, Shelly, Oliker, Olga, Baruch, Ben, and Blum, Ilana. "Rethinking Coordination Of Services To Refugees In Urban Areas: Managing The Crisis In JordanAand Lebanon." Rand Corporation, (2016).

Dabbagh, Salah, Deeb, George, El-Khazen, Farid and Kisirwani, Maroun. "The Lebanese Constitution." Arab Law Quarterly 12, no. 2 (1997): 224-261.

David, E. J. R and Derthick, Annie O. "What Is Internalized Oppression, And So What." Internalized Oppression: The Psychology of Marginalized Groups (2014): 130.

Deeb, Marius. Syria's Terrorist War On Lebanon And The Peace Process. Springer, (2003).

DeJong, Jocelyn, Sbeity, Farah, Schlecht, Jennifer, Harfouche, Manale Yamout, Rouham, Fouad M. Fouad, Manohar, Seema, and Robinson, Courtland. "Young Lives Disrupted: Gender And Well-Being Among Adolescent Syrian Refugees in Lebanon," Conflict and Health 11, no. 1 (2017).

Dionigi, Filippo. "The Syrian Refugee Crisis In Lebanon: State Fragility And Social Resilience." LSE Middle East Centre paper series, 15. Middle East Centre, LSE, London, UK. (2016).

Dionigi, Filippo. "Rethinking Borders: The Dynamics Of Syrian Displacement To Lebanon," Middle East Law And Governance 9, no. 3 (2017): 232-248.

Effective Intrapersonal Interventions," Reproductive Health Matters 24, no. 47, https://www.tandfonline.com/doi/pdf/10.1016/j.rhm.2016.04.008.

El Khazen, Farid. "Permanent Settlement Of Palestinians In Lebanon: A Recipe For Conflict," Journal of Refugee Studies 10, no. 3 (1997): 275-293.

El Khazen, Farid. "Political Parties In Postwar Lebanon: Parties In Search Of Partisans," Middle East Journal 57, no. 4 (2003): 605-624.

El-Husseini, Rola. "Pax Syriana," Elite Politics In Postwar Lebanon Syracuse University Press. (2012). 
El-Masri, Roula, C. Harvey and R. Garwood. 'Shifting Sands: Changing Gender Roles Among Refugees In Lebanon'. Joint Research Report: Oxfam and Resource Center for Gender Equality, (2013).

Faletar, Sanjica, Tanacković, Maja Krtalić, Darko Lacović. "Newspapers As A Research Source: Information Needs And Information Seeking Of Humanities Scholars." In "Digital Transformation And The Changing Role Of News Media In The 21st Century." IFLA Newspapers Section Pre-Conference. 2014.

Fassin, Didier. "Humanitarianism: A Nongovernmental Government," Nongovernmental Politics (2007): 149-160.

Fawaz, Mona. "Planning and the Refugee Crisis: Informality As A Framework of Analysis and Reflection," Planning Theory 16, no. 1 (2017): 99-115.

Feller, Erika. "The Evolution Of The International Refugee Protection Regime' (2001a)," Washington University Journal of Law and Policy 5: 129.

Filippo, Dionigi. "The Syrian Refugee Crisis In Lebanon: State Fragility And Social Resilience" LSE, Middle East Centre paper series, 15. UK (2016), 25.

Filippo, Dionigi. "The Syrian Refugee Crisis In Lebanon: State Fragility And Social Resilience." LSE, London, UK. (2016).

Finnemore, Martha and Sikkink, Kathryn. "Taking Stock: The Constructivist Research Program In International Relations And Comparative Politics." Annual Review of political Science 4, no. 1 (2001): 391-416.

Foran, Siobhán, Swaine, Aisling, and Burns, Kate. "Improving The Effectiveness Of Humanitarian Action: Progress In Implementing The Inter-Agency Standing Committee (IASC) Gender Marker," Gender \& Development 20, no. 2 (2012): 233247.

Francis, Ellen. "Hostility Grows Towards Syrian Refugees In Lebanon." Reuters. (August 28, 2017): https://www.reuters.com/article/us-lebanon-refugeestensionidUSKCN1B8128

Frangieh, Ghida. "Relations Between UNHCR And Arab Governments: Memoranda Of Understanding In Lebanon And Jordan." Middle East Centre Blog (2016).

Frangieh, Ghida. "Lebanon Places Discriminatory Entry Restrictions On Syrians," Legal

Agenda 22, (2015),

http://legalagenda.com/en/article.php?id=679\&folder=articles\&lang=en. 
Freedman, Jane. "Mainstreaming Gender in Refugee Protection," Cambridge Review of International Affairs 23, no. 4 (2010).

Freedman, Jane. Gendering the International Asylum and Refugee Debate (Basingstoke: Palgrave Macmillan, 2015)

Gade, Tine. "Lebanon On The Brink," Norwegian Institute of International Affairs, Policy Brief 23. (2016), https://core.ac.uk/download/pdf/154676181.pdf.

Gerard, Alison and Pickering, Sharon. "Gender, Securitization And Transit: Refugee Women And The Journey To The EU," Journal of Refugee Studies 27, no. 3 (2014): 338-359.

Ghezelbash, Daniel. Refuge Lost: Asylum Law in an Interdependent World. Cambridge University Press, (2018).

Gibson, Sarah. "Abusing Our Hospitality: Inhospitableness And The Politics Of Deterrence," Mobilizing Hospitality: The Ethics of Social Relations in a Mobile World (2007): 159-177.

Given, Lisa M. ed, The SAGE Encyclopedia of Qualitative Research Methods. SAGE, (2008), 844.

Golder, Ben, and Williams, George. "Balancing National Security And Human Rights:

Assessing The Legal Response Of Common Law Nations To The Threat Of Terrorism." Journal of Comparative Policy Analysis 8, no. 01 (2006): 43-62.

Grip, Lina. "Coping with Crises: Forced Displacement In Fragile Contexts," in SIPRI Yearbook 2017: Armaments, Disarmament and International Security (Oxford, England: Oxford University Press, 2016), 256.

Haddad, Emma. "The Refugee In International Society: Between Sovereigns." Vol. 106. Cambridge University Press, (2008), 35.

Haddad, Emma. The Refugee In International Society: Between Sovereigns. Cambridge University Press, (2008).

Haddad, Simon. "The origins Of Popular Opposition To Palestinian Resettlement In Lebanon," International Migration Review, Vol 38, No.2, (2004).

Hammerstad, Anne. The Rise And Decline Of A Global Security Actor: UNHCR, Refugee Protection, and Security. Oxford University Press, (2014).

Hanafi, Sari, and Long, Taylor. "Governance, Governmentalities, And The State Of 
Exception In The Palestinian Refugee Camps Of Lebanon," Journal of Refugee Studies 23, no. 2 (2010): 134-159.

Hansen, Lene. “The Little Mermaid's Silent Security Dilemma And The Absence Of

Gender In The Copenhagen School," Millennium: Journal of International Relations 29, no. 2 (2000): 285-306.

Hansen, Lene. "Theorizing The Image For Security Studies: Visual Securitization And The Muhammad Cartoon Crisis," European Journal of International Relations 17, no. 1 (2011): 51-74.

Harb, Imad K. "The Hezbollah-Iran Pivot: The Controlling Agencies Behind Lebanon's

Sectarian Politics." Center for Security Studies, SAGE International Australia, (2016).

Harriso, Lisa and Callan, Theresa. Key Research Concepts In Politics And International Relations. SAGE Publications Limited, 2013, 98.

Harvey, Claire, Garwood, Rosa and El-Masri, Roula. "Shifting Sands: Changing Gender Roles Among Refugees In Lebanon," Oxfam International, (2013).

Hasselbarth, Sarah. Islamic Charities In The Syrian Context In Jordan And Lebanon. Friedrich-Ebert-Stiftung (2014), 31. https://library.fes.de/pdffiles/bueros/beirut/10620.pdf

Helou, Marguerite. "Lebanese Women and Politics: A Comparison Between Two Field Studies," Al-Raida Journal, (2001), 33-40.

Helou, Marguerite. "Women's Political Participation In Lebanon: Gaps In Research And Approaches," Al-Raida Journal (2014): 74-84. Ho, Anita and Pavlish, Carol. "Indivisibility Of Accountability And Empowerment In

Tackling Gender-Based Violence: Lessons From A Refugee Camp In

Rwanda," Journal of Refugee Studies 24, no. 1 (2011).

Hoffman, John. "Gender And Sovereignty: Feminism, The State And International Relations." Springer, (2001).

Husem, Erik. "The Syrian Involvement In Lebanon: An Analysis Of The Role Of Lebanon 
In Syrian Regime Security, From Ta'if To The Death Of Hafiz al-Assad (19892000)," FORSVARETS FORSKNINGSINSTITUTT (FFI) Norwegian Defence Research

Establishment. (2002): https://admin.ffi.no/no/Rapporter/02-03005.pdf

Huysmans, Jef. The Politics Of Insecurity: Fear, Migration And Asylum In The EU. Routledge, (2006):7.

Hyndman, Jennifer, and Giles, Wenona. "Waiting For What? The Feminization Of Asylum In Protracted Situations," Gender, Place \& Culture 18, no. 3 (2011): 361379.

Hyndman, Jennifer. "Managing Difference: Gender And Culture In Humanitarian Emergencies," Gender, Place and Culture: A Journal of Feminist Geography 5, no. 3 (1998): 241-260.

Hyndman, Jennifer. Managing Displacement: Refugees And The Politics Of Humanitarianism. University of Minnesota Press, (2000).

Institut Des Sciences Politiques USJ, Survey On Perceptions Of Syrian Refugees In Lebanon, (March, 2015), http://www.sciences-po.usj.edu.lb/ pdf/Executive\%20Summary.pdf

Jacobsen, Karen and Landau, Loren B. "The Dual Imperative in Refugee Research: Some Methodological and Ethical Considerations in Social Science Research on Forced Migration," Disasters 27, no. 3 (2003): 185-206.

Jacobsen, Katja Lindskov. The Politics Of Humanitarian Technology: Good Intentions, Unintended Consequences And Insecurity. Routledge, (2015).

Janmyr, Maja and Mourad, Lama. "Modes Of Ordering: Labelling, Classification And Categorization In Lebanon's Refugee Response," Journal of Refugee Studies (2017).

Janmyr, Maja, "Precarity In Exile: The Legal Status Of Syrian Refugees In Lebanon," Refugee Survey Quarterly 35, no. 4 (2016): 58-78.

Janmyr, Maja. "No Country Of Asylum: Legitimizing Lebanon's Rejection Of The 1951 Refugee Convention," International Journal of Refugee Law 29, no. 3 (2017): 438465 .

Janmyr, Maja. "UNHCR And The Syrian Refugee Response: Negotiating Status And Registration In Lebanon," The International Journal of Human Rights 22, no. 3 (2018): 393-419. 
Jaulin, Thibaut. "Citizenship, Migration, And Confessional Democracy In Lebanon," Middle East Law and Governance 6, no. 3 (2014): 250-271.

Johnson, Heather L. "Click To Donate: Visual Images, Constructing Victims And Imagining The Female Refugee," Third World Quarterly 32, no. 6 (2011): 10151037.

Jones, Katharine and Ksaifi, Leena. Struggling To Survive: Slavery And Exploitation Of Syrian Refugees in Lebanon (London, England: Freedom Fund, 2016), http://freedomfund.org/wp-content/uploads/Lebanon-Report-FINAL8April16.pdf.

Jureidini, Ray. "An Exploratory Study of Psychoanalytic and Social Factors in the Abuse of Migrant Domestic Workers by Female Employers in Lebanon." KAFA (enough) Violence \& Exploitation, (2011).

Kail C. Ellis. "Lebanon: The Struggle Of A Small Country In A Regional Context." Arab Studies Quarterly (1999): 5-25.

Kamal, Dib. Warlords and Merchants: The Lebanese Business And Political Establishment. Ithaca Press, (2004).

Katzenstein, Peter J. ed. The Culture Of National Security: Norms And Identity In World Politics. Columbia University Press, (1996), 26.

Kneebone, Susan. "Women Within The Refugee Construct: 'Exclusionary Inclusion' In Policy And Practice-The Australian Experience," International Journal of Refugee Law 17, no. 1 (2005): 7-42.

Koning, Edward Anthony. "The Three Institutionalisms And Institutional Dynamics:

Understanding Endogenous and Exogenous Change," Journal of Public Policy 36, no. 4 (2016): 639-664.

Krayem, Hassan. "The Lebanese Civil War And The Taif Agreement," Conflict Resolution in the Arab World: Selected Essays (1997): 411-436.

Are John Knudsen. "Syria's refugees in Lebanon: brothers, burden, and bone of contention." In Lebanon facing the Arab uprisings, pp. 135-154. Palgrave Pivot, London, 2017.

Lansing, Melissa. "Terrorism, Securitization Of The Nation And Refugee Flows: Implications Of Policies And Practices In a Post-911 Era." PhD dissertation, University of Ottawa (Canada), 2007. 
Latour, Bruno. "On Actor-Network Theory. A Few Clarifications Plus More Than A Few Complications," Soziale welt 47, no. 4 (1996).

Lautze, Sue, Hammock, John. Saving Lives and Livelihoods: The Fundamentals of a Livelihood Strategy (Medford, MA: Feinstein International Famine Center, Tufts University 1997).

Lenette, Caroline, Brough, Mark and Cox, Leonie. "Everyday Resilience: Narratives Of Single Refugee Women With Children," Qualitative Social Work 12, no. 5 (2013): 637-653.

Lischer, Sarah Kenyon. Dangerous Sanctuaries: Refugee Camps, Civil War, And The Dilemmas of Humanitarian Aid Ithaca, NY: Cornell University Press, (2015), 26.

Locher, Birgit, Prügl, Elisabeth. "Feminism And Constructivism: Worlds Apart Or Sharing The Middle Ground?" International Studies Quarterly 45, no. 1 (2001): 111-129.

Locher, Brigit and Prügl, Elizabeth, "Feminism And Constructivism: Worlds Apart Or Sharing The Middle Ground?” International Studies Quarterly, 45(1),2001.1 11129.

Loveless, Jeremy. "Crisis In Lebanon: Camps For Syrian Refugees?." Forced Migration Review, no. 43, (May, 2013): 66-68. www.fmreview.org/en/fragilestates/loveless.pdf. Manly, Mark. "UNHCR's Mandate And Activities To Address Statelessness In Europe," European Journal of Migration and Law 14, no. 3 (2012): 261-277. Mansour, Kholoud. "UN Humanitarian Coordination In Lebanon The Consequences of Excluding Syrian actors International" Chatham House The Royal Institute of International Affairs. (March 2017).

Mansour, Maya and Abou-Aad, Sarah. "Women's Citizenship Rights In Lebanon." Research and Policy-Making in the Arab World. (2012).

Mansour-Ille, Dina and Hendow, Maegan. "From Exclusion To Resistance: Migrant Domestic Workers And The Evolution Of Agency In Lebanon," Journal of Immigrant \& Refugee Studies (2018): 1-21.

Marks, Jesse. "Pushing Syrian Refugees To Return," Carnegie Middle East Center, March 1, 2018, http://carnegie-mec.org/sada/75684.

Marsella, Anthony and Ring, Erin. "Human Migration And Immigration: An

Overview." Migration: Immigration and Emigration in

International

Perspective (2003): 3-22. 
McAuliffe, Marie. "Lebanon: Struggling On In The Face Of Donor Fatigue," The Interpreter, LOWY Institute, (May 18, 2016), https://www.lowyinstitute.org/theinterpreter/lebanon-struggling-face-donorfatigue.

McCormack, Tara. "Power and Agency In The Human Security Framework," Cambridge Review of International Affairs 21, no. 1 (2008): 113-128.

McCourt, David M. "Practice Theory And Relationalism As The New

Constructivism." International Studies Quarterly 60, no. 3 (2016): 475-485.

McDonald, Mark. "Securitization And The Construction of Security", European Journal of International Relations 14, no 4. (2008): 563-587.

McDonald, Matt. "Securitization and the Construction of Security," European Journal of International Relations 14, no. 4 (2008): 563-587.

McIntyre, Alice. Participatory Action Research. SAGE, vol. 52, (2007).

Meger, Sara. "The Fetishization Of Sexual Violence In International Security," International Studies Quarterly 60, no. 1 (2016): 149-159.

Meier, Daniel. "Lebanon: the refugee issue and the threat of a sectarian confrontation." Oriente moderno 94, no. 2 (2014): 382-401.

Merry, Sally Engle, and Levitt, Peggy. "The Vernacularization Of Women's Human Rights.” Human Rights Futures (2017).

Merry, Sally Engle. Human Rights and Gender Violence: Translating International Law Into Local Justic.Chicago, IL: University of Chicago Press, (2009).

Mertens, Donna M. and Hesse-Biber, Sharlene. "Triangulation And Mixed Methods Research: Provocative Positions" Sage Journals (2012): 75-79.

Mertus, Julie. "Sovereignty, Gender, And Displacement," in Edward, Newman, and Van Selm, Joanne. Refugees and Forced Displacement. International Security, Human Vulnerability And The State. Tokyo United Nations University Press, (2003).

Mikyoung, Kim. "Securitization Of Human Rights: North Korean Refugees in East Asia," ABC-CLIO, (2012):73.

Milner, James. "Introduction: Understanding Global Refugee Policy," Oxford, Journal of Refugee Studies (2014): 477-494. 
Mordechai, Nisan "The Syrian Occupation Of Lebanon," Coalition for Responsible Peace in the Middle East, (2000).

Mourad, Lama. "Inaction As Policy-Making: Understanding Lebanon's Early Response To The Refugee Influx," POMEPS Studies no. 25 (March, 2017): 49-55.

Naber, Nadine. "Arab American Femininities: Beyond Arab Virgin/American(ized) Whore," Feminist Studies 32, no. 1 (2006): 87-111.

Nachmias, David and Nachmias, Chava. "Content Analysis," in Research Methods in the Social Sciences, ed. Edward Arnold, London, England, (1976), 132-39.

Naimou, Angela. "Double Vision: Refugee Crises And The Afterimages Of Endless War," College Literature 43, no. 1 (2016): 226-233.

Naufal, Hala, "Syrian Refugees In Lebanon: The Humanitarian Approach Under Political Divisions," Migration Policy Centre Research Report; 2012/13 16, : http://cadmus.eui.eu/bitstream/handle.

Ní Aoláin, Fionnuala. "Women, Vulnerability, And Humanitarian

Emergencies," Michigan. Journal. Gender \& Law. 18 (2011).

Noll, Gregor. "Securitizing Sovereignty? States, Refugees, And The Regionalization Of International Law," Refugees and Forced Displacement (2003): 277-305.

Norton, Augustus Richard. “Lebanon After Ta'if: Is the Civil War Over?," Middle East Journal 45, no. 3 (1991): 457-473.

Olivius, Elisabeth. "(Un)Governable Subjects: The Limits of Refugee Participation In The Promotion Of Gender Equality In Humanitarian Aid," Journal of Refugee Studies 27, no. 1 (2013): 42-61.

Olivius, Elisabeth. "Constructing Humanitarian Selves and Refugee Others: Gender Equality and the Global Governance of Refugees," International Feminist Journal of Politics 18, no. 2 (2016): 276.

Olivius, Elisabeth. "Governing Refugees Through Gender Equality: Care, Control, Emancipation," PhD. dissertation, Umeå universitet, (2014), 2.

Ostrand, Nicole. "The Syrian Refugee Crisis: A Comparison Of Responses By Germany, Sweden, The United Kingdom, And The United States," Journal on Migration \& Human Security. 3 (2015): 255.

Pande, Amrita. "From "balcony talk" and "practical prayers" to illegal collectives: Migrant domestic workers and meso-level resistances in Lebanon." Gender \& Society 26, no. 3 (2012): 382-405. 
Pasquetti, Silvia, and Picker, Giovanni. "Urban Informality And Confinement: Toward A Relational Framework," International Sociology 32, no. 4 (2017): 532 544. Patrick, Stewart. “Are Ungoverned Spaces A Threat?” Council on Foreign Relations (2010). : https://www.cfr.org/expert-brief

Preston, Scott. "The confessional model and sectarian politics: Lessons from Lebanon and the future of Iraq." (2013).

Perthes, Volker. "From Front State To Backyard? Syria And The Risks Of Regional Peace," in Economic and Political Impediments to Middle East Peace. London, England: Palgrave Macmillan, (2000), 225-240.

Pickering, Sharon. "Women And Extra Legal Border Crossing." In Women, Borders, And Violence, pp. 1-16. Springer, New York, NY, (2011).

Price, Richard and Reus-Smit, Christian. "Dangerous liaisons? Critical International

Theory And Constructivism." European Journal of International Relations 4, no. 3 (1998): 259-294.

Prügl, Elisabeth. "Social Mechanisms: A Methodological Tool For Feminist IR." In The Art of World-Making, pp. 160-174. Routledge, 2017, 302.

Pulvirenti, Mariastella and Mason, Gail. "Resilience And Survival: Refugee Women And Violence," Current Issues Criminal Justice. HeinOnline. 23 (2011): 37-52.

Rabil, Robert. The Syrian Refugee Crisis In Lebanon: The Double Tragedy of Refugees and Impacted Host Communities. Lexington Books, (2016).

Raffaela, Puggioni. "Refugees, Institutional Invisibility, And Self-Help Strategies: Evaluating Kurdish Experience In Rome," Journal of Refugee Studies 18, no. 3 (2005): 319-339.

Riedel, Bruce and Saab, Bilal Y. "Lessons For Lebanon From Nahr El-Bared." $O p-E d$, Brookings, (October 4, 2007).

Riskedahl, Diane. "The Sovereignty Of Kin: Political Discourse In Post-Ta'if Lebanon," PoLAR: Political and Legal Anthropology Review 34, no. 2 (2011).

Roland, Paris. "Human Security: Paradigm Shift Or Hot Air?" International Security 26, no. 2 (2001): 87-102.

Romano, Julia Craig. "Humanitarian Crisis: Impact Of Syrian Refugees In Lebanon,"

Middle East Program Wilson Center, (October 29, 2013): 
https://www.wilsoncenter.org/event/humanitarian-crisis-impact-syrianrefugeeslebanon.

Romany, Celina "Women As Aliens: A Feminist Critique Of The Public/Private Distinction In International Human Rights Law," Harv. Hum. Rts. J. 6 (1993).

Romola, Sanyal. "A no-camp policy: Interrogating informal settlements in Lebanon." Geoforum 84 (2017): 117-125.

Rosenow-Williams, Kerstin, and Behmer, Katharina. "A Gendered Human Security Perspective On Humanitarian Action In IDP And Refugee Protection," Refugee Survey Quarterly 34, no. 3 (2015): 1-23.

Ruggie, John Gerard. "What Makes The World Hang Together? Neo-Utilitarianism And The Social Constructivist Challenge." International Organization 52, no. 4 (1998): 855-885.

Runyan, Anne Sisson. Global Gender Issues in the New Millennium. Routlege, (2018).

Rustum Shehadeh, Lamia. "Gender-Relevant Legal Change In Lebanon," Feminist Formations (2010): 210-228.

Saldaña, Johnny. The Coding Manual for Qualitative Researchers. SAGE, (2015).

Saldaña, Johnny. The Coding Manual For Qualitative Researchers. SAGE, (2016).

Salem, Paul. "The Future Of Lebanon." Foreign Affairs. 85, (2006).

Saliba, Issam M. "Refugee Law And Policy In Selected Countries, ” The Law Library of Congress, Global Legal Research Center. (March 2016).

Samari, Goleen. “Syrian Refugee Women's Health In Lebanon, Turkey, And Jordan And Recommendations For Improved Practice." World Med Health Policy. (June, 2017), https://www.ncbi.nlm.nih.gov/pmc/articles/PMC5642924/

Sanyal, Romola. “A No-Camp Policy: Interrogating Informal Settlements In Lebanon," Geoforum, 84 (2017): 117-125.

Schneider, Anne and Ingram, Helen. "Social Construction Of Target Populations: Implications For Politics And Policy," American Political Science Review 87, no. 2 (1993): 334-47.

Schultz, Tim. "Combating Statelessness In The Wake Of The Syrian Conflict: A Right

Without A Remedy," Notre Dame Journal of International \& Comparative Law 8, no. 2 (2018). 
Selin, Akyüz and Coşkun, Bezen Balamir. "Gendered (In) Securities: Refugee Camps In Southeastern Turkey," Journal of Conflict Transformation and Security (2014).

Sfeir, Rita. "Migration Is Increasing And The 'Specter' Of Bosnia And Rwanda Present Any Repercussions of Russian Military Intervention On Asylum?" Annahar News, (September 20, 2015), https://newspaper.annahar.com/article/276860-

Shawaf, Nour and El Asmar, Francesca. "We Are Not There Yet: Voices Of Refugees

From Syria In Lebanon," OXFAM, (May, 2017),

https://d1tn3vj7xz9fdh.cloudfront.net/s3fs-public/file_attachments/rr-voicessyrialebanon-refugees-protection-310517-en.pdf

Sikkink, Kathryn. The Justice Cascade: How Human Rights Prosecutions Are Changing World Politics. WW Norton \& Company, (2011), 236.

Singleton Royce A. Jr. and Straits, Bruce C. Approaches To Social Research. Oxford University Press, (2005).

Slaughter, Amy et al., Refugee Self-Reliance: Moving Beyond the Marketplace (Oxford, England: Refugee Studies Center, Oxford, 2017).

Steans, Jill. Gender And International Relations: An Introduction. Rutgers University Press, NJ. (1998).

Steele, Brent J. Alternative Accountabilities In Global Politics: The Scars Of Violence. Routledge, (2013).

Stent, Angela. "Putin's Power Play in Syria: How To Respond To Russia's Intervention," Foreign Affairs 95 (2016).

Sutton-Brown, Camille "Photovoice: A Methodological Guide." Photography And Culture. 7.2 (2014):169-185

Sylvester, Christine. War as Experience: Contributions from International Relations and Feminist Analysis (London, England: Routledge, 2013).

Szczepanikova, Alice. "Gender Relations In A Refugee Camp: A Case Of Chechens Seeking Asylum In The Czech Republic," Journal of Refugee Studies 18, no. 3 (2005): 281-298.

Szczepanikova, Alice. "Performing Refugeeness In The Czech Republic: Gendered Depoliticisation Through NGO Assistance," Gender, Place \& Culture 17, no. 4 (2010): 461-477. 
Tamang, Dipti. "Gendering International Security: Seeing Feminist Theories As International Relations." International Studies 50, no. 3 (2013): 226-239.

Tamang, Dipti. "Gendering International Security: Seeing Feminist Theories As International Relations." International Studies 50, no. 3 (2013): 226-239.

Tarazi, Leila. Fawaz. An Occasion For War: Civil Conflict In Lebanon And Damascus In 1860. University of California Press, (1994).

Thaddeus, Patrick Jackson. "Foregrounding Ontology: Dualism, Monism, And IR theory." Review of International Studies 34, no. 1 (2008): 129-153.

Thibaut, Jaulin. "Citizenship, Migration, And Confessional Democracy In Lebanon," Middle East Law and Governance 6, no. 3 (2014): 250-271.

Thompson, Elizabeth. "Public And Private In Middle Eastern Women's History." Journal of Women's History 15, no. 1 (2003): 52-69.

Tickner, J. Ann, and Sjoberg, Laura. "Feminism", in International Relations Theory, Discipline and Diversity, 3rd ed., ed. Tim Dunne, Milja Kurki, and Steve Smith (Oxford: Oxford University Press, 2013).

Tickner, J. Ann. "Re-Visioning Security." International Relations Theory Today (1995): 175-97.

Tickner, J. Ann. "You Just Don't Understand: Troubled Engagements Between Feminists and IR Theorists," International Studies Quarterly 41, no. 4 (1997): 611632.

Traboulsi, Fawwaz. A History of Modern Lebanon. Pluto Press, (2007).

Turk, Volker and Eyster, Elizabeth. "Strengthening Accountability In UNHCR," International Journal of Refugee Law 22, no. 2 (2010): 159-172.

Ungar, Michael, Brown, Marion, Liebenberg, Linda and Othman, Rasha. "Unique Pathways To Resilience Across Cultures,” Adolescence 42, no. 166 (2007): 287.

Wang, Caroline and Burris, Mary Ann. "Photovoice: Concept, Methodology, And Use For Participatory Needs Assessment," Health Education \& Behavior 24, no. 3 (1997): 369387.

Wang, Caroline C. and Redwood-Jones, Yanique A. "Photovoice Ethics: Perspectives From Flint Photovoice," Health Education \& Behavior 28, no. 5 (2001): 560-572.

Wang, Caroline C. "Photovoice: A Participatory Action Research Strategy Applied To Women's Health,” Journal of Women's Health 8, no. 2 (1999): 185-192. 
Watson, Adam. "Hedley Bull, States Systems And International Societies." Review of International Studies 13.2 (1987): 147-153.

Watson, Scott D. "Manufacturing Threats: Asylum Seekers As Threats Or Refugees." Journal of International Law \& Internationall Relations. 3 (2007).

Wendt, Alexander. Social Theory Of International Politics. Cambridge University Press, (1999).

Wiedman, Dennis, and Martinez, Iveris L. "Organizational Culture Theme Theory And Analysis Of Strategic Planning For A New Medical School," Human Organization 76, no. 3 (2017).

Williams, Michael C. "Securitization As Political Theory: The Politics of the Extraordinary," International Relations 29, no. 1 (2015): 114-120.

Wilmott, Annabelle Cathryn. "The Politics Of Photography: Visual Depictions Of Syrian Refugees In UK Online Media." Visual Communication Quarterly 24, no. 2 (2017): 67-82.

Yasmine Rola and Moughalian, Catherine. "Systemic Violence Against Syrian Refugee Women And The Myth Of Effective Intrapersonal Interventions," Reproductive Health Matters, (2016).

Yasmine, Rola and Moughalian, Catherine. "Systemic Violence Against Syrian Refugee Women and the Myth of Effective Intrapersonal Interventions," Reproductive Health Matters 24, no. 47 (2016): 27-35.

Yuval-Davis, Nira, Anthias, Floya, and Kofman, Eleonore. "Secure Borders And Safe Haven And The Gendered Politics of Belonging: Beyond Social Cohesion," Ethnic and Racial Studies 28, no. 3 (2005): 513-535.

Zahar, Marie-Joëlle. "Peace By Unconventional Means: Lebanon's Ta'if agreement." Ending Civil Wars: The Implementation of Peace Agreements (2002): 567-597.

Zeinab, Cherri et al., "Early Marriage and Barriers to Contraception Among Syrian Refugee Women in Lebanon: A Qualitative Study," International Journal of Environmental Research and Public Health 14, vol. 8 (2017).

Zeinab, Cherri, González, Pedro Arcos, and Delgado, Rafael Castro. "The LebaneseSyrian Crisis: Impact Of Influx Of Syrian Refugees To An Already Weak State," Risk Management and Healthcare Policy 9 (2016).

Zetter Roger and Ruaudel, Héloïse. "Development and Protection Challenges of the Syrian Refugee Crisis," Forced Migration Review 47 (September 2014). 
Zwingel, Susanne. "How Do Norms Travel? Theorizing International Women's Rights In Transnational Perspective." International Studies Quarterly 56, no. 1 (2012): 115-129.

Zwingel, Susanne. Translating International Women's Rights: The CEDAW Convention In Context. Palgrave Macmillan, (2016).

Zwingel, Susanne. Translating International Women's Rights. Palgrave Macmillan UK, (2016).

"300 Thousand Syrian Women Pregnant Will Give Birth In Lebanon In 2017," Addiyar News, (March 3, 2017), https://www.addiyar.com/article/1359928-3002017.

"A Convoy Of 300 Syrian Displaced Returned From The Town Of Arsal To The Syrian Town Isal Al-Ward", An-Nahar, (July 12, 2017), https://www.annahar.com/article/617319F.

"Abu Khalil: Without The Syrian Crisis, Electricity Would Have Been 24/24," Lebanon News, LBC News, (February 21, 2017), www.lbcgroup.tv/news/d/lebanon/304003/24/24.

"Bou Saab Continued With Lazarene Preparations For The Donor Conference And The IDP Education Plan," Lebanonfiles Local News, (January 13, 2016), http://www.lebanonfiles.com/news/985407.

"Extremist Ain El Hilweh Group Threatens Escalation," The Daily Star, (May 8, 2017), http://www.dailystar.com.lb/News/Lebanon-News/2017/May-08/404971extremistain-al-hilweh-group-threatensescalation.ashx.

"International Plea For Syrian Refugee Jobs Sparks Anger In Lebanon," Arab News, (June 24, 2018), http://www.arabnews.com/node/1292241/middle-east.

"Lebanon 'Moves Right Way' On ID," BBC News, February

24, 2009, http://news.bbc.co.uk/2/hi/middle_east/7906125.stm

"Lebanon and Jordan Close Their Borders To Syrian Refugees," The Chronicle, (December 22, 2014), https://chronicle.fanack.com/refugees/lebanon-andjordanclose-their-borders-to-syrian-refugees/.

"Lebanon Between The Largest Displacement and the Least Aid," Emirates News Agency,

(June

6 , 2017), https://www.zawya.com/mena/en/story/Some_60000_Syrian_refugees_in_Lebano n__Jordan_could_lose_assistance_warns_UNHCR-WAM20170606192048379. 
"Lebanon Cabinet Votes To Stop Accepting Syrian Refugees," Daily Star, (October 23, 2014): www.dailystar.com.lb/News/Lebanon-News/2014/Oct-23/275075refugeecrisis-tops-lebanoncabinetagenda.ashx.

"Lebanon Elects Six Women To Parliament." The Daily Star, (May 09, 2018): http://www.dailystar.com.lb /News/Lebanon-Elections/2018/May09/448633lebanon-elects-six-women-to-parliament.ashx

"Lebanon First Ever Womens Affairs Minister Man Jean Ogasapian Rights Equal." Independent. (December 19, 2016): https://www.independent.co.uk/news/world/middle-east/lebanon-first-everwomensaffairs-minister-man-jean-ogasapian-rights-equal-a7484221.html

"Lebanon Freezes UNHCR Staff Residency Applications In Row Over Syrian Refugees," Reuters, (June 8, 2018): https://www.reuters.com/article/us-lebanonsyria-refugeesunhcr/lebanon-freezes-unhcr-staff-residency-applications-in-rowover-syrianrefugees-idUSKCN1J41JE.

"Lebanon Wants UN to Facilitate Return Of Syrian Refugees," Associated Press, (June 14, 2018), https://abcnews.go.com/International/wireStory/lebanonfacilitate-returnsyrian-refugees-55891878.

"Lebanon's President Aoun Calls For National Unity, Liberating Palestinian Territories," Albawaba, (November 1, 2016), http://www. albawaba.com/news/lebanon'spresident-aoun-calls-national-unity-liberatingpalestinian-territories-899220.

"Patriarch al-Ra'i: "Syrian Refugees Threaten Lebanon Security." Orient News, (December 26, 2016): https://www.orientnews.net/en/news_show/129448/0/Patriarch-al-Rai-“Syrian-refugeesthreatenLebanon-security

"Refugee Children Resorting To 'Survival Sex' To Pay People Smugglers Says UN," International Business Times, (October, 2015), http://www. ibtimes.co.uk/refugeechildren-resorting-survival-sex-pay-people-smugglers-saysun-1525534.

"Roula Yaacoub's Husband Found Not Guilty After Beating Her To Death." Beirut.

(Novemeber 1, 2018), https://www.beirut.com/l/56670

"Syria's Civil War Explained From The Beginning," AlJazeera,(2016), http://www.aljazeera.com/news/2016/05/syria-civilwar-explained160505084119966.html. 
"Syrian Children In Lebanon Forced To Work: Report," Al Jazeera News, (April 12, 2016), https://www.aljazeera.com/news/2016/04/syrian-children-lebanon-forcedworkreport-160412051345859.html.

"Syrian President Bashar Al-Assad Wins Third Term." BBC NEWS, World, Middle East. (June 5, 2014). : http://www.bbc.com/news/world-middle-east-27706471

"Syrian Refugee Women in Lebanon Face Abuse, Exploitation." Agence France Press, The Straits Times, (February 2, 2016), https://www.straitstimes.com/world/middleeast/syrian-refugee-women-inlebanon-face-abuse-exploitation.

"Syrian Refugee Women Tell Stories About Sexual Exploitation In Lebanon," Naharnet Newsdesk, (August, 2014), http://www.naharnet.com/stories/ar/141494.

"Syrian Women Rise Above Differences And Forge A Statement Of Unity," UN Women News, (May 23, 2016), http://www.unwomen.org/en/news/stories/2016/5/syrianwomen-rise-abovedifferences-and-forge-a-statement-of-unity.

"Syrians Entering Lebanon Face New Restrictions." BBC News. (January 5, 2015): https://www.bbc.com/news/world-middle-east-30657003

"Syrians Who Obtain Work Permits in Lebanon Risk Losing Refugee Aid," Lebanon News, The Daily Star, (March 6, 2017): http://www.dailystar.com.lb/News/LebanonNews/2017/Mar-06/396311-syrianswho-obtain-work-permits-in-lebanon-risk-losingrefugee-status.ashx.

"The Future of Syria: How A Victorious Bashar Al-Assad Is Changing Syria." The Economist, (June 28, 2018): https://www.economist.com/middle-eastandafrica/2018/06/28/how-a-victorious-bashar-al-assad-is-changing-syria

"Two-Thirds Of Syrian Refugees In Lebanon 'Employed'," Almanar TV Archive, (March 4, 2014), http://archive.almanar.com.lb/english/article.php?id=144153.

"U.S. Welcomes Lebanon Plan For Syrian Refugees," The Daily Star, (January 4, 2013), http://www.dailystar.com.lb/News/Politics/2013/Jan-04/200934-uswelcomeslebanon-plan-for-syrian-refugees.

"Woman's Murder Prompts Mass Eviction Of Syrians From Lebanese Town," Reuters, (October 5, 2017): https://www.reuters.com/article/us-mideast-crisislebanonrefugees/womans-murder-prompts-mass-eviction-of-syrians-fromlebanese-townidUSKBN1CA18S. 
Bajec, Alessandra, "Lebanon's Political Crisis Drags On As Politicians Agree to Extend

Their Mandate A Third Time," Al-Araby News, (June 20, 2017), https://www.alaraby.co.uk/english/indepth/2017/6/20/lebanons-political-crisisdragson-with-third-term-extension.

Barnard, Anne. “A Refugee Crisis In Lebanon Hides In Plain Sight.” New York Times. (November 12 , 2015), https://www.nytimes.com/2015/11/13/world/middleeast/arefugee-crisis-inlebanon-hides-in-plain-sight.html

Ibrahim, Arwa. Syria: 'Absentees Law' Could See Millions Of Refugees Lose Lands." AlJazeera News. (April 7, 2018): www.aljazeera.com/news/2018/04/syriaabsenteeslaw-millions-refugees-lose-lands180407073139495.html

Gallagher, Ashley. "Syrian Refugees Are Turning to Prostitution at Super Nightclubs," Vice News, (June 11, 2014), https://news.vice.com/article/syrian-refugees-areturningto-prostitution-at-super-nightclubs.

Atassi, Bassma. "Syria's War Widows Fight For Survival." Al Jazzera News, (July, 2014), https://www.aljazeera.com/humanrights/2014/07/syrian-women-struggleas-soleproviders-201478122435631439.html

Walsh, Bryan. "Alan Kurdi's Story: Behind The Most Heartbreaking Photo Of 2015," TIME Magazine, (December 29, 2015), http://time.com/4162306/alan-kurdisyriadrowned-boy-refugee-crisis.

Alfred, Charlotte. "Dangerous Exit: Who Controls How Syrians In Lebanon Go Home."

News Deeply, $\quad$ (August $\quad 8, \quad$ 2018).

https://www.newsdeeply.com/refugees/articles/2018/08/08/dangerous-exitwhocontrols-how-syrians-in-lebanon-go-home.

Ward, Clarissa. "Syrian Refugees Sell Daughters In Bid to Survive," CBS News, (May 15, 2013), http://www.cbsnews.com/news/syrian-refugees-selldaughters-in-bid-tosurvive/.

Meier, Daniel. "La Strategie Du Regime Assad Au Liban Entre 1970 Et2013. Du Pouvoir Symbolique A La Coercion." Revue EurOrient, n 41, (2013): 171-188.

Meier, Daniel. "Lebanon: The Refugee Issue And The Threat Of A Sectarian Confrontation." Oriente moderno 94, no. 2 (2014): 382-401. 
Enders, David. "Merkel Finds A Familiar Attitude To Refugees In Lebanon." The National. (June 23, 2018), https://www.thenational.ae/world/mena/merkel-findsafamiliar-attitude-to-refugees-in-lebanon-1.743220

Evans, Dominic. "Syria War, Refugees To Cost Lebanon \$7.5 Billion: World Bank," Reuters, (September 19, 2013), https://www.reuters.com/article/us-syriacrisislebanon-idUSBRE98I0T320130919.

Irshaid, Faisal. "Anti-Syrian Hostility In Lebanon Spawns Social Media Backlash," BBC News, (April 4, 2014): https://www.bbc.coober m/news/world-middle-east26871736.

Azar, Georgi. "Lebanese President Draws Fire With Naturalization Decree." Annahar News. (June 1, 2018): https://en.annahar.com/article/812753-lebanesepresidentdraws-fire-with-naturalization-decree

Mahmoud, Haytham. "Syrian Refugees Change The Lebanese Labor Scene," AlArabiya, (July " 8, 2016), http://english.alarabiya.net/en/business/economy/2016/07/08/Syrianrefugeeschange-the-Lebanese-labor-scene.html.

Black, Ian. "Syria and Lebanon To Establish Diplomatic Relations." The Guardian. (October 14, 2008). https://www.theguardian.com/world/2008/oct/14/syrialebanon

Tyab, Imtiaz. “Anti-Syrian Hostility Surges In Lebanon,” Al-Jazeera, (October 25, 2017): https://www.aljazeera.com/news/2017/10/anti-syrian-hostility-surgeslebanon171025105854684.html

Northam, Jackie. "For Syrian Refugees, Needs Are Growing And Aid Is Declining."

National Public Radio. $\quad$ (September 14 , 2015):

https://www.npr.org/sections/parallels/2015/09 /14/440280540/for-syrianrefugeesneeds-are-growing-and-aid-is-declining

Chaaban, Jad. "Should Lebanon Get More Funds For Hosting Refugees?," Al Jazeera, (April 5, 2017), https://www.aljazeera.com/indepth/features/2017/04/lebanonfundshosting-refugees-170405082414586.html.

Haines-Young, James. "Lebanon's Bassil Meets UNHCR to Defuse Refugee Row," The National, (June 17, 2018), https://www.thenational.ae/world/mena/lebanon-sbassilmeets-unhcr-to-defuse-refugee-row-1.741039. 
Davison, John. "Redrawing The Middle East: A Generation Of Syrian Children Who Don't Count," Thompson Reuters, (May 3, 2016): http://www.reuters.com/investigates/special-report/syria-refugeesstateless/.

Davison, John. "Syrians In Lebanon Hit By Arrests, Curfews And Hostility After Bombing," Reuters, (July 25, 2016): www.reuters.com/article/us-mideast-crisissyrialebanon/syrians-in-lebanon-hit-by-arrests-curfews-and-hostility-afterbombingsidUSKCN1051KO.

Wood, Josh. "Syrian War Deals Heavy Blow To Lebanon's Export Business," The National News, (September 26, 2015), https://www.thenational.ae/world/syrianwardeals-heavy-blow-to-lebanon-s-export-business-1.127856.

Ensor, Josie. "The Muslim Refugees Converting To Christianity To Find Safety," The

Telegraph, (January 30, 2017), https://www.telegraph.co.uk/news/2017/01/30/muslim-refugeesconvertingchristianity-find-safety

Shaheen, Kareem. "Lebanon Sex Trafficking: Syrian Woman Describes NineMonth
Ordeal,"
The
Guardian,
(August
1 , 2016),

https://www.theguardian.com/world/2016/aug/01/lebanon-sex-traffickingsyrianwoman-describes-nine-month-ordeal.

Shaheen, Kareem,"Dozens Of Syrians Forced Into Sexual Slavery In Derelict Lebanese

House," The Guardian, (April 30,
2016),

https://www.theguardian.com/world/2016/apr/30/syrians-forced-sexualslaverylebanon.

Jones, Katharine. "Syrian Refugees In Lebanon Are Falling Into Slavery And Exploitation." The Conversation. (April 13, 2016), https://theconversation.com/syrianrefugees-in-lebanon-are-falling-into-slaveryand-exploitation-57521.

Estatie, Lamia. "Lebanon Detains Men Behind Assault On Syrian Refugee," BBC News, (July 19, 2017), http://www.bbc.com/news/blogs-trending-40653714.

Lebanon News, "Bassil Calls On Expats To Reclaim Citizenship," The Daily Star, (February 4, 2017), http://www.dailystar.com.lb/News/LebanonNews/2017/Feb04/392246-bassil-calls-on-expats-to-reclaim-citizenship.ashx. 
Lebanon News, "Lebanon Witnesses Rise In Syrian Refugee Child Labor Over Past Year,"

The Daily Star, (June 14, 2018),

http://www.dailystar.com.lb/News/LebanonNews/2018/Jun-14/453154-lebanon-

witnesses-rise-in-syrian-refugee-child-laborover-past-year.ashx.

Lebanon News, "Small Drug Cartel Operating In Dora, Jounieh Arrested," The Daily Star,

(April 5, 2018), http://www.dailystar.com.lb/News/Lebanon-

News/2018/Apr05/444244-small-drug-cartel-operating-in-dora-jounieharrested.ashx.

Lebanon News, "UNHCR To Cross 5,500 Syrian Refugees: Derbas," The Daily Star, (August 29 , 2015): https://www.dailystar.com.lb/News/LebanonNews/2015/Apr29/296164-unhcr-tocross-off-5500-syrian-refugeesderbas.ashx.

Fakhreddin, Lina. "Lebanon Between The Largest Displacement And The Least Aid," Assafir News, (January 6, 2015), http://assafir.com/Article/2/394120.

Porter, Lizzie, and Chehayeb, Kareem. "EXCLUSIVE: Lebanese Army Accused Of

Torturing Syrian Refugees," Middle East Eye, (July 17, 2017):

http://www.middleeasteye.net/news/exclusive-syrian-refugees-tortureddeathlebanese-army-481522780.

Hodeib, Mirella. "Hezbollah Fighters Find Nusra's Tactics in Qusair 'Irritatingly Familiar," Daily Star Lebanon, (May 31, 2013),

http://www.dailystar.com.lb/News/Local-News/2013/May31/218984hezbollahfighters-find-nusras-tactics-in-qusair-irritatingly-familiar.ashx. Alloush, Mohamed. "What Is The Truth About The Presence Of 300,000 Pregnant Syrian

Women In Lebanon?," El-Nashra News, (May 3, 2017):

https://www.alaraby.co.uk/english/news/2017/5/5/debunked-300-000syrianrefugees-are-not-pregnant-in-lebanon.

Meaker, Morgan. "When Aid Funds A Country - Not Its Refugees." Devex News. (March 10, 2017): https://www.devex.com/news/when-aid-funds-a-country-notits-refugees 89744 
Meaker, Morgan. "Syrian Refugee Children Reduced To Selling On Beirut's Streets To Feed Their Families," The Guardian, (January 25, 2017), https:// www.theguardian.com/global-development/2017/jan/25/syrian-refugeechildrenselling-beirut-streets-lebanon-support-families.

Loveday, Morris, and Haidamous, Suzan. "Beirut Car Bomb Kills At Least 21," The Washington Post. (August 15, 2013): http://articles.washingtonpost.com

Bulos, Nabih. "In Lebanon, A Rape And Murder Galvanize Anti-Syrian Fervor," Los Angeles Times, (October 13, 2017), http://www.latimes.com/world/middleeast/lafglebanon-syria-slaying-2017-story.html.

Tueni, Nayla. "Lebanon's Baabda Declaration, A National Necessity." Al-Arabiya News. (June 26, 2015). http://english.alarabiya.net/en/views/news/middleeast/2015/06/26/Lebanon-sBaabda-Declaration-a-national-necessity.html

Holmes, Oliver. "New Restrictions In Lebanon Mean Syrian Refugees Live In Fear," Reuters, (April 17, 2015), www.reuters.com/article/us-mideast-crisislebanonrefugees/new-restrictions-in-lebanon-mean-syrian-refugees-live-in-fear.

Habib, O sama . "Tax Evasion Close To \$4.2B Annually: Economist," The Daily Star News, (March 2, 2017), http://www.dailystar.com.lb/Business/Local/2017/Mar02/395690-tax-evasionclose-to-42b-annually-economist.ashx.

Mouamar, Patricia. "Viewpoints: Impact Of Syrian Refugees On Host Countries," BBC News, (August 24, 2013), https://www.bbc.com/news/world-23813975.

Astih, Paula. "Lebanon: Public Discontent Over Continuous Power Cuts," Asharq $A l$ -

Awsat Newspaper, (December 23, 2017), https://aawsat.com/english/home/article/1121661/lebanon-public-discontentovercontinuous-power-cuts?amp.

Hall, Richard. "After Trump's Ban, Lebanon Renews Calls To Send Back Syrian Refugees," Public Radio International, (February 6, 2017), www.pri.org/stories/201702-06/after-trump-s-ban-lebanon-renews-calls-sendback-syrian-refugees.

Hall, Richard. “Lebanon Doesn't Want Syrian Refugees Getting Too Comfortable, Even in Winter," Agence France-Presse, (February 15, 2016), https://www.pri.org/stories/2016-02-15/lebanon-doesnt-want-syrian-refugeesgettingtoo-comfortable-even-winter. 
Pollard, Ruth. "Lebanese Citizenship Law Strips Women Of Identity And Property." Reuters. (May 25, 2016), https://www.reuters.com/article/us-lebanonwomenproperty-rights/lebanese-citizenship-law-strips-women-of-identity-andpropertyidUSKCNOYH03O

Yarzeh, Ruth Sherlock. "Expat Syrians Join the Crush To Support Assad In Parody Election," Telegraph UK, (May 28, 2014).

Yarzeh, Ruth Sherlock, "In Lebanon, Syrian Refugees Met With Harassment And Hostility," NPR, (September 2017): https://www.npr.org/sections/parallels/2017/09/02/547906231/in-lebanonsyrianrefugees-met-with-harassment-and-hostility.

Nakhoul, Samia. "Analysis: Killing Of Security Chief Raises Fears For Lebanon." Reuters. Beirut. (October 22, 2012). Retreived from: https://en.wikipedia.org/wiki/Wissam_alHassan\#cite_note-samia2212-19

Perry, Tom. "Lebanon Near 'Breaking Point' Over Syrian Refugee Crisis: PM Hariri," Reuters, (March 31, 2017): http://www.reuters.com/article/us-mideast-crisissyrialebanon-idUSKBN1722JM.

DeGhett, Torie Rose. "Is Syria About To Become Iran's New Vietnam?," Vice News, (October 7, 2015), https://news.vice.com/article/is-syria-about-to-becomeiransvietnam.

Al-Saadi, Yazan. "The Diversion Strategy: Lebanese Racism, Classism, And The Refugees." Al-Akhbar (June 10, 2014). Al-Akhbar. : https://english.alakhbar.com/node/20121.

\section{UN Documents And Reports:}

“'Unprecedented' 65 Million People Displaced by War And Persecution in 2015." UN News Centre, http://www.un.org/apps/news/story.asp?NewsID=54269 \#. WahMY8h96bg.

"1951 Refugee Convention And 1967 Protocol Relating To The Status of Refugees," United Nations, General Assembly, http://www.unhcr.org/3b66c2aa10.

"A Longing To Go Homes, In Safety And Dignity: Intentions And Perceptions Of Syrian Refugees In Lebanon About Their Future." UNHCR, Lebanon, (January 2018). : https://data2.unhcr.org/fr/documents/download/63310 
“Amnesty International Annual Report 2015/2016." Releif Web: http://reliefweb.int/report/lebanon/amnesty-international-regrets-lebanon-sdecisionoverturn-its-open-border-policy.

“Amnesty International Regrets Lebanon's Decision To Overturn Its Open Border Policy

Towards Refugees And Refusal To Address Discrimination Against Women And Migrants," Amnesty International, (March 16, 2016),

http://reliefweb.int/report/lebanon/amnesty-international-regrets-lebanon-sdecisionoverturn-its-open-border-policy.

“Annual Results Report. Water, Sanitation And Hygiene." UNICEF. (2016), 41. "Are We Listening? Acting on Our Commitments to Women and Girls Affected by the Syrian Conflict," International Rescue Committee, IRC. (2014), 15.

"Assessment Of The Impact Of Syrian Refugees In Lebanon And Their Employment

Profile,' International

Labor Organization, (2013),

https://www.ilo.org/wcmsp5/groups/public/---arabstates/--robeirut/documents/publication/wcms_240134. pdf.

"Briefing Note For Countries On The 2016 Human Development Report: Lebanon," United Nations Development Program (UNDP), (2016): http://hdr.undp.org/sites/all/themes/hdr_theme/country-notes/JOR.pdf.

"Childhood In The Shadow Of War: Voices Of Young Syrians," Save The Children, (2015), http://resourcecentre.savethechildren.se/sites/default/files/documents/childhoodinthe-shadow-of-war.pdf.

"Concluding Observations On The Combined Fourth And Fifth Periodic Reports Of Lebanon." CEDAW. UN Doc. CEDAW/C/LBN/4-5, (November 3, 2015): http://docstore.ohchr.org/SelfServices/FilesHandler.ashx?

"Consideration Of Reports Submitted By States Parties Under Article 18 Of The Convention Fourth And Fifth Periodic Reports Of States Parties Due In 2014 Lebanon"

United Nations $\quad$ (May 15, 2014):

https://nclw.org.lb/wpcontent/uploads/2017/10/CEDAW-Fourth-andFifth-Periodic-Report-Lebanon.pdf 
"Country Operations Plan." UNHCR Regional Office In Lebanon, (2004), : http://www.unhcr.org/3fd9c6a14.pd

“Country Operations Plan.” UNHCR, 2004. Retrieved from. http://www.unhcr.org/3fd9c6a14.pdf

Did The PLO Die In Lebanon?" Al Jazeera, July $28,2009$.

https://www.aljazeera.com/programmes/plohistoryofrevolution/2009/07/2009728 $55032594820 . h t m l$

"Ensuring Birth Registration For The Prevention Of Statelessness." UNHCR. Ending Statelessness Within 10 Years, (2017):https://www.unhcr.org/ke/wpcontent/uploads/sites/2/2017/11/Good -Practices-Paper-on-Ensuring-BirthRegistration-for-the-Prevention-ofStatelessness.pdf

"Ensuring Birth Registration For the Prevention of Statelessness." UNHCR. Ending Statelessness Within 10 Years.

(2017):https://www.unhcr.org/ke/wpcontent/uploads/sites/2/2017/11/Good -Practices-Paper-on-Ensuring-Birth Registration -for-the-Prevention-ofStatelessness.pdf

"Female Refugees From Syria In Iraq, Jordan And Lebanon: Lebanon Gender Profile," United Nations Economic and Social Commission of Western Asia (ESCWA), E/ESCWA/ECW/2013/Technical paper 4, (2014), 15.

"Following The Money Lack Of Transparency In Donor Funding For Syrian Refugee

Education," Human Rights Watch, (September 14, 2017),

https://www.hrw.org/report/2017/09/14/following-money/lack-transparencydonorfunding-syrian-refugee-education.

"Following the Money: Lack Of Transparency In Donor Funding For Syrian Refugee

Education," Human Rights Watch, (September 14, 2017),

https://www.hrw.org/report/2017/09/14/following-money/lack-transparencydonorfunding-syrian-refugee-education.

"Food Security Sector, Monthly Dashboard," UN Inter-Agency Coordination Lebanon, (July, 2015), http://data.unhcr.org/syrianrefugees/download.php?id=9506. 
"Government Of Lebanon And UNHCR, Lebanon Crisis Response Plan 20152016." UNHCR Portal (2015), https://data2.unhcr.org/en/documents/download/44245. "Growing Up Without An Education: Barriers To Education For Syrian Refugee Children

$$
\text { In Lebanon," Human Rights Watch, (July 19, }
$$
2016),

https://www.hrw.org/report/2016/07/19/growing-without-

education/barrierseducation-syrian-refugee-children-lebanon.

"Growing Up Without An Education: Barriers To Education For Syrian Refugee Children

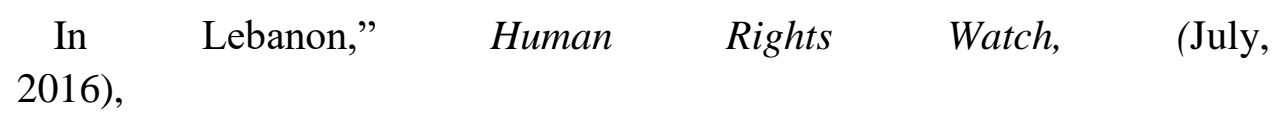

https://www.hrw.org/report/2016/07/19/growing-without-

education/barrierseducation-syrian-refugee-children-lebanon.

"Human Rights Watch Submission To The CEDAW Committee Of Lebanon's Periodic Report 62nd Session," Human Rights Watch, (February, 2015), https://tbinternet.ohchr.org/Treaties/CEDAW/Shared\%20Documents/ LBN/INT_ CEDAW_NGO_LBN_19385_E.pdf.

"I Just Wanted to be Treated like a Person: How Lebanon's Residency Rules Facilitate Abuse of Syrian Refugees," Human Rights Watch, (January 12, 2016), https://www.hrw.org/report/2016/01/12/i-just-wanted-be-treatedperson/howlebanons-residency-rules-facilitate-abuse.

"I Want a Safe Place: Refugee Women From Syria Uprooted and Unprotected in Lebanon" Amnesty International, (2015): https://www.amnesty.org/download/Documents/MDE2417852015ENGLISH.PD F.

"I Want A Safe Space: Refugee women from Syria uprooted and unprotected in Lebanon."

Amnesty International, (February, 2016): https://www.alnap.org/system/files/content/resource/files/main/i-want-asafeplace.pdf

"Identifying the Legislative Gaps that Need to Be Filled for the Application of Security Council Resolution 1325." United Nations Economic and Social Commission For Western Asia-(ESCWA). (2000) on Women, Peace and Security in Selected Arab States." E/ESCWA/ECW/2015/Technical Paper.8, (March 17, 2015), womenpeacesecurity-legisislative-gaps-resolution-1325-english.pdf. 
"Lebanon Annual Report 2014 Highlights," KAFA, (2014): http://www.kafa.org.lb/StudiesPublicationPDF/ PRpdf-82635689245975040950.pdf.

"Lebanon Annual Report 2014 Highlights," KAFA, (2014): http://www.kafa.org.lb/StudiesPublicationPDF/ PRpdf-82635689245975040950.pdf.

"Lebanon Immigration Detention Profile," Global Detention Project, (February 2018), https://www.globaldetentionproject.org /countries/middle-east/lebanon.

"Lebanon Security And Justice Sector Wide Assessment," UNDP, (March 2016), file:///C:/Users/Jessy/Downloads/ SecurityandJusticeSectorWideAssessment.pdf.

"Lebanon: At Least 45 Local Curfews Imposed On Syrian Refugees." Human Rights Watch. (October 3, 2014), https://www.hrw.org/news/2014/10/03/lebanon-least45local-curfews-imposed-syrian-refugees

"Lebanon: Economic and Social Impact Assessment of the Syrian Conflict." World Bank Report, available at: http://documents.worldbank.org/curated/ en/2013/09/18292074/lebanon-economic-social-impact-assessment-syrianconflict.

"Lebanon: Mass Evictions Of Syrian Refugees," Human Rights Watch, (April 20, 2018), https://www.hrw.org/news/2018/04/20/lebanon-mass-evictions-syrianrefugees.

"Lebanon: New Entry Requirements For Syrians Likely To Block Would-Be Refugees,"

Amnesty International, (January 6, 2015),

www.amnesty.org/en/documents/document/?indexNumber=mde24\%2F002\%2F2 015 \&language $=$ en.

"Lebanon: Reveal Fate of Disappeared Syrians: Military Intelligence Detains Six Calling for Democratic Change In Their Country," Human Rights Watch, (March 9, 2011), https://www.hrw.org/news/2011/03/09/lebanon-reveal-fate-disappearedsyrians. "Lebanon: Syrian Women At Risk Of Sex Trafficking," Human Rights Watch, (July 28,

2016), https://www.hrw.org/news/2016/07/28/lebanon-syrian-women-risksextrafficking. 
"Lebanon: Waste Crisis Posing Health Risks," Human Rights Watch, (December 1, 2017), https://www.hrw. org/news/2017/12/01/lebanon-waste-crisis-posinghealth-risks.

"Lebanon-UNHCR Memorandum Of Understanding" Frontiers Center. (November, 2003):

http://www.frontiersruwad.org/pdf/FR_Public_Statement_MOU_Nov_2003.pdf

"Palestinian Employment In Lebanon: Facts And Challenges: Labor Force Survey Among Palestinian Refugees Living In Camps And Gatherings In Lebanon.” International Labour Organisation (ILO), Committee for the Employment of Palestinian Refugees (CEP), United Nations Peace Building Fund, (2012), 58.

"Protection Sector, Monthly Dashboard," UN Inter-Agency Coordination Lebanon, (July 2015), http://data.unhcr.org/ syrianrefugees/download.php?id=9508.

"Pushed to the Edge: Syrian Refugees Face Increased Restrictions in Lebanon," Amnesty

International. (June 2015). www.amnesty.nl/sites/

default/files/public/pushed_to_the_edge_syrian

_refugees_face_increased_restrictions_in_lebanon.pdf

"Q\&A For Syrians Seeking Registration," United Nations, (July 15, 2017), https://www.refugees-lebanon.org/en/news/88/qa-for-syrians-seeking-registration.

"Reform of the KAFALA (Sponsorship) System," Migrant Forum In Asia, Policy Brief No. 2, (July 3, 2013) : http://www.ilo.org/dyn/migpractice/docs/132/PB2.pdf.

"Refugees From Syria: Lebanon," UNHCR, (March 2015), 6. http://reliefweb.int/report/lebanon/refugees-syria-lebanon-march-2015.

"Refugees From Syria: Lebanon," UNHCR, March 2015, 6, http://reliefweb.int/report/lebanon/refugees-syria-lebanon-march-2015.

"Regional Refugee and Resilience Plan (3RP), Funding Requirements: Lebanon." United Nations. (December 29, 2015):

http://data.unhcr.org/syrianrefugees/country.php?id=122.

"Self-Protection And Coping Strategies Of Refugees From Syria And Host Communities In Lebanon," OXFAM, (July, 2015):https://d1tn3vj7xz9fdh.cloudfront.net/s3fspublic/file_attachments/rrlebanon-refugees-protection-300616-en.pdf. 
"SGBV Dashboard," Interagency, Lebanon, January-August 2016. http://data.unhcr.org/syrianrefugees/working_group.php?Page=Country\&Locatio $\mathrm{nId}=122 \& \mathrm{Id}=47$.

"SGBV Dashboard." Interagency, Lebanon, January - August 2016, https://data2.unhcr.org/en/situations/ syria/ location/71.

"SGBV Dashboard." Lebanon Interagency. (August 2016): http://data.unhcr.org/ syrianrefugees/working_group.php?Page=Country\&LocationId=122\&Id=47

"States Parties to the 1951 Convention Relating to the Status of Refugees and the 1967 Protocol," UNHCR, http://www.unhcr.org/3b73b0d63.html.

"Struggling To Survive: Slavery And Exploitation of Syrian Refugees In Lebanon," Freedom Fund, (April 12, 2016),

http://freedomfund.org/wpcontent/uploads/Lebanon-Report-FINAL8April16.pdf.

"Syria Crisis Response, Situation Report." World Food Programme, Lebanon, (September, 2015), http://data.unhcr.org /syrianrefugees/download.php?id=9670.

"Syria Regional Refugee Response, Information Portal," United Nations High

Commissioner for Refugees (UNHCR), http://data.unhcr.org/syrianrefugees/country.php?id=122.

"Syria Regional Refugee Response." UNHCR. (August 11, 2018): http://data.unhcr.org /syrianrefugees /regional.php.

"Syria's Good Neighbors: How Jordan And Lebanon Sheltered Millions Of Refugees," Washington Institute, (September 2015), http://www.washingtoninstitute.org/policyanalysis/view/syrias-good-neighborshow-jordan-and-lebanon-sheltered-millions-ofrefugees.

"Syrian Refugees In Lebanon Surpass One Million," UNHCR, Press Releases, (April 3, 2014), http://www.unhcr.org/533c15179.html.

"Syrian Refugees In Lebanon," Syrian Civic Platform, (September 29, 2017), http://www.scplatform.net/en/syrian-refugees-in-lebanon/.

"Syrian Refugees Resort to Child Labor in Lebanon," The World Staff, PRI, (September 5, 2017), https://www.pri.org/stories/2017-09-05/syrian-refugeesresort-child-laborlebanon.

"The 2015-16 Lebanon Crisis Response Plan." UNHCR, (December 15, 2014), http://www.alnap.org/resource/20702, 
"The Consequences Of Limited Legal Status For Syrian Refugees In Lebanon," Norwegian Refugee Council, (December 2013), 27, https://reliefweb.int/sites/reliefweb.int/files/resources/9687105.pdf.

“The Situation Of Human Rights In Lebanon." ALEF, Annual Report 2017, (March,

2018), 11,

https://alefliban.org/wpcontent/uploads/2018/04/annual_report_2017_v03 -2 .pdf.

"The Situation of Human Rights in Lebanon: Annual Report." ALEF, (2015), alefliban.org/wp-content/uploads/2016/10/ALEF_Human-Rights-inLebanon_2015.

"The Syrian Refugee Crisis: Labour Market Implications In Jordan And Lebanon," European Economy Discussion Paper, European Union. (2016), https://ec.europa.eu/info/sites/info/files/dp029_en.pdf.

"Too Close For Comfort: Syrians In Lebanon." International Crisis Group Middle East

Report 141.

:http://www.operationspaix.net/DATA/DOCUMENT/7965 v Too_Close

_For_Comfort_Syrians_in_Lebanon_Middle_East_Report_N141.pdf

"Too Close For Comfort: Syrians In Lebanon." The International Crisis Group (ICG) Middle East Report,(2013), 9.

"Trapped in Lebanon: The Alarming Human Rights And Human Security Situation Of Syrian Refugees In Lebanon," (May2016),https://alefliban.org/wpcontent/uploads/2016/11/Trapped-In-Lebanon_ALEF_PAX_May2016.pdf. "Trapped in Lebanon: The Alarming Human Rights and Human Security Situation of Syrian Refugees in Lebanon," ALEF, (May, 2016), https://alefliban.org/wpcontent/uploads/2016/11/Trapped-In-Lebanon_ALEF_PAX_May2016.pdf.

"Trapped In Lebanon: The Alarming Human Rights And Human Security Situation Of Syrian Refugees In Lebanon." ALEF, (May 2016), 18: https://alefliban.org/wpcontent/uploads/2016/11/Trapped-In-Lebanon ALEF_PA $X_{\text {_ May2016.pdf. }}$

"Treaty Of Brotherhood, Cooperation, And Coordination Between The Syrian Arab Republic And The Lebanese Republic" United Nations Treaty Series; (1992). 154: https://peacemaker.un.org/sites/peacemaker.un.org/files /LY_910522-Treaty BrotherhoodCooperationCoordination.pdf. 
"Uncharted Waters: Thinking Through Syria's Dynamics, Middle East Briefing no. 31" International Crisis Group Damascus/Brussels (November 24, 2011).

"UNHCR 2016 Regional Refugee \& Resilience Plan - Funding Snapshot As Of End Of 2016." UNHCR, (December 31, 2016), https://alefliban.org/wpcontent/uploads/2017/03/ALEF_AnnualReport_2016.pdf

"UNHCR Country Operation Profile: Lebanon." UNHCR, (2013), : http://www.almonitor.com/pulse/ar/contents/articles/originals/2013/06/iraqkurdistan-syrianrefugees-aid.html\#

"VASyR 2017: Vulnerability Assessment of Syrian Refugees in Lebanon," World Food

Program, United Nations Children's Fund (UNICEF), and UNHCR, (2016), http://documents.wfp.org/stellent/ groups/public/documents/ ena/wfp289533.pdf. "VASyR 2017: Vulnerability Assessment of Syrian Refugees in Lebanon," World Food

Program, United Nations Children's Fund (UNICEF), and UNHCR, (2016): http://documents.wfp.org/stellent/groups/public/documents/ena/ wfp289533.pdf.

"Vulnerability Assessment Of Syrian Refugee Men In Lebanon," International Rescue

Committee, Lebanon, (January 2016). https://www.rescue.org/sites/default/files/document/464/ irclebanonrefugeemensvulnerabilityassessment.pdf.

"Without Protection: Women's Rights under Lebanese Personal Status Laws." Human Rights Watch. (January, 2015).

"Women And The Refugee Crisis: A News Update From Lebanon," Global Fund For Woman, (2015): https://www.globalfundforwomen.org/news-updaterefugeecrisis/\#.WVovCoiGPIU.

"World Report 2014 Events of 2013 2014." Human Rights Watch, https://www.hrw.org/sites/ default/files/wr2014_web_0.pdf.

Amnesty International Focus Group Discussion, (October 6, 2015), Saadnyal, Bekaa Valley.

Amnesty International interviews with refugee women from Syria and with NGOs working with refugees, June and (October 2015), Lebanon.

Bassem Chit, Mohamad Ali Nayel, "Understanding Racism Against Syrian Refugees In Lebanon", Civil Society Knowledge Centre, Lebanon Support, (November 1, 
2013), http://cskc.daleel-madani.org/paper/understanding-racism-against-syrianrefugeeslebanon.

Batl Sadliwal. "Including Women, Excluding Migrants, And Reimagining National Belonging InTthe GCC," World Peace Foundation, (March 12, 2018), https://sites.tufts.edu/reinventingpeace/2018/03/12/including-womenexcludingmigrants-and-reimagining- national-belonging-in-the-gcc/.

Conflict Analysis Report, "The Burden Of Scarce Opportunities: The Social Stability Context In Central And West Bekaa," UN Development Program, (March, 2017), https://reliefweb.int/report/lebanon/burden-scarce-opportunities-socialstabilitycontext-central-and-west-bekaa-conflict.

Dalya Mitri, "Challenges Of Aid Coordination In A Complex Crisis: An Overview Of Funding Policies And Conditions Regarding Aid Provision To Syrian Refugees In Lebanon," Civil Society Knowledge Center (2014).

Geneviève Colas, Secours Catholique-Caritas France, and Olivier, Peyroux, "Trafficking In Human Beings," Caritas, (2016), http://www.caritas.eu/sites/default/files/report_trafficking_in_conflict_and_postconflict_situations_en.pdf.

Government of Lebanon and the United Nations, "Lebanon Crisis Response Plan 2015-2016," (2015).

Government of Lebanon and the United Nations, Lebanon Crisis Response Plan: 2017-2020, (2017).

Government of Lebanon and the United Nations, Lebanon Crisis Response Plan: 2017- 2020, (2017).

Human Rights Watch, "Our Homes Are Not For Strangers: Mass Evictions Of Syrian

Refugees By Lebanese Municipalities," (April 20, 2018), https://www.hrw.org/report/2018/04/20.

Janice G. Raymond, "Pity The Nations: Women Refugees In Lebanon." Coalition Against

Trafficking in Women Report, (December 6, 2017),

http://www.catwinternational.org/Home/Article/727-pity-the-nationswomenrefugees-in-lebanon.

Karim El Mufti. "Official Response To The Syrian Refugee Crisis In Lebanon: The Disastrous Policy Of No-Policy", Civil Society Knowledge Center, Lebanon 
Support, (January 10, 2014): http://civilsociety-centre.org/paper/official-responsesyrianrefugee-crisis-lebanon-disastrous-policy-no-policy

Kristen Chick, "To Fight Domestic Violence Among Syrian Refugees, an Outreach to

Men," The Christian Science Monitor, (August 26, 2017),

https://www.csmonitor.com/World/Middle-East/2017/0426/To-fight-

domesticviolence-among-Syrian-refugees-an-outreach-to-men.

OXFAM, Discussion Paper, "Lebanon: Looking Ahead In Times Of Crisis,"

(December 2015),

https://www.oxfam.org/sites/www.oxfam.org/files/file_attachments/dpleb anon-looking-ahead-time-crisis-141215-en_0.pdf.

Sima Ghaddar. "Lebanon Treats Refugees As A Security Problem-And It Doesn't Work." The Century Foundation. (April 4, 2017), https://tcf.org/content/commentary/lebanontreats-refugees-security-problemdoesnt-work/?agreed=1

Syrian American Society Foundation, "The Need For Chronic Disease Support For Refugees," Relief Web, (May 21, 2018), https://reliefweb.int/report/lebanon/needchronic-disease-support-refugees.

UNHCR and International Rescue Committee "Vulnerability Assessment Of Syrian Refugee Men In Lebanon." International Rescue Committee. (January 2016): https://www.rescue.org/sites/default/files/document/464/irclebanonrefugeemensv ulne rabilityassessment.pdf

UNHCR Regional Office In Lebanon, Country Operations Plan 1 (2004), http://www.unhcr.org/3fd9c6a14.pd UNHCR, “Country Operations Plan," 2004, http://www.unhcr.org/3fd9c6a14.pdf.

United Nations Children's Fund (UNICEF), United Nations High Commissioner for Refugees (UNHCR), and the United Nations World Food Programme (WFP), Vulnerability Assessment of Syrian Refugees in Lebanon Report, VASyR-2017, 2017, https://data2.unhcr.org/fr/documents/download/61312. 


\author{
APPENDICES \\ Appendix A: Gender Marker Guidance Note
}

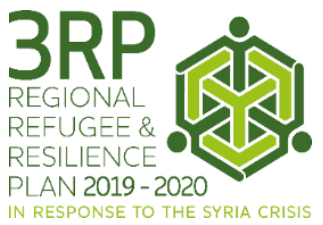

\title{
Gender Marker
}

The Inter-Agency Standing Committee (IASC) Gender Marker is a tool that is used to code humanitarian Sector Response Plans (SRPs) on a 0-2 scale based on programming design. This will be applied to each of the country operation's SRPs under the 3RP. A sector response that is designed well and intentionally addresses the needs and capacities of women, girls, men and boys, be it a resilience development activity or humanitarian activity, has the best chance of being implemented in a way that assists all of these groups to improve their lives.

The codes tell whether or not a SRP is designed well enough to ensure that women, girls, men and boys will benefit equally from it. If the activity has potential to generate gender equality results, the marker predicts whether the gender results are likely to be limited or significant.

A gender code is assigned based on three critical components: 1) there is gender analysis in the needs assessment that provides relevant sex and age-disaggregated data and gives insight into local gender issues 2) this needs assessment is used to identify sector responses and activities and 3) gender-related outputs or performance indicators. There has been a high level of donor interest in the IASC Gender Marker.

\section{Gender Analysis of Needs Activities Outcomes}

\begin{tabular}{|l|l|}
\hline Gender Marker & \multicolumn{1}{c|}{ Description } \\
\hline Gender Code 0 & $\begin{array}{l}\text { Gender is not reflected in any component of the Sector Response Plan. There } \\
\text { is risk that the Plan will unintentionally nurture existing gender inequalities or } \\
\text { deepen them. In principle, the Code 0 is used until a project has been } \\
\text { properly assessed. }\end{array}$ \\
\hline Gender Code 1 & $\begin{array}{l}\text { The Sector Response Plan is designed to contribute in some limited way to } \\
\text { gender equality. Gender dimensions are meaningfully included in only one or } \\
\text { two of the three essential components: needs assessment, sector responses and } \\
\text { performance indicators. }\end{array}$ \\
\hline $\begin{array}{l}\text { Gender Code } \\
\text { 2a }\end{array}$ & $\begin{array}{l}\text { The Sector Response Plan is designed to contribute significantly to gender } \\
\text { equality. The different needs of women, girls, boys and men have been } \\
\text { analyzed and integrated well in all three essential components: the needs } \\
\text { assessment, sector responses and performance indicators. } \\
\text { Mainstreaming }\end{array}$ \\
\hline $\begin{array}{l}\text { Gender Code } \\
\text { 2b }\end{array}$ & $\begin{array}{l}\text { The principal purpose of the Sector Response Plan is to advance gender } \\
\text { equality. The entire Plan either: }\end{array}$ \\
\hline
\end{tabular}




\begin{tabular}{|l|l|}
\hline Targeted Actions & $\begin{array}{l}\text { a) Targets women, girls, boys and men who have specific needs or suffer } \\
\text { from discrimination } \\
\text { b) Focuses on building gender-specific services or more equal relations } \\
\text { between women and men. }\end{array}$ \\
\hline
\end{tabular}

It is the responsibility and accountability of Sector Leads to advance gender equality in their respective areas. All sectors should therefore have a gender marker code for the overall sector plan. Sectors may wish to have a gender marker code at the output level, but these will not be published in the 3RP plan.

Sector process for Gender Marker:

- $\quad$ Prior to the design phase, the Sector Leads would contact and inform Gender Focal Points and GenCap Advisers, where present, about the process and support-needs/expectations in terms of project review (re Gender Marker) $^{719}$.

- During the planning phase, GenCap Advisers will regularly discuss with sector leads the development of the sector plan.

- After reviewing the first draft of the plan GenCap Advisers will provide a matrix with comments and recommendations for revision of Gender Marker codes for each sector to Sector Leads and Agency Gender Focal Points.

- It is the responsibility of Sector Leads to, where necessary, strengthen gender mainstreaming in their sector plans.

- Sector reviewing teams should consider GenCap comments and whether these have been incorporated. It is therefore crucial for GenCap to participate in initial discussions and planning/review meetings so that members are clear on Gender Markers expectations.

- Revised plans can be sent back to GenCap for a second review. Further comments can be made and Gender Marker codes revised in the matrix.

- The GenCap's final matrix/comment sheet is shared with ALL Sector Leads so they are aware which projects in which sectors need attention. Sector Leads are asked to review and ensure that only ACCURATE codes have been entered in the system.

- Codes are finalized at the country level after consultations and clearance at country level.

Gender mainstreaming means the distinct needs, capacities, and contributions of women, girls, men and boys are integrated in a meaningful way in the three critical components of the SRP: the needs assessment, sector responses and performance indicators. These activities would be code $2 \mathrm{a}$. Examples of gender mainstreamed activities for each sector appear in the sector-specific Gender Marker tip sheets posted on the web portal.

${ }^{719}$ Ideally, the Protection Sector should appoint a Gender/Protection Focal Point to each Sector in order to support the process. 
A Sector Response Plan (SRP) designed well enough to warrant a good gender code (2a) must be based on gender analysis which is the engine for ensuring gender is addressed throughout the activity (gender mainstreaming). This means exploring women's as well as men's needs and the different risks they face, the various roles and activities they undertake, their coping skills and ideas on solving problems. The most reliable information on the different realities facing males and females will come from the women, girls, boys and men themselves in consultations segregated by sex and age (whether by focus groups or individual interviews) and facilitated by a same-sex facilitator. A well-designed activity will be grounded in activity teams listening to the diversity of male and female voices, both young and old.

Women, girls, boys and men have immediate "practical" survival needs particularly in humanitarian crises. Most practical needs arise from inadequate living conditions. They include access to safe water, food, adequate housing and personal safety. Women, girls, boys and men also have longer-term "strategic" needs and interests. These often focus on having choices, mobility and power to shape their own lives. Men and women, girls and boys, share some, but not all, practical and strategic needs. It is especially important to understand and respond to their different needs that arise from the division of labour and responsibilities between males and females as well as from women's subordinate position in society.

Both practical and strategic needs can, and wherever possible should be, addressed in gender mainstreamed activities (code 2a).

The gender marker is a sector tool. The following steps can improve the capacity of your sector to incorporate gender equality measures:

1. Sector leads/coordinators ensure that gender equality is a priority in the SRP and is visible in all plan elements. It is important to ensure gender issues are identified and addressed in the SRP. The SRP provides a foundation for the design of activities and also demonstrates thorough integration of gender issues.

2. Build capacity of sector members and activity partners to design gender-responsive activities that feed into the SRP through using the Gender Marker. Use the sector-specific tip sheets and the how-to-code tip sheet so that partners can practice coding their own activities. Field experience already shows that this practice helps teams see how to strengthen the gender dimensions of their activity design.

3. Explore and facilitate links for sector partners with a gender specialist who is familiar with the gender marker and can answer questions.

4. Train the Peer Review Panel on how to assign gender codes in advance. Coding must be quick, easy and accurate during the time-pressed vetting process. Use the how-to-code tip sheet as a guide and practice coding.

5. Provide the Review Panel with contact details of the Gender Marker Focal Point who will be available to help resolve any coding confusion during the vetting.

6. Advise the Sector Chairs on the assigned gender code for the SRP and provide suggestions on how to improve (if applicable).

7. A GenCap Advisor, UNDP Gender Regional Advisor or Focal Point will review the codings for Sector Response Plans and provide feedback to the sector coordinators about to meaningfully incorporate gender equality measures (see above).

\section{The Gender Marker codes will be recorded in the 3RP documents.}


The responsibility for accurate gender coding rests with the Peer Review Panel. The gender code will be inserted into a dedicated 'Gender Marker' field in the 3RP Template.

It is essential that the gender code be accurate. The Inter-Agency Task Force or equivalent Refugee Heads of

Agency Meeting will ensure that each Peer Review Panel has verified the gender code for each Sector Response Plan. The GenCap Activity will verify coding and offer support where needed to consider how to incorporate gender equality measures into the SRPs.

Country operations are encouraged to review the performance indicators at the Mid-Year Review for indications of equitability of access to resources across sex and age.

Tip sheets for sectors on how to code using the Gender Marker are available on the Syria Refugee Response web portal and are featured on http://humanitarianresponse.info, including

https://www.humanitarianresponse.info/en/operations/philippines/document/gender-marker-tip-sheets 


\section{Appendix B: FIU Ethical Board Approval Form}

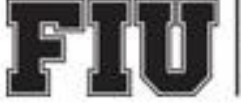

FLORIDA

INTERNATIONAL

UNIVERSITY

\section{MEMORANDUM}

To:

Dr. Susanne Zwijugel

CC:

From: Jessy Abouarab

Maria Melendez-Vargas, MIBA, IRB Coordinator

April 23, 2018

Protocol Title:
"Beyond Security: The case of Syrian Women Refugees in Lebanon"
Office of Research Integrity Research Compliance, MARC 414

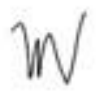

The Social and Behavioral Institutional Review Board of Florida Intemational University has reapproved your study for the use of human subjects via the Expedited Review process. Your study was found to be in compliance with this institution's Federal Wide Assurance (00000060).

$\begin{array}{llll}\text { IRB Protocol Approval \#: } & \text { IRB-17-0140-CR01 } & \text { IRB Approval Date: } & \text { 04/20/18 } \\ \text { TOPAZ Reference \#: } & 105664 & \text { IRB Expiration Date: } & 05 / 01 / 19\end{array}$

As a requirement of IRB Apmroval you are required to:

1) Submit an IRB Amendment Form for all proposed additions or changes in the procedures involving human subjects. All additions and changes must be reviewed and approved by the IRB prior to implementation.

2) Promptly submit an IRB Event Report Form for every serious or unusual or unanticipated adverse event, problems with the rights or welfare of the human subjects, and/or deviations from the approved protocol.

3) Utilize copies of the date stamped consent document(s) for obtaining consent from subjects (unless waived by the IRB). Signed consent documents must be retained for at least three years after the completion of the study. 4) Receive annual review and re-approval of your study prior to your IRB expiration date. Submit the IRB Renewal Form at least 30 days in advance of the study's expiration date.

5) Submit an IRB Project Completion Report Form when the study is finished or discontinued.

HIPAA Privacy Rule: N/A

Special Conditions: N/A

For further information, you may visit the IRB website at http://research fiu.edu/irb.

MMViem. 


\section{Appendix C: Expert Interview Consent Form:}

\section{FUU IRB Approval: $\quad 04 / 20 / 2018$ \\ FUU IRB Expiration: $05 / 01 / 2019$ \\ \begin{tabular}{l|l}
\hline FIU IRB Number: & IRB-17-0140 \\
\hline
\end{tabular}

FIU

\section{ADULT CONSENT TO PARTICIPATE IN A RESEARCH STUDY \\ Beyond Security: The case of Syrian Women Refugees in Lebanon}

\section{PURPOSE OF THE STUDY}

You are being asked to be in a research study. The purpose of this study is to leam "What security strategies have been developed for Syrian refugees, and how?"

\section{NUMBER OF STUDY PARTICIPANTS}

If you decide to be in this study, you will be one of three potential participants in this research study.

\section{DURATION OF THE STUDY}

Your participation will require approximately 40 to 60 minutes.

\section{PROCEDURES}

If you agree to be in the study, we will ask you to do the following thing: Sit for a one-time Audio-recorded Expert Interview, where your confidentiality as a participant in this study will remain secure. All questions are exploratory in nature and professionally geared to provide greater insights into the creation process of the Lebanon Crisis Response Plan policy.

\section{RISKS AND/OR DISCOMFORTS}

The potential risk associated with you participating in this study ds sopsidered to be no greater than minimal and include the possibility of slight discomfort in answering questions regarding the LCRP plan. The proposed study is exploratory in nature and does not include intervention. All your responses will be anonymous and will not be linked to your contact information. You can decide not to answer any question, stop the interview or withdraw from the study, without penalty, at any time.

BENEFITS The following benefits may be associated with your participation in this study:

There is no direct benefit to participate. However, you may receive indirect benefit through raising awareness, potential policy changes, and projects that may form in the future, providing more gender sensitive measures when managing refugees. 


\begin{tabular}{l|l}
\hline FU IRB Approval: & $04 / 20 / 2018$ \\
\hline FU IRB Expiration: & $05 / 01 / 2019$ \\
\hline FU IRB Number: & IRB-17-0140 \\
\hline
\end{tabular}

You will help me understand the security strategies developed for Syrian refugees by providing greater insights into the creation process of a policy.

\section{ALTERNATIVES}

There are no known alternatives available to you other than not taking part in this study. However, any significant new findings developed during the course of the research, which may relate to your willingness to continue participation will be provided to you.

\section{CONFIDENTIALITY}

The records of this study will be kept private and will be protected to the fullest extent provided by law. In any sort of report we might publish, your identity will remain confidential. However, being an expert employee, your answers will reflect your organization's official point of views that might be identified from the dissertation. Research records will be stored securely and only the researcher will have access to the records. However, your records may be reviewed for audit purposes by authorized University or other agents who will be bound by the same provisions of confidentiality.

\section{COMPENSATION \& COSTS}

You will not be responsible for any costs nor get compensated to participate in this study.

\section{RIGHT TO DECLINE OR WITHDRAW}

Your participation in this study is voluntary. You are free to participate in the study or withdraw your consent at any time during the study. Your withdrawal or lack of participation will not affect any benefits to which you are otherwise entitled. The investigator reserves the right to remove you without your consent at such time that they feel it is in the best interest.

\section{RESEARCHER CONTACT INFORMATION}

If you have any questions about the purpose, procedures, or any other issues relating to this research study you may contact Jessy Abouarab at Florida International University, +1-305-924 3135, Jabou002@fiu.edu

\section{IRB CONTACT INFORMATION}

If you would like to talk with someone about your rights of being a subject in this research study or about ethical issues with this research study, you may contact the FIU Office of Research Integrity by phone at 305-348-2494 or by email at ori@fiu.edu.

\section{PARTICIPANT AGREEMENT}

I have read the information in this consent form and agree to participate in this study. I have had a chance to ask any questions I have about this study, and they have been answered for me. I understand that $I$ will be given a copy of this form for my records. 
Signature of Participant

Printed Name of Participant

Signature of Person Obtaining Consent
FU IRB Approval: $\quad 04 / 20 / 2018$

FUU IRB Expiration: $05 / 01 / 2019$

\begin{tabular}{l|l}
\hline Fu IRB Number: & IRB-17-0140 \\
\hline
\end{tabular}

Date

Date

Page 3 of 3

Appendix D: Photovoice Consent Form 


\begin{tabular}{l|l}
\hline FU IRB Approvalt & $04 / 20 / 2018$ \\
\hline FU IRB Expiration: & $05 / 01 / 2019$ \\
\hline FUU IRB Number: & IRB-17-0140
\end{tabular}

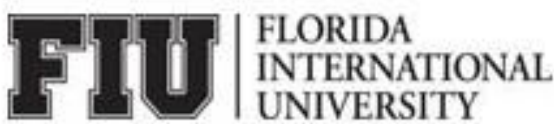

\begin{abstract}
ADULT CONSENT TO PARTICIPATE IN A RESEARCH STUDY
\end{abstract}
Beyond Security: The case of Syrian Women Refugees in Lebanon

PURPOSE OF THE STUDY

You are being asked to be in a research study. The purpose of this study is to learn "What are the Syrian women refugees' daily (in)securities?"

\section{NUMBER OF STUDY PARTICIPANTS}

If you decide to be in this study, you will be one of three potential participants in this research study.

\section{DURATION OF THE STUDY}

Your participation will require approximately one to two weeks.

\section{PROCEDURES}

If you agree to be in the study, we will ask you to do the following things:

Contextualize, Plan and Analyze the Syrian refugees' daily insecurities through photographic images and their respective critics.

- You would first git for a one-day training session in order to learn on how to plan and conduct ethically the different methodologies of photographic techniques and narratives without jeopardizing or upset any of the refugees or the refugee workers or police/security.

- Subsequently, you will have a two-week period to take photographs ethically that do not include sensitive information or recognizable faces that would jeopardize the person's wellbeing.

- Afterwards, we will set a final one-day session to discuss and analyze the different photos and select the ones deemed fit to exhibit after final reflection.

\section{RISKS AND/OR DISCOMFORTS}

The potential risk associated with you participating in this study is sppsidered top be no greater than minimal and include the possibility of slight discomfort in taking certain sensitive pictures of the Syrian refugees' sites. All your photographic input will be anonymous and will not be linked to your contact information. If you do not wish to continue, you have the right to withdraw from the study, without penalty, at any time.

\section{BENEFITS}

The following benefits may be associated with your participation in this study: 


\begin{tabular}{l|l}
\hline FU IRB Approval: & $04 / 20 / 2018$ \\
\hline FU IRB Expiration: & $05 / 01 / 2019$ \\
\hline FU IRB Number: & IRB-17-0140 \\
\hline
\end{tabular}

There is no direct benefit to individual participants. However, you may receive indirect benefit through raising awareness, potential policy changes, and projects that may form in the future, providing more gender sensitive measures when managing refugees.

\section{ALTERNATIVES}

There are no known alternatives available to you other than not taking part in this study.

However, any significant new findings developed during the course of the research, which may relate to your willingness to continue participation, will be provided to you.

\section{CONFIDENTIALITY}

The records of this study will be kept private and will be protected to the fullest extent provided by law. In any sort of report we might publish, we will not include any information that will make it possible to identify a subject. Research records will be stored securely and only the researcher will have access to the records. However, your records may be reviewed for audit purposes by authorized University or other agents who will be bound by the same provisions of confidentiality.

\section{COMPENSATION \& COSTS}

You will not be responsible for any costs nor get compensated to participate in this study.

\section{RIGHT TO DECLINE OR WITHDRAW}

Your participation in this study is voluntary. You are free to participate in the study or withdraw your consent at any time during the study. Your withdrawal or lack of participation will not affect any benefits to which you are otherwige entitled. The investigator reserves the right to remove you without your consent at such time that they feel it is in the best interest.

\section{RESEARCHER CONTACT INFORMATION}

If you have any questions about the purpose, procedures, or any other issues relating to this research study you may contact Jessy Abouarab at Florida International University, +1-305-924 3135, Jabou002@fiu.edu

\section{IRB CONTACT INFORMATION}

If you would like to talk with someone about your rights of being a subject in this research study or about ethical issues with this research study, you may contact the FIU Office of Research Integrity by phone at 305-348-2494 or by email at ori@ fiuedu.

\section{PARTICIPANT AGREEMENT}

I have read the information in this consent form and agree to participate in this study. I have had a chance to ask any questions I have about this study, and they have been answered for me. I understand that I will be given a copy of this form for my records. 


\begin{tabular}{l|l}
\hline FU IRB Approval: & $04 / 20 / 2018$ \\
\hline FU IRB Expiration: & $05 / 01 / 2019$ \\
\hline FU IRB Number: & IRE-17-0140 \\
\hline
\end{tabular}

Signature of Participant

Printed Name of Participant

Signature of Person Obtaining Consent
Date

Date

Page 3 of 3 


\section{CURRICULUM VITAE \\ JESSY ABOUARAB}

\section{EDUCATION}

Fall 2013-Present

Spring 2007

Spring 2004

2015- 2016

2016- 2018-19

2017- 2019

2017- 2019

2015- 2018

Nov. 2015

April 2018

April 2017

Nov. 2015

March 2019

Summer 2018
Ph.D. International Relations

Florida International University, USA

Major Field: Foreign Policy \& Security Studies

Minor Field: Comparative Area Studies

Graduate Certificates: Middle East \& Central Asian Studies

Women \& Gender Studies

M.A. International Affairs \& Diplomacy

Notre Dame University of Louaize, Lebanon

B.A Political Science

American University of Beirut, Lebanon

Instructor

International Law (In-person)

Introduction to Women \& Gender Studies (In-person, Online)

LGBT \& Beyond (In-person, Online)

Academic coach

Introduction to Global Gender and Women's Studies

Academic Advisor

Students in the Center for Women's and Gender Studies

Organizer/Chair

2015 Women, Sexuality, and Gender Student Association Conference

Guest Speaker

Hearts Honors Hour: Refugee Discrimination. Honors College, Florida International University, Miami, Florida

2017, Building Bridges: The Role of Woman Studies in Diversity.

Honors College, Florida International University, Miami, Florida

Facilitator

2015 Panel: Where are women's rights? Women, Sexuality, and Gender Student Association Conference, Miami, Florida

Discussant

2019, Panel: Civil Wars, Agency and Victimization, The International Studies Association Annual Convention, Toronto, Canada

Fellowships

Dissertation Year Fellowship

University Graduate School Florida International University

Outreach

Student President of Women Gender Sexuality Association, Florida International University, Miami, Florida 
Volunteer

Kristy house Child Advocacy Center Miami, Florida

Volunteer

International Rescue Committee, Miami, Florida

Member of TITLE IX Diversity Week Program

Florida International University, Miami, Florida

\section{PUBLICATIONS \& PRESENTATIONS}

The Organizational Longitudinal Analysis of the Lebanon Crisis Response Plan(LCRP). (Manuscript in preparation)

Alternative (In)security: Using Photovoice to Explore Refugee Anxieties in Lebanon (Manuscript in preparation)

The Organizational Longitudinal Analysis of Lebanon Crisis Response Plan - (LCRP)

The International Studies Association Annual Convention, Toronto, Canada, March 2019

In Search of an Identity: Tracing the Lebanese Syrian Rapport and Refugee (In)security Practices International Studies Association Northeast Conference, Baltimore, Nov. 2018 Silenced Bodies: The multiple discrimination of Syrian Refugee Women in the case of Lebanon World Congress for Middle Eastern Studies (WOCMES), Sevilla, Spain, Jul. 18 Alternative (In)Security: Using Photovoice to Explore Refugee Anxieties in Lebanon Gendering International Relations Working Group-British International Studies Association, Newcastle University, UK, April 2018

The Legal Status of Syrian Refugee Women in Lebanon: Six Years Later Annual Conference of the Association of Global South Studies. Marrakesh, Morocco, Dec.2017

Beyond security: The Photovoice Case of Syrian Women Refugees in Lebanon The International Studies Association Northeast Conference, Baltimore, USA, Nov. 2017 The Multiple Understandings of Refugee Security: The geopolitical Case of Syrian women Refugees in Lebanon The International Studies Association- Intelligence Studies Section. Washington, DC, USA, October 2017

Strengthening Accepted Norms: Securitizing Violence Against Women The International Studies Association Northeast Conference, Baltimore, USA, November 2015

Human trafficking within Europe: The Progressing but Limited Role of the European Union Women \& Gender Studies Graduate Student Association (WSGSA), March 2014 